O LICENCIAMENTO AMBIENTAL DE PORTOS DE AREIA

DA BACIA DO RIO CORUMBATAÍ COMO INSTRUMENTO PARA A

RECUPERAÇÃO DE ÁREAS DE PRESERVAÇÃO PERMANENTE

\author{
ELISA HARDT ALVES VIEIRA
}

Dissertação apresentada à Escola Superior de Agricultura "Luiz de Queiroz”, Universidade de São Paulo, para obtenção de título de Mestre em Recursos Florestais, com opção em Conservação de Ecossistemas Florestais.

P I R A C I C A B A

Estado de São Paulo - Brasil

Junho - 2005 
O LICENCIAMENTO AMBIENTAL DE PORTOS DE AREIA

DA BACIA DO RIO CORUMBATAÍ COMO INSTRUMENTO PARA A

RECUPERAÇÃO DE ÁREAS DE PRESERVAÇÃO PERMANENTE

\section{ELISA HARDT ALVES VIEIRA}

Biólogo

Orientador: Prof. Dr. WALTER DE PAULA LIMA

Dissertação apresentada à Escola Superior de Agricultura "Luiz de Queiroz”, Universidade de São Paulo, para obtenção de título de Mestre em Recursos Florestais, com opção em Conservação de Ecossistemas Florestais.

P I R A C I C A B A

Estado de São Paulo - Brasil

Junho - 2005 
Dados Internacionais de Catalogação na Publicação (CIP) DIVISÃO DE BIBLIOTECA E DOCUMENTAÇÃO - ESALQ/USP

\section{Vieira, Elisa Hardt Alves}

O licenciamento ambiental de portos de areia da bacia do Rio Corumbataí como instrumento para a recuperação de áreas de preservação permanente / Elisa Hardt Alves Vieira. - - Piracicaba, 2005.

186 p. : il.

Dissertação (mestrado) - - Escola Superior de Agricultura Luiz de Queiroz, 2005. Bibliografia.

1. Areia 2. Bacia hidrográfica 3. Legislação ambiental 4. Licenciamento 5. Mata ciliar - Áreas de conservação 6. Mineração 7. Reabilitação de áreas degradadas 8. Rio Corumbataí I. Título

CDD 634.9224

"Permitida a cópia total ou parcial deste documento, desde que citada a fonte - O autor" 
Dedico esse trabalho ao Erico e à minha mãe que sempre me apoiaram em tudo 


\section{AGRADECIMENTOS}

Agradeço ao professor Dr. Walter de Paula Lima pela oportunidade, pela confiança e pelos ensinamentos;

Á Dra. Maria José Brito Zakia pela amizade, pela disposição, pela confiança e pela orientação;

Ao professor Dr. José Salatiel Rodrigues Pires, a quem devo a escolha e a criação da temática desse trabalho;

Ao Msc. Erico Fernando Lopes Pereira-Silva pelo companheirismo, pela paciência, pelos ensinamentos e pelas essenciais colaborações à esse trabalho;

À Dra. Lucia Vidor de Sousa Reis pela presteza no acesso aos arquivos da Cetesb e pela participação na banca de qualificação com suas sugestões e correções;

À Dra. Giselda Durigan pela participação na banca de qualificação, com suas essenciais contribuições;

À Dra. Carla Daniela Câmara pela disposição em participar da banca de qualificação;

À Eliete Nunes Secamilli pela amizade e essencial colaboração na intermediação dos contatos com os empreendedores; 
Aos professores Dr. Sergius Gandolfi e Dr. Vinícius Castro Souza e à MSc. Juliana de Paula Souza pelas sugestões e revisões de nomenclatura das listagens florísticas;

Ao Dr. Fernando F. Barros Ferraz pela ajuda na confecção dos mapas digitais da bacia;

À todos os funcionários da CETESB, DEPRN, DNPM, DAEE e da Polícia Ambiental que fizeram parte deste trabalho respondendo aos questionários. Em especial, ao tenente André Vianna da Polícia Ambiental de Rio Claro, à engenheira Irene do DEPRN Rio Claro, à Lucíola da CETESB Piracicaba e ao geólogo José Teodorico de Melo Ribeiro do DNPM de São Paulo;

À todos os empreendedores e funcionários que colaboraram com a permissão de acesso aos portos de areia visitados e que prontamente participaram das entrevistas. Em especial ao empresário e diretor regional do Sindareia José Edvaldo Tietz, pela confiança e atenção;

À CAPES pela bolsa de estudo concedida. 
SUMÁRIO

Página

LISTA DE FIGURAS ................................................................................... viii

LISTA DE TABELAS _............................................................................ xi

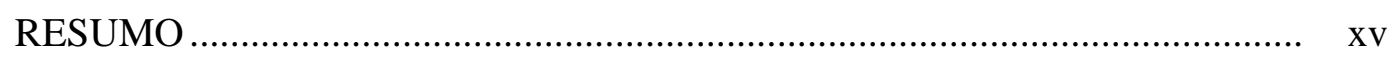

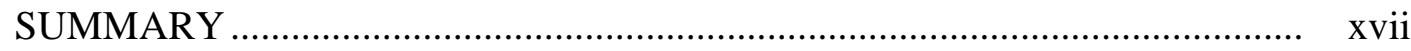

1 INTRODUÇÃO ………………............................................................... 1

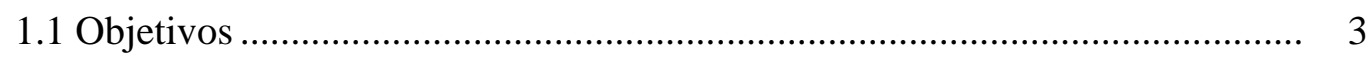

2 REVISÃO DE LITERATURA ................................................................. 5

2.1 Mineração de areia no Estado de São Paulo ................................................... 5

2.2 Histórico da legislação ambiental da mineração ............................................. 6

2.3 Licenciamento ambiental da mineração de areia no Estado de São

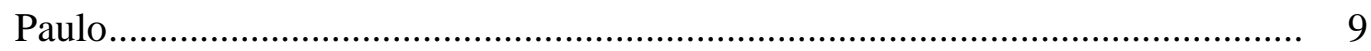

2.4 Impactos ambientais da mineração de areia................................................. 12

2.5 Recuperação de matas ciliares .................................................................... 17

3 MATERIAL E MÉTODOS ................................................................ 24

3.1 Área de estudo................................................................................ 24

3.1.1 Caracterização edafoclimática .............................................................. 27

3.1.2 Caracterização do uso e da cobertura do solo ................................................ 31

3.1.3 Caracterização fitogeográfica................................................................... 33

3.1.4 Caracterização sócio-econômica............................................................ 34

3.2 Estratégia de estudo ............................................................................ 36

3.2.1 Análise dos processos de licenciamento .................................................. 36 


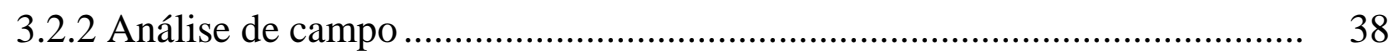

3.2.2.1 Caracterização florística....................................................................... 40

3.2.2.2 Zoneamento dos plantios................................................................... 41

3.2.2.3 Análise dos plantios ............................................................................ 42

3.2.2.4 Análise visual dos plantios................................................................. 44

3.2.2.5 Integridade das margens dos corpos d’água ......................................... 44

3.2.2.6 Avaliação final da recuperação das APPs ............................................... 46

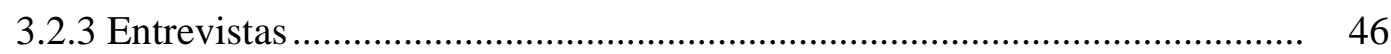

4 RESULTADOS E DISCUSSÃO ............................................................ 48

4.1 Atividade de extração de areia na Bacia do Corumbataí ................................. 48

4.2 Análise da recuperação das APPs ............................................................... 56

4.2.1 Caracterização florística.......................................................................... 56

4.2.1.1 Composição florística dos plantios ....................................................... 56

4.2.1.2 Composição florística dos projetos ........................................................ 77

4.2.1.3 Similaridade florística ...................................................................... 98

4.2.2 Zoneamento dos plantios ................................................................... 104

4.2.3 Cobertura do solo por sombreamento da copa nas zonas de plantios .......... 110

4.2.4 Caracterização visual da vegetação das zonas de plantio ............................ 115

4.2.5 Integridade das margens dos corpos d'água............................................... 122

4.2.6 Avaliação final da recuperação das APPs................................................. 124

4.3 Percepção ambiental e legal dos mineradores............................................. 126

4.4 Condições e recursos dos órgãos ambientais públicos envolvidos na

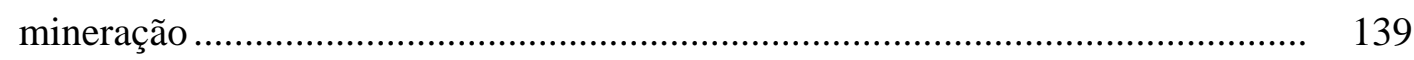

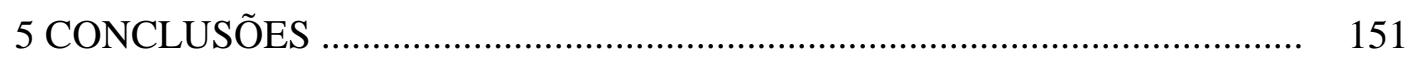

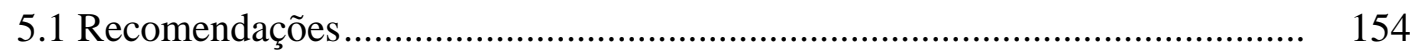

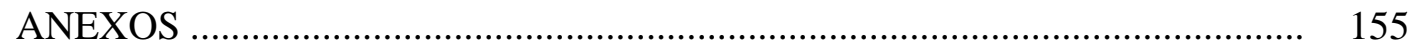

REFERÊNCIAS BIBLIOGRÁFICAS ............................................................ 163

APÊNDICES ...................................................................................... 183 


\section{LISTA DE FIGURAS}

Página

1 Localização e limites da Bacia Hidrográfica do Rio Corumbataí e sua divisão em cinco sub-bacias

2 Rede hidrográfica principal da Bacia do Rio Corumbataí, destacando o Rio Corumbataí e o seu principal tributário, o Rio Passa Cinco.

3 Municípios abrangidos pela Bacia Hidrográfica do Rio Corumbataí, com destaque daqueles que fazem parte da APA CorumbataíBotucatu-Tejupá

4 Erodibilidade dos solos da Bacia Hidrográfica do Rio Corumbataí 30

5 Uso e ocupação do solo da Bacia do Corumbataí .....

6 Distribuição das linhas de amostragem dos plantios nas terceiras e quartas linhas paralelas ao corpo d’água nos sentidos interior-margem e margem-interior

7 Desenho esquemático da cobertura do solo das áreas de plantio, obtida pelo sombreamento da copa $\left(\mathrm{m}^{2}\right)$ sobre a área da parcela, representada pelo espaçamento entre as mudas.

8 Planilha utilizada em campo na análise visual quali-quantitativa da APP em recuperação nos portos de areia da Bacia do Rio Corumbataí, SP.

9 Avaliação final da recuperação das APPs dos portos de areia da Bacia Hidrográfica do Rio Corumbataí....

10 Registros do DNPM dos pedidos de diplomas legais para exploração e aproveitamento mineral no período de 1973 a 2004 para a Bacia do Rio Corumbataí, SP 
11 Apresentação da distribuição dos 36 empreendimentos de extração de areia na Bacia do Rio Corumbataí, SP

12 Distribuição dos empreendimentos de extração de areia da Bacia do Rio Corumbataí, SP, em seus municípios

13 Produção máxima, mínima e média de areia $\left(\mathrm{m}^{3} / \mathrm{mês}\right)$ dos empreendimentos da Bacia do Rio Corumbataí, SP

14 Tempos máximo, mínimo e médio de obtenção dos diplomas legais de exploração mineral junto ao DNPM para os empreendimentos da Bacia do Rio Corumbataí, SP. TAP - Tempo de Aproveitamento de Pesquisa, TCL - Tempo de Concessão de Lavra e TL - Tempo de Licenciamento .....

15 Tempos máximo, mínimo e médio de obtenção das Licenças Ambientais junto à CETESB para os empreendimentos da Bacia do Rio Corumbataí, SP. TLI - Tempo de Licença de Instalação e TLO Tempo de Licença de Operação

16 Distribuição do número de espécies por família para as 19 áreas de plantio dos portos de areia de leito de rio da Bacia do Rio Corumbataí, SP.

17 Distribuição do número de espécies por família para os 23 projetos de reflorestamento dos portos de areia de leito de Rio da Bacia do Rio Corumbataí, SP

18 Dendrograma de similaridade de Jaccard entre área natural e 19 áreas de plantio de portos de areia da Bacia do Rio Corumbataí, SP. A linha tracejada indica o valor mínimo de similaridade (Mueller-Dombois \& Ellenberg, 1974).

19 Dendrograma de similaridade de Jaccard entre área natural e 23 projetos de plantio de portos de areia da Bacia do Rio Corumbataí, SP. A linha tracejada indica o valor mínimo de similaridade (MuellerDombois \& Ellenberg, 1974) . 
20 Imagens do zoneamento das áreas de plantio dos portos de areia da Bacia do Rio Corumbataí. As zonas estão indicadas pelas letras “a”, "b” e “c”, de acordo com um gradiente decrescente de altura e de mortalidade dos plantios

21 Taxa de mortalidade das mudas nas zonas de plantio dos 19 portos de areia de leito de rio estudados na Bacia do Rio Corumbataí, SP

22 Altura máxima, mínima e média das mudas nas zonas de plantio dos 19 portos de areia de leito de rio estudados na Bacia do Rio Corumbataí, SP.

23 Distribuição das classes de altura dos indivíduos amostrados nas linhas de plantio dos 19 portos de areia de leito de rio estudados na Bacia do Rio Corumbataí, SP

24 Percentagem de recobrimento do solo com gramíneas ou serapilheira nas zonas de plantio dos 19 portos de extração de areia por dragagem em leito de rio da Bacia do Rio Corumbataí, SP....

25 Imagens da avaliação da recuperação das APPs de portos de areia da Bacia do Rio Corumbataí. Categorias de classificação: ótimo (A), bom (B), regular (C) e ruim (D)

26 Histórico de uso do solo de portos de areia de leito de rio da Bacia do Rio Corumbataí, SP. Informações obtidas em entrevistas junto aos proprietários

27 Plano de uso futuro do solo de portos de areia de leito de rio da Bacia do Rio Corumbataí, SP. Informações obtidas em entrevistas junto aos proprietários.

28 Freqüência de visitas dos órgãos ambientais nas minerações de areia da Bacia do Rio Corumbataí, SP. Informações obtidas em entrevistas com os proprietários 


\section{LISTA DE TABELAS}

Página

1 Área total (ha) da Bacia Hidrográfica do Rio Corumbataí e de suas divisões em cinco principais sub-bacias....................................................... 26

2 Classes de declividade da Bacia do Rio Corumbataí ..................................... 28

3 Valores em área (ha) e valores relativos (\%) das classes de solos predominantes na Bacia do Rio Corumbataí.....

4 Modificações no uso e na cobertura do solo da Bacia do Corumbataí no período de 1991-2001

5 Apresentação dos 23 portos de extração de areia de leito da Bacia do Rio Corumbataí, entre eles os 19 portos que tiveram seus plantios estudados

6 Caracterização dos empreendimentos de extração de areia por cava e leito na Bacia do Rio Corumbataí, SP, em relação à área de lavra (ha), tipo de autorização e destino da areia produzida.

7 Percentagem de pequenos, médios e grandes empreendimentos de extração de areia por cava e leito na Bacia do Rio Corumbataí, SP

8 Lista de espécies arbóreas registradas nas 19 áreas de plantios dos portos de areia de leito de rio da Bacia do rio Corumbataí, SP.

9 Matriz binária de presença e ausência das espécies arbóreas identificadas nas áreas de plantios dos portos de areia da Bacia do Rio Corumbataí, SP

10 Lista de espécies arbóreas indicadas nos 23 projetos de reflorestamento dos portos de areia da Bacia do Rio Corumbataí, SP 
11 Matriz binária de presença e ausência das espécies arbóreas indicadas nos projetos de plantios dos portos de areia da Bacia do Rio Corumbataí, SP

12 Número de espécies, espécies comuns e percentagem de aproveitamento das listagens florísticas dos projetos teóricos de recuperação nas implantações florísticas dos plantios dos portos de areia da Bacia do Rio Corumbataí, SP

13 Zoneamento das áreas de plantio dos 21 portos de areia visitados na Bacia do Rio Corumbataí, SP. As zonas estão indicadas pelas letras “a”, "b” e "c", de acordo com um gradiente decrescente de altura e de sobrevivência dos plantios. Plantio: EF - efetivado; NEF - não efetivado; $\mathrm{T}$ - tentativa

14 Espaçamento e densidade apresentados nos projetos e observados nos plantios dos 19 portos de areia visitados na Bacia do Rio Corumbataí, SP.

15 Espaçamento e densidade apresentados nos projetos e observados nos plantios dos 19 portos de areia visitados na Bacia do Rio Corumbataí, SP.

16 Valores de percentagem de cobertura da copa por área de plantio e idade dos plantios dos 21 portos de areia visitados na Bacia do Rio Corumbataí, SP

17 Análise visual das zonas de plantio dos 19 portos de areia de leito de rio da Bacia do Rio Corumbataí, SP

18 Valores médio, mínimo e máximo referentes aos custos e benefícios dos portos de areia de leito de rio da Bacia do Rio Corumbataí, SP. Custos com plantio de mudas, legalização do empreendimento e aquisição de equipamentos. Benefícios referentes a venda de areia no porto. Informações obtidas em entrevistas junto aos proprietários

19 Respostas dos proprietários dos portos de areia da Bacia do Rio Corumbataí, SP, quanto à necessidade de uma cartilha informativa a 
respeito dos procedimentos legais e ambientais para o licenciamento mineral

20 Participação dos órgãos na prestação de assistência durante as visitas às mineradoras de areia da Bacia do Rio Corumbataí, SP. Informações obtidas em entrevistas.

21 Respostas dos proprietários entrevistados a respeito da importância do reflorestamento das margens dos rios da Bacia do Rio Corumbataí, SP.....

22 Respostas dos proprietários entrevistados a respeito da necessidade de diversidade de espécies no reflorestamento das matas ciliares da Bacia do Rio Corumbataí, SP.

23 Respostas dos proprietários dos portos de areia da bacia do Rio Corumbataí, SP a respeito dos benefícios da atividade de extração de areia ao meio ambiente

24 Qualificação e atualização dos técnicos dos órgãos envolvidos no licenciamento de portos de areia em relação às questões ambientais e legais da extração mineral. Informações obtidas em entrevistas com os funcionários

25 Respostas dos funcionários entrevistados a respeito se os recursos materiais, humanos e financeiros disponíveis aos seus órgãos estão assegurando suas atribuições no licenciamento das atividades de extração de areia em leito de rio na Bacia do Rio Corumbataí

26 Carência de recursos materiais, humanos e financeiros dos órgãos envolvidos no licenciamento da extração de areia. Informações obtidas em entrevistas com os funcionários.

27 Procedimentos, recursos e critérios não aplicados e que seriam importantes na avaliação do impacto da atividade de extração de areia em leito de rio. Informações obtidas em entrevistas com os funcionários 
28 Principais leis e normas legais aplicadas pelos órgãos entrevistados no que tange a extração de areia em leito. Informações obtidas em entrevistas com os funcionários

29 Respostas dos funcionários entrevistados a respeito da possibilidade do licenciamento ambiental de portos de areia trazer contribuições ambientais.

30 Contribuições ambientais do licenciamento ambiental de portos de areia. Informações obtidas em entrevistas junto aos funcionários dos órgãos envolvidos

31 Principais causas da demora na obtenção das licenças ambientais necessárias para a implantação dos portos de areia. Informações obtidas em entrevistas com os funcionários... 


\title{
O LICENCIAMENTO AMBIENTAL DE PORTOS DE AREIA DA BACIA DO RIO CORUMBATAÍ COMO INSTRUMENTO PARA A RECUPERAÇÃO DE ÁREAS DE PRESERVAÇÃO PERMANENTE
}

\author{
Autora: ELISA HARDT ALVES VIEIRA \\ Orientador: Prof. Dr. WALTER DE PAULA LIMA
}

\section{RESUMO}

Este trabalho avaliou se os instrumentos legais do licenciamento ambiental da extração de areia contribuem para a recuperação das Áreas de Preservação Permanente (APP), além disso, investigou as condições e os recursos dos órgãos envolvidos e o grau de informação dos proprietários. A área de estudo foi a Bacia Hidrográfica do Rio Corumbataí, localizada no Estado de São Paulo. A estratégia de estudo se baseou: a) na análise dos processos de licenciamento ambiental e mineral dos 36 empreendimentos existentes na bacia; b) na análise de campo dos plantios em APP de 21 portos de extração de areia de leito de rio; c) em entrevistas com 15 empreendedores e 15 funcionários dos cinco principais órgãos envolvidos. Foi verificado que a maioria dos órgãos envolvidos apresentam alguma dificuldade na atribuição de suas funções dentro do licenciamento, o que reside principalmente da carência de recurso humano, além da carência de recursos financeiros e materiais e de condições de preparo dos técnicos envolvidos. As irregularidades ambientais e legais dos portos de areia são função de uma soma de fatores, entre eles, a falta de informação e negligência dos 
empreendedores e a lentidão e os elevados custos do licenciamento ambiental e mineral. A avaliação final mostrou que 52\% dos plantios podem ser classificados como ruins, $38 \%$ como regulares e somente $10 \%$ puderam ser considerados como bom e ótimo. Na maioria das vezes, as técnicas de reflorestamento utilizadas não atenderam aos critérios mínimos para o restabelecimento da estrutura e da função de uma floresta. Foi evidenciado ainda uma situação preocupante de perda de biodiversidade, uma vez que a maioria dos plantios e projetos de reflorestamento possui baixa diversidade em espécies e uma tendência à homogeneidade florística quando comparado com áreas naturais. Chama a atenção o insucesso dos plantios efetivados. Grande parte deles apresentou alta mortalidade, baixa densidade, baixa cobertura do solo por sombreamento da copa, fisionomia florestal sem estrutura vertical bem definida, serapilheira ausente ou escassa e regeneração ausente ou de baixas quantidade e qualidade. Os projetos de recuperação por reflorestamento não são satisfatoriamente cumpridos pelos empreendedores e a maioria mostrou uma listagem florística idêntica a de outros projetos. Além disso, se fossem implementados, na sua maioria, não garantiriam a manutenção da biodiversidade natural das matas ciliares. De acordo com os resultados, pode-se inferir que os atuais instrumentos legais do licenciamento ambiental dos portos de areia não estão contribuindo para a recuperação das APP da Bacia do Rio Corumbataí. Entretanto, o licenciamento ambiental da atividade parece estar contribuindo com a conservação das matas naturais ainda existentes na bacia, em função da atual política ambiental de não desmatamento de novas matas em APP. 


\section{EVALUATING THE EFFICIENCY OF THE LICENSING PROCESS OF SAND MINING SITES IN THE CORUMBATAI RIVER BASIN AS A EXTRATEGY FOR THE RESTORATION OF RIPARIAN VEGETATION}

Author: ELISA HARDT ALVES VIEIRA

Adviser: Prof. Dr. WALTER DE PAULA LIMA

\section{SUMMARY}

The purposes of this work were to evaluate whether the environmental licensing legislation for sand mining contributes to the recovery of the riparian vegetation of the Permanent Preservation Areas (river buffer zones), as well as the conditions and resources availability of the involved agencies, and the land owners' information level. The study area was the Corumbatai River basin, located in the State of São Paulo. The study strategy involved: a) the analysis of the environmental licensing procedures of the 36 existing mining sites in the river basin; b) field analysis of the seedlings growth in the revegetated areas in the 21 sand mining sites; c) interviews with 15 entrepreneurs and 15 officers of the five main agencies involved. It was observed that most agencies have problems with their own attributions in the licensing process, mainly owing to human resource deficiencies, lack of financial and material resources, and poor conditions for the adequate technical capacitating of the responsible officers. The environmental and legal irregularities of the sand mining sites are due to several factors, such as entrepreneurs' misinformation and negligence, slowness and high costs involved 
in the environmental and mineral licensing. A final evaluation showed that 52\% of the revegetation areas could be classified as bad, $38 \%$ as regular, and only $10 \%$ could be considered good or excellent. Generally, the revegetation techniques used did not meet the minimal criteria for reestablishing the riparian forest structure and function. A worrying situation regarding biodiversity loss was also evidenced, since most of the revegetation projects presented low species diversity and a tendency to floristic homogeneity, as compared to what is observed in natural areas. Most of the revegetated areas showed high mortality rate, low density, little soil cover due to canopy shading, poorly defined vertical structure, absense or inadequate litter and absence or low regeneration quantity and quality. Revegetation projects are not succesfully accomplished by the entrepreneurs and most of them showed an identical floristic list of species to those found in previous projects. Moreover, if such projects were implemented, they would probably not guarantee the maintenance of the natural biodiversity of riparian forests. According to the results, it can be inferred that the current environmental licensing legislation of sand mining sites are not contributing to the recovery of the riparian vegetation in the Corumbatai River basin. However, the environmental licensing of the sand mining activity may seem to be contributing to the conservation of the remaining natural forests in the basin, due to the current environmental policy that prohibities the cutting of riparian forests. 


\section{INTRODUÇÃO}

Embora a própria Constituição Federal de 1988 considere a mineração uma atividade degradadora do meio ambiente e o Conselho Nacional do Meio Ambiente (Resolução CONAMA 01/86) determine a realização de Avaliação de Impacto Ambiental (AIA) a todas atividades minerárias potencialmente causadoras de significativa degradação ambiental, as mineradoras de areia da Bacia do Rio Corumbataí, a maioria de leito de rio, se isentam da apresentação do AIA, por atenderem aos critérios de dispensa estipulados pela Resolução CONAMA 10/90, que norteia, junto com as Resoluções SMA 42/94 e 04/99, o licenciamento ambiental dos minérios de classe II (jazidas de substâncias minerais de emprego imediato na construção civil) no Estado de São Paulo.

Nesse contexto de ausência de AIA, cabe ao licenciamento o importante papel de controle da degradação ambiental da mineração de areia e fica a cargo dos órgãos ambientais competentes a responsabilidade de avaliar as condições ambientais dos empreendimentos e permitir ou não as suas atividades.

Incontestavelmente a atividade de mineração de areia é essencial ao desenvolvimento econômico da sociedade capitalista atual. Muitos defendem que a atividade é também essencial no dessassoreamento de rios já degradados, mas, infelizmente essa atividade traz junto com esses benefícios uma série de prejuízos ao ambiente.

Os processos operacionais nas atividades de mineração implicam em diferentes formas de degradação ao meio ambiente, sendo que as mais comuns estão associadas 
com a retirada da vegetação (Almeida, 2002). Carpi Junior (2001), avaliando os riscos ambientais e os processos erosivos sobre os recursos hídricos de uma bacia hidrográfica do Estado de São Paulo, identificou diversas inconformidades e impactos ambientais relacionados à atividade de extração de areia, dos quais se destacaram a instalação dos portos de areia em Áreas de Preservação Permanente (APP), a destruição e o soterramento da mata ciliar remanescente pela areia extraída e depositada nas margens, quedas de árvores, o desbarrancamento e a descaracterização das margens, além de alterações do fluxo natural do rio.

Embora os impactos da extração da areia em leito de rio sejam menos visíveis a olho nu, são de grande magnitude, já que é uma atividade causadora de grande desequilíbrio nos ecossistemas aquáticos (Brigante et al., 2003a), causando alterações na qualidade da água em virtude da redisponibilização de metais provenientes da ressuspensão do sedimento (Espíndola et al., 2003; Silvério, 1999), do aumento da turbidez (Brigante et al., 2003b) e da diminuição do pH (Christensen, 1998, citado por Espíndola et al., 2003), além de outros fatores.

A exploração de areia em leito de rio também afeta as margens desses corpos d’água, com a desestabilização dos taludes, o aumento da erosão (Bacci, 1994), o desbarrancamento das margens, o alargamento e aprofundamento da calha do rio (Martos, 1992), o assoreamento e a inundação das áreas de várzea (Almeida, 2002).

Embora os órgãos ambientais competentes realizem uma série de exigências para o licenciamento dessa atividade, não há uma definição clara das atribuições de cada órgão licenciador no controle de todos os problemas de degradação promovidos por essa extração mineral. Na prática, a maior exigência está no plantio de espécies nativas nas matas ciliares, protegidas pelo Código Florestal Brasileiro (Lei Federal 4.771/65) como APP.

O que se tem constatado é que os projetos para restauração florestal não têm atendido aos requisitos mínimos necessários para o restabelecimento dos processos ecológicos nas áreas de recuperação, requisitos esses relacionados principalmente com as diversidades florística e genéticas das florestas implantadas (Barbosa, 2002, 
Kageyama \& Gandara, 2001, Parrota et al., 1997; Souza et al. 1992 e Vencovsky, 1987 citados por Rozza et al., 2003).

Em trabalhos de políticas públicas desenvolvidos pelo Instituto de Botânica de São Paulo com o objetivo de avaliar a eficácia de projetos de reflorestamento com espécies nativas, ficou constatada uma significativa perda de diversidade biológica e o declínio de reflorestamentos realizados nos últimos quinze anos (Barbosa \& Potomati, 2003).

As causas da não recuperação das áreas alteradas são decorrentes de diversos fatores, muitas vezes externos à vontade dos mineradores (Martos, 1992), embora outras vezes decorrentes da falta de responsabilidade desses empreendedores pelos danos (Mueller, 1998), por completo distanciamento e desconhecimento da necessidade e da função desses plantios. Segundo Brugnaro (2000), o desinteresse na reposição de matas ciliares pode ser explicado, sob a ótica do setor privado, pela interferência no direito de propriedade e pelo fato da reposição representar uma externalidade de mercado.

\subsection{Objetivos}

O objetivo central deste trabalho foi o de avaliar se os instrumentos legais do licenciamento ambiental da extração de areia contribuem efetivamente para a recuperação das APPs. No âmbito dessa proposta, esse trabalho teve como objetivos secundários:

i. Investigar as condições e os recursos dos órgãos responsáveis pelo licenciamento ambiental e mineral da extração de areia;

ii. Verificar o grau de informação dos proprietários desses empreendimentos a respeito das questões ambientais e legais que norteiam o licenciamento ambiental dessa atividade mineradora.

Com esse trabalho, deverão ser respondidas as seguintes questões: 
1. Os projetos de recuperação por reflorestamento são satisfatórios na reabilitação das Áreas de Preservação Permanente e são devidamente cumpridos pelos empreendedores?

2. Os órgãos competentes possuem condições e recursos necessários para análise dos projetos de recuperação e de instalação dos empreendimentos e para monitoramento de seus cumprimentos?

3. As irregularidades ambientais e legais dos portos de areia ocorrem por negligência dos proprietários, por falta de informação desses empreendedores a respeito das questões ambientais e legais do licenciamento ou por entraves burocráticos do processo de licenciamento? 


\section{REVISÃO DE LITERATURA}

\subsection{Mineração de areia no Estado de São Paulo}

O Estado de São Paulo é o maior produtor e consumidor de areia no Brasil. O estado é responsável por 32\% da produção de agregados para construção civil do País. Em 2000, o País produziu em torno de 380 milhões de toneladas de agregados, e deste montante, 226 milhões de toneladas corresponderam à produção de areia. Das 2000 empresas dedicadas à extração de areia no País, 60\% tem produção inferior a $6000 \mathrm{~m}^{3} /$ mês e são em grande parte pequenas empresas de cunho familiar (Coelho, 2001).

Depois de longos anos de clandestinidade, retratada nas últimas décadas, de milhares de pequenos portos de areia espalhados por todo o Estado de São Paulo (Hermann, 1992), hoje as principais regiões produtoras de areia do estado atingiram o importante objetivo de regularização ambiental e mineral perante os órgãos envolvidos com essa atividade (Akimoto, 2001).

Atualmente, o setor produtivo de areia no estado pode ser polarizado em dois grandes grupos: o setor que abastece a Região Metropolitana de São Paulo (RMSP), maior centro consumidor do produto no País, com consumo mensal de 1,5 milhão de metros cúbicos, e aquele que abastece o interior do estado e a Baixada Santista, que atualmente vem alcançando magnitude semelhante à existente na capital paulista (Akimoto, 2001).

Uma das regiões de maior produção de areia para a RMSP é a região do Vale do Paraíba que, em 1998, produzia em torno de $800 \mathrm{mil} \mathrm{m}^{3}$ mensais deste bem mineral (Silva, 1998), fornecendo em torno de 50\% da areia consumida na Capital e na Grande 
São Paulo. Outros centros produtores para a RMSP de destaque são as regiões de Mogi das Cruzes, de Itaquaquecetuba, de Araçariguama, do Vale do Ribeira, a zona sul do município de São Paulo e os municípios de Sorocaba e Bofete (Akimoto, 2001).

O setor que abastece o interior do estado e a Baixada Santista concentra-se no aproveitamento de reservas existentes nos leitos das principais drenagens que banham essas regiões, com destaque para os rios Tietê, Paraná, Grande, Mogi-Guaçu, Piracicaba, Ribeirão do Iguape e Paranapanema (Akimoto, 2001).

\subsection{Histórico da legislação ambiental da mineração}

O Código de Mineração de 1967 não estabelece padrões ambientais de execução da atividade mineral, além de não mencionar a recuperação ambiental das áreas alteradas (Toy \& Griffith, 2002).

Somente com a promulgação da Política Nacional do Meio Ambiente (PNMA), Lei 6.938/81, foi que a manutenção da integridade ambiental do ecossistema explorado passou a fazer parte de uma nova política ambiental, extremamente influenciada pelos princípios do direito ambiental internacional.

Essa nova política ambiental instituiu, entre outras coisas, o licenciamento ambiental na esfera federal, grande marco na legislação ambiental brasileira. No entanto, para o Estado de São Paulo, antes mesmo da PNMA, o licenciamento ambiental já era previsto desde 1976, com a promulgação da Lei 997/76, regulamentada pelo Decreto 8.468, que atribuiu à Companhia Estadual de Tecnologia e Saneamento Básico (CETESB) o papel de aplicá-la (Dias, 2001).

Outra grande contribuição da PNMA foi o estabelecimento da recuperação de áreas degradadas como um de seus princípios, a partir da aplicação de responsabilidade civil objetiva ao poluidor que fica obrigado, independentemente da culpa, a indenizar ou reparar os danos causados ao meio ambiente e a terceiros afetados por sua atividade, bastando a prova de nexo causal, ou seja, a relação de causa e efeito.

Esse princípio de recuperação de áreas contido na PNMA foi regulamentado no Estado de São Paulo pelo Decreto 97.632/89 (Dias, 2001), em que os empreendimentos 
que se destinam à exploração de recursos minerais devem incluir, quando da apresentação de seus estudos ambientais, um Plano de Recuperação de Área Degradada (PRAD) para a aprovação do órgão técnico competente. A Secretaria do meio Ambiente (SMA) do Estado de São Paulo editou neste mesmo ano a Resolução SMA 18/89, com um roteiro básico para elaboração do PRAD, que prevê, entre outras coisas, a identificação e quantificação das espécies vegetais a serem utilizadas na recomposição da paisagem.

No final da década de 80 a Constituição Federal de 1988 consolida os princípios, as diretrizes e os instrumentos adotados pela PNMA, defendendo o princípio básico de que "Todos têm direito ao meio ambiente ecologicamente equilibrado, bem de uso comum do povo e essencial à qualidade de vida, impondo-se ao Poder Público e à coletividade o dever de defendê-lo e preservá-lo para as presentes e futuras gerações” (Art. 225).

Um avanço considerável da Constituição Federal de 1988 foi identificar a mineração como atividade degradadora do ambiente pelo simples fato dessa atividade existir, definindo no parágrafo $2^{\circ}$ do artigo 225 que "aquele que explorar recursos minerais fica obrigado a recuperar o meio ambiente degradado, de acordo com a solução técnica exigida pelo órgão público competente”. Com isso, o explorador de bens minerais passou a ter caracterizada constitucionalmente a sua obrigação de recuperar o ambiente degradado em razão de sua atividade (Machado, 2003).

Os procedimentos necessários para essa recuperação prevista constitucionalmente nem sempre apresentaram regras claras, principalmente quando se trata de normas para revegetação. Por isso, no Estado de São Paulo, a Resolução SMA 42 de 1996 representou um grande avanço nesse sentido, ainda que seja aplicada apenas às atividades de mineração de areia na Bacia do Paraíba do Sul.

Essa resolução SMA reuniu várias medidas obrigatórias para a revegetação, servindo como referência na avaliação do desempenho de revegetações, como a sua determinação de que uma área só pode ser considerada revegetada e estar isenta de cuidados com a manutenção (plantio estabelecido) quando alcança o sombreamento total da área e quando as árvores atingem três metros de altura. Essa resolução também 
inovou com o condicionamento do licenciamento à prévia definição de áreas aptas a mineração de areia, preconizando o zoneamento ambiental minerário da bacia, que só veio a se tornar realidade em 1999, com a Resolução SMA 28.

Segundo CONSEMA (1998), essa idéia de um instrumento de gestão e planejamento regionalizado se fortaleceu em meados da década de 90, quando os Estudos de Impacto Ambiental (EIA) já se mostravam ineficazes ao longo dos anos no efetivo controle da atividade minerária.

No Estado de São Paulo, mesmo com as normas reguladoras da atividade minerária (Resolução SMA 66/95, substituída pela SMA 04/99) e com as sansões já previstas para os empreendimentos irregulares (Decreto 8.468/76), a Lei de Crimes Ambientais (Lei Federal 9.605/98) teve papel fundamental na adequação do seu licenciamento minerário. Uma das inovações dessa lei foi a adoção de responsabilidade penal de pessoas jurídicas, permitindo a condenação de empresas (Machado, 2003).

$\mathrm{O}$ art. 55 dessa lei menciona que "executar pesquisa, lavra ou extração de recursos minerais sem a competente autorização, permissão, concessão ou licença, ou em desacordo com a obtida" configura a pena de detenção, de seis meses a um ano, e multa. O dever de recuperação na exploração mineral, já imposto expressamente pela Constituição Federal de 88, foi tutelado penalmente por esse mesmo artigo (Machado, 2003), que diz que "incorre nas mesmas penas quem deixa de recuperar a área pesquisada ou explorada, nos termos da autorização, permissão, licença, concessão ou determinação do órgão competente”.

Mesmo incorrendo em penalidades, nem sempre as áreas exploradas são recuperadas. Além disso, quando as recuperações envolvem a revegetação dessas áreas, segundo Barbosa \& Martins (2005), a diversidade vegetal empregada é muito baixa. Isso levou a Secretaria do Meio Ambiente do estado a promulgar a Resolução SMA 21/01, alterada e ampliada pela Resolução SMA 47/03. Essas resoluções fixam, entre outras orientações, o número de espécies arbóreas nativas a serem utilizadas nos reflorestamentos heterogêneos e prioriza o uso de espécies ameaçadas de extinção, além de enfatizar o uso de medidas de recuperação baseadas no processo de sucessão ecológica. 


\subsection{Licenciamento ambiental da mineração de areia no Estado de São Paulo}

Embora o licenciamento ambiental em área de extração mineral seja previsto em lei desde 1976 no Estado de São Paulo, até o início da década de 90 poucas empresas tinham sua situação regularizada junto aos órgãos ambientais estaduais, ou mesmo no Departamento Nacional de Produção Mineral (DNPM).

Ao lado das enormes dificuldades burocráticas impostas para a regularização do empreendimento minerário figurava um sistema de fiscalização tão precário que a operação de minas em situação irregular era a situação mais comum. (Dias, 2001).

Segundo Martos (1992), essa situação pôde ser justificada pelo fato do minerador interessado em legalizar suas atividades junto aos órgãos responsáveis se enveredar por caminhos longos e complicados, pois tem que passar pelo crivo de pelo menos cinco órgãos (DEPRN, CETESB, SMA, DNPM e Prefeitura Municipal da área da jazida), além do fato da legalização ser um processo caro, demorado e trabalhoso que acaba levando o pequeno empreendedor ao desânimo.

A partir do final da década de 90, com a Lei de Crimes Ambientais, o número de portos de areia licenciados ficou bem próximo do total de empresas mineradoras, embora as dificuldades de legitimação desses empreendimentos não tenham mudado.

Ainda que nos dias de hoje a maioria dos portos de areia estejam licenciados (legalmente regularizados), é freqüente a ocorrência de alguma irregularidade ambiental nas áreas de extração, como a degradação da mata ciliar, ecossistema marginal ao rio de reconhecida importância ecológica.

Um dos marcos da legislação ambiental no Brasil foi a Resolução CONAMA 001/86, que definiu os empreendimentos passíveis de aprovação de AIA para o seu licenciamento, previsto desde 1981, pela PNMA na esfera federal, e desde 1976, no Estado de São Paulo.

Essa resolução definiu, em 1986, a mineração como uma atividade modificadora do meio ambiente e, por isso, passível de AIA; no entanto, as normas e os procedimentos de licenciamento ambiental para o setor mineral só foram regulamentados em 1990, com as Resoluções CONAMA 009/90 e 010/90. 
Embora esteja prevista pela Resolução CONAMA 10/90 a realização de EIA e seu respectivo Relatório de Impacto Ambiental (RIMA) para que os empreendimentos minerários, inclusive os de classe II $^{1}$, obtenham Licença de Instalação (LI), isto, no entanto, não é observado na prática. Essa resolução entendeu que nem sempre as atividades minerárias são potencialmente causadoras de significativa degradação ao meio ambiente, ficando a critério do órgão ambiental competente a dispensa de alguns empreendimentos de apresentação de EIA/RIMA em função de sua natureza, localização, porte e demais peculiaridades.

Nessas condições, a Secretaria do Meio Ambiente do Estado de São Paulo, a fim de disciplinar os procedimentos para o licenciamento ambiental dos empreendimentos minerários em âmbito estadual, além de uniformizar as interpretações dos diversos diplomas legais incidentes sobre a atividade, editou a Resolução SMA 04/99 que determinou, entre outras coisas, que a CETESB só pode dispensar um empreendimento da apresentação de EIA/RIMA quando este atender, simultaneamente, a uma série de requisitos. Entre esses requisitos se destaca a extração de materiais de utilização imediata na construção civil, com área total licenciada inferior a 100 hectares e produção mensal inferior a 5.000 metros cúbicos. Com isso, no intuito de não serem obrigados a apresentar EIA, o qual tem um custo financeiro considerável, a grande maioria das empresas de extração de areia possui porte menor ou igual a 100 ha e relatam extração mensal inferior a $5.000 \mathrm{~m}^{3}$.

Portanto, na ausência de elaboração de AIA, cabe ao licenciamento o importante papel de controle da degradação ambiental da mineração de areia, ficando a cargo dos órgãos ambientais competentes a responsabilidade de avaliar as condições ambientais dos empreendimentos e permitir ou não as suas atividades.

Segundo o art. $1^{0}$ da Resolução SMA 04/99, “o licenciamento ambiental das atividades de extração mineral será realizado de forma integrada pelos órgãos do SEAQUA ${ }^{2}$ e em articulação com os órgãos federal, estaduais e municipais responsáveis pelo licenciamento e concessão para exploração mineral”. Com isso, o

\footnotetext{
${ }^{1}$ Minérios de classe II - Jazidas de substâncias minerais de emprego imediato na construção civil.

2 SEAQUA - Secretaria Estadual de Administração da Qualidade Ambiental, Proteção Controle, Desenvolvimento e Uso Adequado dos Recursos Naturais.
} 
desenvolvimento das atividades minerárias, nas suas diversas etapas, depende da avaliação e anuência prévia de órgãos vinculados aos diferentes níveis de governo com atribuições específicas, porém, muitas vezes interdependentes, o que implica numa grande complexidade de procedimentos de regularização dos empreendimentos minerários frente à legislação vigente (São Paulo, 1999).

Os pedidos de licença ambiental de empreendimentos de extração de areia para utilização imediata na construção civil são protocolados nas agências ambientais da CETESB mediante a apresentação de Relatório de Controle Ambiental (RCA) e Plano de Controle Ambiental (PCA) (Art. $4^{\circ}$ SMA 4/99).

O PCA é uma exigência adicional ao EIA/RIMA prevista pela Resolução CONAMA 009/90 para concessão de LI, enquanto que o RCA está previsto pela Resolução CONAMA 010/90 na hipótese de dispensa do EIA/RIMA de atividade de extração mineral da classe II.

Outro documento muitas vezes apresentado pelo empreendedor com área já lavrada e não contemplada no licenciamento é o Plano de Recuperação de Área Degradada (PRAD). Esse documento, assim como o PCA, formaliza o compromisso do empreendedor em recuperar a área explorada, apresenta projetos, como por exemplo, o de recomposição de áreas degradadas e as plantas finais de como ficará a área após o término da extração mineral, além de apresentar os prazos e cronogramas que permitam aos órgãos ambientais licenciadores e fiscalizadores o acompanhamento da recuperação devida e prometida (Ribeiro, 2004).

Infelizmente, os planos de recuperação podem deixar de ser esse plano de ação e se tornarem apenas mais uma exigência burocrática, como acontece com muitos dos projetos teóricos exigidos. Segundo Dias (2001), há evidências de um grande deslocamento entre o projeto teórico proposto (discutido, negociado e aprovado) e a realidade instalada e em operação. Em geral, o proponente não implementa as medidas mitigadoras ou a implementa de maneira inadequada ou insuficiente.

A mesma autora evidencia a necessidade de uma etapa de acompanhamento dos empreendimentos licenciados, etapa representada por um conjunto de atividades 
desenvolvidas durante e após a implementação do projeto, depois de tomada a decisão de prosseguir.

Por mais bem elaborados que sejam os projetos de licenciamento e por mais bem conduzido que seja o processo decisório, de nada valerá o esforço se os compromissos assumidos não forem cumpridos, o que pode ser garantido com a fiscalização.

\subsection{Impactos ambientais da mineração de areia}

É inegável que no mundo moderno a mineração assume contornos de importância decisiva para o desenvolvimento, pois se observa que o minério extraído da natureza está em muitos produtos utilizados. Entretanto, esta dependência gera um ônus para a sociedade, com o surgimento de áreas degradadas que ao final da exploração, na maioria das vezes, não podem mais ser ocupadas racionalmente (Kopezinski, 2000).

O custo dessa degradação ambiental nada mais é do que uma externalidade sócio-ambiental da atividade, ou seja, efeito negativo resultante da produção mineral que não foi arcado pelas entidades geradoras, mas que foi imposto a terceiros.

A não incorporação das externalidades negativas ao processo de produção e desenvolvimento mineral gera passivos ambientais, que, no futuro, podem ser imputados aos empreendedores por possuírem legalmente o dever de recuperar o meio ambiente degradado.

O conceito de passivo ambiental ainda é controverso, não havendo consenso quanto à definição do termo. Segundo Milaré (2001), é um valor monetário decorrente de inobservância a requisitos legais, custos de adequações operacionais e de recuperação ambiental. Já Trigueiro (2003) define passivo como o “conjunto de obrigações, contraídas de forma voluntária ou involuntária, que exigem a adoção de ações de controle, preservação e recuperação ambiental”. Entretanto, para a realização do presente trabalho foi adotado o conceito de passivo ambiental costumeiramente utilizado no âmbito de sistema de gestão ambiental, o qual define como "um dano ambiental presente, decorrente de atividades do passado ou de um acidente” (Moreira, 2004). 
Nesse contexto, um dano ou passivo ambiental pode ser evitado pela aplicação de alguns princípios do direito ambiental, como os princípios da precaução e da prevenção, descritos por Machado (2003), em relação aos impactos ambientais negativos, durante a fase de planejamento do empreendimento.

O CONAMA define impacto ambiental, na sua Resolução 01/86, como “...qualquer alteração das propriedades físicas, químicas e biológicas do meio ambiente, causada por qualquer forma de matéria ou energia resultante das atividades humanas, que, direta ou indiretamente, afetam:

I - a saúde, a segurança e o bem estar da população;

II - as atividades sociais e econômicas;

III - a biota;

IV - as condições estéticas e sanitárias do meio ambiente;

$V$ - a qualidade dos recursos ambientais”.

A extração de minerais, como qualquer outra atividade humana, interfere no meio ambiente, inclusive alterando outros recursos naturais, o que justifica a necessidade de uma avaliação prévia da compatibilidade do seu desenvolvimento com a preservação ambiental.

Os danos ambientais da atividade de mineração, quando comparados aos danos de demais agentes degradadores, como as atividades agrosilvopastoris, podem ser considerados locais e de grande intensidade (Kobiyama et al., 2001), e na sua maioria das vezes quando previstos e avaliados, podem ser reversíveis.

A proximidade entre as áreas de extração de areia e os centros urbanos tem trazido uma série de conflitos de uso do solo e da água (Almeida, 2002). Essa proximidade pode ser explicada pelo fato da areia ser um bem mineral de uso in natura pela construção civil e do preço dos produtos minerais ser bastante influenciado pela distância entre a mina e o local de consumo (Bitar, 1997). Essa relação de proximidade tem como conseqüências a desvalorização imobiliária das propriedades vizinhas às minerações e os transtornos que o transporte de produção mineral promove no tráfego urbano. O estabelecimento de relações entre a atividade mineral e outras formas de uso do solo tem ocorrido de maneira conflituosa e a ausência de soluções negociadas, 
mediadas e institucionalizadas, tem levado ao fechamento das minerações ou à manutenção de riscos às populações das áreas circunvizinhas (Bitar et al., 1990).

As minerações de areia têm sido grandes causadoras de impactos ambientais negativos para o meio físico, como o assoreamento e a mudança do percurso dos rios, mudanças dos sistemas de drenagens, erosão, movimentos de massa (Kopezinski, 2000), alteração da superfície topográfica e da paisagem e, com o transporte dos materiais extraídos, problemas como o excesso de poeira e de vibrações e a compactação do solo (Bitar et al., 1990). Outros impactos ao meio físico de menor intensidade são os resíduos sólidos resultantes do processo de peneiramento e os ruídos provocados principalmente pelos equipamentos de extração, carregamento e transporte (Godoy, 2002).

Os principais impactos dessa atividade no meio biológico são a supressão da vegetação, a perda e destruição de solos superficiais férteis (Bitar et al., 1990) e conseqüente perda de hábitat e de biodiversidade.

O desmatamento de áreas para a implantação do porto e de outras instalações como bacias de decantação, pátios de manobra e vias de circulação, resulta não só na perda direta de espécies da flora, como também na perda indireta de espécies da fauna e flora afetadas pela perda de condições e recursos outrora disponíveis no hábitat, além da inestimável perda de diversidade genética.

Além disso, a atividade é potencialmente causadora de poluição atmosférica por queima de combustível, de contaminação de água e solo por óleos e graxas utilizados nos motores dos equipamentos e de alterações na qualidade da água.

O tipo de lavra utilizado na exploração mineral é um dos principais determinantes do nível de impacto acarretado ao ecossistema (Silva, 1997). Existem dois métodos principais de extração de areia, a dragagem em leito de rio e a cava a céu aberto.

A lavra a céu aberto permite um maior aproveitamento do corpo mineral, mas produz uma maior quantidade de estéril, de poeira, de vibrações, de poluições da água, no caso de não serem adotadas técnicas de controle de poluição (Silva, 1997).

Embora a extração de areia pelo método de cava tenha pouca interferência direta no meio hídrico, é considerada pela legislação uma atividade predatória, já que instala-se 
nas margens do rio com freqüente retirada da vegetação ciliar nativa. O desmatamento em grandes dimensões, somado ao desmonte de encostas por jateamento hidráulico ou escavadeiras e a deposição de grandes quantidades de material estéril (bota-fora) tem como conseqüência o aumento do potencial de erosão da área (Bacci, 1994).

A extração em leito de rio consiste na dragagem de material das camadas de sedimentos arenosos no fundo dos rios através de um sistema de bombeamento (draga). Bombas de sucção, instaladas sobre flutuadores, são acopladas às tubulações que efetuam o transporte da areia na forma de polpa (mistura de material arenoso e água) até as peneiras de separação do minério dos outros materiais. No processo de lavagem e peneiramento das areias são liberadas, como rejeito, as frações finas (argilosa) que costumam ser dispostas em tanques de decantação, nos quais sofrem um processo de clarificação natural e retornam ao corpo d’água.

A exploração de areia em leito de rio afeta principalmente as margens desse corpo d’água. Com a retirada da mata ciliar para implantação dos portos de areia, os taludes muitas vezes se desestabilizam e geram um maior aporte de sedimentos, aumentando assim as chances de erosão ao redor do estabelecimento (Bacci, 1994). Essa atividade pode provocar ainda o desbarrancamento das margens, alargamento e aprofundamento da calha do rio, e, em caso de cursos fluviais de pequeno porte, é relativamente comum o desvio do curso mediante diques de contenção (Martos, 1992).

De modo geral, as alterações na calha do rio são resultado da má operação das dragas. Os operadores das máquinas não possuem a formação necessária para o conhecimento das conseqüências do aprofundamento das dragas nas margens e no fundo do corpo d’água.

Se existirem focos de erosão ou má drenagem também haverá aumento na carga de sedimentos nos cursos de água, causando o seu assoreamento e favorecendo a ocorrência de inundações. Isto pode acontecer quando rejeitos são depositados em pilhas de bota-fora e ficam expostos principalmente ao efeito da chuva (Almeida, 2002).

Outro possível impacto causado pela extração em leito de rio é a contaminação das águas superficiais e subterrâneas pelos efluentes líquidos e pelos produtos químicos 
utilizados no processo de lavagem do material (Oliveira, 2000), além da possibilidade de vazamento de óleo das dragas.

Segundo Espíndola et al. (2003), a extração de areia em leito de rio não é considerada poluidora, mas sim degradadora do meio ambiente. Apesar de não ser geradora direta de metais além das concentrações naturais presentes no solo local, essa atividade pode contribuir indiretamente para a introdução de metais nas águas intersticiais e no hipolíminio da coluna d’água, uma vez que, promovendo a ressuspensão de sedimentos, ocorre a reoxidação dos mesmos, podendo ocasionar a mobilização de metais para a fase aquosa, ou seja, ocorre redisponibilização dessas substâncias em níveis potencialmente tóxicos (Christensen, 1998 citado por Espíndola et al., 2003).

Silvério (1999), trabalhando com microcosmos de sedimentos submetidos à aeração natural dos ventos, bioturbação e condições artificiais de dragagem e aeração, observou que a aeração artificial dos sedimentos promove aumento na mobilização de metais potencialmente biodisponíveis e conseqüente aumento nas respostas de toxicidade.

Outra conseqüência da aeração e oxidação dos sedimentos durante as operações de dragagem é a possibilidade de redução do $\mathrm{pH}$ em níveis letais para a vida aquática, diretamente, ou pela liberação de metais (Christensen, 1998, citado por Espíndola et al., 2003).

O principal e mais visível efeito impactante da dragagem sobre a água é o aumento da turbidez decorrente do aumento dos sólidos totais suspensos. A turbidez, quando é alta, afeta a qualidade da água, reduzindo a transparência e diminuindo a capacidade das plantas aquáticas de realizar a fotossíntese, além de provocar a obstrução das guelras dos peixes, danificar os ovos e afetar a população de macroinvertebrados (Brigante et al., 2003b)

Brigante et al. (2003a) afirmam que a atividade de extração de areia em leito de rio causa desequilíbrios nos sistemas aquáticos. Em um trecho do Rio Mogi-Guaçu, considerado crítico pela intensidade da atividade de mineração, as análises químicas e toxicológicas da água e do sedimento revelaram condições de distúrbios e contaminação 
desses compartimentos por metais e efeitos tóxicos agudos provocados especialmente pelo sedimento.

\subsection{Recuperação de matas ciliares}

Embora a atividade de mineração de areia em leito de rio seja responsável por muitos impactos ao ambiente, o impacto ambiental mais perceptivo é o desmatamento das florestas ciliares dos corpos de água em que estes empreendimentos estão inseridos.

A conceituação de florestas ciliares abrange todos os tipos de vegetação arbórea vinculada à beira dos rios. Trata-se de uma vegetação florestal ocorrente nas margens dos cursos d'água, independente de sua região de ocorrência e de sua composição florística (Ab’Saber, 2000). O conceito de ecossistema ripário engloba a mata ciliar e o conjunto de interações ripárias, compondo uma unidade geoecológica da paisagem que apresenta extrema dinâmica, diversidade e complexidade (Lima, 2003).

As zonas ripárias constituem a interface entre os ecossistemas terrestre e aquático e caracterizam um ecótono que desempenha importante papel ambiental de manutenção dos recursos hídricos, em termos de vazão, de qualidade da água e equilíbrio das interações ecológicas (Lima, 2003).

Além disso, as matas ripárias desempenham controle significativo nos processos que mantêm a saúde da microbacia hidrográfica e do ecossistema aquático, mantendo a estabilidade das margens dos rios, a dinâmica e hidráulica dos canais, e o controle da temperatura da água através do sombreamento que proporcionam, além de permitirem a dissipação de energia e a criação de micro hábitats diversificados (Lima, 2003). Também regulam a capacidade de armazenamento de água na bacia e retêm a poluição difusa com a contenção do fluxo de nutrientes e sedimentos deslocados dos ecossistemas terrestres (Simões, 2001).

A mata ciliar apresenta uma alta variação em termos de estrutura, composição e distribuição espacial das espécies (Lima \& Zakia, 2000), constituindo um mosaico de condições ecológicas distintas, cada qual com suas particularidades fisionômicas, florísticas e estruturais (Rodrigues, 2000). Segundo Rodrigues \& Nave (2000), essas 
formações possuem baixos valores de similaridade florística, mesmo entre áreas de grande proximidade espacial, o que torna muito complexa a definição de sua composição florística.

Essa heterogeneidade é função da complexa integração de diversos fatores, como o tamanho da faixa florestal, a performance diferencial das espécies na dinâmica sucessional, o estado de conservação ou degradação dos remanescentes existentes, o acaso da chegada de propágulos no processo de estabelecimento dessas formações florestais (Rodrigues \& Shepherd, 2000; Rodrigues \& Nave, 2000), a interação entre a hidrologia e a geologia local, especialmente na escala de microbacia (Lima, 2003), bem como a heterogeneidade espacial e temporal das características físicas do ambiente, além de outros fatores que atuam na seletividade das espécies (Rodrigues, 2000).

As variações espaciais das características físicas do ambiente podem estar embasadas no gradiente topográfico típico da condição ribeirinha, que permite a existência de gradientes de umidade, de fertilidade e de constituição física do solo (Rodrigues, 1992; Durigan \& Leitão Filho, 1995). Já as variações temporais importantes para a heterogeneidade vegetacional podem estar relacionadas com as flutuações climáticas do Pleistoceno-Holoceno (Oliveira-Filho \& Ratter, 1995) e com as fragmentações e perturbações antrópicas atuais e passadas (Lima, 1989; Behling, 1995).

As alterações antrópicas que mais ocasionam o desmatamento das formações ciliares envolvem processos de ocupação e abertura de terras, marcados pela perspectiva temporal de ganho econômico em curto prazo (Mueller, 1998).

Esse processo de ocupação, não só para a agricultura, mas para outras atividades como a de mineração, tem acarretado prejuízos ambientais irreversíveis que dificilmente serão absorvidos pelos agentes que os ocasionaram, simplesmente por não assumirem a responsabilidade pelos danos (Mueller, 1998). Segundo Martos (1992), as principais causas da não recuperação das áreas alteradas por portos de areia são externas à vontade dos mineradores, já que a crise econômica do País, a falta de culturas geral e ambiental e a inadequação da legislação para este tipo de atividade são as reais responsáveis pela não restauração e não reabilitação das áreas degradadas pela atividade minerária. 
Outro motivo que leva ao desinteresse na reposição de matas ciliares é que essa atividade de recuperação afeta diretamente as empresas que exploram economicamente essas áreas e, sob a ótica privada, representa uma interferência no direito de propriedade. A análise do custo-benefício da reposição e da manutenção dessas áreas consiste em uma tarefa complexa, em que, de um lado há um aparente interesse social em dispor de mais qualidade ambiental, ao passo que por outro lado benefícios ou danos ambientais são externalidades não captadas pelo mercado e não são adequadamente incluídos no processo de decisão empresarial (Brugnaro, 2000).

A reposição de matas ciliares consiste em uma perspectiva que pode vir do consenso, da decisão política ou por força legal (Brugnaro, 2000). Na prática a reposição tem ocorrido por força legal. A principal exigência dos órgãos ambientais competentes tem sido a adoção do reflorestamento como medida mitigadora dos impactos da ocupação das matas ciliares, as quais são reconhecidas por lei (Código Florestal Brasileiro - Lei Federal 4.771/65) como APPs. No entanto, as atividades de recuperação exigidas pelos órgãos ambientais não devem se resumir no plantio de algumas árvores nas margens do rio (Bacci, 1994), sendo necessário que os órgãos monitorem a obrigatória adoção de medidas e técnicas que assegurem a efetiva proteção e manutenção das funções ecológicas destas áreas.

A ocupação das áreas de mata ciliar pelas atividades de mineração tem conduzido à perda irreversível de parte da biodiversidade. Segundo Kageyama et al. (1989), a recomposição dessas áreas degradadas é importante para a restauração das funções básicas de manutenção da diversidade animal e vegetal, do restabelecimento do regime hídrico e de nutrientes e da contenção da erosão. Tanto na recuperação como na restauração de áreas degradadas devem ser considerados detalhes da ecologia básica, sendo muito significativa a preocupação com os processos e interações ecológicas (Reis \& Kageyama, 2003).

Para se avaliar o perfil de alteração em matas ciliares devem ser levados em consideração os fatores externos que estão interligados aos processos degradantes (Chesworth, 1992, citado por Kopezinski, 2000). Estudos para recuperação paisagística de áreas de extração de areia mostraram que em alguns casos é necessário desassorear 
corpos d'água próximos à área de extração para depois reiniciar o processo de recuperação da área através de revegetação (Srishendruder et al., 1984, citado por Kopezinski, 2000).

A recuperação através da regeneração artificial, respaldada pelo plantio de espécies vegetais, é considerada uma ação essencial à reestruturação de parte da diversidade perdida, pois acelera o processo de sucessão natural (Lourenzo, 1991).

Dias \& Griffith (1998) destacam que o processo de recuperação dessas áreas, além de complexo, demanda tempo, devendo ser iniciado no planejamento do empreendimento e finalizado após o encerramento das atividades minerárias, para que haja o restabelecimento das condições de equilíbrio e da sustentabilidade que existiam no sistema natural.

No Brasil, importantes subsídios para a recuperação de áreas degradadas têm surgido de estudos da ecologia florestal dos diferentes ecossistemas impactados. Existem várias atividades recomendadas para a recuperação de formações ciliares, como o simples isolamento da área nos casos em que a resiliência foi mantida. Quando a degradação resulta numa baixa resiliência, são necessárias ações complementares como a identificação e a retirada de fatores de degradação da floresta ciliar (Rodrigues \& Gandolfi, 2000), como acontece nos processos de degradação promovida pela extração de areia.

Com o objetivo de estabelecer normas para recuperação de áreas degredadas do Estado de São Paulo, foi promulgada a Resolução SMA 21/01 que estabeleceu um número mínimo de espécies vegetais a serem plantadas por hectare reflorestado.

O modelo de recuperação de mata ciliar degradada mais empregado atualmente é o de plantio de espécies nativas. Para aplicação desse modelo são necessários alguns cuidados prévios, como a utilização de vegetação heterogênea com ocorrência regional e seleção de espécies mais adaptáveis às condições de umidade do solo (Barbosa, 2000).

A recuperação de matas ciliares tem se baseado em critérios de distribuição das espécies, determinados através de levantamentos florísticos e estudos fitossociológicos de áreas naturais adjacentes e combinados às categorias de grupos ecofisiológicos de sucessão. Botelho et al. (1995) consideram o critério sucessional como o de maior êxito 
devido ao rápido recobrimento do solo e à garantia de auto-renovação da floresta. Contudo, sabe-se que a carência de inventários florestais somada à baixa diversidade de espécies disponíveis nos viveiros é uma realidade a ser transposta para que aumentem os casos de recuperações bem sucedidas.

Um outro critério recomendado para recuperação de áreas é a formação de um substrato no local que daria condição ao solo degradado de receber e de sustentar as espécies vegetais (Williams et al., 1990), conduzindo o processo de regeneração e consolidando uma nova camada de solo fértil, que acaba por controlar a erosão e evitar a poluição de águas, além de promover o retorno de vida ao solo.

No caso da restauração de áreas mineradas esse critério pode ser aplicado pela transferência ou transplante de propágulos alóctones, aproveitando-se a camada superficial do solo antes da eliminação da floresta e espalhando-a na área degradada, constituindo um banco de sementes. Segundo Rodrigues \& Gandolfi (2000) dados mostram que este procedimento é eficiente devido aos seus baixos custos e fácil operacionalização.

Apesar da grande variedade de métodos de recuperação, ainda é necessário o estabelecimento de indicadores de avaliação e monitoramento que possibilitem análises periódicas das propostas de recuperação e assim verificar se os objetivos estão sendo alcançados. O uso de indicadores tem sido largamente discutido na literatura (Van der Haveren et al, 1997; Andersen, 1997; Janzen, 1997; Sautter, 1998; Rodrigues \& Gandolfi, 1998) e, devido à grande diversidade de ambientes e de situações de recuperação, é pouco provável que sejam eleitos critérios ou indicadores de uso universal (Rodrigues \& Gandolfi, 2000).

Segundo Lima \& Zakia (1998), para análise dos possíveis efeitos de uma atividade florestal sobre os recursos hídricos, devem ser utilizados indicadores hidrológicos, os quais inclusive operam em diferentes escalas, envolvendo aspectos tais como a inadequação de estradas, a compactação do solo, a erosão, variações na turbidez e no oxigênio dissolvido da água e inclusive a adequação da atividade frente à representatividade da área como ecossistema. Neste sentido, a extensão e a condição da mata ciliar podem ser consideradas indicadores hidrológicos pertencentes à escala meso, 
dentro do conjunto de escalas proposto por Lima \& Zakia (1998). Todavia, essa condição por si só, não garante a manutenção da saúde hidrológica do corpo d’água $\left(\right.$ Lima $\left.^{3}\right)$. Essa saúde hidrológica, por sua vez, seria uma condição viável e compatível com o uso dos recursos naturais.

Nesse contexto, a degradação das formações ciliares não deve ser discutida sem antes considerar a sua inserção no contexto do uso e ocupação do solo, uma vez que o uso incorreto da paisagem e fundamentalmente dos solos (Rodrigues \& Gandolfi, 2000) prejudica a função de proteção física da mata ciliar.

A Secretaria do Meio Ambiente do Estado de São Paulo, com o objetivo de desenvolver um programa de repovoamento florestal, realizou o levantamento dos projetos de plantio em matas ciliares bem sucedidos no estado, com bons resultados no que diz respeito ao desempenho de indicadores de medidas, mais especificamente, parâmetros biométricos, como altura das árvores, tamanho das copas e fechamento do dossel, bem como indicadores de restabelecimento dos processos ecológicos nessas florestas plantadas (São Paulo, 2002).

Muitos desses projetos de recuperação têm atribuído seu sucesso à presença de fragmentos florestais contíguos que possibilitam a ação de agentes dispersores, facilitam e aumentam o aporte de propágulos e permitem uma otimização do processo de regeneração das áreas plantadas.

Outro fator importante para o sucesso dos plantios é o automonitoramento proposto por Prado Filho \& Souza (2002a; b), que consiste em uma ferramenta para a gestão de empreendimentos através do acompanhamento das áreas degradadas que passaram por intervenções de recuperação. Oliveira \& Ribeiro Junior (2000) sugerem o acompanhamento de variáveis físicas, químicas e biológicas do substrato, bem como da evolução da cobertura vegetal implantada e da fauna local que sofreu algum tipo de impacto decorrido da degradação e que estaria em processo de recuperação. O automonitoramento serviria, inclusive, como respaldo da sociedade a respeito do

\footnotetext{
3 LIMA, W.P. (Universidade de São Paulo. Departamento de Ciências Florestais). Anotações de aula, 2004.
} 
desempenho ambiental de um empreendimento passível de impacto sobre o meio ambiente (Prado Filho \& Souza, 2002a). 


\section{MATERIAL E MÉTODOS}

\section{1 Área de estudo}

A Bacia Hidrográfica do Rio Corumbataí (BHC) compõe uma das sub-bacias do Rio Piracicaba e está localizada no centro do Estado de São Paulo, em sua maior parte na Depressão Periférica Paulista, mais especificamente na região do Médio Tietê, entre as latitudes $22^{\circ} 04^{\prime} 46^{\prime \prime}$ s e $22^{\circ} 41^{\prime} 28^{\prime}$ 's e longitudes $47^{\circ} 26^{\prime} 23^{\prime}$ 'W e $47^{\circ} 56^{\prime} 15^{\prime \prime} \mathrm{W}$ (Figura 1).

Essa bacia hidrográfica possui 170.775,6 ha, divididos em cinco sub-bacias de menores dimensões: Alto Corumbataí, Médio Corumbataí, Baixo Corumbataí, Passa Cinco e Ribeirão Claro (Valente, 2001) (Tabela 1).

O principal corpo d’água dessa bacia é o Rio Corumbataí, um rio de classe II (Decreto Estadual 20/77), que tem sua origem na Serra do Cuscuzeiro, a $1058 \mathrm{~m}$ de altitude, no município de Analândia e sua foz no Rio Piracicaba, já no município de Piracicaba (Brugnaro, 2000). Juntamente com seus principais tributários (ribeirão Cabeça, ribeirão Passa Cinco e ribeirão Claro) o rio Corumbataí é essencial no abastecimento em quantidade e qualidade de água de oito municípios da bacia, o que equivale a uma população de 500.000 habitantes aproximadamente (IPEF, 2001) (Figura 2).

A bacia hidrográfica em estudo compõe efetivamente os limites dos municípios de Corumbataí, Ipeúna, Rio Claro e Santa Gertrudes e parte dos limites de Analândia, Charqueada, Itirapina e Piracicaba (Mendes, 2004) (Figura 3). As principais atividades econômicas dessa região estão cunhadas no cultivo da cana-de-açúcar, na pastagem, na fruticultura e nos reflorestamentos comerciais (Garcia 2005). 

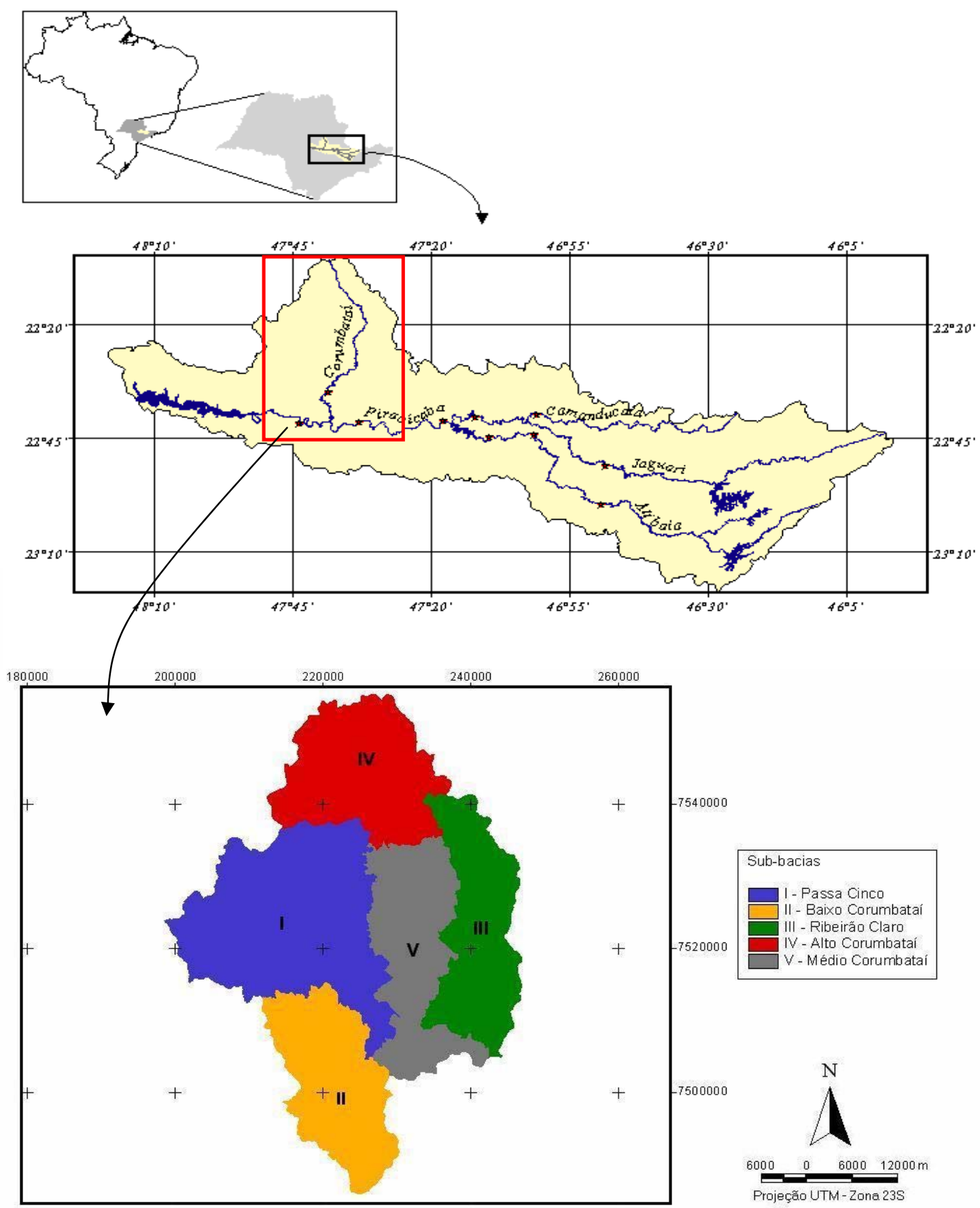

Figura 1 - Localização e limites da Bacia Hidrográfica do Rio Corumbataí e sua divisão em cinco sub-bacias. Fontes: banco de dados do Plano diretor da Bacia do Rio Corumbataí elaborado por IPEF (2001) e Projeto piracena (2005) 
Tabela 1. Área total (ha) da Bacia Hidrográfica do Rio Corumbataí e de suas divisões em cinco principais sub-bacias

\begin{tabular}{lc}
\hline Sub-bacias & Área (ha) \\
\hline Alto Corumbataí & 31801,68 \\
Médio Corumbataí & 29316,60 \\
Baixo Corumbataí & 28724,84 \\
Passa Cinco & 52757,60 \\
Ribeirão Claro & 28174,90 \\
Total & 170775,62 \\
\hline
\end{tabular}

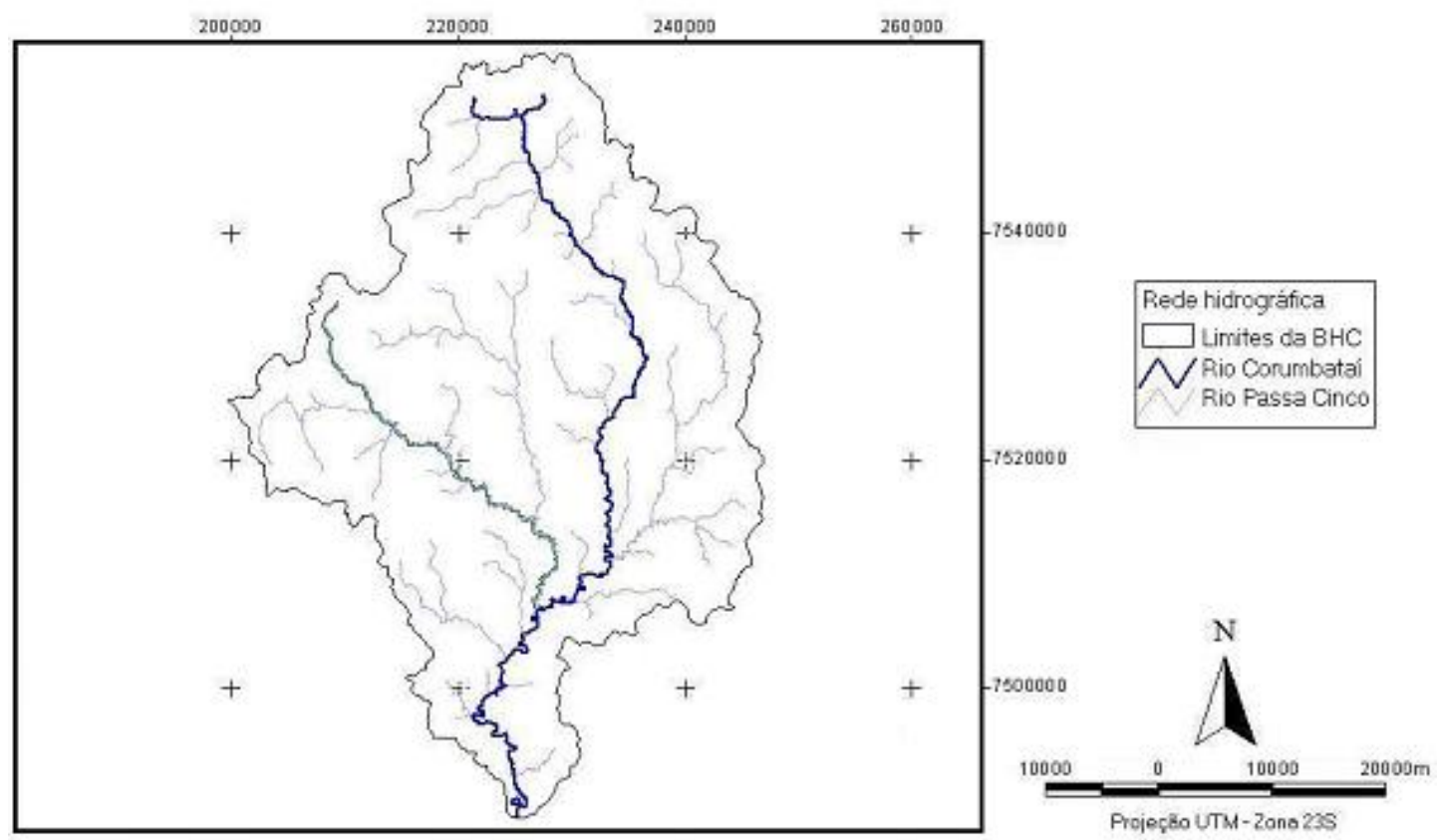

Figura 2 - Rede hidrográfica principal da Bacia do Rio Corumbataí, destacando o Rio Corumbataí e o seu principal tributário, o Rio Passa Cinco. Fonte: banco de dados do Plano diretor da Bacia do Rio Corumbataí elaborado por IPEF, 2001

Pelo fato da região ter crescente expansão urbana aliada ao desenvolvimento expressivo do setor primário e ainda, por possuir características importantes do relevo, 
como as cuestas basálticas de grande fragilidade ambiental, e manter áreas ocupadas por vegetação remanescente (Camargo, 1995 e Gross, 1995, citados por IPEF, 2001), foi instituída pelo Decreto $n^{0}$. 20.960, de 8 de junho de 1983, a Área de Proteção Ambiental (APA) Corumbataí-Botucatu-Tejupá (IPEF, 2001), com o intuito de preservar a diversidade biológica e os recursos naturais e permitir o uso sustentável de parte desses recursos (Camargo, 1995, citado por IPEF, 2001) (Figura 3).

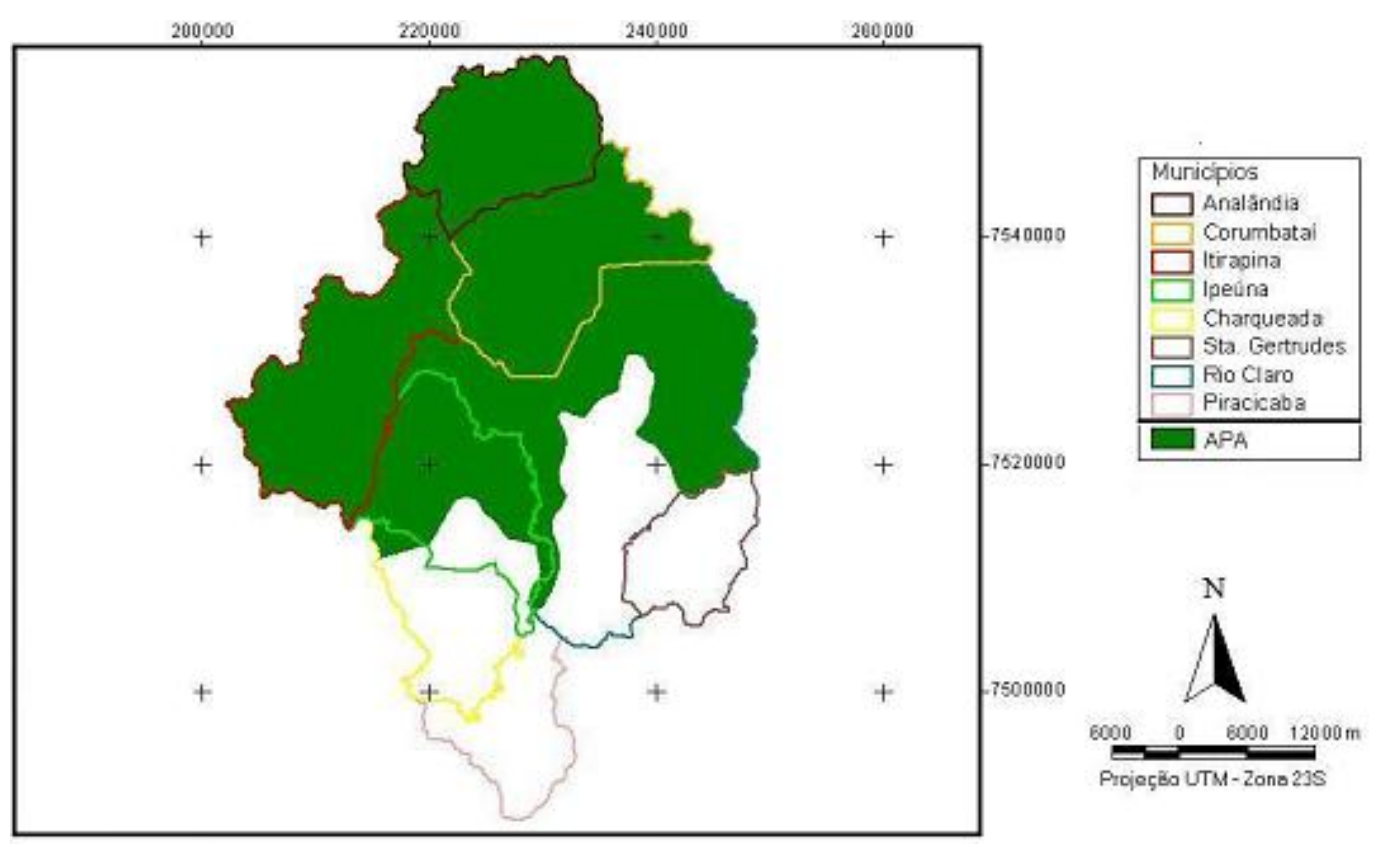

Figura 3 - Municípios abrangidos pela Bacia Hidrográfica do Rio Corumbataí, com destaque daqueles que fazem parte da APA Corumbataí-Botucatu-Tejupá. Fonte: banco de dados do Plano diretor da Bacia do Rio Corumbataí elaborado por IPEF, 2001

\subsubsection{Caracterização edafoclimática}

As condições climáticas da região podem ser classificadas, segundo Köppen (1948), como clima Cwa, subtropical, de inverno seco, verão quente e chuvoso com temperatura média do mês mais quente superior a $22^{\circ} \mathrm{C}$. 
Os dados climáticos do município de Piracicaba no período de 2000 a 2004 (CIIAGRO, 2005) indicam a ocorrência de duas estações climáticas bem definidas, uma chuvosa, entre outubro e março, que corresponde a 72,2\% da precipitação anual e outra seca, entre abril e setembro, correspondendo a 27,8\% da precipitação anual. A precipitação anual média do município nesse período foi de $1.266,8 \mathrm{~mm}$, com maior precipitação em janeiro $(264,84 \mathrm{~mm})$ e menor precipitação em junho $(23,16 \mathrm{~mm})$.

O relevo da bacia em estudo é muito heterogêneo, variando entre áreas planas e muito íngremes (Tabela 2). Predominam terrenos fortemente inclinados nas sub-bacias do Rio Passa Cinco e do Alto Corumbataí, enquanto que nas sub-bacias do Médio Corumbataí e do Ribeirão Claro predominam extensas áreas planas e pouco íngremes (Valente, 2001).

Tabela 2. Classes de declividade da Bacia do Rio Corumbataí

\begin{tabular}{lll}
\hline Classe de declividade (\%) & Área (ha) & Área (\%) \\
\hline$<2$ & 684,38 & 40,08 \\
$2-5$ & 14649,08 & 8,58 \\
$5-10$ & 30521,40 & 17,87 \\
$10-15$ & 25409,24 & 14,88 \\
$15-45$ & 29474,44 & 17,26 \\
$45-70$ & 1657,64 & 0,97 \\
$>70$ & 625,00 & 0,37 \\
Total & 17775,62 & 100,00 \\
\hline
\end{tabular}

A Bacia do Corumbataí é composta pelas formações geológicas Rio Claro, Pirambóia, Corumbataí e Iratí. A formação Corumbataí é a de maior expressão na área de estudo pelo fato de representar o substrato dos leitos dos principais rios da bacia. Entretanto, o predomínio de areia fina em todo o leito do Rio Corumbataí pode estar relacionado à grande área ocupada pelas formações Pirambóia e Botucatu, uma vez que a fração arenosa encontrada no leito desse rio é muito semelhante à dessas formações (Bacci, 1994). 
A formação Botucatu pode ocorrer eventualmente em faixas amplas, com espessura média de 50 a 70m, não ultrapassando 150m (Soares, 1972, citado por Bacci, 1994) e podendo se apresentar coberta por extensos areais aluvionares ou coluviais, provindos de áreas mais altas da bacia (Bacci, 1994).

A ocorrência de fração de areia média associada a uma fração mais grosseira, pode representar influência da formação Rio Claro ou influência de frações mais grosseiras de eventuais afloramentos da formação Pirambóia, que podem ser visualizados em regiões onde ocorrem voçorocas e extração de cascalho do leito de rios (Bacci, 1994).

A heterogeneidade do relevo, associada às condições climáticas e geológicas da bacia e influenciada por outros fatores, condiciona a grande variedade de solos ocorrentes nessa área. Os grandes grupos de solos encontrados são os Latossolos, Argissolos, Nitossolos, Gleissolos, Chernossolos e Neossolos (Valente, 2001).

Os Latossolos e os Argissolos predominam na bacia, com 76,32\% da área total, sendo seguidos pelos Neossolos, com 22,43\% e os Gleissolos, Nitossolos e Chernossolos em menor percentagem (Tabela 3).

Tabela 3. Valores em área (ha) e valores relativos (\%) das classes de solos predominantes na Bacia do Rio Corumbataí

\begin{tabular}{llll}
\hline Tipo de Solo & Sigla & Área (ha) & Área (\%) \\
\hline Latossolo Roxo & LR & 11476,52 & 6,72 \\
Latossolo VermelhoEscuro & LE & 3016,56 & 1,77 \\
Latossolo Vermelho Amarelo & LV & 36838,04 & 21,58 \\
Podzólico Vermelho Amerelo & PV & 74198,24 & 43,46 \\
Podzólico Vermelho Escuro & PE & 4769,60 & 2,79 \\
Terra Roxa Estruturada & TE & 691,80 & 0,41 \\
Areia Quartzosa & AQ & 15067,24 & 8,83 \\
Solos Litólicos & Li & 23224,28 & 13,6 \\
Solos Hidromórficos & Hi & 689,36 & 0,4 \\
Brunizem Avermelhado & BV & 312,12 & 0,18 \\
\hline
\end{tabular}


Quanto ao potencial de erodibilidade, há a predominância de solos com alto valor dessa variável na bacia. Cerca de 56,7\% dos solos da área são classificados como de erodibilidade muito alta e 31,6\% como de erodibilidade alta (Figura 4), o que influi diretamente na turbidez dos corpos d’água (IPEF, 2001), sendo essa suscetibilidade maior nos terrenos mais arenosos e naqueles mais escarpados, independentemente do tipo de substrato (Reis, 2004).

Na região que abrange os municípios de Analândia, Corumbataí e Itirapina, ocorre elevada erosividade dos solos e valores médios dessa variável ocorrem na região dos municípios de Santa Gertrudes e Rio Claro. Confrontando essa erosividade com a elevada erodibilidade da bacia, fica evidente que as regiões com os valores mais elevados e médios de erosividade têm maior predisposição à ocorrência de erosão (IPEF, 2001).

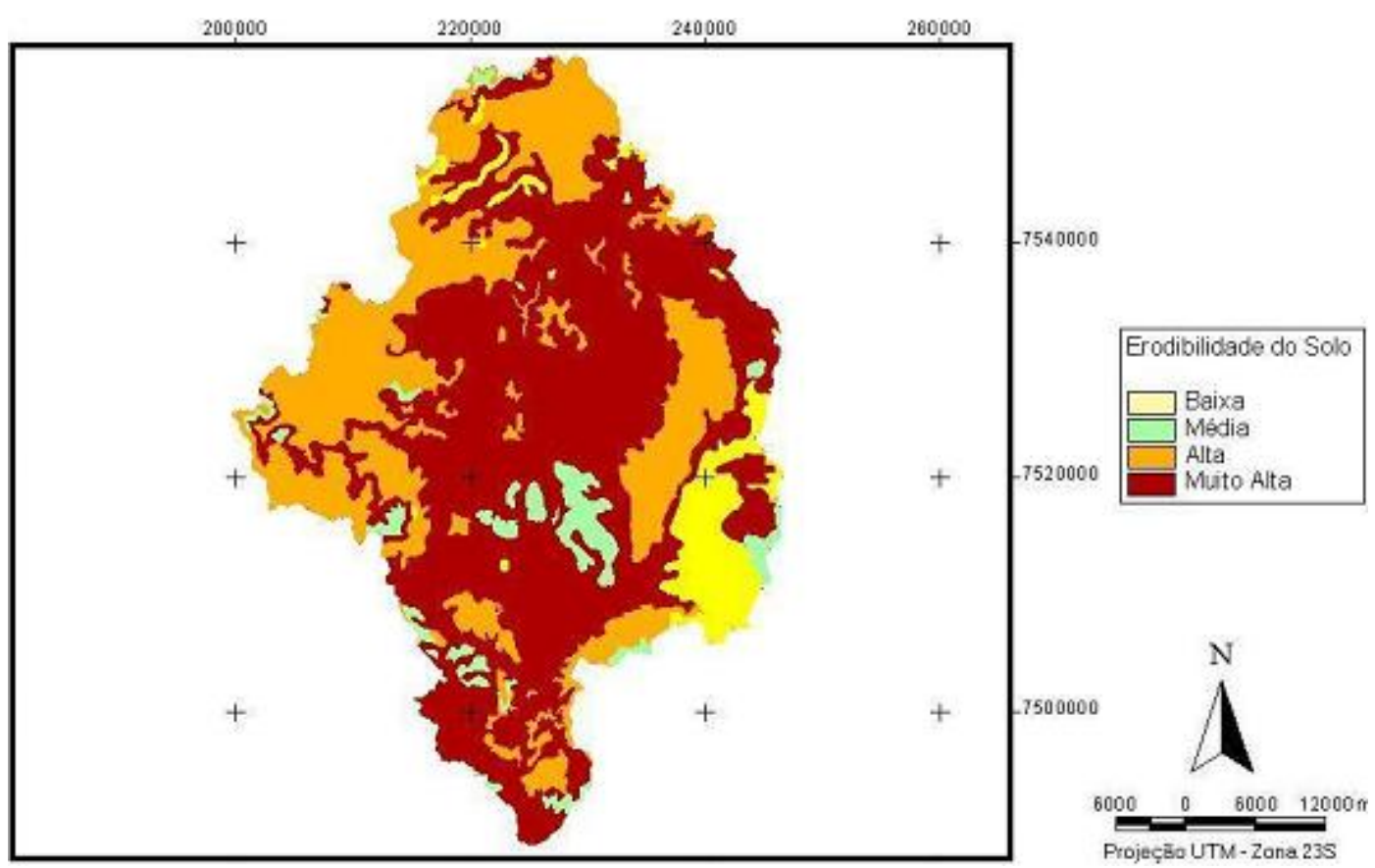

Figura 4 - Erodibilidade dos solos da Bacia Hidrográfica do Rio Corumbataí. Fonte: banco de dados do Plano diretor da Bacia do Rio Corumbataí elaborado por IPEF, 2001 


\subsubsection{Caracterização do uso e da cobertura do solo}

Com relação ao uso do solo da bacia, podem ser atribuídos 10 tipos principais de uso apresentados na Figura 5. A maior parte da área da bacia está ocupada pela pastagem, sendo seguida pela monocultura de cana-de-açúcar, florestas nativas e plantadas, fruticultura e áreas urbanas.

Na sub-bacia do Alto Corumbataí predomina a atividade de pastagem, enquanto que no Médio Corumbataí estão concentradas as principais fontes de poluição industrial e urbana. No trecho que corresponde à sub-bacia do Baixo Corumbataí predominam as atividades de extração de areia em leito de rio e a monocultura da cana-de-açúcar (Fischer, 2003).

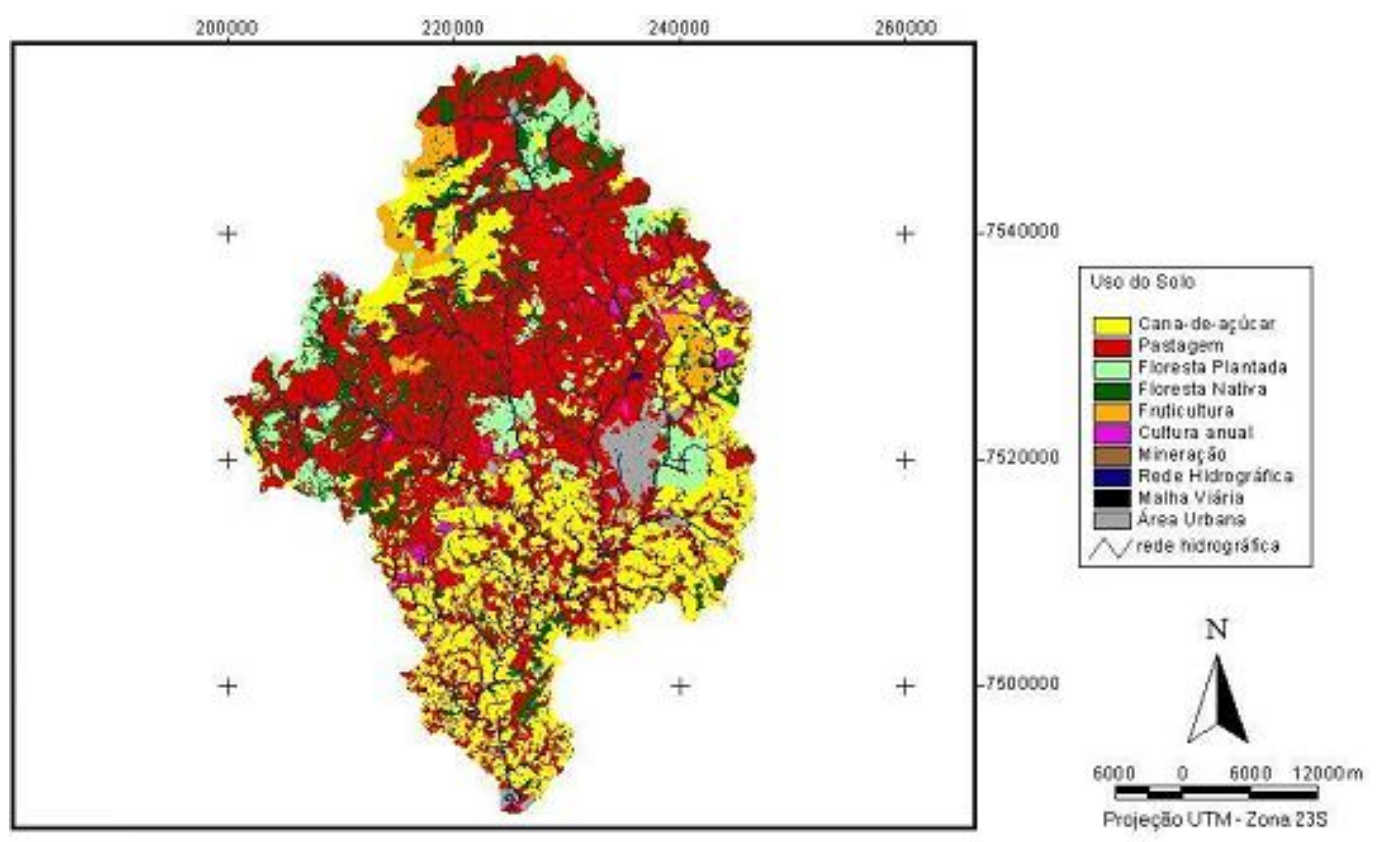

Figura 5 - Uso e ocupação do solo da Bacia do Corumbataí. Fonte: banco de dados do Plano diretor da Bacia do Rio Corumbataí elaborado por IPEF, 2001

Das Áreas de Preservação Permanente (APP), 6,10\% são classificadas como de alta prioridade para a recuperação e conservação e 14,7\% são classificadas como de alta 
prioridade de recuperação. As APPs destinadas à pastagem correspondem a 56,49\% da área da bacia, havendo ainda outros usos como monocultura de cana-de-açúcar, fruticultura com predominância de cítricos, culturas anuais, florestas plantadas e áreas urbanas (Mendes, 2004).

A bacia do Rio Corumbataí deveria possuir, em termos legais, cerca de 35\% de cobertura florestal, representada por $20 \%$ de reserva legal e cerca de $15 \%$ de APP, representadas, principalmente, pelas matas ciliares (IPEF, 2001). No entanto, a percentagem total de cobertura florestal ocorrente na bacia representa 12,26\% da área total, o que significa, portanto, um déficit de cerca de $23 \%$ de cobertura florestal (IPEF, 2001).

A evolução da paisagem da bacia, de acordo com resultados obtidos por Koffler (1993), Brugnaro (2000) e Valente (2001), válidos para os anos de 1991, 1998 e 2001, respectivamente, demonstra que a bacia possui uma matriz de uso e cobertura predominantemente agrícola (Valente, 2001) e que os principais usos do solo da bacia apresentaram ligeira variação, como no caso das pastagens, bem como da monocultura de cana-de-açúcar, que teve um leve decréscimo, e um incremento significativo na cobertura florestal nativa (Tabela 4).

Tabela 4. Modificações no uso e na cobertura do solo da Bacia do Corumbataí no período de 1991-2001

\begin{tabular}{lcccc}
\hline Uso e cobertura do solo (\%) & $\mathbf{1 9 9 1}$ & $\mathbf{1 9 9 6}$ & $\mathbf{1 9 9 8}$ & $\mathbf{2 0 0 1}$ \\
\hline Pastagem & 47,0 & 39,7 & 40,8 & 43,7 \\
Cana-de-açúcar & 31,8 & 35,2 & 26,7 & 25,6 \\
Floresta Plantada & 6,9 & 10,3 & 16,5 & 7,3 \\
Floresta Nativa & 4,9 & 7,2 & 9,6 & 11,1 \\
Fruticultura & 2,1 & - & 0,8 & 2,8 \\
Cultura Anual & 0,4 & 2,7 & 2,3 & 1,0 \\
Mineração & - & - & 0,1 & 0,1 \\
\hline
\end{tabular}




\subsubsection{Caracterização fitogeográfica}

A distribuição da cobertura vegetal original da região esteve condicionada às características relacionadas ao clima, ao tipo de solo e principalmente ao relevo da BHC (Oliveira \& Prado, 1984, citado por Valente, 2001).

As características dos solos e do clima favoreceram a existência de florestas e formações savânicas que naturalmente recobriam a área da bacia (Koffler, 1993). Essa relação entre vegetação original e solos possibilitou o desenvolvimento de fitofisionomias savânicas sobre solos muito profundos, permeáveis e de baixo potencial nutricional e de floresta tropical subcaducifólia sobre solos profundos de textura argilosa com maior teor de nutrientes (Oliveira \& Prado 1984, citado por Valente, 2001). Entretanto, essas características edáficas e climáticas também favoreceram a expansão agrícola, o que desencadeou o processo de fragmentação da vegetação original (Koffler, 1993) atualmente distribuídas em 5.828 fragmentos aproximadamente (Valente, 2001).

Os trabalhos de Troppmair (1969) e Camargo et al. (1971) mostram que a expansão da cultura cafeeira, nos meados do século XIX, foi o fator responsável pela devastação da cobertura vegetal original da bacia do rio Corumbataí. Segundo Garcia (2005), além das atividades de cafeicultura, o avanço das ferrovias com máquinas a vapor e as numerosas olarias e serrarias que se instalaram na região no século XIX, teriam sido responsáveis pelo desaparecimento da vegetação original, restando atualmente apenas fragmentos de diversos tamanhos e condições de conservação.

Atualmente, restam pequenos fragmentos da paisagem original da bacia, em sua maioria inferiores a cinco hectares (Brito, 2001). De acordo com Rodrigues (1999), os remanescentes ainda existentes representam as formações da floresta estacional semidecidual, floresta ripária, floresta paludosa, floresta estacional decidual e as formas fitofisionômicas da savana (cerrado lato sensu).

Esse predomínio de pequenos fragmentos florestais é comum em paisagens de Floresta Atlântica (Rodrigues, 1992) em virtude do histórico de exploração e evolução do uso da terra que esse bioma vem sofrendo. Nesse contexto de devastação, o principal 
problema deste padrão é que, quanto mais área florestada estiver contida em pequenos fragmentos, mais intensamente estariam sujeitas aos efeitos de borda (Rodrigues, 1992).

Rodrigues (1999) destaca a importância da preservação dos poucos remanescentes de vegetação natural ainda existentes na região, especialmente em virtude do pouco conhecimento acumulado a respeito dessas unidades fitogeográficas e a elevada diversidade regional, com um grande número de espécies em estreita relação com a diversidade de ambientes ainda existentes.

\subsubsection{Caracterização sócio-econômica}

Segundo estimativas populacionais apresentadas por Brugnaro (2000), a população da bacia gira em torno de 493 mil habitantes, com maior número nos município de Piracicaba (302.886 habitantes) e Rio Claro (153.389 habitantes). Do total de habitantes da bacia, 4,6\% estão presentes na zona rural, o que é baixo se for considerado que, no Estado de São Paulo, 6,9\% da população vive fora das cidades.

Segundo Garcia (2005), o desenvolvimento industrial da região se encontra estagnado economicamente e tem pouca expressividade, apesar dessa região apresentar inúmeras condições favoráveis ao desenvolvimento industrial, como privilegiado posicionamento geográfico, proximidade da capital, infraestrutura ferroviária e rodoviária, contingente de mão-de-obra, etc. Segundo o autor, os municípios que compõem a bacia, em sua maioria, têm uma industrialização baseada em pequenas e médias indústrias, com destaque para o município de Rio Claro, que pode ser considerado de importância secundária no cenário industrial paulista.

Ainda segundo o autor supracitado, as principais atividades econômicas da bacia estão ligadas ao setor primário, destacando-se a monocultura da cana-de-açúcar, a produção de Pinus spp. e Eucalyptus spp., a pastagem e a fruticultura. As atividades de mineração têm um papel tradicional na estrutura industrial da região, com desenvolvimento mais acentuado da extração de calcários silicosos, argila e barro, bem como da extração de areia, concentrada nas sub-bacias do Alto e Médio Corumbataí (Garcia, 2005). 
A principio, a atividade ceramista da região se baseava no fabrico de lajotas coloniais e telhas francesas e paulistas. A partir de meados da década de 80 foram deixados de lado os métodos artesanais de produção que passaram a ser substituídos pelo método de monoqueima. Essa tecnologia melhorou a qualidade dos produtos, otimizou o abastecimento interno e possibilitou a exportação para o Mercosul, colocando a região como importante pólo ceramista do País. A abundância de argila, principal matéria prima para essas empresas, aliada à tecnologia avançada, permite que a produção regional chegue a 5,5 milhões de metros quadrados de pisos e revestimentos e gere, em 17 indústrias de cerâmica, 4.800 empregos diretos e indiretos (Garcia, 2005).

Quanto à mineração de areia, Bacci (1994) relata que essa atividade começou a aparecer na bacia a partir da segunda metade de o século XIX, quando as suas cabeceiras, sem a proteção natural da mata, começaram a perder a areia do paleo-deserto Botucatu. Um dos primeiros relatos de exploração de areia na região foi em 1895, quando foi utilizado esse mineral para a construção da Usina Corumbataí. No entanto, somente em 1967, com a publicação do Código de Mineração, os portos de areia passaram a ser regulamentados. Embora os primeiros pedidos de licenciamento no DNPM surjam apenas em 1973.

Ainda segundo Bacci (1994), no final da década de 80, a produção de areia da bacia decaiu, resultando no abandono dos trechos de extração. Este declínio na produção foi atribuído principalmente às mudanças morfológicas do relevo e de aproveitamento dos solos agrícolas em toda a bacia. Além disso, a recessão econômica e a pressão burocrática das prefeituras e dos órgãos ambientais também contribuíram para o fechamento de algumas mineradoras.

Em meados da década de 90, os estudos de Bacci (1994) identificaram sete empresas de extração de areia licenciadas na bacia, e muitas dessas empresas ainda se mantêm ativas juntamente com outras que surgiram e se regularizaram legalmente. 


\subsection{Estratégia de estudo}

Com o intuito de alcançar os objetivos propostos anteriormente, esta pesquisa teve como estratégia de estudo a execução de três etapas de trabalho detalhadas a seguir na seqüência cronológica em que foram desenvolvidas.

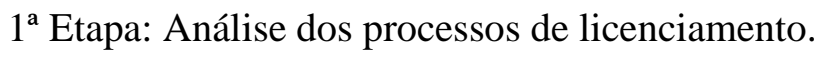

$2^{\mathrm{a}}$ Etapa: Análise de campo.

$3^{\text {a }}$ Etapa: Entrevistas.

O cumprimento dessas etapas permitiu caracterizar:

a) a atividade de extração de areia na bacia do Rio Corumbataí $\quad$ Etapa 1

b) a recuperação das Áreas de Preservação Permanente Etapa 2

c) a percepção ambiental e legal do setor privado Etapa 3

d) as condições e recursos dos órgãos ambientais públicos envolvidos

\subsubsection{Análise dos processos de licenciamento}

Durante o período de maio de 2003 a agosto de 2004, foram consultados os documentos presentes nos processo de licenciamento ambiental das empresas mineradoras de areia a céu aberto e em leito de rio da bacia, encontrados na CETESB Piracicaba, unidade responsável pelos empreendimentos da bacia hidrográfica em estudo.

Os processos de licenciamento possuem importantes instrumentos legais de controle da degradação ambiental, como o PCA e o RCA.

Os planos de recomposição vegetal apresentados pelo empreendedor foram analisados e aprovados pelo DEPRN como medida compensatória e de pré-requisito para a obtenção de licença de instalação do empreendimento. Além disso, o responsável 
pela atividade assina junto a esse órgão um Termo de Compromisso em que se compromete a cumprir as medidas de recuperação acordadas.

Durante as consultas aos processos de licenciamento, foram analisados os planos de recuperação vegetal de todos os portos de areia de extração por dragagem em leito de rio ou de córrego, em que foram obtidas as informações de área e idade dos plantios, espaçamento e densidade das mudas, espécies plantadas, números de espécies plantadas, distribuição das espécies por estádio sucessional e empresas responsáveis pelos projetos. Os dados levantados nesses documentos foram apresentados em paralelo aos estudos de campo realizados nas áreas de plantios com o intuito de facilitar a apresentação dos resultados e das discussões.

Além dos documentos já relacionados, os processos de licenciamento contêm o Memorial de Caracterização do Empreendimento (MCE), que apresenta em formulário padrão as principais características do empreendimento, como a área objeto de pedido de licença e os produtos e rejeitos finais; registro de contatos entre a CETESB, o solicitante e diversos órgãos envolvidos; laudos de vistorias da CETESB, do DEPRN e da Polícia Ambiental; solicitações e concessões de licenças de instalação e funcionamento dos empreendimentos.

Em consulta aos processos da CETESB, foi utilizado um roteiro de coleta de dados com informações pertinentes ao trabalho. Somam-se a esses dados, as informações coletadas, em junho de 2004, em consulta ao Cadastro Mineiro do DNPM, sistema de acesso on line aos arquivos de cadastro das empresas, atualizados no mínimo semanalmente, segundo informações obtidas junto ao órgão (Apêndice 1).

O conjunto de informações obtidas foi reunido em um banco de dados em Excel ${ }^{\circledR}$ for Windows ${ }^{\circledR}$ que permitiu a caracterização da atividade de extração de areia dessa bacia em relação à sua produção, extensão, perspectivas futuras, destino de consumo, tempo médio para as concessões de licenças ambientais junto à CETESB e para a autorização de pesquisa, concessão de lavra e registro de licença, junto ao DNPM.

Embora nem sempre seja fácil a identificação, nos arquivos da CETESB, dos empreendimentos existentes em uma bacia hidrográfica, conforme verificado por Dias (2001), que cita as constantes alterações das razões sociais das empresas e a existência 
de vários projetos de uma empresa em um mesmo município, neste estudo conseguiu-se concretizar a consulta à quase totalidade, ou talvez á totalidade, de processos da bacia registrados na CETESB, o que permitiu o tratamento dos dados com generalização estatística na contextualização da atividade de extração de areia na bacia.

\subsubsection{Análise de campo}

Foram selecionados para análise de campo os 23 portos de dragagem de areia em leito de rio ocorrentes na bacia (Tabela 5), já que esse é o principal método de extração de areia na Bacia do Rio Corumbataí, conforme constatado no levantamento dos processos de licenciamento.

No período de junho a setembro de 2004, foram realizadas visitas a 21 portos de areia de extração em leito de rio ativos no cadastro do DNPM, dentre esses, 19 foram estudados em relação à qualidade de seus plantios (Tabela 5).

Esta etapa do trabalho foi dificultada pela dependência da colaboração voluntária e irrestrita dos mineradores que determinavam as datas e o tempo de permanência disponível, uma vez que as visitas, com duração média de quatro horas, foram, na grande maioria das vezes, obrigatoriamente acompanhadas pelos proprietários ou seus sócios.

Depois de algumas visitas de observação de campo, ainda em caráter de reconhecimento preliminar, realizadas no início do desenvolvimento deste trabalho, ficou constatado que a totalidade dos empreendimentos analisados utiliza o plantio de mudas como método de revegetação. Por isso, foram selecionados modelos de avaliação condizentes com esse método, com avaliação de alguns parâmetros a partir das linhas de plantio.

As 19 áreas de plantio analisadas foram avaliadas sob dois aspectos. O primeiro considerou se o projeto de recuperação concordado é satisfatório e foi efetivamente implantado, de modo quantitativo e qualitativo. O segundo avaliou se a revegetação representou a recuperação ambiental dessas áreas degradadas. Isso responde se o 
licenciamento de portos de areia contribuiu na recuperação de Áreas de Preservação Permanente.

Tabela 5. Apresentação dos 23 portos de areia de leito da Bacia do Rio Corumbataí, entre eles os 19 portos que tiveram seus plantios estudados

\begin{tabular}{|c|c|c|c|c|c|c|}
\hline Porto & Município & Corpo d' água & Coordenadas & $\begin{array}{c}\text { Projeto } \\
\text { (ha) }\end{array}$ & $\begin{array}{c}\text { Plantio } \\
\text { (ha) }\end{array}$ & $\begin{array}{l}\text { Idade } \\
\text { (anos) }\end{array}$ \\
\hline 1 & Charqueada & Rio Corumbataí & $22^{\circ} 35^{\prime} 30,4^{\prime \prime} ; 47^{\circ} 42^{\prime} 14,7^{\prime \prime}$ & 0,2 & 0,022 & 16 \\
\hline 2 & Charqueada & Rio Corumbataí & $22^{\circ} 34^{\prime} 51,5^{\prime \prime} ; 47^{\circ} 41^{\prime} 1,2^{\prime \prime}$ & 1,75 & 1,75 & $2-5$ \\
\hline 3 & Charqueada & Rio Corumbataí & $22^{\circ} 34^{\prime} 56^{\prime \prime} ; 47^{\circ} 41^{\prime} 43^{\prime \prime}$ & 1,8 & 1,8 & 4 \\
\hline 4 & Charqueada & Rio Corumbataí & $22^{\circ} 33^{\prime} 41,4^{\prime \prime} ; 47^{\circ} 40^{\prime} 59,9 ”$ & 0,9 & 0,9 & 7 \\
\hline 5 & Charqueada & Rio Corumbataí & $22^{\circ} 33^{\prime} 41,4^{\prime \prime} ; 47^{\circ} 40^{\prime} 59,9^{\prime \prime}$ & 0,6 & 0,6 & 7 \\
\hline 6 & Charqueada & Rio Corumbataí & $22^{\circ} 32^{\prime} 20,4^{\prime \prime} ; 47^{\circ} 40^{\prime} 8,6^{\prime}$ & 4,24 & 4,24 & $6-7$ \\
\hline 7 & Charqueada & Rib.Fregadoli/Charqueadinha & $22^{\circ} 31^{\prime} 6,3^{\prime \prime} ; 47^{\circ} 45^{\prime} 16,6^{\prime \prime}$ & 0,86 & 0,18 & 6 \\
\hline 8 & Charqueada & Ribeirão Fregadoli & $22^{\circ} 31^{\prime} 6,3^{\prime \prime} ; 47^{\circ} 45^{\prime} 16,6^{\prime \prime}$ & 0,36 & 0,12 & 6 \\
\hline 9 & Corumbataí & Cór. Doria/Rio Corumbataí & $22^{\circ} 12^{\prime} 42,6^{\prime \prime} ; 47^{\circ} 37^{\prime} 38,4^{\prime \prime}$ & 0,57 & 0,57 & 7 \\
\hline 10 & Corumbataí & Córrego do Jacú & $22^{\circ} 13^{\prime} 55,1^{\prime \prime} ; 47^{\circ} 28^{\prime} 29,4^{\prime \prime}$ & 0,05 & 0,05 & 8 \\
\hline 11 & Corumbataí & Córrego Cachoeirina & $22^{\circ} 15^{\prime} 29,4^{\prime \prime} ; 47^{\circ} 35^{\prime} 21,8^{\prime \prime}$ & 0,274 & 0,274 & 3 \\
\hline 12 & Corumbataí & Rio Corumbataí & $22^{\circ} 20^{\prime} 3,2^{\prime \prime} ; 47^{\circ} 40^{\prime} 16,5^{\prime \prime}$ & 0,15 & 0,15 & 14 \\
\hline 13 & Ipeúna & Rio Passa Cinco & $22^{\circ} 26^{\prime} 57,7^{\prime \prime} ; 47^{\circ} 39^{\prime} 27,7^{\prime \prime}$ & 0,27 & 0,27 & 5 \\
\hline 14 & Ipeúna & Rio Passa Cinco & $22^{\circ} 25^{\prime} 7,5^{\prime \prime} ; 47^{\circ} 42^{\prime} 45,6^{\prime}$ & 0,79 & 0,79 & 4 \\
\hline 15 & Ipeúna & Rio Passa Cinco & $22^{\circ}{ }^{\prime} 52,7^{\prime \prime} ; 47^{\circ} 42^{\prime} 27,4^{\prime \prime}$ & 0,87 & 0,652 & 4 \\
\hline 16 & Ipeúna & Rio Passa Cinco & $22^{\circ} 23^{\prime} 16,2^{\prime \prime} ; 47^{\circ} 45^{\prime} 9,6^{\prime \prime}$ & 1,3 & 1,3 & 6 \\
\hline 17 & Rio Claro & Rio Corumbataí & $22^{\circ} 16^{\prime} 14^{\prime \prime} ; 47^{\circ} 34^{\prime} 41,8^{\prime \prime}$ & 0,665 & 0,665 & 4 \\
\hline 18 & Rio Claro & Rio Corumbataí & $22^{\circ} 16^{\prime} 14^{\prime \prime} ; 47^{\circ} 34^{\prime} 41,8^{\prime \prime}$ & 0,25 & 0,25 & 3 \\
\hline 19 & Rio Claro & Rio Cabeça & $22^{\circ} 20^{\prime} 3,2^{\prime \prime} ; 47^{\circ} 40^{\prime} 16,5^{\prime}$ & 0,303 & 0,1 & 6 \\
\hline 20 & Corumbataí & Rio Corumbataí & $22^{\circ} 12^{\prime} 42,6^{\prime \prime} ; 47^{\circ} 37^{\prime} 38,4^{\prime \prime}$ & 0,975 & 0 & - \\
\hline 21 & Charqueada & Ribeirão Fregadoli & $22^{\circ} 30^{\prime} 22,8^{\prime \prime} ; 47^{\circ} 46^{\prime} 24,7^{\prime \prime}$ & 0,817 & 0 & - \\
\hline 22 & Rio Claro & Rio Corumbataí & $22^{\circ} 31^{\prime} 21,5^{\prime \prime} ; 47^{\circ} 39^{\prime} 5,5^{\prime \prime}$ & 0,15 & ? & ? \\
\hline 23 & Ipeúna & Rib. Monjolo Grande & $22^{\circ} 22^{\prime} 24,7^{\prime \prime} ; 47^{\circ} 43,4^{\prime} 41,9^{\prime \prime}$ & 0,256 & $?$ & $?$ \\
\hline Total & & & & 18,4 & $\geq 14,68$ & \\
\hline
\end{tabular}




\subsubsection{Caracterização florística}

No levantamento florístico das 19 áreas de plantio analisadas foram registradas as espécies arbóreas encontradas nas linhas de plantio através de caminhamento, método expedito de levantamento florístico qualitativo (Figueiras et al., 1994). Não foram incluídos na amostragem indivíduos arbustivo-arbóreos regenerantes.

As espécies foram identificadas em campo e o material não identificado foi coletado para posterior identificação através de comparações com as coleções de exsicatas do Herbário da Universidade Estadual de Campinas, através de consultas à bibliografia especializada e, quando necessário, de auxílio de especialistas.

Foram elaboradas duas listas de espécies arbóreas, uma a partir do levantamento florístico das 19 áreas de plantio analisadas e outra a partir de 23 listagens florísticas dos projetos de plantio aprovados pelo DEPRN.

Essas listas foram organizadas em famílias de acordo com o sistema proposto por Cronquist (1988). A nomenclatura das espécies foi sinonimizada de acordo com a base de dados $\mathrm{W}^{3}$ Tropicos do Missouri Botanical Garden (Missouri Botanical Garden, 2004) e de revisões taxonômicas recentes, adotando o sistema de autores proposto por Brummit \& Powell (1992).

Foram utilizados dois tipos de classificação sucessional. As espécies foram agrupadas em pioneiras (P) e não-pioneiras (NP), segundo os critérios adotados pela Resolução SMA 21/01, e em pioneiras (Pi), secundárias iniciais (Si), secundárias tardias (St) e não-caracterizadas (Nc), segundo os critérios de classificação sucessional propostos por Gandolfi et al. (1995), modificado por Gandolfi (2000).

Segundo Gandolfi (2000), são classificadas como Nc as espécies com pouca informação ou que ocorrem em baixa densidade e de forma bastante dispersa, representando um resíduo do processo de classificação sucessional.

A classificação de grande parte das espécies amostradas nos plantios foi obtida em Leitão Filho et al. (1993), Gandolfi et al. (1995), Bernacci \& Leitão Filho (1996), Ivanauskas et al. (1999) e Fonseca \& Rodrigues (2000). As espécies não citadas nesses 
trabalhos foram classificadas com base na observação de seu comportamento e hábito no campo e por consulta a especialistas.

As listas florísticas também foram organizadas numa matriz binária de presença e ausência que serviu de base para comparação florística por similaridade, quantificada através do Índice de Similaridade de Jaccard (Magurran, 1988), onde:

$$
\mathrm{ISJ}=\frac{c}{a+b-c}
$$

Sendo: $\quad$ ISJ = Índice de Similaridade de Jaccard

$a$ = número total de espécies presentes no local A;

$b=$ número total de espécies presentes no local B;

$c$ = número de espécies comuns aos locais A e B.

As relações de similaridade foram estabelecidas através de análise multivariada de classificação, realizada no programa FITOPAC, elaborado por Shepherd (1995).

$\mathrm{Na}$ classificação por agrupamento foi elaborado dendrograma em modo Q (agrupamento de objetos), a partir do coeficiente de associação de Jaccard e do método de Agrupamento de Associação Média, conhecido em inglês pelo nome de "Arithmetic Average Clustering” ou UPGMA (Sneath \& Sokal, 1973). A escolha de UPGMA como método de agrupamento teve como critério a capacidade de melhor evidenciar a estrutura dos dados e o menor grau de distorção ou maior coeficiente cofenético (CC), conforme estabelece Valentin (2000).

\subsubsection{Zoneamento dos plantios}

O desenvolvimento das mudas no campo varia em função de uma série de fatores ambientais, ecofisiológicos e edáficos, como geadas, condições de luminosidade na copa e disponibilidade de água e nutrientes no solo (Mäkinen, 1999). Além disso, seu desenvolvimento varia em função das condições de implementação, como a qualidade e o espaçamento das mudas, além da idade, da condução e da manutenção dos plantios.

Considerando a existência dessas variações dentro de uma mesma área de plantio, foi necessária a divisão dessas áreas em subunidades homogêneas, zoneadas 
visualmente em campo a partir de variações no tamanho (altura) e na mortalidade das mudas. Além disso, as zonas foram classificadas em áreas de plantio efetivado (presença de mudas), não efetivado (ausência de plantio) e áreas de tentativa (ausência de mudas e presença de covas) em que o plantio efetuado fracassou.

\subsubsection{Análise dos plantios}

Os parâmetros ou indicadores da qualidade dos plantios foram obtidos a partir da análise de quatro linhas de 50 metros de plantio. Ou, quando necessário o zoneamento, a partir da análise de duas linhas de 50 metros por zona de plantio identificada.

A distribuição das linhas de amostragem no campo teve como critério a seleção das terceiras e quartas linhas paralelas ao corpo d’água nos sentidos interior-margem e margem-interior, minimizando assim as influências dos efeitos de borda das primeiras linhas de plantio (Figura 6).

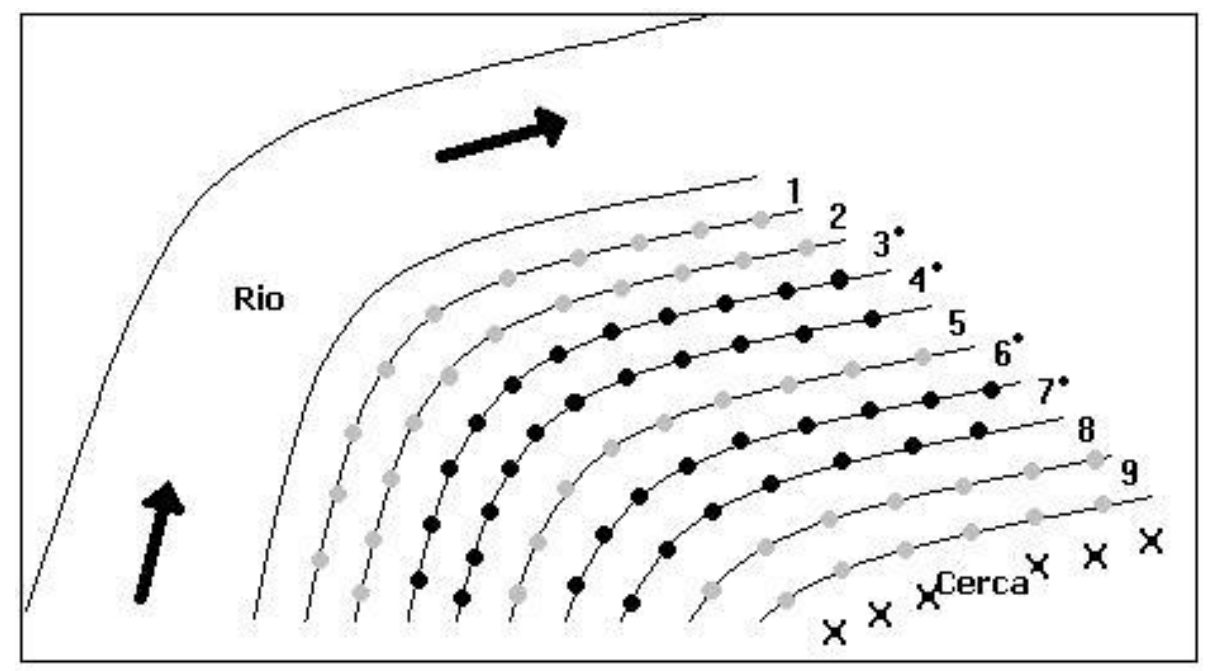

Figura 6 - Distribuição das linhas de amostragem dos plantios nas terceiras e quartas linhas paralelas ao corpo d’água nos sentidos interior-margem e margeminterior 
Em cada linha eram registradas as espécies ocorrentes e estimados os valores de altura, de mortalidade e de cobertura da copa dos indivíduos. A altura dos indivíduos foi medida com o auxílio de vara graduada, a mortalidade estimada pela ausência de indivíduos nas linhas a partir do espaçamento observado em campo e a cobertura da copa estimada pela projeção do diâmetro da copa sobre uma trena.

A partir dos valores lineares de diâmetro (D) das copas foram obtidas as áreas de circunferência (C) (eq. 1), o que permitiu quantificar uma medida em área do sombreamento da copa $\left(\mathrm{m}^{2}\right)$ sobre a área da parcela, representada pelo espaçamento entre as mudas do plantio, conforme apresentado na Figura 7.

$$
\mathrm{C}=\pi \cdot(\mathrm{D} / 2)^{2}
$$

Onde: $\pi=3,14$; $\mathrm{C}=$ circunferência; e $\mathrm{D}$ = diâmetro.
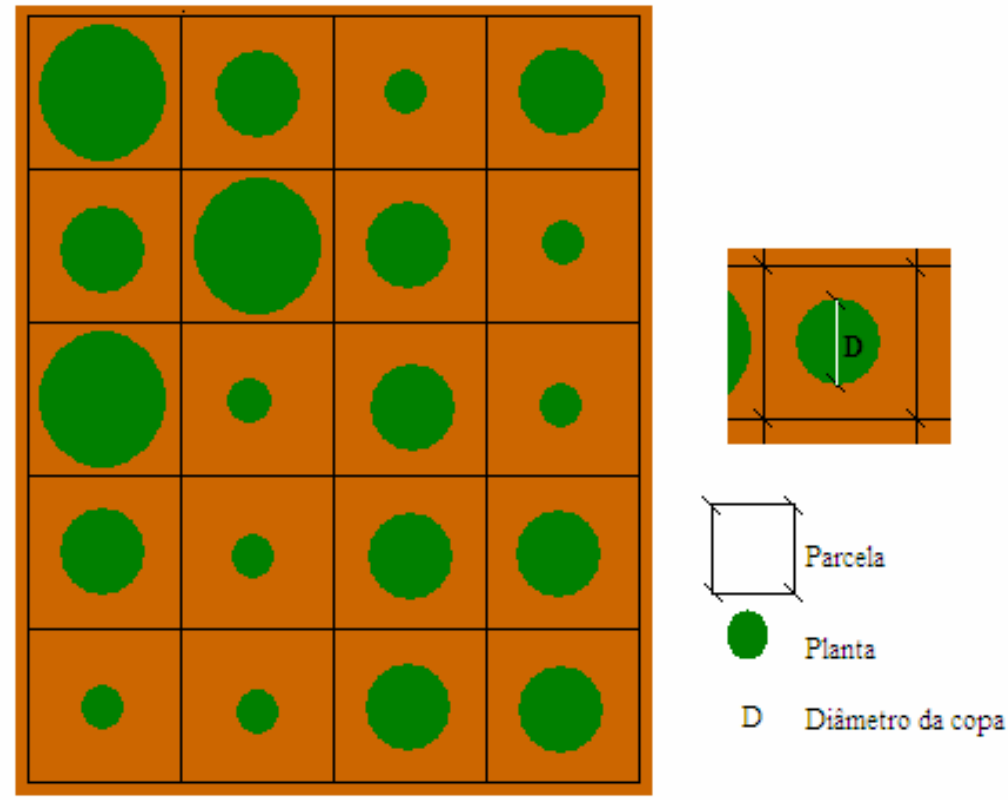

Figura 7 - Desenho esquemático da cobertura do solo das áreas de plantio, obtida pelo sombreamento da copa $\left(\mathrm{m}^{2}\right)$ sobre a área da parcela, representada pelo espaçamento entre as mudas 


\subsubsection{Análise visual dos plantios}

As zonas de plantio foram submetidas a um diagnóstico fitofisionômico e do seu estado de conservação, com documentação fotográfica. A fitofisionomia foi caracterizada a partir de análises visuais de campo baseadas na presença e na ausência de dossel, sub-bosque, serapilheira, diásporos, clareiras naturais e de regeneração natural. Além disso, essas zonas de plantio foram avaliadas quanto ao seu entorno imediato, recobrimento do solo, limpeza do plantio e quanto ao vigor, presença de gado, evidência de injúrias e dominância das suas plantas matrizes.

Algumas dessas características foram classificadas subjetivamente em categorias qualitativas (bom, regular e ruim) e quantitativas (abundante, regular e escasso), conforme apresentado na planilha de campo (Figura 8).

O recobrimento do solo foi estimado pela análise visual do índice de preenchimento de um quadrado metálico vazado de 40 x $40 \mathrm{~cm}$ (Martim \& Coker, 1992), lançado aleatoriamente entre as linhas de plantio, em número médio de seis vezes, variando de acordo com o tamanho da área amostrada. Nessa análise, foram considerados como componentes do recobrimento do solo a presença de gramíneas e de serapilheira.

\subsubsection{Integridade das margens dos corpos d’água}

Durante as visitas de campo, juntamente com a avaliação visual da vegetação, diagnosticou-se a integridade das margens dos locais de circulação das dragas de extração de areia, que foi classificada subjetivamente em três categorias qualitativas (boa, regular e crítica), baseadas na condição de cobertura e de erosão do solo (Figura 8). 


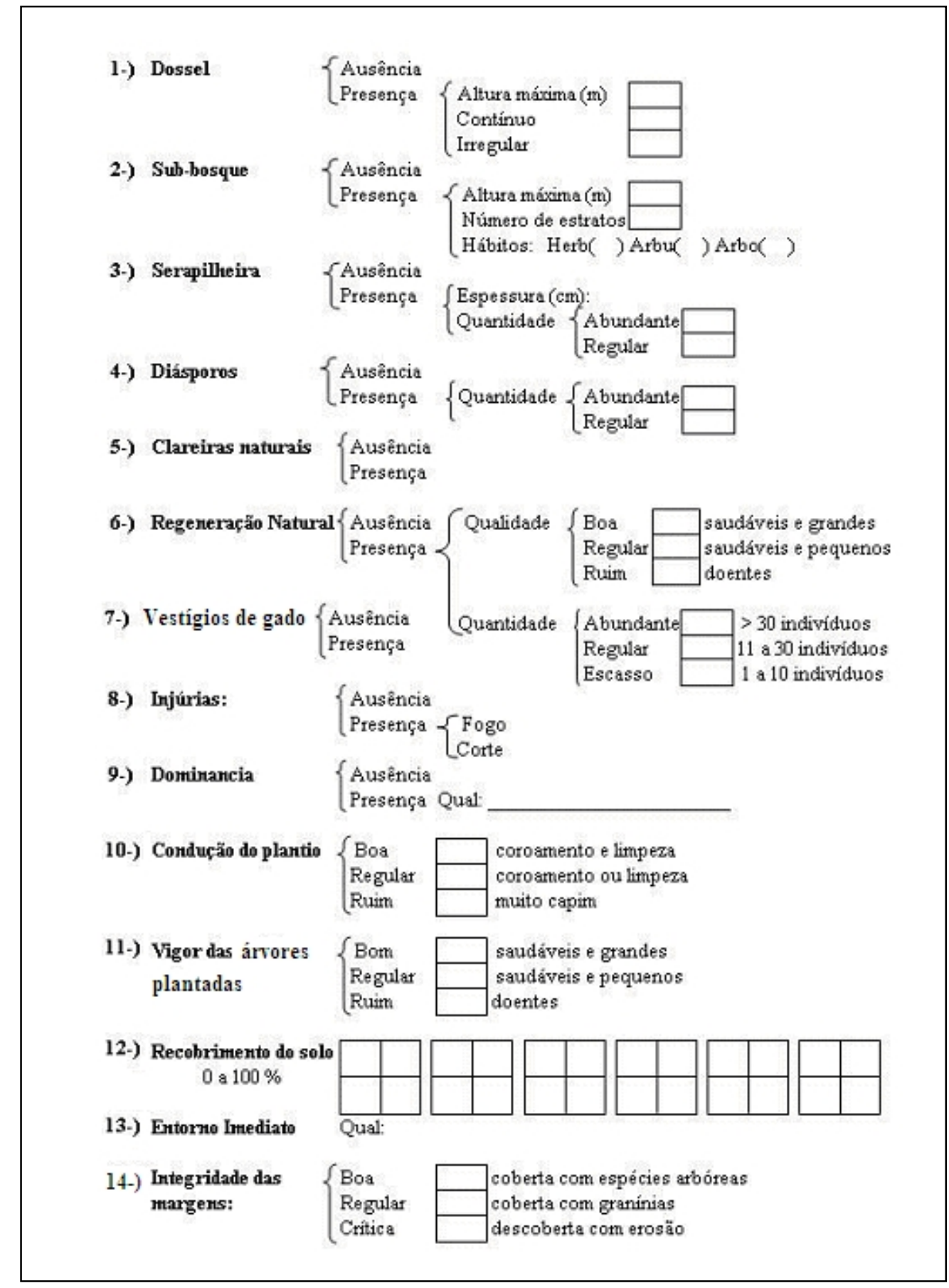

Figura 8 - Planilha utilizada em campo na análise visual quali-quantitativa da APP em recuperação nos portos de areia da Bacia do Rio Corumbataí, SP 


\subsubsection{Avaliação final da recuperação das APPs}

A reunião dos resultados de caracterização florística, fitofisionômica e de cobertura do solo permitiu uma classificação final da recuperação das APPs revegetadas em quatro categorias qualitativas (ótimo, bom, regular e ruim) (Figura 9).

\begin{tabular}{|c|c|c|c|c|c|}
\hline \multirow[t]{2}{*}{ Porto } & Ruim & Regular & \multicolumn{2}{|l|}{ Bom } & Ótimo \\
\hline & $\mathrm{ND}(\mathbf{)} \mathrm{OE}(\mathbf{)}$ & FF ( ) FI ( ) & PE ( ) & RI（ ) & DF ( ) \\
\hline \multicolumn{6}{|c|}{$\begin{array}{l}\text { ND (Nada) = Ausência de plantio; } \\
\text { OE (Ocupação do espaço) = Plantio implantado; } \\
\text { PE (Proteção do entorno) = Presença de florestas naturais ou artificiais próximas } \\
\text { ao plantio; } \\
\text { FF (Fisionomia florestal) = Ocorrência de estratos na vegetação e presença de } \\
\text { serapilheira; } \\
\text { FI (Florística implantada) = Implantação do número mínimo de espécies } \\
\text { previstas pelas Resoluções SMA 21/2001 e 47/2003; } \\
\text { RI (Regeneração interna) = Presença de diásporos e indivíduos regenerantes; } \\
\text { DF (Dinâmica florestal) = Presença de clareiras naturais e regeneração interna }\end{array}$} \\
\hline
\end{tabular}

Figura 9 - Avaliação final da recuperação das APPs dos portos de areia da Bacia Hidrográfica do Rio Corumbataí

Essa classificação utilizou como critério o enquadramento ou não dos plantios avaliados em características fundamentais para o desenvolvimento de um plantio bem sucedido, como a presença de uma fisionomia florestal, a implantação de diversidade florística adequada (Resoluções SMA 21/2001 e 47/2003), a ocorrência de regeneração e dinâmica florestal e a proteção do entorno. Essas características foram selecionadas de acordo com Gandolfi ${ }^{4}$.

\subsubsection{Entrevistas}

Foram realizados diagnósticos da percepção ambiental e legal dos mineradores de areia através de um modelo de investigação baseado em análises qualitativas

\footnotetext{
${ }^{4}$ GANDOLFI, S. (ESALQ-USP. Laboratório de Restauração Florestal, Piracicaba). Comunicação pessoal, 2004.
} 
realizadas através de questionários respondidos em entrevistas (Apêndice 2). Essa investigação teve como objetivo identificar as causas das irregularidades ambientais e legais comumente encontradas nesses tipos de empreendimentos. Pressupõem-se, entre outras causas, a negligência e a falta de informação dos proprietários e funcionários, os altos custos e a demora dos processos de licenciamento, e a excessiva burocracia dos órgãos ambientais.

A caracterização das condições e dos recursos dos órgãos ambientais públicos envolvidos na atividade de extração de areia foi baseada no mesmo modelo de investigação anterior, com a variação no modo de resposta dos questionários, respondidos por carta ou e-mail enviados aos funcionários da CETESB, do Departamento de Água e Energia Elétrica (DAEE), do DEPRN, do DNPM e da Polícia Ambiental (Apêndice 3). Essa investigação buscou analisar as condições dos funcionários no que tange à atividade de mineração, analisando o grau de esclarecimento e as disponibilidades de acesso às informações pelos funcionários a respeito de conceitos legais e ambientais da extração de areia, além de considerar os recursos materiais e financeiros disponíveis e a capacidade de suporte do órgão no monitoramento e na fiscalização das áreas mineradoras.

As respostas obtidas nesta etapa de entrevistas colaboram muito na interpretação das razões da contribuição ou da não contribuição do licenciamento ambiental na recuperação e conservação das APPs, além de serem indispensáveis à inserção das incertezas cognitivas e éticas derivadas dos valores conflitivos entre os interesses dos órgãos ambientais, dos empreendedores e do ambiente.

Segundo o novo paradigma da ciência pós-normal (Funtowicz \& Ravetz, 1993), essas incertezas cognitivas e éticas são importantes para as tomadas de decisão, que devem ser no âmbito das comunidades estendidas de pares, com a participação dos sujeitos implicados no processo, o que é indispensável na democratização da produção e circulação do conhecimento (Gomes, 1999). 


\section{RESULTADOS E DISCUSSÃO}

\subsection{Atividade de extração de areia na Bacia do Rio Corumbataí}

Os primeiros pedidos de diplomas legais para exploração e aproveitamento da areia na Bacia do Rio Corumbataí datam de 1973, conforme registros do DNPM, em que constam seis pedidos para essa década. Na década de 80, esses pedidos aumentaram em 1/3, mas somente na década de 90 houve uma grande busca pela legalização da atividade, quando o número de pedidos triplicou em relação há 20 anos atrás (Figura 10).

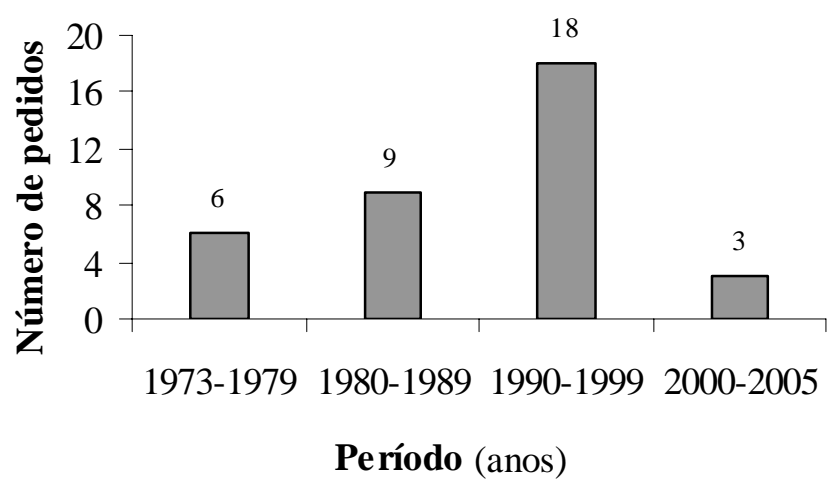

Figura 10 - Registros do DNPM dos pedidos de diplomas legais para exploração e aproveitamento mineral no período de 1973 a 2004 para a Bacia do Rio Corumbataí, SP 
A maioria dos pedidos foi formalizada entre os anos de 1998 e 1999, quando aumentaram as pressões para a regularização ambiental e mineral da atividade, conforme relatado pelos próprios empreendedores da bacia. A regulamentação da Lei de Crimes Ambientais contribuiu para a consolidação desse novo cenário.

Segundo Akimoto (2001), a regularização mineral nesse período foi influenciada pela possibilidade das empresas optarem, junto ao DNPM, a partir de 1995, pelo regime de autorização e concessão. Isso proporcionou às empresas a visão de longo prazo e de planejamento de seus investimentos, livrando-as dos sobressaltos que as flutuações políticas municipais proporcionavam a cada eleição ou desavença política.

O autor acrescenta ainda que as regularizações desse período também foram conseqüências de uma legislação mais clara para o setor, com o surgimento das Resoluções SMA 26/93, 50/95, 04/99 e 28/99.

Estudos de Bacci (1994) da primeira metade da década de 90 registraram apenas sete portos de areia com autorização de exploração junto ao DNPM na bacia do Rio Corumbataí, uma vez que muitos dos pedidos de exploração cadastrados não haviam ainda sido aprovados.

A atividade de extração de areia na bacia está atualmente representada por 36 empreendimentos ativos no cadastro do DNPM (Anexo A, Figura 11), sendo a maioria por dragagem em leito de rio (67\% dos empreendimentos).

Embora, atualmente, as empresas ilegais com endereço fixo tenham diminuído significativamente na bacia, ou, muito provavelmente, tenham acabado, em função de maiores pressões legais, ainda são registrados pela Polícia Ambiental alguns Autos de Infração por atividade extrativa não autorizada.

Segundo a Polícia Ambiental ${ }^{5}$, existem os chamados “portos de areia móveis”, que funcionam no período da cheia e que utilizam bombas e dragas transportada via terrestre até as margens dos rios e córregos. Esses extratores ilícitos de areia removem o minério durante um pequeno intervalo de tempo, sem possibilidade de flagrante e essa areia extraída é comercializada sem qualquer retorno tributário ou garantia da manutenção da integridade ambiental da área explorada. Infelizmente existe maior

\footnotetext{
${ }^{5}$ Polícia Ambiental de Rio Claro. Comunicação pessoal, 2004.
} 
dificuldade em fiscalizar essas atividades esporádicas e muitas vezes a Polícia Ambiental conta com as denúncias de moradores da região para aplicar as punições necessárias.

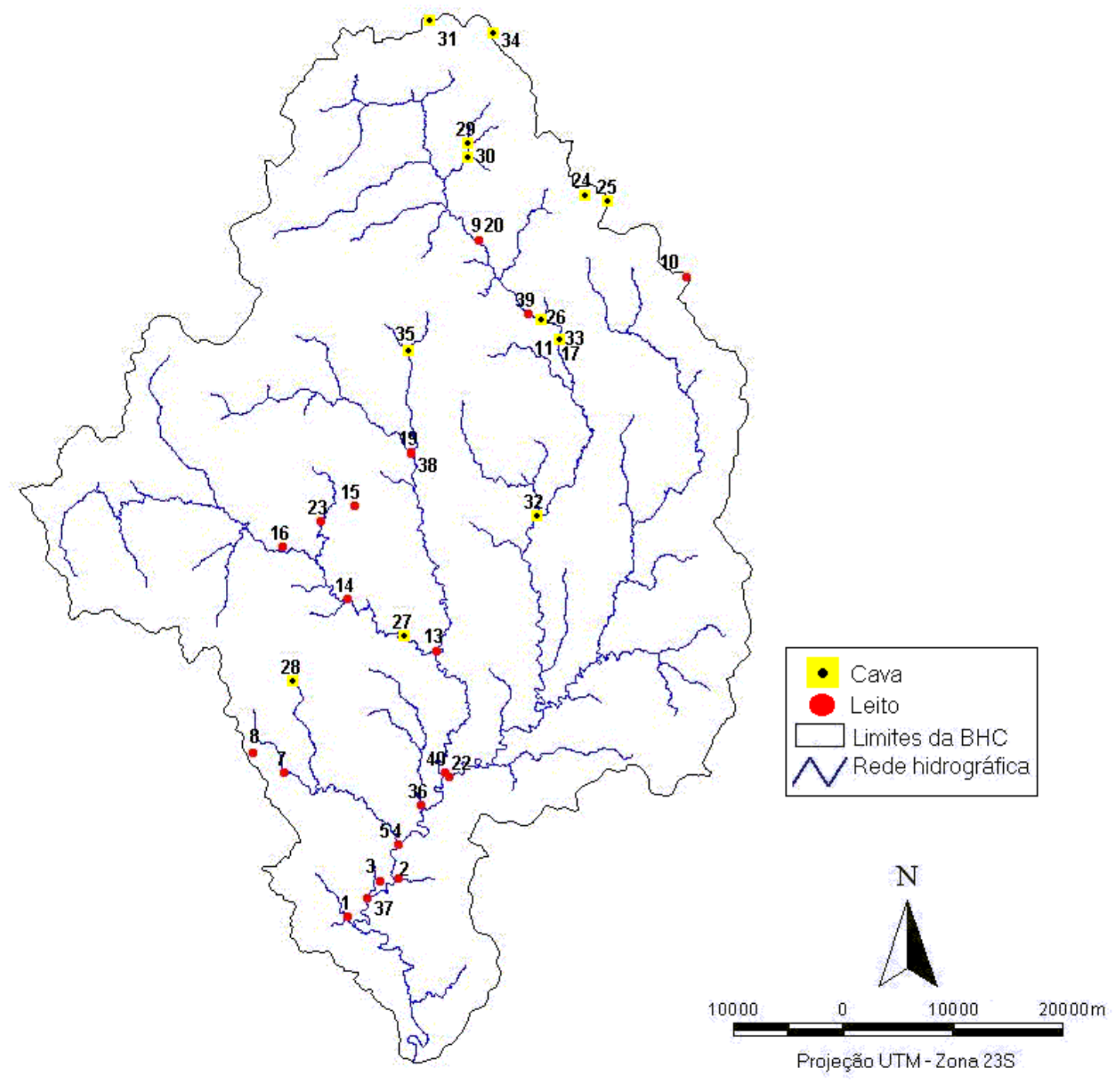

Figura 11 - Apresentação da distribuição dos 36 empreendimentos de extração de areia na Bacia do Rio Corumbataí, SP

As empresas mineradoras de areia se distribuem em seis municípios da bacia e concentram seus empreendimentos em Charqueada e Corumbataí (55\% dos 
empreendimentos) (Figura 12). No município de Charqueada, a maioria dos portos extrai areia em leito, enquanto que em Analândia todos os empreendimentos mineram em cava.

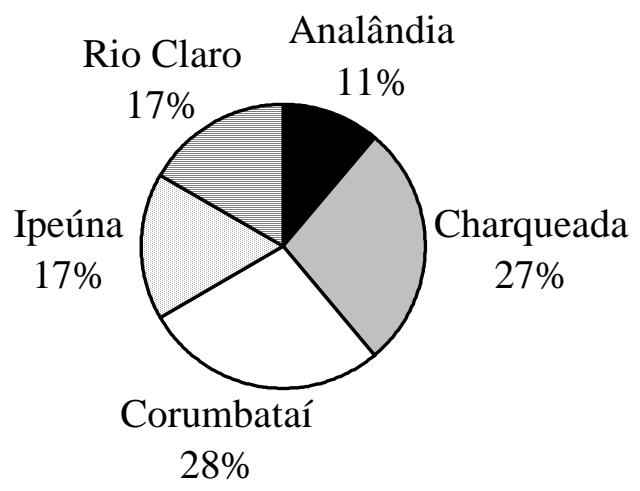

Figura 12 - Distribuição dos empreendimentos de extração de areia da Bacia do Rio Corumbataí, SP, em seus municípios

Quando se leva em consideração apenas a mineração em leito de rio, existem 24 concessões ativas no DNPM, que corresponde 23 unidades produtivas licenciadas na CETESB, denominadas portos de areia. Algumas dessas concessões se referem a uma mesma unidade produtiva, enquanto outras são referentes a mais de um empreendimento. Por essa razão, o número de portos em leito de rio (23 portos) não é obrigatoriamente o número de autorizações concedidas (24 portos).

A maioria dos portos de areia com esse tipo de extração (65\%) são áreas arrendadas, o que pode representar um menor comprometimento do minerador na recuperação da área explorada.

Os empreendimentos ativos no DNPM possuem autorização de exploração por três diferentes diplomas legais, os regimes por concessão de lavra, por licenciamento e por guia de utilização (na fase de autorização de pesquisa ou de requerimento de lavra). Nas extrações por cava predominam os diplomas legais de concessão e de guia de utilização da lavra, enquanto que em leito, o licenciamento é o tipo de autorização de exploração predominante (Tabela 6). 
Tabela 6. Caracterização dos empreendimentos de extração de areia por cava e leito na Bacia do Rio Corumbataí, SP, em relação à área de lavra (ha), tipo de autorização e destino da areia produzida

\begin{tabular}{|c|c|c|c|c|c|c|c|}
\hline $\begin{array}{c}\text { Tipo de } \\
\text { extração }\end{array}$ & $\begin{array}{l}\text { Área d } \\
\text { Máx. }\end{array}$ & $\begin{array}{l}\text { e lavra (ha) } \\
\text { Mín. Med. }\end{array}$ & $\begin{array}{c}\text { Concessão } \\
\text { de lavra }\end{array}$ & Licenciamento & $\begin{array}{c}\text { Guia de } \\
\text { utilização }\end{array}$ & $\begin{array}{c}\text { Construção } \\
\text { Civil }\end{array}$ & $\begin{array}{cc}\text { Uso } \\
\text { Industrial }\end{array}$ \\
\hline Cava & 655 & $\begin{array}{ll}9,91 & 125\end{array}$ & $42 \%$ & $16 \%$ & $42 \%$ & $50 \%$ & $50 \%$ \\
\hline Leito & 257 & $0,71 \quad 42$ & $30 \%$ & $43 \%$ & $26 \%$ & $78 \%$ & $22 \%$ \\
\hline
\end{tabular}

O licenciamento é um regime que depende da autorização do proprietário do solo para exploração, além de depender, segundo PEQUENA e média mineração... (1997), de um bom relacionamento nas prefeituras, já que cabe às autoridades municipais da jazida a outorga da licença específica que será posteriormente avaliada junto ao DNPM.

Além disso, o regime de licenciamento é exclusivo aos empreendimentos de produção de areia de emprego imediato na construção civil, que é o caso de $78 \%$ dos empreendimentos de leito da bacia e apenas de 50\% dos de cava (Tabela 6). Também é exclusivo aos empreendimentos com área máxima de 50 ha, como são os casos de 83\% dos empreendimentos de leito e de $58 \%$ dos de cava.

As areias de uso industrial, que correspondem a $50 \%$ da produção dos empreendimentos de cava e apenas $22 \%$ dos de leito (Tabela 6), contrariamente daquelas utilizadas na construção civil, vinculam-se ao regime de autorização e concessão de lavra, em que estão previstas duas fases distintas, a de autorização de pesquisa e a de concessão de lavra.

A maioria da areia de uso industrial da bacia está destinada a confecção de moldes para fundição de ferro, aço e outros metais (Anexo A) em função da predominância de areia de granulometria fina na bacia.

Atualmente, está autorizada pelo DNPM a exploração de 2476,87 ha de lavra na bacia, sendo que pouco mais que um terço dessa área está destinada à extração de areia por dragagem. As unidades de extração por cava possuem área média de lavra três vezes maior que as unidades de leito (Tabela 6). 
Considerando as definições da Resolução SMA 26/93, observou-se que enquanto os empreendimentos de cava são em sua maioria de médio a grande porte, os empreendimentos de leito são de pequeno a médio porte (Tabela 7).

Tabela 7. Percentagem de pequenos, médios e grandes empreendimentos de extração de areia por cava e leito na Bacia do Rio Corumbataí, SP

\begin{tabular}{cccc}
\hline Tipo de & \multicolumn{3}{c}{ Tamanho } \\
extração & Pequeno & Médio & Grande \\
\hline Cava & $8 \%$ & $67 \%$ & $25 \%$ \\
Leito & $22 \%$ & $74 \%$ & $4 \%$ \\
\hline
\end{tabular}

A Resolução SMA 26/93 considera como pequeno empreendimento aquele com área inferior a 10 ha e produção menor que $1000 \mathrm{~m}^{3} /$ mês; médio empreendimento, aquele com área entre 10 e 100 ha e produção entre 1000 e $5000 \mathrm{~m}^{3} / \mathrm{mês}$ e grande empreendimento aquele com área superior a 100 ha e produção superior a $5000 \mathrm{~m}^{3} / \mathrm{mês}$.

A bacia em estudo produz um total de cerca de 70.000.000 $\mathrm{m}^{3} /$ mês de areia, com produção bastante variável entre as unidades de extração. A produção dos empreendimentos de cava é, assim como as áreas de lavra, superior em um terço a produção em leito (Figura 13).

Quando comparada com a produção de grandes centros produtores, como o Vale do Paraíba, a produção da bacia não é tão significativa, pois representa cerca de $10 \%$ dessa produção, segundo valores apresentados por Bauermeister et al. (1997) e Akimoto (2001).

De acordo com a opção do minerador em relação ao regime de exploração mineral, há uma diferença no tempo de obtenção dos diplomas legais. O regime por licenciamento, apesar de ser mais ágil na sua obtenção, representa uma menor segurança ao proprietário, uma vez que essa licença é normalmente concedida por um ano. 


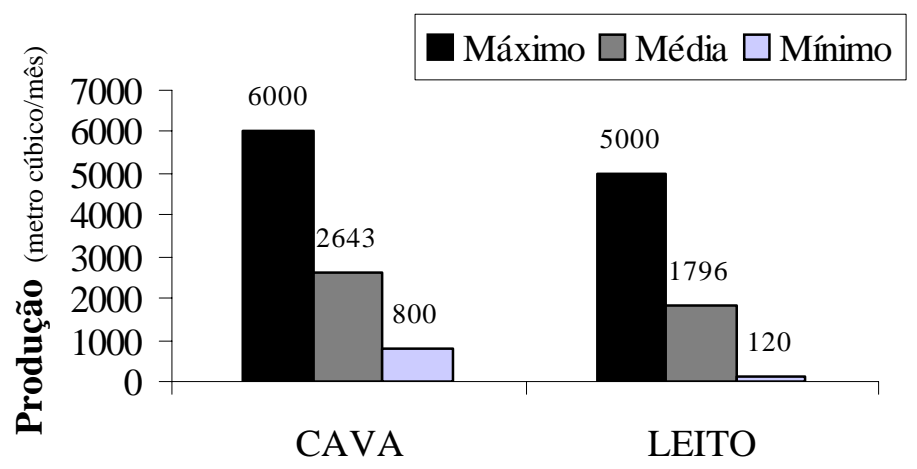

Figura 13 - Produção máxima, mínima e média de areia ( $\mathrm{m}^{3}$ /mês) dos empreendimentos da Bacia do Rio Corumbataí, SP

Os empreendimentos da bacia regularizados pelo regime de licenciamento aguardaram em média dois anos para a obtenção desse diploma legal, enquanto que os regularizados pelo regime de concessão aguardaram em média seis anos, o correspondente a três para obtenção da autorização de pesquisa e outros três para concessão de lavra (Figura 14). Isso sem contar o tempo de pesquisa mineral da jazida.

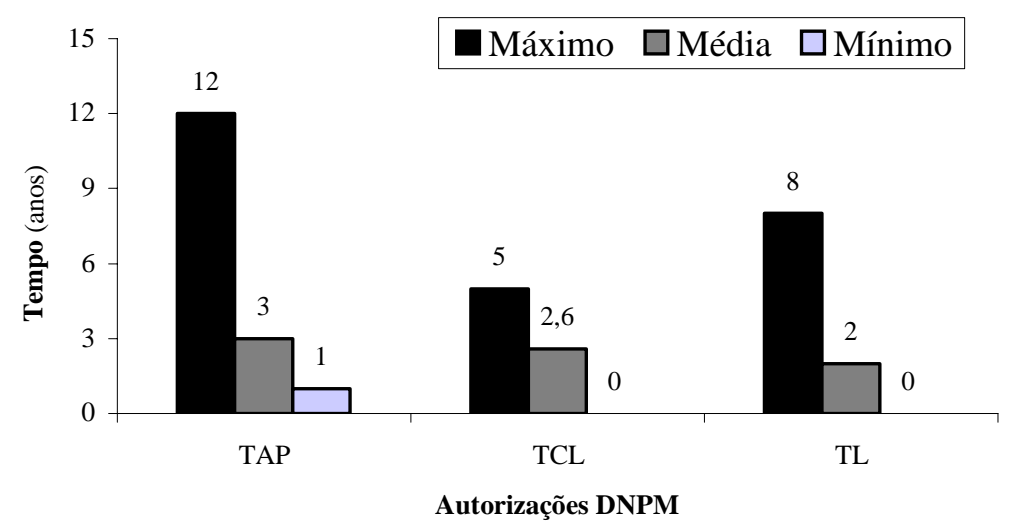

Figura 14 - Tempos máximo, mínimo e médio de obtenção dos diplomas legais de exploração mineral junto ao DNPM para os empreendimentos da Bacia do Rio Corumbataí, SP. TAP - Tempo de Aproveitamento de Pesquisa, TCL - Tempo de Concessão de Lavra e TL - Tempo de Licenciamento 
O tempo médio de concessão de lavra é ainda maior quando se considera o período de pesquisa mineral, que normalmente gira em torno de dois anos.

Ao contrário do normalmente relatado pelos empreendedores, o tempo para obtenção das licenças ambientais junto à CETESB não parece ser o único e principal responsável pelo impasse no processo de regularização da atividade, já que foi, na maioria das vezes, inferior ao necessário à obtenção das autorizações minerais. Em média, as licenças foram obtidas no prazo de dois anos; um ano para obtenção da Licença de Instalação (LI) e outro para a Licença de Operação (LO) (Figura 15).

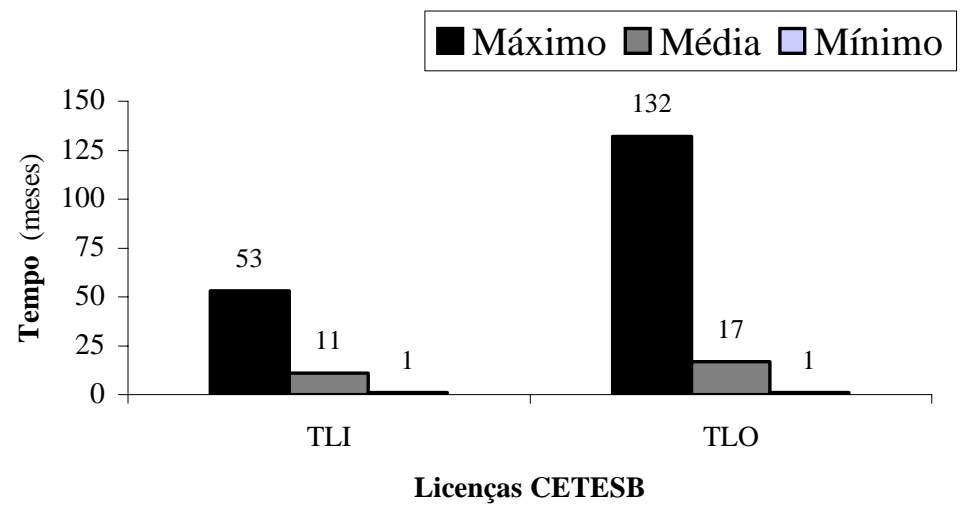

Figura 15 - Tempos máximo, mínimo e médio de obtenção das Licenças Ambientais junto à CETESB para os empreendimentos da Bacia do Rio Corumbataí, SP. TLI - Tempo de Licença de Instalação e TLO - Tempo de Licença de Operação

No entanto, o tempo para obtenção dessas licenças, em 68\% dos casos, ainda está acima do prazo determinado pela Resolução CONAMA 237/97, em que a LI deve ser obtida no prazo de dois a seis meses. Na maioria das vezes, o atraso esteve relacionado com a falta de documentações para a continuidade do processo ou com a espera da obtenção de respostas de órgãos inter-relacionados.

De acordo com os registros do Cadastro Mineiro do DNPM, existem atualmente 16 empresas solicitando Requerimento de Pesquisa, 43 estão em fase de Autorização de Pesquisa e 21 em fase de solicitação de Requerimento de Lavra. Essas constatações 
mostram que na construção de um cenário futuro para a bacia, a extração de areia tem boas perspectivas de continuidade, embora muitos empreendedores estejam prevendo o abandono das áreas pela pouca rentabilidade das jazidas.

\subsection{Análise da recuperação das APPs}

Do total de 23 empreendimentos de extração de areia de leito de rio encontrados na Bacia do Rio Corumbataí, apenas dois (Portos 22 e 23) não foram visitados, por recusa dos proprietários na autorização da pesquisa. Nesses dois casos, a coleta de dados se restringiu aos projetos de revegetação disponíveis na CETESB, que são de livre consulta pública.

Durante a visita aos empreendimentos, foi constatado que dois portos (Portos 20 e 21) não tinham as áreas de plantio previstas pelo projeto apresentado aos órgãos ambientais nos anos de 1999 e 2002, respectivamente. Na verdade, o Porto 21 chegou a implementar um plantio, fracassado pelas inundações recorrentes no local.

Todas as outras empresas visitadas (Porto 1 ao 19) possuíam alguma faixa de APP revegetada por plantio de espécies arbóreas, na sua maioria dispostas em linhas. Essas áreas de plantio foram caracterizadas quanto à sua diversidade florística e, após zoneamento, quanto à sua fitofisionomia florestal e cobertura da copa.

\subsubsection{Caracterização florística}

Além das 19 áreas de plantio estudadas, foi realizada a caracterização florística das 23 listas de espécies dos projetos de recuperação, o que permitiu verificar se esses projetos foram satisfatórios e efetivamente implantados pelo empreendedor.

\subsubsection{Composição florística dos plantios}

Através do levantamento florístico por caminhamento nas 19 áreas de plantio, que juntas somaram 14,68 ha (Tabela 5), foram registradas 137 espécies arbóreas, 
pertencentes a 88 gêneros e 41 famílias. Do total de espécies registradas, cinco foram indicadas apenas como gênero, 11 como família e 11 como morfoespécie (Tabela 8). A não identificação de todos os indivíduos como espécie pode ser atribuída a falta de material adequado para identificação, como folhas, flores e frutos.

Segundo a classificação sucessional apresentada na Resolução SMA 21/01, das 137 espécies registradas nas áreas de plantio, 62 espécies não foram classificadas por essa resolução; 50 espécies (66\%) são pioneiras (P) e 26 (34\%) não-pioneiras (NP) (Tabela 8).

De acordo com a classificação sucessional descrita na literatura consultada e nas observações de campo, 32 espécies (35\%) são pioneiras (Pi), 33 (37\%) secundárias iniciais (Si), 25 (28\%) secundárias tardias (St) e 48 não foram caracterizadas (Nc); (Tabela 8). Deve-se salientar que essa distribuição em categorias de sucessão está baseada apenas na riqueza de espécies, tendo sido desconsiderada a densidade de indivíduos nos plantios.

As famílias Fabaceae (21 espécies), Caesalpiniaceae (14 espécies), Mimosaceae (14 espécies), Myrtaceae (10 espécies) e Bignoniaceae (7 espécies) apresentaram as maiores riquezas em espécies (Figura 16) e juntas representaram 12\% de todas as famílias registradas e suas espécies corresponderam a $48 \%$ do total de espécies amostradas nesse levantamento.

Embora a divisão em famílias deste trabalho siga o sistema de Cronquist (1988), segundo o sistema de Engler (1954) citado por Joly (1993), as três famílias mais abundantes dessas áreas de plantio, Caesalpiniaceae, Fabaceae e Mimosaceae, formam a grande família Leguminosae, com 49 espécies.

A família Leguminosae é uma das mais freqüentes em ecossistemas tropicais e é uma das mais importante do estrato superior das matas ciliares do Estado de São Paulo (Leitão Filho, 1982). Muitas espécies dessa família fixam nitrogênio através de associações simbióticas e são importantes sob o ponto de vista econômico e ecológico, pois podem dispensar o uso total ou parcial de fertilizantes à base de nitrogênio, contribuindo para a viabilização de reflorestamentos e minimizando possíveis impactos ambientais decorrentes da utilização de insumos dessa categoria (Barberi et al., 1998). 
Tabela 8. Lista de espécies arbóreas registradas nas 19 áreas de plantios dos portos de areia de leito de rio da Bacia do rio Corumbataí, SP

\begin{tabular}{|c|c|c|c|c|c|}
\hline \multirow[t]{2}{*}{ Família } & \multirow[t]{2}{*}{ Espécie } & \multirow[t]{2}{*}{ Nome Popular } & \multirow[t]{2}{*}{ Ecossistema/Bioma** } & \multicolumn{2}{|c|}{$\mathbf{C S}^{* * *}$} \\
\hline & & & & SMA & Lit. \\
\hline \multirow[t]{3}{*}{ ANACARDIACEAE } & Astronium sp. & & & & Nc \\
\hline & Schinus molle L. & aroeira-salsa & & & $\mathrm{Pi}$ \\
\hline & Schinus terebinthifolius Raddi & aroeira-pimenteira & RES/FOD/FES/MC/MP/CER & $\mathrm{P}$ & $\operatorname{Pi}(1)$ \\
\hline ANNONACEAE & Xylopia brasiliensis Spreng. & pindaíba & RES/FOD/FES/MC/MP & NP & Si (3) \\
\hline \multirow[t]{2}{*}{ APOCYNACEAE } & Tabernaemontana hystrix Steud. & leiteiro & RES/FOD/FES/MC/CER & $\mathrm{P}$ & Nc \\
\hline & Thevetia peruviana (Pers.) K. Schum.* & chapéu-de-napoleão & & & Nc \\
\hline \multirow[t]{2}{*}{ ASTERACEAE } & Asteraceae sp. & & & & Nc \\
\hline & Gochnatia polymorpha (Less.) Cabrera & candeia & FOD/FOM/FES/MC/MP/CER & $\mathrm{P}$ & $\mathrm{Pi}(4)$ \\
\hline \multirow[t]{7}{*}{ BIGNONIACEAE } & Jacaranda sp. & & & & Nc \\
\hline & Tabebuia avellanedae Lorentz ex Griseb. & ipê-roxo & RES/FOD/MC/CER & & St \\
\hline & Tabebuia chrysotricha (Mart. ex A. DC.) Standl. & ipê-amarelo-cascudo & FOD/FES/MP & NP & St \\
\hline & Tabebuia roseoalba (Ridl.) Sandwith & ipê-branco & FES/FED & NP & St \\
\hline & Tabebuia sp. & & & & Nc \\
\hline & Tabebuia vellosoi Toledo & ipê-amarelo-liso & FOD/FES/MC & NP & St (2) \\
\hline & Zeyheria tuberculosa (Vell.) Bureau & ipê-bolsa-de-pastor & FOD/FES/MC/CER & $\mathrm{P}$ & $\mathrm{Si}$ \\
\hline BIXACEAE & Bixa orellana L.* & urucum & & & Nc \\
\hline \multirow[t]{2}{*}{ BOMBACACEAE } & Bombacopsis glabra (Pasquale) Robyns* & castanha-de-praia & & & $\mathrm{Si}$ \\
\hline & Ceiba speciosa (A. St.-Hil.) Ravenna & paineira & FOD/FES/MC/MP/FED & $\mathrm{P}$ & Si (3) \\
\hline \multirow[t]{2}{*}{ BORAGINACEAE } & Cordia superba Cham. & baba-de-boi & FOD/FES/MC & $\mathrm{P}$ & $\mathrm{Si}$ \\
\hline & Cordia trichotoma (Vell.) Arráb. ex Steud. & louro-pardo & FOD/FES/MC/CER & NP & $\operatorname{Si}(5)$ \\
\hline BURSERACEAE & Protium heptaphyllum (Aubl.) Marchand & almecega & FOD/FES/MC/MP/CER & NP & $\mathrm{Si}$ \\
\hline CAESALPINIACEAE & Bauhinia bongardii Steud. & pata-de-vaca & & & $\mathrm{Si}$ \\
\hline
\end{tabular}


Tabela 8. Lista de espécies arbóreas registradas nas 19 áreas de plantios dos portos de areia de leito de rio da Bacia do rio Corumbataí, SP

\begin{tabular}{|c|c|c|c|c|c|}
\hline \multirow[t]{2}{*}{ Família } & \multirow[t]{2}{*}{ Espécie } & \multirow[t]{2}{*}{ Nome Popular } & \multirow[t]{2}{*}{ Ecossistema/Bioma** } & \multicolumn{2}{|c|}{$\mathrm{CS}^{* * *}$} \\
\hline & & & & SMA & Lit. \\
\hline & Bauhinia forficata Link & pata-de-vaca & FOD/FES/MC & $\mathrm{P}$ & $\mathrm{Pi}(3)$ \\
\hline & Caesalpinia echinata Lam.* & pau-brasil & & & St \\
\hline & Caesalpinia ferrea Mart.* & pau-ferro & & & St \\
\hline & Caesalpinia pluviosa DC.* & sibipiruna & & & Nc \\
\hline & Caesalpinia sp. & & & & Nc \\
\hline & Cassia ferruginea (Schrader) Schrader ex DC. & chuva-de-ouro & FOD/FES/MC & $\mathrm{P}$ & St (3) \\
\hline & Cassia sp. & & & & Nc \\
\hline & $\begin{array}{l}\text { Copaifera langsdorffii (Desf.) Kuntze } \\
\text { Hymenaea courbaril var. stilbocarpa (Hayne) Y.T. }\end{array}$ & óleo-de-copaíba & FOD/FES/MC/MP/FED/CER & $\mathrm{NP}$ & St (1) \\
\hline & Lee \& Langenh. & jatobá & FOD/FES/MC & $\mathrm{NP}$ & St (2) \\
\hline & Peltophorum dubium (Spreng.) Taub. & canafístula & FOD/FES/MC/FED/CER & $\mathrm{P}$ & $\mathrm{Si}(5)$ \\
\hline & Pterogyne nitens Tul. & amendoin-do-campo & FOD/FES/MC & $\mathrm{P}$ & $\mathrm{Pi}$ \\
\hline & Schizolobium parahyba (Vell.) S.F. Blake & ficheira & RES/FOD/FES/MC & $\mathrm{P}$ & $\mathrm{Pi}(3)$ \\
\hline & Senna spectabilis (DC.) H.S. Irwin \& Barneby & cassia-do-nordeste & FES & & $\mathrm{Pi}$ \\
\hline CARICACEAE & Jacaratia spinosa (Aubl.) A. DC. & jaracatiá & FOD/FES/MC & $\mathrm{P}$ & $\mathrm{Pi}(5)$ \\
\hline \multirow[t]{2}{*}{ CECROPIACEAE } & Cecropia glaziovi Snethlage & embaúba-vermelha & RES/FOD/FES/MC & & $\operatorname{Pi}(2)$ \\
\hline & Cecropia pachystachya Trécul & embaúva-branca & RES/FOD/FES/MC/MP/CER & $\mathrm{P}$ & $\operatorname{Pi}(1)$ \\
\hline CHRYSOBALANACEAE & Licania tomentosa (Benth.) Fritsch* & oiti & & & Nc \\
\hline CLUSIACEAE & $\begin{array}{l}\text { Calophyllum brasiliense Cambess. } \\
\text { Terminalia brasiliensis (Cambess. ex A. St.-Hil.) }\end{array}$ & guanandi & RES/FOD/FES/MC/MP & $\mathrm{NP}$ & Nc \\
\hline COMBRETACEAE & Eichler & capitão-do-campo & FOD/FES/MC/MP/CER & NP & St \\
\hline \multirow[t]{3}{*}{ EUPHORBIACEAE } & Alchornea glandulosa Poepp. & tapiá-guaçu & RES/FOD/FES/MC/MP & $\mathrm{P}$ & $\mathrm{Pi}(3)$ \\
\hline & Alchornea triplinervia (Spreng.) Müll. Arg. & tapiá & RES/FOD/FOM/FES/MC/MP/CER & & $\mathrm{Pi}(1)$ \\
\hline & Croton floribundus Spreng. & capixingui & FOD/FES/MC/MP/CER & $\mathrm{P}$ & $\mathrm{Pi}(1)$ \\
\hline
\end{tabular}


Tabela 8. Lista de espécies arbóreas registradas nas 19 áreas de plantios dos portos de areia de leito de rio da Bacia do rio Corumbataí, SP

\begin{tabular}{|c|c|c|c|c|c|}
\hline \multirow[t]{2}{*}{ Família } & \multirow[t]{2}{*}{ Espécie } & \multirow[t]{2}{*}{ Nome Popular } & \multirow[t]{2}{*}{ Ecossistema/Bioma** } & \multicolumn{2}{|c|}{$\mathrm{CS}^{* * *}$} \\
\hline & & & & SMA & Lit. \\
\hline & Croton urucurana Baill. & sangra-d'água & FOD/FES/MC & $\mathrm{P}$ & $\mathrm{Pi}$ \\
\hline & Sapium glandulatum (Vell.) Pax & leiteira & RES/FOD/FOM/FES/MC/MP/CER & $\mathrm{P}$ & $\operatorname{Pi}(1)$ \\
\hline \multirow[t]{20}{*}{ FABACEAE } & Centrolobium tomentosum Guillemin ex Benth. & araribá & RES/FOD/FES/MC/CER & $\mathrm{P}$ & Si (4) \\
\hline & Clitoria fairchildiana R. A. Howard* & sombreiro & & & Nc \\
\hline & Dalbergia brasiliensis Vogel & caroba-brava & FOD/FES/MC & & St (1) \\
\hline & Dalbergia sp. & & & & Nc \\
\hline & Erythrina crista-galli L. & crista-de-galo & FOD/FES/MC & $\mathrm{P}$ & $\mathrm{Si}$ \\
\hline & Erythrina falcata Benth. & suinã & FOD/FOM/FES/MC/MP & $\mathrm{P}$ & Si \\
\hline & Erythrina mulungu Mart. & mulumgu & FES & $\mathrm{P}$ & Nc \\
\hline & Erythrina speciosa Andrews & suinã-vermelho & RES/FOD & $\mathrm{P}$ & $\mathrm{Si}$ \\
\hline & Erythrina velutina Willd. & corticeira & & & Nc \\
\hline & Erythrina verna Vell. & mulungu-coral & FES & $\mathrm{P}$ & Nc \\
\hline & Lonchocarpus guillemineanus (Tul.) Malme & embira-de-sapo & RES/FOD/FES/MC & $\mathrm{P}$ & Si (3) \\
\hline & Lonchocarpus muehlbergianus Hassl. & feijão-cru & FOD/FES/MC & $\mathrm{P}$ & $\operatorname{Si}(5)$ \\
\hline & Machaerium acutifolium Vogel & bico-de-pato & FOD/MC/CER & $\mathrm{NP}$ & $\mathrm{Pi}$ \\
\hline & Machaerium nyctitans (Vell.) Benth. & bico-de-pato & RES/FOD/FES/MC/MP/FED & $\mathrm{P}$ & Si (1) \\
\hline & Machaerium opacum Vogel* & jacarandá-do-cerrado & & & Nc \\
\hline & Macherium sp. & & & & Nc \\
\hline & Myroxylon peruiferum L. f. (VU) & cabreúva & FOD/FES/MC/MP/FED & $\mathrm{NP}$ & St (3) \\
\hline & Ormosia arborea (Vell.) Harms & olho-de-cabra & RES/FOD/FES/MC/CER & $\mathrm{NP}$ & St (3) \\
\hline & Platypodium elegans Vogel & amendoim-do-campo & FOD/FES/MC/MP/CER & $\mathrm{NP}$ & $\mathrm{Si}(4)$ \\
\hline & Poecilanthe parviflora Benth. & coração-de-negro & FES/MC & NP & St \\
\hline
\end{tabular}


Tabela 8. Lista de espécies arbóreas registradas nas 19 áreas de plantios dos portos de areia de leito de rio da Bacia do rio Corumbataí, SP

\begin{tabular}{|c|c|c|c|c|c|}
\hline \multirow[t]{2}{*}{ Família } & \multirow[t]{2}{*}{ Espécie } & \multirow[t]{2}{*}{ Nome Popular } & \multirow[t]{2}{*}{ Ecossistema/Bioma** } & \multicolumn{2}{|c|}{$\mathrm{CS}^{* * *}$} \\
\hline & & & & SMA & Lit. \\
\hline \multirow[t]{2}{*}{ FLACOURTIACEAE } & Casearia gossypiosperma Briq. & pau-espeto & FOD/FES/MC/CER & NP & $\operatorname{Si}(3)$ \\
\hline & Casearia sylvestris Sw. & guaçatonga & RES/FOD/FES/MC/MP/CER & $\mathrm{P}$ & $\operatorname{Pi}(1)$ \\
\hline LAURACEAE & Nectandra megapotamica (Spreng.) Mez & canela & FOD/FES/MC & NP & $\mathrm{Pi}$ \\
\hline LECYTHIDACEAE & Cariniana estrellensis (Raddi) Kuntze & jequitibá-branco & RES/FOD/FES/MC/MP/CER & NP & St (1) \\
\hline LYTHRACEAE & Lafoensia pacari A. St.-Hil. & dedaleiro & RES/FOD/FOM/FES/MC/MP/FED/CER & $\mathrm{P}$ & $\mathrm{Si}(4)$ \\
\hline \multirow[t]{5}{*}{ MELIACEAE } & Cabralea canjerana (Vell.) Mart. & canjerana & RES/FOD/FOM/FES/MC/MP/CER & NP & St (2) \\
\hline & Cedrela fissilis Vell. & cedro & FOD/FOM/FES/MC/MP/CER & $\mathrm{P}$ & $\operatorname{Si}(1)$ \\
\hline & Guarea guidonia (L.) Sleumer & marinheiro & FOD/FES/MC/MP & $\mathrm{P}$ & St \\
\hline & Meliaceae sp. & & & & Nc \\
\hline & Trichilia sp. & & & & Nc \\
\hline \multirow[t]{12}{*}{ MIMOSACEAE } & Acacia mangium Willd.* & acácia & & & Nc \\
\hline & Acacia polyphylla DC. & monjoleiro & RES/FOD/FES/MC/FED/CER & $\mathrm{P}$ & $\operatorname{Pi}(3)$ \\
\hline & Anadenanthera colubrina (Vell.) Brenan & angico-branco & FOD/MC/CER & $\mathrm{P}$ & $\mathrm{Pi}$ \\
\hline & Anadenanthera macrocarpa (Benth.) Brenan & angico-vermelho & FES/MC & $\mathrm{P}$ & $\mathrm{Pi}$ \\
\hline & Anadenanthera peregrina (L.) Speg. & angico-vermelho & FOD/FES/CER & & $\mathrm{Pi}$ \\
\hline & Enterolobium contortisiliquum (Vell.) Morong & orelha-de-negro & FOD/FES/MC & $\mathrm{P}$ & $\operatorname{Si}(4)$ \\
\hline & Inga laurina (Sw.) Willd. & ingá & RES/FOD/FES/MC/MP & NP & Si (3) \\
\hline & Inga marginata Willd. & ingá-feijão & RES/FOD/FES/MC/MP & $\mathrm{P}$ & $\mathrm{Si}$ \\
\hline & Inga vera Willd. & ingá & FOD/FES/MC & $\mathrm{P}$ & $\operatorname{Si}(4)$ \\
\hline & Leucaena leucocephala (Lam.) de Wit* & leucena & & & Nc \\
\hline & Mimosa bimucronata (DC.) Kuntze & maricá & RES/FOD/FES/MC & $\mathrm{P}$ & Nc \\
\hline & Mimosa caesalpiniifolia Benth.* & sansão-do-campo & & & $\mathrm{Pi}$ \\
\hline
\end{tabular}


Tabela 8. Lista de espécies arbóreas registradas nas 19 áreas de plantios dos portos de areia de leito de rio da Bacia do rio Corumbataí, SP

\begin{tabular}{|c|c|c|c|c|c|}
\hline \multirow[t]{2}{*}{ Família } & \multirow[t]{2}{*}{ Espécie } & \multirow[t]{2}{*}{ Nome Popular } & \multirow[t]{2}{*}{ Ecossistema/Bioma** } & \multicolumn{2}{|c|}{$\mathrm{CS}^{* * *}$} \\
\hline & & & & SMA & Lit. \\
\hline & Piptadenia gonoacantha (Mart.) J. F. Macbr. & pau-jacaré & RES/FOD/FES/MC/MP/CER & $\mathrm{P}$ & Si (1) \\
\hline & Plathymenia reticulata Benth. & candeia & FOD/CER & & Nc \\
\hline \multirow[t]{2}{*}{ MORACEAE } & Ficus guaranitica Chodat & figueira & RES/FOD/FES/MC/MP/FED/CER & $\mathrm{P}$ & St (3) \\
\hline & Morus alba L.* & amoreira & & & Nc \\
\hline MYRSINACEAE & Rapanea sp. & & & & Nc \\
\hline \multirow[t]{10}{*}{ MYRTACEAE } & Calyptranthes lucida DC. & goiabinha & & & St \\
\hline & Eucalyptus citriodora Hook* & eucalipto-cheiroso & & & Nc \\
\hline & Eugenia brasiliensis Lam. (VU) & grumixama & RES/FOD/FOM/FES & NP & St \\
\hline & Eugenia involucrata DC. & cerejeira & FOD/FOM/FES/MC & $\mathrm{NP}$ & Si (3) \\
\hline & Eugenia pyriformis Cambess. & uvaia & FOD/FES/MC/CER & NP & St \\
\hline & Eugenia sp. & & & & Nc \\
\hline & Eugenia uniflora L. & pitanga & FOD/FOM/FES/MC/FED & NP & St (5) \\
\hline & Psidium cattleyanum Sabine & araça & RES/FOD & $\mathrm{P}$ & Si (1) \\
\hline & Psidium guajava L. & goiaba & & & $\mathrm{Pi}$ \\
\hline & Syzygium cumini (L.) Skeels* & jambolão & & & Nc \\
\hline OLEACEAE & Ligustrum japonicum Thunb.* & alfeneiro & & & Nc \\
\hline PINACEAE & Pinus taeda L.* & pinheiro & & & Nc \\
\hline POLYGONACEAE & Triplaris americana $\mathrm{L}$. & pau-formiga & & & $\mathrm{Si}$ \\
\hline RHAMNACEAE & Rhamnidium elaeocarpum Reissek & saguaraji & FOD/FES/MC & $\mathrm{P}$ & $\operatorname{Si}(3)$ \\
\hline \multirow[t]{2}{*}{ ROSACEAE } & Eriobotrya japonica (Thunb.) Lindl.* & ameixa & & & Nc \\
\hline & Prunus myrtifolia (L.) Urb. & pessegueiro-bravo & RES/FOD/FOM/FES/MC/MP/CER & $\mathrm{P}$ & $\mathrm{Si}(1)$ \\
\hline RUBIACEAE & Genipa americana L. & genipapo & FES/MC & NP & St \\
\hline
\end{tabular}


Tabela 8. Lista de espécies arbóreas registradas nas 19 áreas de plantios dos portos de areia de leito de rio da Bacia do rio Corumbataí, SP

\begin{tabular}{|c|c|c|c|c|c|}
\hline \multirow[t]{2}{*}{ Família } & \multirow[t]{2}{*}{ Espécie } & \multirow[t]{2}{*}{ Nome Popular } & \multirow[t]{2}{*}{ Ecossistema/Bioma** } & \multicolumn{2}{|c|}{$\mathrm{CS}^{* * *}$} \\
\hline & & & & SMA & Lit. \\
\hline & Rubiaceae sp. & & & & $\mathrm{Nc}$ \\
\hline \multirow[t]{4}{*}{ RUTACEAE } & Metrodorea nigra A. St.-Hil. & carrapateiro & FOD/FES/MC/MP/FED & & $\mathrm{Si}(3)$ \\
\hline & Rutaceae sp. & & & & Nc \\
\hline & Zanthoxylum rhoifolium Lam. & mamica-de-cadela & FOD/FOM/FES/MC/MP/FED/CER & $\mathrm{P}$ & $\operatorname{Pi}(1)$ \\
\hline & Zanthoxylum sp. & mamica-de-porca & & & Nc \\
\hline SALICACEAE & $\begin{array}{l}\text { Salix humboldtiana Willd. } \\
\text { Allophylus edulis (A. St.-Hil., Cambess. \& A. Juss.) }\end{array}$ & salgueiro & MC & & $\mathrm{Pi}$ \\
\hline \multirow[t]{2}{*}{ SAPINDACEAE } & Radlk. & chau-chau & FOD/FOM/FES/MC/MP/CER & $\mathrm{P}$ & $\operatorname{Pi}(1)$ \\
\hline & Sapindaceae sp. & & & & Nc \\
\hline SAPOTACEAE & Pouteria torta (Mart.) Radlk. & abiu-piloso & FOD/FES/CER & NP & St \\
\hline SOLANACEAE & Solanum paniculatum L. & jurubeba & FOD/FES/MC/FED/CER & & $\mathrm{Pi}$ \\
\hline STERCULIACEAE & Guazuma ulmifolia Lam. & mutambo & FOD/FES/MC/CER & $\mathrm{P}$ & $\mathrm{Pi}$ \\
\hline \multirow[t]{3}{*}{ TILIACEAE } & Heliocarpus popayanensis Kunth & algodoeiro & FES/MC & $\mathrm{P}$ & $\mathrm{Pi}$ \\
\hline & Luehea divaricata Mart. & açoita-cavalo-miúda & FOD/FES/MC/MP/FED/CER & $\mathrm{P}$ & $\mathrm{Si}(1)$ \\
\hline & Luehea grandiflora Mart. & açoita-cavalo-graúdo & FOD/FES/MC/CER & $\mathrm{P}$ & $\mathrm{Si}(4)$ \\
\hline ULMACEAE & Trema micrantha (L.) Blume & pau-pólvora & RES/FOD/FES/MC/CER & $\mathrm{P}$ & $\mathrm{Pi}(1)$ \\
\hline VERBENACEAE & Citharexylum myrianthum Cham. & pau-viola & RES/FOD/FES/MC/MP & $\mathrm{P}$ & $\mathrm{Pi}(1)$ \\
\hline \multirow[t]{6}{*}{ MORFOESPÉCIES } & Indeterminada 1 & & & & Nc \\
\hline & Indeterminada 2 & & & & Nc \\
\hline & Indeterminada 3 & & & & Nc \\
\hline & Indeterminada 4 & & & & Nc \\
\hline & Indeterminada 5 & & & & Nc \\
\hline & Indeterminada 6 & & & & Nc \\
\hline
\end{tabular}


Tabela 8. Lista de espécies arbóreas registradas nas 19 áreas de plantios dos portos de areia de leito de rio da Bacia do rio Corumbataí, SP

\begin{tabular}{llll}
\hline Família & Espécie & Nome Popular & Ecossistema/Bioma** \\
& & SMA & Lit. \\
\hline & Indeterminada 7 & Nc \\
Indeterminada 8 & Nc \\
Indeterminada 9 & Nc \\
Indeterminada 10 & Nc \\
Indeterminada 11 & Nc \\
\hline
\end{tabular}

\section{* Espécie exótica para o Estado de São Paulo.}

** Ocorrências naturais nos biomas/ecossistemas do Estado de São Paulo (Resolução SMA 47/2003). RES = Vegetação de Restinga; FOD = Floresta Ombrófila Densa; FON = Floresta Ombrófila Mista; FES = Floresta Estacional Semidecidual; MC = Mata Ciliar; MP = Mata Paludosa; FED = Floresta Estacional Decidual; e CER = Cerrado.

*** Classificações sucessionais segundo literatura disponível e Resolução SMA 21/2001. P = pioneira ou secundária inicial; NP = secundária tardia ou clímax; Pi = pioneira; $\mathrm{Si}$ = secundária inicial; e St = secundária tardia. (1) - Gandolfi et al. (1995); (2) - Leitão Filho et al. (1993); (3) - Bernaci e Leitão Filho (1996); (4) Ivanauskas et al. (1999); e (5) Fonseca et al. (2000).

VU - categoria Vulnerável das espécies ameaçadas de extinção para o Estado de São Paulo de acordo com a Resolução SMA 48/2004. 


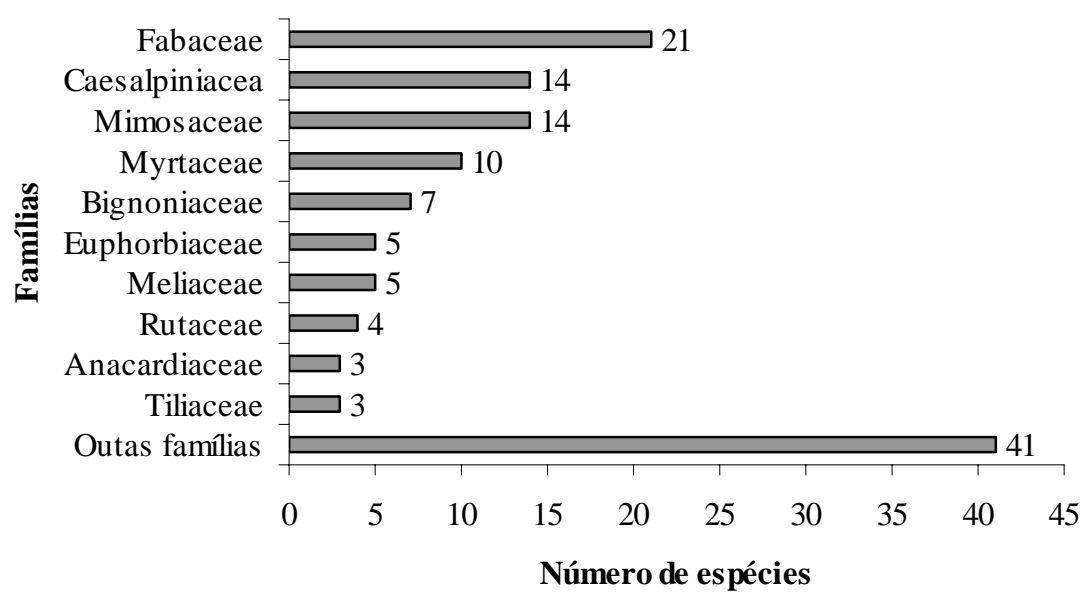

Figura 16 - Distribuição do número de espécies por família para as 19 áreas de plantio dos portos de areia de leito de rio da Bacia do Rio Corumbataí, SP

O uso de Leguminosae consiste em uma estratégia importante nos processos de restauração e recuperação. Por isso, espécies deste grupo têm sido largamente utilizadas nos projetos de revegetação de áreas degradadas. Essa estratégia pode garantir a sustentabilidade do ecossistema através dos seus efeitos diretos na matéria orgânica, aumentando a retenção de água, a estabilidade dos agregados do solo, a disponibilidade de nitrogênio no sistema e a diversidade e atividade biológicas no solo, além de reduzir a lixiviação e os processos erosivos (Maschio et al., 1992 e Parrota, 1992 citados por Barberi et al., 1998).

Embora Myrtaceae não seja uma família de importância na fixação de nitrogênio, essa família assume grande importância ecológica em ambientes de vegetações ripárias naturais. Rodrigues \& Nave (2000) apresentaram os resultados de quarenta e três trabalhos realizados em florestas ciliares do Brasil extra amazônico em que Myrtaceae foi família de maior riqueza florística, com 106 espécies arbustivo-arbóreas. A riqueza florística dessa família em matas ciliares naturais tem sido verificada por diversos autores (Bertani et al., 2001; Sanchez et al., 1999; Sampaio et al., 1997; Felfili, 1994; Salis et al., 1994). 
Apesar do grande número de espécies arbóreas registradas nas 19 áreas (137 espécies), houve uma má distribuição delas nos plantios, com ocorrência de poucas espécies na maioria das áreas (Tabela 9). Em média, foram identificadas 25 espécies por área de plantio. Há casos em que a diversidade foi inferior a 10 espécies, como o Porto 1, em que foi plantada apenas a espécie Salix humboldtiana, e os Portos 7 e 10. Em contrapartida, foram registradas 62 espécies no Porto 6 em uma área de 4,24 ha, e 43 espécies no Porto 13 em 0,27 ha.

Além disso, 59 espécies (39\% das listadas) foram amostradas em apenas uma das áreas de plantio e 26 espécies (58\%) em uma ou duas das áreas de plantio. Foram utilizadas as mesmas 11 espécies (8\%) em quase metade das áreas de plantio (47\%) (Tabela 9).

Resultados semelhantes foram encontrados por Barbosa et al. (2003) na investigação de 98 áreas de recuperação florestal no Estado de São Paulo a partir de plantio de espécies nativas. Os referidos autores ressaltam, entre outras condicionantes, a aplicação de um maior número de espécies (maior riqueza) como condição para o sucesso do plantio.

A biodiversidade das matas ciliares é um aspecto muito importante a ser considerado na recuperação dessa formação (Barbosa, 2000). Desta forma, a diversidade de espécies arbóreas de uma floresta implantada deve ser o mais semelhante possível à que ocorre naturalmente.

O número de espécies arbóreas encontradas em matas ciliares naturais da região é muito superior ao registrado nessas áreas de plantios. Bertani et al. (2001) registraram 107 espécies em 0,36 ha de um fragmento de floresta ribeirinha do Rio Passa Cinco, Ipeúna, SP e; Salis et al. (1994) encontraram 81 espécies em 0,30 ha de um remanescente de mata ciliar do Rio Jacaré-Pepira, Brotas, SP. 
Tabela 9. Matriz binária de presença e ausência das espécies arbóreas identificadas nas áreas de plantios dos portos de areia da Bacia do Rio Corumbataí, SP

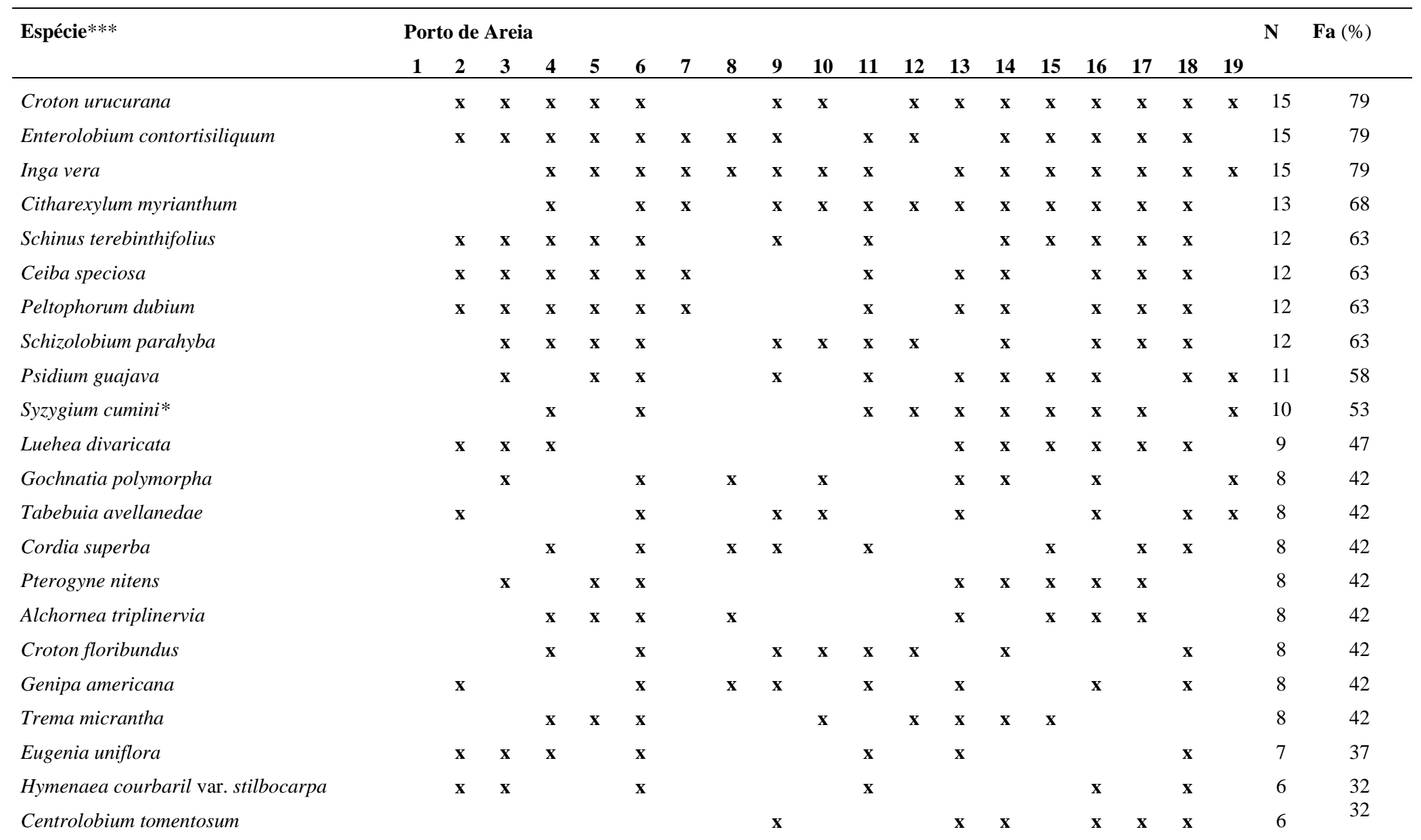


Tabela 9. Matriz binária de presença e ausência das espécies arbóreas identificadas nas áreas de plantios dos portos de areia da Bacia do Rio Corumbataí, SP

\begin{tabular}{|c|c|c|c|c|c|c|c|c|c|c|c|c|c|c|c|c|c|c|c|c|c|}
\hline \multirow[t]{2}{*}{ Espécie** } & \multicolumn{4}{|c|}{ Porto de Areia } & \multirow[b]{2}{*}{5} & \multirow[b]{2}{*}{6} & \multirow[b]{2}{*}{7} & \multirow[b]{2}{*}{8} & \multirow[b]{2}{*}{9} & \multirow[b]{2}{*}{10} & \multirow[b]{2}{*}{11} & \multirow[b]{2}{*}{12} & \multirow[b]{2}{*}{13} & \multirow[b]{2}{*}{14} & \multirow[b]{2}{*}{15} & \multirow[b]{2}{*}{16} & \multirow[b]{2}{*}{17} & \multirow[b]{2}{*}{18} & \multirow[b]{2}{*}{19} & \multirow{2}{*}{$\mathbf{N}$} & \multirow[t]{2}{*}{ Fa $(\%)$} \\
\hline & 1 & 2 & 3 & 4 & & & & & & & & & & & & & & & & & \\
\hline Erythrina mulungu & & $\mathbf{x}$ & $\mathbf{x}$ & & & $\mathbf{x}$ & & & & & & $\mathbf{x}$ & & $\mathbf{x}$ & $\mathbf{x}$ & & & & & 6 & 32 \\
\hline Luehea grandiflora & & & & & $\mathbf{x}$ & $\mathbf{x}$ & $\mathbf{x}$ & & & & & $\mathbf{x}$ & & & $\mathbf{x}$ & & $\mathbf{x}$ & & & 6 & 32 \\
\hline Cecropia pachystachya & & & & & $\mathbf{x}$ & $\mathbf{x}$ & & & $\mathbf{x}$ & & & & $\mathbf{x}$ & & & $\mathbf{x}$ & & & & 5 & 26 \\
\hline Machaerium nyctitans & & $\mathbf{x}$ & $\mathbf{x}$ & & & $\mathbf{x}$ & & & & & & & $\mathbf{x}$ & & $\mathbf{x}$ & & & & & 5 & 26 \\
\hline Acacia polyphylla & & & $\mathbf{x}$ & & & $\mathbf{x}$ & & & & & & & & $\mathbf{x}$ & & $\mathbf{x}$ & & & $\mathbf{x}$ & 5 & 26 \\
\hline Psidium cattleyanum & & & & $\mathbf{x}$ & & & & & & & $\mathbf{x}$ & & $\mathbf{x}$ & $\mathbf{x}$ & & $\mathbf{x}$ & & & & 5 & 26 \\
\hline Triplaris americana & & & & $\mathbf{x}$ & $\mathbf{x}$ & $\mathbf{x}$ & & & & & $\mathbf{x}$ & & & & & & & $\mathbf{x}$ & & 5 & 26 \\
\hline Metrodorea nigra & & & & $\mathbf{x}$ & $\mathbf{x}$ & & & & & & $\mathbf{x}$ & & & $\mathbf{x}$ & & & & $\mathbf{x}$ & & 5 & 26 \\
\hline Guazuma ulmifolia & & $\mathbf{x}$ & $\mathbf{x}$ & & $\mathbf{x}$ & $\mathbf{x}$ & & & $\mathbf{x}$ & & & & & & & & & & & 5 & 26 \\
\hline Heliocarpus popayanensis & & & & $\mathbf{x}$ & & & & & & & $\mathbf{x}$ & & $\mathbf{x}$ & $\mathbf{x}$ & & & $\mathbf{x}$ & & & 5 & 26 \\
\hline Bombacopsis glabra* & & & & $\mathbf{x}$ & $\mathbf{x}$ & & & & & & & & & $\mathbf{x}$ & & & & $\mathbf{x}$ & & 4 & 21 \\
\hline Protium heptaphyllum & & & & $\mathbf{x}$ & & & & & & & $\mathbf{x}$ & & & & & & $\mathbf{x}$ & $\mathbf{x}$ & & 4 & 21 \\
\hline Caesalpinia ferrea* & & & $\mathbf{x}$ & & & & $\mathbf{x}$ & & & & & & & & $\mathbf{x}$ & & & $\mathbf{x}$ & & 4 & 21 \\
\hline Licania tomentosa* & & & & $\mathbf{x}$ & $\mathbf{x}$ & $\mathbf{x}$ & & & & & & & & & & & & $\mathbf{x}$ & & 4 & 21 \\
\hline Lonchocarpus guillemineanus & & $\mathbf{x}$ & & & & $\mathbf{x}$ & & & & & & & & & & $\mathbf{x}$ & & & $\mathbf{x}$ & 4 & 21 \\
\hline Casearia sylvestris & & $\mathbf{x}$ & & & & $\mathbf{x}$ & & & & & $\mathbf{x}$ & & & & & & & & $\mathbf{x}$ & 4 & 21 \\
\hline Cabralea canjerana & & & & & $\mathbf{x}$ & $\mathbf{x}$ & & & & & $\mathbf{x}$ & & & & & $\mathbf{x}$ & & & & 4 & 21 \\
\hline Anadenanthera colubrina & & $\mathbf{x}$ & & & & & & & & & & & & $\mathbf{x}$ & & $\mathbf{x}$ & & $\mathbf{x}$ & & 4 & 21 \\
\hline Eugenia pyriformis & & & & & & $\mathbf{x}$ & & $\mathbf{x}$ & & & & & $\mathbf{x}$ & $\mathbf{x}$ & & & & & & 4 & 21 \\
\hline Rhamnidium elaeocarpum & & & $\mathbf{x}$ & & & & & & & & $\mathbf{x}$ & $\mathbf{x}$ & & & & & & $\mathbf{x}$ & & 4 & 21 \\
\hline Eriobotrya japonica* & & & & & & $\mathbf{x}$ & & & & & $\mathbf{x}$ & & $\mathbf{x}$ & & & & & $\mathbf{x}$ & & 4 & 21 \\
\hline Solanum paniculatum & & $\mathbf{x}$ & & & & & & & & & & $\mathbf{x}$ & $\mathbf{x}$ & & & & $\mathbf{x}$ & & & 4 & 21 \\
\hline
\end{tabular}


Tabela 9. Matriz binária de presença e ausência das espécies arbóreas identificadas nas áreas de plantios dos portos de areia da Bacia do Rio Corumbataí, SP

\begin{tabular}{|c|c|c|c|c|c|c|c|c|c|c|c|c|c|c|c|c|c|c|c|c|c|}
\hline \multirow[t]{2}{*}{ Espécie** } & \multicolumn{4}{|c|}{ Porto de Areia } & \multirow[b]{2}{*}{5} & \multirow[b]{2}{*}{6} & \multirow[b]{2}{*}{7} & \multirow[b]{2}{*}{8} & \multirow[b]{2}{*}{9} & \multirow[b]{2}{*}{10} & \multirow[b]{2}{*}{11} & \multirow[b]{2}{*}{12} & \multirow[b]{2}{*}{13} & \multirow[b]{2}{*}{14} & \multirow[b]{2}{*}{15} & \multirow[b]{2}{*}{16} & \multirow[b]{2}{*}{17} & \multirow[b]{2}{*}{18} & \multirow[b]{2}{*}{19} & \multirow[t]{2}{*}{$\mathbf{N}$} & \multirow[t]{2}{*}{$\mathbf{F a}(\%)$} \\
\hline & 1 & 2 & 3 & 4 & & & & & & & & & & & & & & & & & \\
\hline Schinus molle & & & & & & & & & & & $\mathbf{x}$ & & & & & & $\mathbf{x}$ & $\mathbf{x}$ & & 3 & 16 \\
\hline Jacaranda sp. & & $\mathbf{x}$ & & $\mathbf{x}$ & & $\mathbf{x}$ & & & & & & & & & & & & & & 3 & 16 \\
\hline Cordia trichotoma & & & & & & $\mathbf{x}$ & & & & & & & & $\mathbf{x}$ & & $\mathbf{x}$ & & & & 3 & 16 \\
\hline Bauhinia bongardii & & & & & & $\mathbf{x}$ & & & & & & & $\mathbf{x}$ & & & & $\mathbf{x}$ & & & 3 & 16 \\
\hline Erythrina crista-galli & & & $\mathbf{x}$ & & & $\mathbf{x}$ & & & $\mathbf{x}$ & & & & & & & & & & & 3 & 16 \\
\hline Erythrina verna & & & & & & & & & & & & & $\mathbf{x}$ & $\mathbf{x}$ & & $\mathbf{x}$ & & & & 3 & 16 \\
\hline Myroxylon peruiferum (VU) & & & & $\mathbf{x}$ & & $\mathbf{x}$ & & & & & & & & $\mathbf{x}$ & & & & & & 3 & 16 \\
\hline Ormosia arborea & & & & & & $\mathbf{x}$ & & & & & & & $\mathbf{x}$ & $\mathbf{x}$ & & & & & & 3 & 16 \\
\hline Poecilanthe parviflora & & & & & & $\mathbf{x}$ & & & & & & & $\mathbf{x}$ & & & $\mathbf{x}$ & & & & 3 & 16 \\
\hline Anadenanthera macrocarpa & & & & & & $\mathbf{x}$ & & & & & & $\mathbf{x}$ & & & & & $\mathbf{x}$ & & & 3 & 16 \\
\hline Inga marginata & & & & & $\mathbf{x}$ & $\mathbf{x}$ & & & & & & & & $\mathbf{x}$ & & & & & & 3 & 16 \\
\hline Morus alba* & & & & & & & & & & & & $\mathbf{x}$ & & & $\mathbf{x}$ & & $\mathbf{x}$ & & & 3 & 16 \\
\hline Eugenia brasiliensis (VU) & & & & & & & & & & & $\mathbf{x}$ & & $\mathbf{x}$ & & $\mathbf{x}$ & & & & & 3 & 16 \\
\hline Rutaceae sp. & & & & & & $\mathbf{x}$ & & & $\mathbf{x}$ & & & & & & & $\mathbf{x}$ & & & & 3 & 16 \\
\hline Tabebuia sp. & & & & & & $\mathbf{x}$ & & & & & & & & & & & $\mathbf{x}$ & & & 2 & 10 \\
\hline Tabebuia chrysotricha & & & & & & $\mathbf{x}$ & & & & & & & & & & $\mathbf{x}$ & & & & 2 & 10 \\
\hline Zeyheria tuberculosa & & & $\mathbf{x}$ & & & & & & & & & & & & & $\mathbf{x}$ & & & & 2 & 10 \\
\hline Bixa orellana L.* & & & & $\mathbf{x}$ & $\mathbf{x}$ & & & & & & & & & & & & & & & 2 & 10 \\
\hline Bauhinia forficata & & & & & & & $\mathbf{x}$ & & & & & & & $\mathbf{x}$ & & & & & & 2 & 10 \\
\hline Caesalpinia pluviosa* & & & & & & & & & & & & & & $\mathbf{x}$ & $\mathbf{x}$ & & & & & 2 & 10 \\
\hline Cassia sp. & & & $\mathbf{x}$ & & & & & & & & & & $\mathbf{x}$ & & & & & & & 2 & 10 \\
\hline Copaifera langsdorffii & & $\mathbf{x}$ & & & & $\mathbf{x}$ & & & & & & & & & & & & & & 2 & 10 \\
\hline
\end{tabular}


Tabela 9. Matriz binária de presença e ausência das espécies arbóreas identificadas nas áreas de plantios dos portos de areia da Bacia do Rio Corumbataí, SP

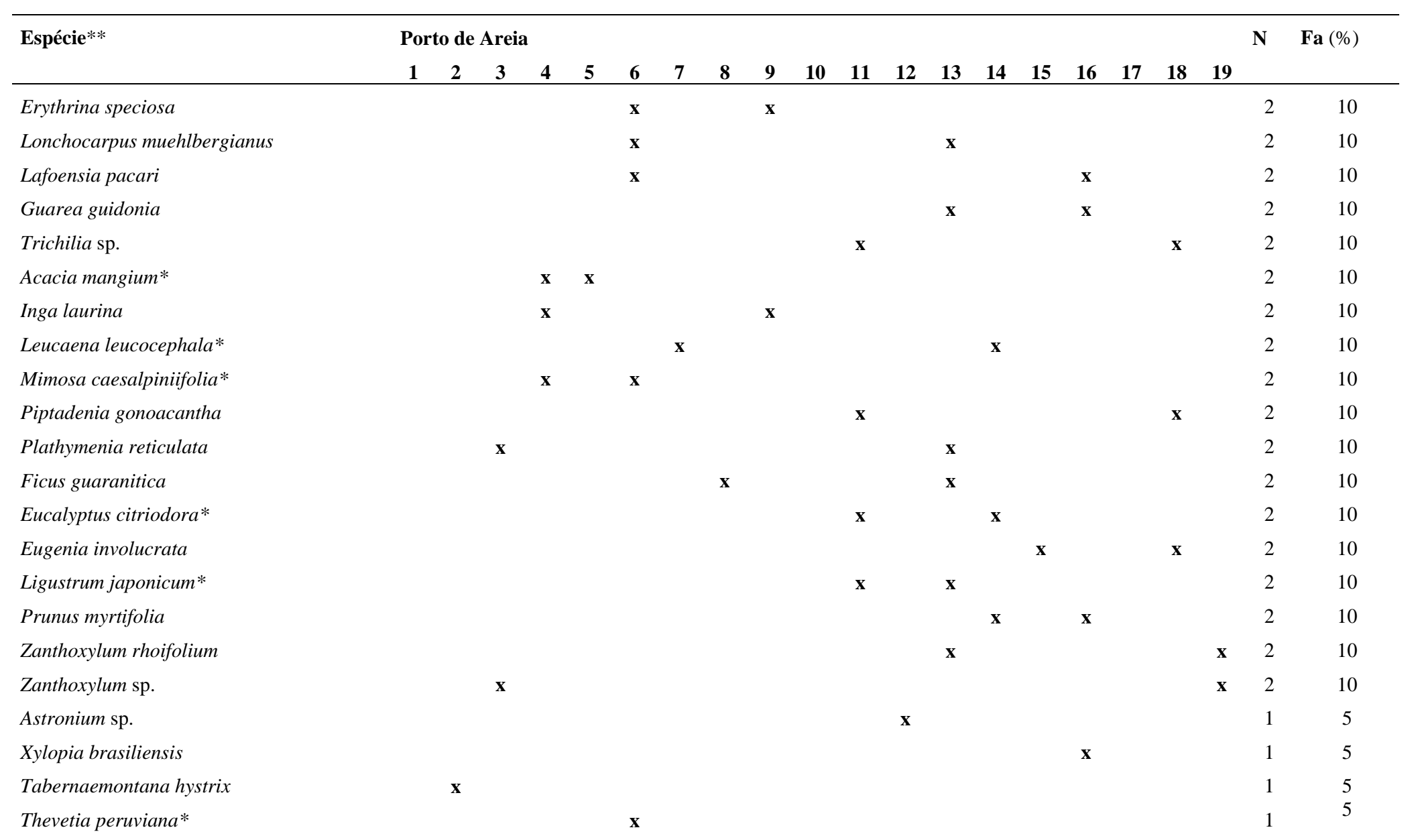


Tabela 9. Matriz binária de presença e ausência das espécies arbóreas identificadas nas áreas de plantios dos portos de areia da Bacia do Rio Corumbataí, SP

\begin{tabular}{|c|c|c|c|c|c|c|c|c|c|c|c|c|c|c|c|c|c|c|c|c|c|}
\hline \multirow[t]{2}{*}{ Espécie** } & \multicolumn{4}{|c|}{ Porto de Areia } & \multirow[b]{2}{*}{5} & \multirow[b]{2}{*}{6} & \multirow[b]{2}{*}{7} & \multirow[b]{2}{*}{8} & \multirow[b]{2}{*}{9} & \multirow[b]{2}{*}{10} & \multirow[b]{2}{*}{11} & \multirow[b]{2}{*}{12} & \multirow[b]{2}{*}{13} & \multirow[b]{2}{*}{14} & \multirow[b]{2}{*}{15} & \multirow[b]{2}{*}{16} & \multirow[b]{2}{*}{17} & \multirow[b]{2}{*}{18} & \multirow[b]{2}{*}{19} & \multirow{2}{*}{$\mathbf{N}$} & \multirow[t]{2}{*}{ Fa (\%) } \\
\hline & 1 & 2 & 3 & 4 & & & & & & & & & & & & & & & & & \\
\hline Asteraceae sp. & & & & $\mathbf{x}$ & & & & & & & & & & & & & & & & 1 & 5 \\
\hline Tabebuia roseoalba & & & & & & & & & & & & & & $\mathbf{x}$ & & & & & & 1 & 5 \\
\hline Tabebuia vellosoi & & & & & & $\mathbf{x}$ & & & & & & & & & & & & & & 1 & 5 \\
\hline Caesalpinia echinata* & & & & & & & & & & & & & & & & $\mathbf{x}$ & & & & 1 & 5 \\
\hline Caesalpinia sp. & & & & & & & & & & & & & & & & $\mathbf{x}$ & & & & 1 & 5 \\
\hline Cassia ferruginea & & & & & & & & & & & & & $\mathbf{x}$ & & & & & & & 1 & 5 \\
\hline Senna spectabilis & & & & & & $\mathbf{x}$ & & & & & & & & & & & & & & 1 & 5 \\
\hline Jacaratia spinosa & & & & & & & & & & & & & $\mathbf{x}$ & & & & & & & 1 & 5 \\
\hline Cecropia glaziovi & & $\mathbf{x}$ & & & & & & & & & & & & & & & & & & 1 & 5 \\
\hline Calophyllum brasiliense & & & & & & & & & & & & & $\mathbf{x}$ & & & & & & & 1 & 5 \\
\hline Terminalia brasiliensis & & & & $\mathbf{x}$ & & & & & & & & & & & & & & & & 1 & 5 \\
\hline Alchornea glandulosa & & & & & & & & $\mathbf{x}$ & & & & & & & & & & & & 1 & 5 \\
\hline Sapium glandulatum & & & & & & $\mathbf{x}$ & & & & & & & & & & & & & & 1 & 5 \\
\hline Clitoria fairchildiana* & & & & & & $\mathbf{x}$ & & & & & & & & & & & & & & 1 & 5 \\
\hline Dalbergia brasiliensis & & & & & & & & & & & & & & $\mathbf{x}$ & & & & & & 1 & 5 \\
\hline Dalbergia sp. & & & & & & & & & $\mathbf{x}$ & & & & & & & & & & & 1 & 5 \\
\hline Erythrina falcata & & & & & & $\mathbf{x}$ & & & & & & & & & & & & & & 1 & 5 \\
\hline Erythrina velutina & & & & & & & & & $\mathbf{x}$ & & & & & & & & & & & 1 & 5 \\
\hline Machaerium acutifolium & & & & & & $\mathbf{x}$ & & & & & & & & & & & & & & 1 & 5 \\
\hline Machaerium opacum* & & & & & & $\mathbf{x}$ & & & & & & & & & & & & & & 1 & 5 \\
\hline Macherium sp. & & & & & & $\mathbf{x}$ & & & & & & & & & & & & & & 1 & 5 \\
\hline Platypodium elegans & & & & & & & & & & & & & $\mathbf{x}$ & & & & & & & 1 & 5 \\
\hline
\end{tabular}


Tabela 9. Matriz binária de presença e ausência das espécies arbóreas identificadas nas áreas de plantios dos portos de areia da Bacia do Rio Corumbataí, SP

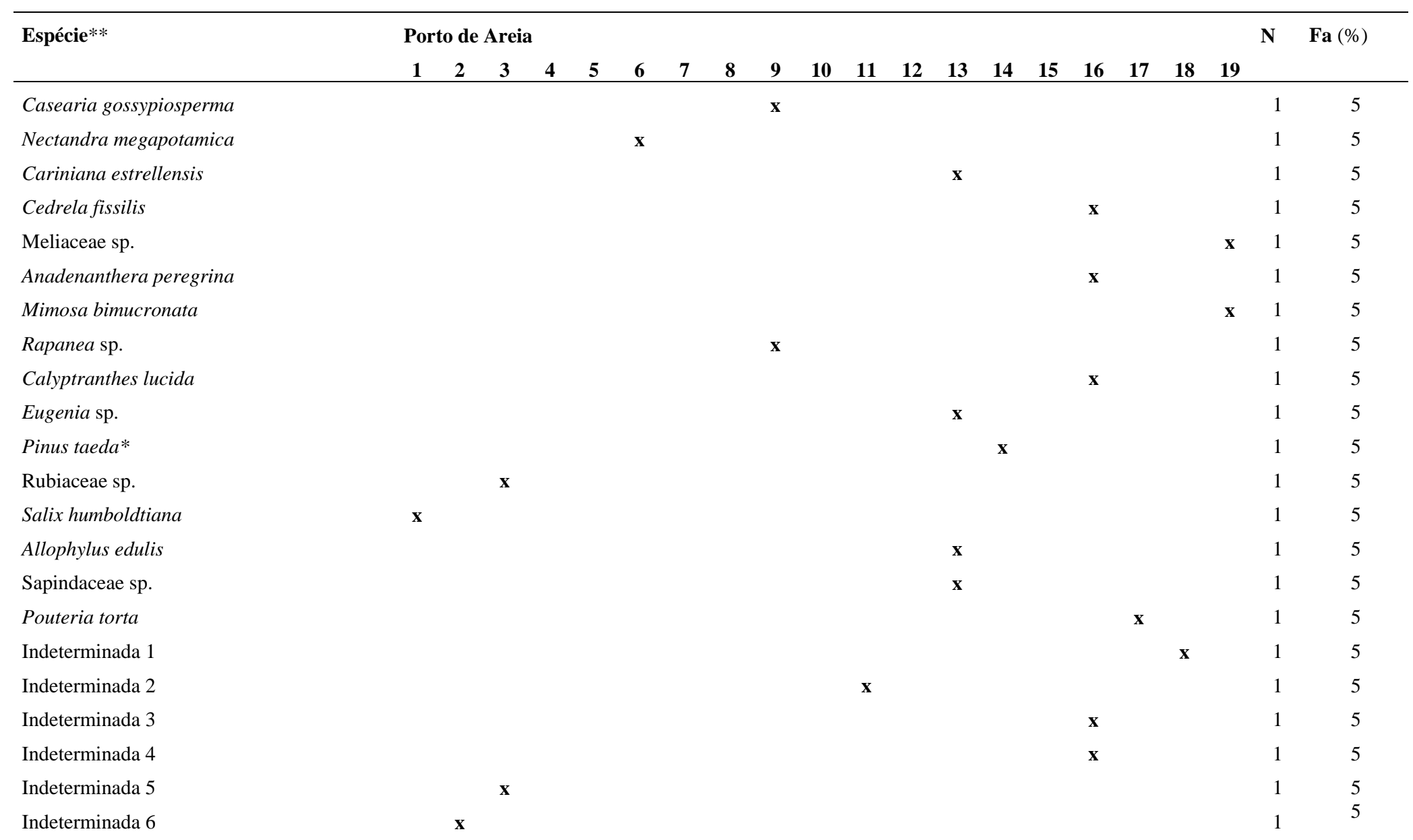


Tabela 9. Matriz binária de presença e ausência das espécies arbóreas identificadas nas áreas de plantios dos portos de areia da Bacia do Rio Corumbataí, SP

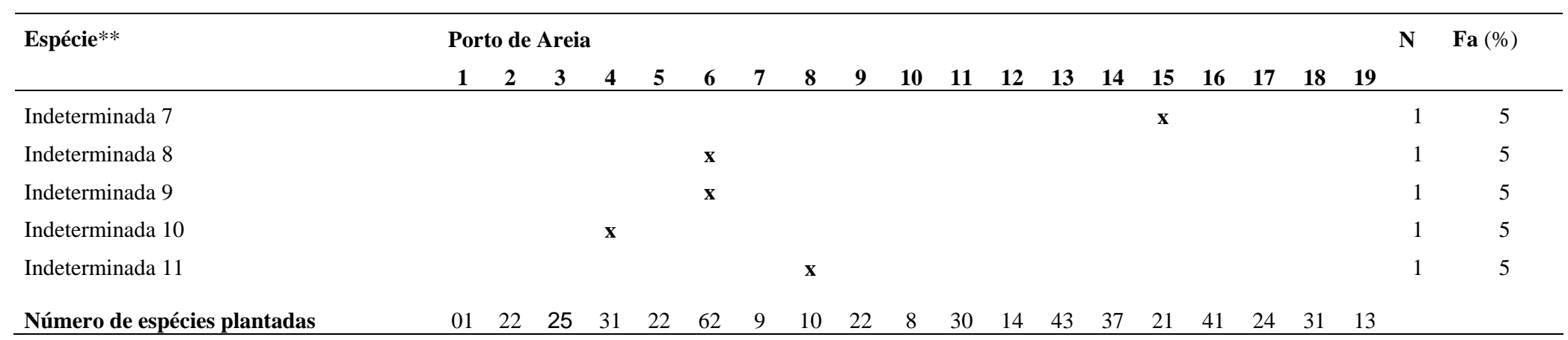

* Espécie exótica para o Estado de São Paulo;

** Espécies organizadas em ordem decrescente de freqüência absoluta (Fa) e de Número de portos (N) com ocorrência da espécie;

VU = espécie vulnerável (Resolução SMA 48/04). 
Ainda não se tem consenso científico sobre o número mínimo de espécies a ser utilizado nesses projetos de recuperação ciliar, mas se aceita que quanto maior o grau de fragmentação das formações naturais da região, maior deve ser o número de espécies usadas, tendo como base o número total de espécies amostradas em levantamentos florísticos de remanescentes florestais da região (Rodrigues \& Nave, 2000).

Contudo, a Resolução SMA 21/01, alterada e ampliada pela Resolução SMA 47/03, considerando a baixa diversidade vegetal das áreas reflorestadas com espécies nativas, nas quais têm sido utilizadas menos de 33 espécies arbóreas, fixa, entre outras orientações, o número de espécies arbóreas nativas a serem utilizadas nos reflorestamentos heterogêneos.

A partir da Resolução SMA 21/01, ficou estabelecido que, em áreas de até 1,0 hectare, devem ser utilizadas no mínimo 30 espécies distintas e, em áreas de até 20 hectares, 50 espécies.

Ainda que os plantios de reflorestamento estudados tenham sido elaborados em data anterior, se aplicada a premissa dessa resolução, 12 dessas áreas (63\%) não cumprem com o número mínimo de espécies proposto (Tabela 9). Das 19 áreas estudadas, 15 são inferiores a um hectare, com extensão média de 0,37 ha e com número médio de 21 espécies. As outras quatro áreas de plantio maiores do que 1,0 hectare tiveram extensão média de 2,27 ha e utilizaram, em média, 37 espécies (Tabelas 5 e 9).

Em estudos efetuados pela SMA foi verificado que poucas espécies vêm sendo utilizadas nos diferentes modelos de repovoamento florestal em todo o Estado de São Paulo, muitas vezes com recomendações errôneas, quanto à sua ocorrência natural nos respectivos biomas (Barbosa \& Martins, 2005).

O uso de poucas espécies, em especial, na recuperação de matas ciliares tem comprometido a principal característica dessas áreas, que é a de eficiente detentora da biodiversidade. Conforme considera as próprias Resoluções SMA 21/01 e 47/03, a perda de diversidade biológica significa a redução de recursos genéticos disponíveis ao desenvolvimento sustentável, na forma de madeira, frutos, forragem, plantas ornamentais e produtos de interesse alimentar, industrial e farmacológico. 
Segundo estudos de Melo (2004), a opção por plantios com baixa riqueza (até 11 espécies) e baixa densidade (até 1240 plantas/ha) não interfere no desempenho do reflorestamento quanto à produção de biomassa. Contudo, não se pode negar que esses modelos podem estar interferindo na biodiversidade natural das matas ciliares.

Um fator fundamental para o sucesso dos plantios consiste na escolha das espécies mais apropriadas a serem utilizadas. Devem ser priorizadas as espécies do próprio ecossistema e da região do plantio, pois estas terão muito mais oportunidade de adaptação ao ambiente, além de garantir a conservação da diversidade regional (Barbosa \& Martins, 2005). O uso de espécies nativas é importante na manutenção de condições e recursos para a fauna e flora local, reestruturando ou mantendo as interações ecológicas dentro do ecossistema.

Segundo Kageyama \& Gandara (2000), a recomendação para o uso de espécies nativas em APPs também se deve ao fato de que as espécies que evoluíram naquele local têm maior probabilidade de ter aí os seus polinizadores, dispersores de sementes e predadores naturais, sendo importantes para que as populações implantadas tenham sua reprodução e regeneração natural normais.

Entre as 137 espécies identificadas, 86 (62\%) fazem parte da listagem da Resolução SMA 47/03. Dessas, 87\% são indicadas pela resolução como de ocorrência natural nas matas ciliares do Estado de São Paulo e 18 espécies (13\% do total registrado) são freqüentemente consideradas pela literatura como exóticas para os biomas do estado (Tabela 8).

Embora não seja recomendado o uso de espécies exóticas na recuperação de APPs, foi registrada nas áreas de plantio uma alta freqüência de espécies de alguma importância econômica que, no entanto, não contribuem com a manutenção da diversidade de espécies nativas do estado, como Syzygium cumini (53\% dos plantios), Bombacopsis glabra (21\%), Caesalpinia ferrea (21\%), Licania tomentosa (21\%) e Eriobotrya japonica (21\%) (Tabela 9).

As Resoluções SMA 21/01 e 47/03 também fixam o uso prioritário das espécies ameaçadas de extinção, que devem ser, segundo a SMA 21/01, no mínimo cinco em projetos de até 1,0 hectare e 10 em até 20 hectares. Mais uma vez, considerando a 
ressalva da data desses reflorestamentos, esses não cumpriram com a proporção atualmente estipulada. De todas as espécies utilizadas nos plantios (137), apenas três (2\%) estão ameaçadas de extinção no Estado de São Paulo, segundo a lista oficial publicada pela Resolução SMA 48/04 (Tabelas 8 e 9).

As espécies mais ocorrentes nas áreas de plantio foram Croton urucurana, Enterolobium contortisiliquum e Inga vera, em 79\% dos portos; Citharexylum myrianthum, em 68\% e; Schinus terebinthifolius, Ceiba speciosa, Peltophorum dubium e Schizolobium parahyba em $63 \%$ dos portos.

Provavelmente essas espécies foram largamente utilizadas em função da facilidade de obtenção de suas mudas em viveiros florestais do Estado de São Paulo. Na listagem de espécies arbóreas nativas encontradas em 43 viveiros de mudas do estado, elaborada por Barbosa \& Martins (2005), C. urucurana está disponível em 70\% desses viveiros, E. contortisiliquum (77\%), I. vera (65\%), C. myrianthum (72\%), S. terebinthifolius (86\%), C. speciosa (84\%), P. dubium (79\%) e S. parahyba (77\%).

Além disso, com exceção de $P$. dubium e S. parahyba, a biologia dessas espécies possui mecanismos adaptativos como estratégia de ocupação e sobrevivência em áreas de mata ciliar de terrenos úmidos e periodicamente inundados.

C. urucurana é uma planta pioneira adaptada a terrenos muito úmidos e brejosos, e é indicada para plantios mistos em áreas ciliares degradadas (Luchi, 2004).

E. contortisiliquum é uma espécie de ampla ocorrência nas matas ciliares (Joly, 1982) que suporta terrenos úmidos ou inundáveis periodicamente, sendo indicada especialmente para recuperação de áreas degradadas (Durigan et al., 2002).

I. vera é uma espécie típica de mata ciliar (Rodrigues, 1992) que é muito utilizada em projetos de reflorestamento, já que, conforme descrito por Lieberg \& Joly (1993), não tem seu crescimento inibido pelo alagamento e suas sementes, além de não serem fotoblásticas, germinam mesmo submersas, originando plântulas capazes de se desenvolver sob a água.

C. myrianthum é uma espécie recomendada para a recomposição de matas ciliares em regiões de terra roxa, mesmo em várzeas permanentemente encharcadas (Durigan, et al., 2002). 
S. terebinthifolius é uma espécie que suporta inundações e encharcamento do solo e geralmente coloniza áreas abertas como margens de rios e terrenos aluviais (Durigan et al., 2002). Essa espécie é recomendada na recuperação de áreas degradadas pela extração de areia pelo seu promissor crescimento em altura e desenvolvimento da copa (Souza et al., 2001).

C. speciosa é uma espécie cujo crescimento também não é inibido pelo alagamento e que apresenta hipertrofia de suas lenticelas, as quais servem como pontos de entrada de ar durante períodos de submersão de suas raízes. Ocorre em áreas sujeitas à inundação esporádicas e na faixa de transição para florestas ciliares (Joly, 1982; Joly \& Crawford, 1982).

\subsubsection{Composição florística dos projetos}

Através da análise dos 23 projetos de plantio das APPs de portos de areia da bacia hidrográfica em estudo, que juntos somaram 18,4 ha (Tabela 5), foram registradas 177 espécies arbóreas, pertencentes a 112 gêneros e 43 famílias. Do total de espécies registradas, 11 foram indicadas apenas como gênero. (Tabela 10).

Ao contrário da lista de espécies dos plantios, o número de espécies nãopioneiras (58\%) indicadas nas listagens florísticas dos projetos foi superior ao de espécies pioneiras (42\%) (Tabela 10).

As listagens florísticas dos projetos dos 19 plantios analisados em campo previam a implantação de plantios com 18\% a mais de diversidade em espécies e em gêneros, além de 9\% a mais de áreas recuperadas (16,2 ha).

Ainda que o número de espécies indicadas pelos projetos de plantio seja superior ao implantado, esse número pode ser considerado insatisfatório. Em média, foram identificadas 31 espécies por área de plantio, com variação entre 4 e 64 espécies e, se considerada a Resolução SMA 21/01, 43\% (13) dos 23 projetos não cumprem com o número mínimo de espécies (Tabela 11).

As áreas de 19 projetos são inferiores a 1,0 hectare, com extensão média de 0,49 ha e com número médio de 30 espécies. Embora, na média esses projetos estejam de 
acordo com a resolução, mais da metade desses portos (10) não cumprem com o mínimo em discussão. Os outros projetos de plantio de áreas maiores do que 1,0 hectare tiveram extensão média de 2,27 ha e indicaram, em média, 45 espécies (Tabelas 5 e 11).

As famílias Fabaceae (21 espécies), Caesalpiniaceae (16 espécies), Mimosaceae (16 espécies), Myrtaceae (13 espécies) e Lauraceae (12 espécies) apresentaram as maiores riquezas em espécies (Figura 17) e juntas representaram apenas $8 \%$ de todas as famílias registradas nos projetos e suas espécies corresponderam a $44 \%$ do total de espécies.

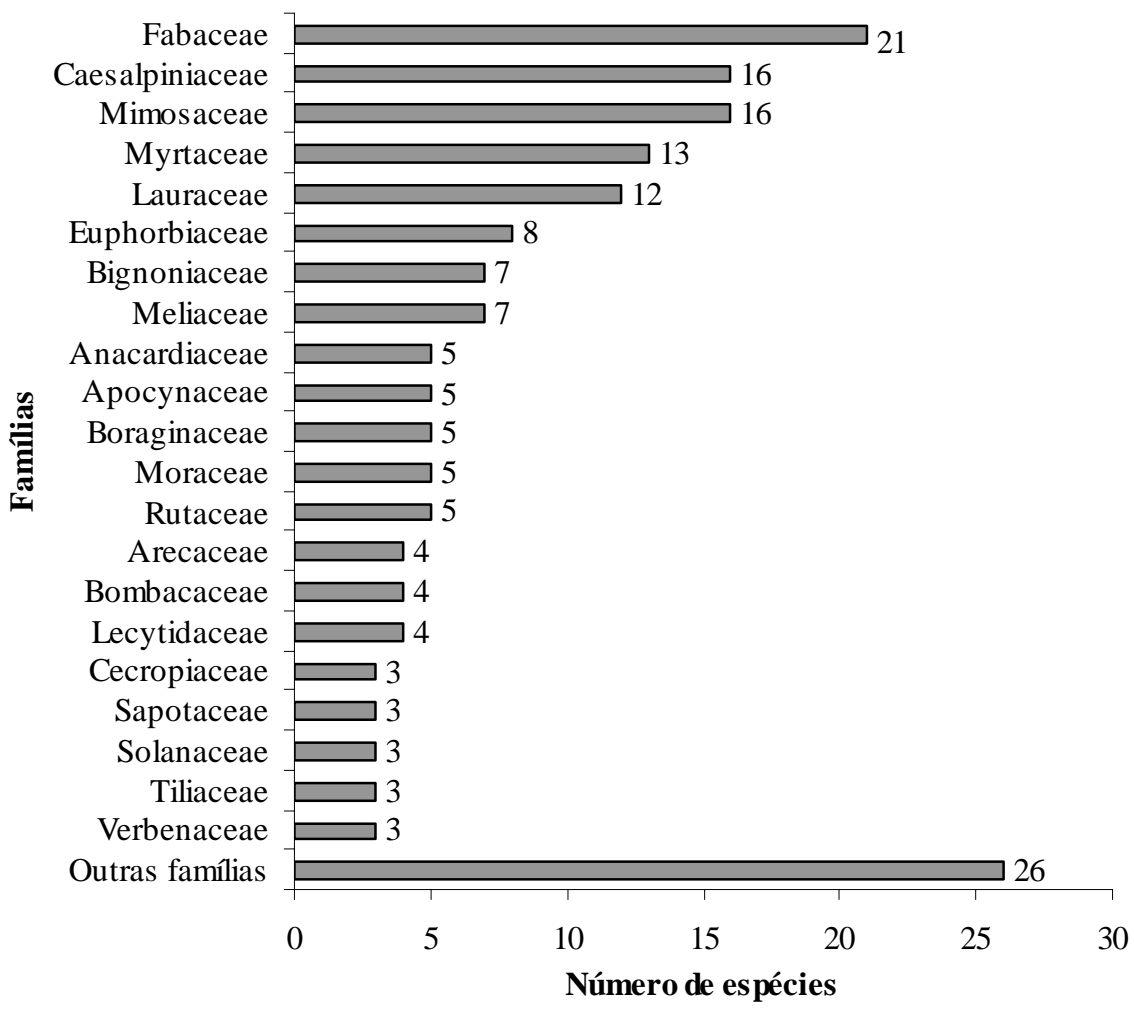

Figura 17 - Distribuição do número de espécies por família para os 23 projetos de reflorestamento dos portos de areia de leito de Rio da Bacia do rio Corumbataí, SP 
Tabela 10. Lista de espécies arbóreas indicadas nos 23 projetos de reflorestamento dos portos de areia da Bacia do Rio Corumbataí, SP

\begin{tabular}{|c|c|c|c|}
\hline Família & Espécie & Nome popular & $\mathrm{CS}^{* *}$ \\
\hline \multirow[t]{5}{*}{ ANACARDIACEAE } & Astronium graveolens Jacq. & guaritá & NP \\
\hline & Lithraea molleoides (Vell.) Engl. & aroeira-mansa & $\mathrm{P}$ \\
\hline & Myracrodruon urundeuva Allemão (VU) & aroeira & NP \\
\hline & Schinus terebinthifolius Raddi & aroeira-pimenteira & $\mathrm{P}$ \\
\hline & Tapirira guianensis Aubl. & peito-de-pomba & $\mathrm{P}$ \\
\hline \multirow[t]{2}{*}{ ANNONACEAE } & Annona cacans Warm. & araticum-cagão & $\mathrm{P}$ \\
\hline & Duguetia lanceolata A. St.-Hil. & corticeira & NP \\
\hline \multirow[t]{5}{*}{ APOCYNACEAE } & Aspidosperma cylindrocarpon Müll. Arg. & peroba-poca & NP \\
\hline & Aspidosperma parvifolium A. DC. & guatambu-oliva & NP \\
\hline & Aspidosperma polyneuron Müll. Arg. & peroba-rosa & NP \\
\hline & Aspidosperma ramiflorum Müll. Arg. & guatambu & NP \\
\hline & Rauvolfia sellowii Müll. Arg. & casca d’anta & $\mathrm{P}$ \\
\hline ARALIACEAE & Dendropanax cuneatus (DC.) Decne. \& Planch. & maria-mole & NP \\
\hline \multirow[t]{4}{*}{ ARECACEAE } & Acrocomia aculeata (Jacq.) Lodd. ex Mart. & macaúba & NP \\
\hline & Euterpe edulis Mart. (VU) & palmito-juçara & NP \\
\hline & Euterpe oleracea Mart.* & açaí & \\
\hline & Syagrus romanzoffiana (Cham.) Glassman & gerivá & $\mathrm{P}$ \\
\hline ASTERACEAE & Gochnatia polymorpha (Less.) Cabrera & candeia & $\mathrm{P}$ \\
\hline \multirow[t]{4}{*}{ BIGNONIACEAE } & Tabebuia avellanedae Lorentz ex Griseb. & ipê-roxo & \\
\hline & Tabebuia chrysotricha (Mart. ex A. DC.) Standl. & ipê-amarelo-cascudo & NP \\
\hline & Tabebuia dura (Bureau ex K. Schum.) Sprague \& Sandwith & ipê-do-brejo & \\
\hline & Tabebuia impetiginosa (Mart. ex DC.) Standl. & ipê-rosa & NP \\
\hline
\end{tabular}


Tabela 10. Lista de espécies arbóreas indicadas nos 23 projetos de reflorestamento dos portos de areia da Bacia do Rio Corumbataí, SP

\begin{tabular}{|c|c|c|c|}
\hline Família & Espécie & Nome popular & $\mathrm{CS}^{* *}$ \\
\hline \multirow{6}{*}{ BOMBACACEAE } & Tabebuia umbellata (Sond.) Sandwith & ipê-da-várzea & NP \\
\hline & Zeyheria tuberculosa (Vell.) Bureau & ipê-bolsa-de-pastor & $\mathrm{P}$ \\
\hline & Bombacopsis glabra (Pasquale) Robyns* & castanha-de-praia & \\
\hline & Ceiba speciosa (A. St.-Hil.) Ravenna & paineira & $\mathrm{P}$ \\
\hline & Eriotheca candolleana (K. Schum.) A. Robyns & paineira & $\mathrm{P}$ \\
\hline & Pseudobombax grandiflorum (Cav.) A. Robyns & imbiruçu & $\mathrm{P}$ \\
\hline \multirow[t]{5}{*}{ BORAGINACEAE } & Cordia ecalyculata Vell. & café-de-bugre & $\mathrm{P}$ \\
\hline & Cordia sellowiana Cham. & chá-de-bugre & $\mathrm{P}$ \\
\hline & Cordia superba Cham. & baba-de-boi & $\mathrm{P}$ \\
\hline & Cordia trichotoma (Vell.) Arráb. ex Steud. & louro-pardo & NP \\
\hline & Patagonula americana L. & guaiuvira & $\mathrm{P}$ \\
\hline BURSERACEAE & Protium heptaphyllum (Aubl.) Marchand & almecega & NP \\
\hline \multirow[t]{11}{*}{ CAESALPINIACEAE } & Bauhinia bongardii Steud. & pata-de-vaca & \\
\hline & Caesalpinia echinata Lam.* & pau-brasil & \\
\hline & Caesalpinia ferrea Mart.* & pau-ferro & \\
\hline & Cassia ferruginea (Schrader) Schrader ex DC. & chuva-de-ouro & $\mathrm{P}$ \\
\hline & Cassia fistula L.* & cassia-fístula & $\mathrm{P}$ \\
\hline & Copaifera langsdorffii (Desf.) Kuntze & óleo-de-copaíba & NP \\
\hline & Hymenaea courbaril var. stilbocarpa (Hayne) Y.T. Lee \& Langenh. & jatobá & NP \\
\hline & Hymenaea stigonocarpa Mart. ex Hayne & jatobá-do-cerrado & \\
\hline & Holocalyx balansae Micheli & alecrim-de-campinas & \\
\hline & Peltophorum dubium (Spreng.) Taub. & canafístula & $\mathrm{P}$ \\
\hline & Pterogyne nitens Tul. & amendoin-do-campo & $\mathrm{P}$ \\
\hline
\end{tabular}


Tabela 10. Lista de espécies arbóreas indicadas nos 23 projetos de reflorestamento dos portos de areia da Bacia do Rio Corumbataí, SP

\begin{tabular}{|c|c|c|c|}
\hline Família & Espécie & Nome popular & $\mathrm{CS}^{* *}$ \\
\hline & Schizolobium parahyba (Vell.) S.F. Blake & ficheira & $\mathrm{P}$ \\
\hline & Senna alata (L.) Roxb. & mata pasto & \\
\hline & Senna bicapsularis (L.) Roxb. & canudo-de-pito & \\
\hline & Senna macranthera (DC. ex Collad.) H.S. Irwin \& Barneby & manduirana & $\mathrm{P}$ \\
\hline & Senna multijuga (Rich.) H.S. Irwin \& Barneby & pau-cigarra & $\mathrm{P}$ \\
\hline CARICACEAE & Jacaratia spinosa (Aubl.) A. DC. & jaracatiá & $\mathrm{P}$ \\
\hline \multirow[t]{3}{*}{ CECROPIACEAE } & Cecropia glaziovi Snethlage & embaúba-vermelha & \\
\hline & Cecropia pachystachya Trécul & embaúva-branca & $\mathrm{P}$ \\
\hline & Cecropia sp. & embaúva & \\
\hline CLUSIACEAE & Calophyllum brasiliense Cambess. & guanandi & NP \\
\hline COMBRETACEAE & Terminalia brasiliensis (Cambess. ex A. St.-Hil.) Eichler & capitão-do-campo & NP \\
\hline ELAEOCARPACEAE & Muntingia calabura $\mathrm{L}$. & calabura & \\
\hline \multirow[t]{8}{*}{ EUPHORBIACEAE } & Alchornea triplinervia (Spreng.) Müll. Arg. & tapiá & \\
\hline & Croton floribundus Spreng. & capixingui & $\mathrm{P}$ \\
\hline & Croton salutaris Casar. & caixeta-mole & \\
\hline & Croton urucurana Baill. & sangra-d'água & $\mathrm{P}$ \\
\hline & Joannesia princeps Vell. & andá-assú & \\
\hline & Sapium marginatum Müll. Arg. & mata-olho & \\
\hline & Savia dictyocarpa Müll. Arg. & guaraiuva & NP \\
\hline & Sebastiania serrata (Baill. ex Müll. Arg.) Müll. Arg. & sebastiana & \\
\hline \multirow[t]{3}{*}{ FABACEAE } & Centrolobium tomentosum Guillemin ex Benth. & araribá & $\mathrm{P}$ \\
\hline & Clitoria fairchildiana R. A. Howard* & sombreiro & \\
\hline & Cyclolobium vecchii A. Samp. ex Hoehne & louveira & NP \\
\hline
\end{tabular}


Tabela 10. Lista de espécies arbóreas indicadas nos 23 projetos de reflorestamento dos portos de areia da Bacia do Rio Corumbataí, SP

\begin{tabular}{|c|c|c|c|}
\hline Família & Espécie & Nome popular & $\mathrm{CS}^{* *}$ \\
\hline & Dalbergia brasiliensis Vogel & caroba-brava & \\
\hline & Erythrina crista-galli L. & crista-de-galo & $\mathrm{P}$ \\
\hline & Erythrina falcata Benth. & suinã & $\mathrm{P}$ \\
\hline & Erythrina mulungu Mart. & mulumgu & $\mathrm{P}$ \\
\hline & Erythrina speciosa Andrews & suinã-vermelho & $\mathrm{P}$ \\
\hline & Erythrina verna Vell. & mulungu-coral & $\mathrm{P}$ \\
\hline & Lonchocarpus guillemineanus (Tul.) Malme & embira-de-sapo & $\mathrm{P}$ \\
\hline & Lonchocarpus muehlbergianus Hassl. & feijão-cru & $\mathrm{P}$ \\
\hline & Lonchocarpus sp. & embira-de-sapo & \\
\hline & Machaerium acutifolium Vogel & bico-de-pato & NP \\
\hline & Machaerium nyctitans (Vell.) Benth. & bico-de-pato & $\mathrm{P}$ \\
\hline & Myrocarpus frondosus Allemão & cabreúva-preta & NP \\
\hline & Myroxylon peruiferum L. f. (VU) & cabreúva & NP \\
\hline & Ormosia arborea (Vell.) Harms & olho-de-cabra & NP \\
\hline & Poecilanthe parviflora Benth. & coração-de-negro & NP \\
\hline & Pterocarpus rohrii Vahl & aldrago & $\mathrm{P}$ \\
\hline & Pterodon pubescens (Benth.) Benth. & faveiro & NP \\
\hline & Sesbania virgata (Cav.) Pers. & sarãnzinho & \\
\hline FLACOURTIACEAE & Casearia sylvestris Sw. & guaçatonga & $\mathrm{P}$ \\
\hline \multirow[t]{4}{*}{ LAURACEAE } & Cryptocarya aschersoniana $\mathrm{Mez}$ & canela-pururuca & NP \\
\hline & Cryptocarya moschata Nees \& C. Mart. & canela & \\
\hline & Nectandra megapotamica (Spreng.) Mez & canela & NP \\
\hline & Nectandra membranacea (Sw.) Griseb. & canela-do-brejo & \\
\hline
\end{tabular}


Tabela 10. Lista de espécies arbóreas indicadas nos 23 projetos de reflorestamento dos portos de areia da Bacia do Rio Corumbataí, SP

\begin{tabular}{|c|c|c|c|}
\hline Família & Espécie & Nome popular & $\mathrm{CS}^{* *}$ \\
\hline & Nectandra oppositifolia Nees \& Mart. & canela amarela & \\
\hline & Nectandra rigida (Kunth) Nees & canela-ferrugem & \\
\hline & Ocotea odorifera (Vellozo) Rohwer & canela-sassafrás & NP \\
\hline & Ocotea oppositifolia S. Yasuda & canela & \\
\hline & Ocotea sp. & & \\
\hline & Persea major (Nees) Kopp & canela-do-brejo & \\
\hline & Persea pyrifolia (D. Don) Spreng. & maçaramduba & NP \\
\hline \multirow[t]{4}{*}{ LECYTHIDACEAE } & Cariniana estrellensis (Raddi) Kuntze & jequitibá-branco & NP \\
\hline & Cariniana legalis (Mart.) Kuntze & jequitibá-rosa & NP \\
\hline & Couroupita guianensis Aubl.* & abricó-de-macaco & \\
\hline & Lecythis pisonis Cambess. & sapucaia & \\
\hline LYTHRACEAE & Lafoensia pacari A. St.-Hil. & dedaleiro & $\mathrm{P}$ \\
\hline MALVACEAE & Hibiscus pernambucensis Arruda & agodão-de-praia & \\
\hline \multirow[t]{2}{*}{ MELASTOMATACEAE } & Tibouchina granulosa (Desr.) Cogn. & quaresmeira & \\
\hline & Tibouchina stenocarpa (DC.) Cogn. & quaresmeira & \\
\hline \multirow[t]{7}{*}{ MELIACEAE } & Cabralea canjerana (Vell.) Mart. & canjerana & NP \\
\hline & Cedrela fissilis Vell. & cedro & $\mathrm{P}$ \\
\hline & Cedrela odorata L. & cedro & $\mathrm{P}$ \\
\hline & Guarea guidonia (L.) Sleumer & marinheiro & $\mathrm{P}$ \\
\hline & Guarea kunthiana A. Juss. & cajambo & \\
\hline & Swietenia macrophylla King* & mogno & \\
\hline & Trichilia pallida Sw. & catiguá & \\
\hline MIMOSACEAE & Acacia polyphylla DC. & monjoleiro & $\mathrm{P}$ \\
\hline
\end{tabular}


Tabela 10. Lista de espécies arbóreas indicadas nos 23 projetos de reflorestamento dos portos de areia da Bacia do Rio Corumbataí, SP

\begin{tabular}{|c|c|c|c|}
\hline Família & Espécie & Nome popular & $\mathrm{CS}^{* *}$ \\
\hline & Anadenanthera colubrina (Vell.) Brenan & angico-branco & $\mathrm{P}$ \\
\hline & Anadenanthera falcata (Benth.) Speg. & angico-preto & $\mathrm{P}$ \\
\hline & Anadenanthera macrocarpa (Benth.) Brenan & angico-vermelho & $\mathrm{P}$ \\
\hline & Anadenanthera peregrina (L.) Speg. & angico-vermelho & \\
\hline & Enterolobium contortisiliquum (Vell.) Morong & orelha-de-negro & $\mathrm{P}$ \\
\hline & Inga edulis Mart. & ingá-mirim & $\mathrm{P}$ \\
\hline & Inga marginata Willd. & ingá-feijão & $\mathrm{P}$ \\
\hline & Inga sessilis (Vell.) Mart. & ingá & NP \\
\hline & Inga sp. & ingá & \\
\hline & Inga vera Willd. & ingá & $\mathrm{P}$ \\
\hline & Leucaena leucocephala (Lam.) de Wit* & leucena & \\
\hline & Mimosa bimucronata (DC.) Kuntze & maricá & $\mathrm{P}$ \\
\hline & Mimosa sp. & bragatinga & \\
\hline & Parapiptadenia rigida (Benth.) Brenan & angico-da-mata & $\mathrm{P}$ \\
\hline & Piptadenia gonoacantha (Mart.) J. F. Macbr. & pau-jacaré & $\mathrm{P}$ \\
\hline \multirow[t]{5}{*}{ MORACEAE } & Ficus glabra Vell. & figueira & \\
\hline & Ficus nymphaeifolia Mill.* & figueira-branca & \\
\hline & Ficus sp. & figueira & \\
\hline & Maclura tinctoria (L.) D. Don ex Steud & taiúva & $\mathrm{P}$ \\
\hline & Morus sp. & amoreira & \\
\hline \multirow[t]{2}{*}{ MYRSINACEAE } & Rapanea ferruginea (Ruiz \& Pav.) Mez & capororoca & $\mathrm{P}$ \\
\hline & Rapanea sp. & & \\
\hline MYRTACEAE & Campomanesia phaea (O. Berg) Landrum & cambuci & NP \\
\hline
\end{tabular}


Tabela 10. Lista de espécies arbóreas indicadas nos 23 projetos de reflorestamento dos portos de areia da Bacia do Rio Corumbataí, SP

\begin{tabular}{|c|c|c|c|}
\hline Família & Espécie & Nome popular & $\mathrm{CS}^{* *}$ \\
\hline & Campomanesia sp. & grumixama & \\
\hline & Eugenia brasiliensis Lam. (categoria VU) & grumixama & NP \\
\hline & Eugenia involucrata DC. & cerejeira & NP \\
\hline & Eugenia leitonii Legrand & araçaramduba & NP \\
\hline & Eugenia pyriformis Cambess. & uvaia & NP \\
\hline & Eugenia sp. & & \\
\hline & Eugenia uniflora L. & pitanga & NP \\
\hline & Hexachlamys edulis (O. Berg) Kausel \& D. Legrand & cereja-do-rio-grande & \\
\hline & Myrciaria trunciflora O. Berg & jabuticabeira & \\
\hline & Psidium cattleyanum Sabine & araça & $\mathrm{P}$ \\
\hline & Psidium guajava $\mathrm{L}$. & goiaba & \\
\hline & Syzygium cumini (L.) Skeels* & jambolão & \\
\hline PHYTOLACACEAE & Gallesia integrifolia (Spreng.) Harms & pau d’alho & $\mathrm{P}$ \\
\hline POLYGONACEAE & Triplaris sp. & pau-formiga & \\
\hline RHAMNACEAE & Rhamnidium elaeocarpum Reissek & saguaraji & $\mathrm{P}$ \\
\hline ROSACEAE & Prunus myrtifolia (L.) Urb. & pessegueiro-bravo & $\mathrm{P}$ \\
\hline RUBIACEAE & Genipa americana L. & genipapo & NP \\
\hline \multirow[t]{5}{*}{ RUTACEAE } & Balfourodendron riedelianum (Engl.) Engl. & pau-marfim & NP \\
\hline & Esenbeckia febrifuga (A. St. Hil.) A. Juss. ex Mart. & limãozinho & \\
\hline & Esenbeckia leiocarpa Engl. & guarantã & NP \\
\hline & Metrodorea nigra A. St.-Hil. & carrapateiro & \\
\hline & Zanthoxylum sp. & mamica-de-porca & \\
\hline SAPINDACEAE & Allophylus edulis (A. St.-Hil., Cambess. \& A. Juss.) Radlk. & chau-chau & $\mathrm{P}$ \\
\hline
\end{tabular}


Tabela 10. Lista de espécies arbóreas indicadas nos 23 projetos de reflorestamento dos portos de areia da Bacia do Rio Corumbataí, SP

\begin{tabular}{|c|c|c|c|}
\hline Família & Espécie & Nome popular & $\mathrm{CS}^{* *}$ \\
\hline \multirow[t]{3}{*}{ SAPOTACEAE } & Chrysophyllum gonocarpum (Mart. \& Eichler) Engl. & aguaí & NP \\
\hline & Pouteria sp. & guapeba & \\
\hline & Pouteria torta (Mart.) Radlk. & abiu-piloso & NP \\
\hline \multirow[t]{3}{*}{ SOLANACEAE } & Solanum granuloso-leprosum Dunal & gravitinga & $\mathrm{P}$ \\
\hline & Solanum pseudoquina A. St.-Hil. & cuivira & \\
\hline & Solanum sp. & & \\
\hline \multirow[t]{2}{*}{ STERCULIACEAE } & Guazuma sp. & & \\
\hline & Guazuma ulmifolia Lam. & mutambo & $\mathrm{P}$ \\
\hline \multirow[t]{3}{*}{ TILIACEAE } & Luehea divaricata Mart. & açoita-cavalo-miúda & $\mathrm{P}$ \\
\hline & Luehea grandiflora Mart. & açoita-cavalo-graúdo & $\mathrm{P}$ \\
\hline & Luehea sp. & açoita-cavalo & \\
\hline ULMACEAE & Trema micrantha (L.) Blume & pau-pólvora & $\mathrm{P}$ \\
\hline \multirow[t]{3}{*}{ VERBENACEAE } & Aloysia virgata (Ruiz \& Pav.) Juss. & lixa & $\mathrm{P}$ \\
\hline & Citharexylum myrianthum Cham. & pau-viola & $\mathrm{P}$ \\
\hline & Vitex polygama Cham. & tarumã & NP \\
\hline VOCHYSIACEAE & Callisthene major Mart. & pau-de-pilão & \\
\hline
\end{tabular}

* Espécie exótica para o Estado de São Paulo

** classificações sucessionais segundo Resolução SMA 21/01. P = pioneira ou secundária inicial; NP = secundária tardia ou clímax;

VU - categoria Vulnerável das espécies ameaçadas de extinção para o Estado de São Paulo de acordo com a Resolução SMA 48/200. 
Tabela 11. Matriz binária de presença e ausência das espécies arbóreas indicadas nos projetos de plantios dos portos de areia da Bacia do Rio Corumbataí, SP

\begin{tabular}{|c|c|c|c|c|c|c|c|c|c|c|c|c|c|c|c|c|c|c|c|c|c|c|c|c|c|}
\hline \multirow[t]{2}{*}{ Espécie } & \multicolumn{23}{|c|}{ Porto de Areia } & \multirow[t]{2}{*}{$\mathbf{N}$} & \multirow{2}{*}{$\begin{array}{l}\mathbf{F a} \\
(\%)\end{array}$} \\
\hline & 1 & 2 & 3 & 4 & 5 & 6 & 7 & 8 & 9 & 10 & 11 & 12 & 13 & 14 & 15 & 16 & 17 & 18 & 19 & 20 & 21 & 22 & 23 & & \\
\hline Croton urucurana & $\mathbf{x}$ & $\mathbf{x}$ & $\mathbf{x}$ & $\mathbf{x}$ & $\mathbf{x}$ & $\mathbf{x}$ & $\mathbf{x}$ & $\mathbf{x}$ & & & $\mathbf{x}$ & $\mathbf{x}$ & $\mathbf{x}$ & $\mathbf{x}$ & $\mathbf{x}$ & $\mathbf{x}$ & $\mathbf{x}$ & & & $\mathbf{x}$ & $\mathbf{x}$ & $\mathbf{x}$ & $\mathbf{x}$ & 19 & 83 \\
\hline Croton floribundus & $\mathbf{x}$ & $\mathbf{x}$ & $\mathbf{x}$ & & & $\mathbf{x}$ & $\mathbf{x}$ & $\mathbf{x}$ & & $\mathbf{x}$ & $\mathbf{x}$ & & $\mathbf{x}$ & & $\mathbf{x}$ & $\mathbf{x}$ & $\mathbf{x}$ & $\mathbf{x}$ & $\mathbf{x}$ & $\mathbf{x}$ & $\mathbf{x}$ & $\mathbf{x}$ & $\mathbf{x}$ & 18 & 78 \\
\hline Psidium guajava & & $\mathbf{x}$ & $\mathbf{x}$ & $\mathbf{x}$ & $\mathbf{x}$ & $\mathbf{x}$ & $\mathbf{x}$ & $\mathbf{x}$ & & & $\mathbf{x}$ & $\mathbf{x}$ & $\mathbf{x}$ & & $\mathbf{x}$ & $\mathbf{x}$ & $\mathbf{x}$ & & $\mathbf{x}$ & $\mathbf{x}$ & $\mathbf{x}$ & $\mathbf{x}$ & $\mathbf{x}$ & 18 & 78 \\
\hline Genipa americana & & $\mathbf{x}$ & $\mathbf{x}$ & & & $\mathbf{x}$ & $\mathbf{x}$ & $\mathbf{x}$ & & $\mathbf{x}$ & $\mathbf{x}$ & $\mathbf{x}$ & $\mathbf{x}$ & $\mathbf{x}$ & $\mathbf{x}$ & $\mathbf{x}$ & $\mathbf{x}$ & $\mathbf{x}$ & & $\mathbf{x}$ & $\mathbf{x}$ & $\mathbf{x}$ & $\mathbf{x}$ & 18 & 78 \\
\hline Copaifera langsdorffii & & $\mathbf{x}$ & $\mathbf{x}$ & & & $\mathbf{x}$ & $\mathbf{x}$ & $\mathbf{x}$ & & $\mathbf{x}$ & $\mathbf{x}$ & & $\mathbf{x}$ & $\mathbf{x}$ & & $\mathbf{x}$ & $\mathbf{x}$ & $\mathbf{x}$ & & $\mathbf{x}$ & $\mathbf{x}$ & $\mathbf{x}$ & & 15 & 65 \\
\hline Eugenia pyriformis & & $\mathbf{x}$ & $\mathbf{x}$ & & & $\mathbf{x}$ & $\mathbf{x}$ & $\mathbf{x}$ & & $\mathbf{x}$ & $\mathbf{x}$ & & $\mathbf{x}$ & $\mathbf{x}$ & & $\mathbf{x}$ & $\mathbf{x}$ & $\mathbf{x}$ & & $\mathbf{x}$ & & $\mathbf{x}$ & & 14 & 61 \\
\hline Luehea divaricata & & $\mathbf{x}$ & $\mathbf{x}$ & $\mathbf{x}$ & $\mathbf{x}$ & $\mathbf{x}$ & $\mathbf{x}$ & $\mathbf{x}$ & & & $\mathbf{x}$ & & $\mathbf{x}$ & $\mathbf{x}$ & & $\mathbf{x}$ & $\mathbf{x}$ & & & & $\mathbf{x}$ & $\mathbf{x}$ & & 14 & 61 \\
\hline Hymenaea courbaril var. stilbocarpa & & $\mathbf{x}$ & $\mathbf{x}$ & & & $\mathbf{x}$ & $\mathbf{x}$ & $\mathbf{x}$ & & & $\mathbf{x}$ & $\mathbf{x}$ & $\mathbf{x}$ & $\mathbf{x}$ & & $\mathbf{x}$ & $\mathbf{x}$ & & & $\mathbf{x}$ & & $\mathbf{x}$ & & 13 & 56 \\
\hline Inga sp. & $\mathbf{x}$ & $\mathbf{x}$ & $x$ & $\mathbf{x}$ & $\mathbf{x}$ & $\mathbf{x}$ & $\mathbf{x}$ & $\mathbf{x}$ & & $\mathbf{x}$ & & $\mathbf{x}$ & & & & $\mathbf{x}$ & & $\mathbf{x}$ & & & & $\mathbf{x}$ & & 13 & 56 \\
\hline Cariniana legalis & & $\mathbf{x}$ & $\mathbf{x}$ & & & $\mathbf{x}$ & $\mathbf{x}$ & $\mathbf{x}$ & & & $\mathbf{x}$ & & $\mathbf{x}$ & & & $\mathbf{x}$ & $\mathbf{x}$ & & & $\mathbf{x}$ & $\mathbf{x}$ & $\mathbf{x}$ & & 12 & 52 \\
\hline Eugenia uniflora & & $\mathbf{x}$ & $\mathbf{x}$ & & & $\mathbf{x}$ & $\mathbf{x}$ & $\mathbf{x}$ & & & $\mathbf{x}$ & & $\mathbf{x}$ & $\mathbf{x}$ & & & $\mathbf{x}$ & & & $\mathbf{x}$ & $\mathbf{x}$ & $\mathbf{x}$ & & 12 & 52 \\
\hline Peltophorum dubium & & $\mathbf{x}$ & $\mathbf{x}$ & $\mathbf{x}$ & $\mathbf{x}$ & $\mathbf{x}$ & $\mathbf{x}$ & $\mathbf{x}$ & & & & & & & $\mathbf{x}$ & $\mathbf{x}$ & & & & & & $\mathbf{x}$ & $\mathbf{x}$ & 11 & 48 \\
\hline Cariniana estrellensis & & $\mathbf{x}$ & $\mathbf{x}$ & & & $\mathbf{x}$ & $\mathbf{x}$ & $\mathbf{x}$ & & & $\mathbf{x}$ & & $\mathbf{x}$ & & & $\mathbf{x}$ & $\mathbf{x}$ & & & $\mathbf{x}$ & $\mathbf{x}$ & & & 11 & 48 \\
\hline Anadenanthera macrocarpa & & $\mathbf{x}$ & $\mathbf{x}$ & & & $\mathbf{x}$ & $\mathbf{x}$ & $\mathbf{x}$ & $\mathbf{x}$ & & & & & & $\mathbf{x}$ & $\mathbf{x}$ & & & & & $\mathbf{x}$ & $\mathbf{x}$ & $\mathbf{x}$ & 11 & 48 \\
\hline Trema micrantha & & $\mathbf{x}$ & $\mathbf{x}$ & & & $\mathbf{x}$ & $\mathbf{x}$ & $\mathbf{x}$ & & $\mathbf{x}$ & & & & & $\mathbf{x}$ & $\mathbf{x}$ & & $\mathbf{x}$ & & & & $\mathbf{x}$ & $\mathbf{x}$ & 11 & 48 \\
\hline Tapirira guianensis & & $\mathbf{x}$ & $\mathbf{x}$ & & & $\mathbf{x}$ & $\mathbf{x}$ & $\mathbf{x}$ & & & $\mathbf{x}$ & & $\mathbf{x}$ & & & $\mathbf{x}$ & $\mathbf{x}$ & & & $\mathbf{x}$ & & & & 10 & 43 \\
\hline Aspidosperma polyneuron & & & & & & & & & $\mathbf{x}$ & $\mathbf{x}$ & $\mathbf{x}$ & & $\mathbf{x}$ & & & $\mathbf{x}$ & $\mathbf{x}$ & $\mathbf{x}$ & & $\mathbf{x}$ & $\mathbf{x}$ & $\mathbf{x}$ & & 10 & 43 \\
\hline Acacia polyphylla & & $\mathbf{x}$ & $\mathbf{x}$ & & & $\mathbf{x}$ & $\mathbf{x}$ & $\mathbf{x}$ & & & & & & $\mathbf{x}$ & $\mathbf{x}$ & $\mathbf{x}$ & & & & & & $\mathbf{x}$ & $\mathbf{x}$ & 10 & 43 \\
\hline Inga vera & & & & & & & & & $\mathbf{x}$ & & $\mathbf{x}$ & & $\mathbf{x}$ & $\mathbf{x}$ & $\mathbf{x}$ & $\mathbf{x}$ & $\mathbf{x}$ & & & $\mathbf{x}$ & & $\mathbf{x}$ & $\mathbf{x}$ & 10 & 43 \\
\hline Psidium cattleyanum & & & & $\mathbf{x}$ & $\mathbf{x}$ & $\mathbf{x}$ & & & & & $\mathbf{x}$ & & $\mathbf{x}$ & $\mathbf{x}$ & $\mathbf{x}$ & & $\mathbf{x}$ & & & $\mathbf{x}$ & & & $\mathbf{x}$ & 10 & 43 \\
\hline Schinus terebinthifolius & & $\mathbf{x}$ & $\mathbf{x}$ & $\mathbf{x}$ & $\mathbf{x}$ & $\mathbf{x}$ & $\mathbf{x}$ & $\mathbf{x}$ & & & & & & $\mathbf{x}$ & & $\mathbf{x}$ & & & & & & & & 9 & 39 \\
\hline Ceiba speciosa & & & & $\mathbf{x}$ & $\mathbf{x}$ & $\mathbf{x}$ & & & & $\mathbf{x}$ & & & & $\mathbf{x}$ & & $\mathbf{x}$ & & $\mathbf{x}$ & & & $\mathbf{x}$ & $\mathbf{x}$ & & 9 & 39 \\
\hline
\end{tabular}


Tabela 11. Matriz binária de presença e ausência das espécies arbóreas indicadas nos projetos de plantios dos portos de areia da Bacia do Rio Corumbataí, SP

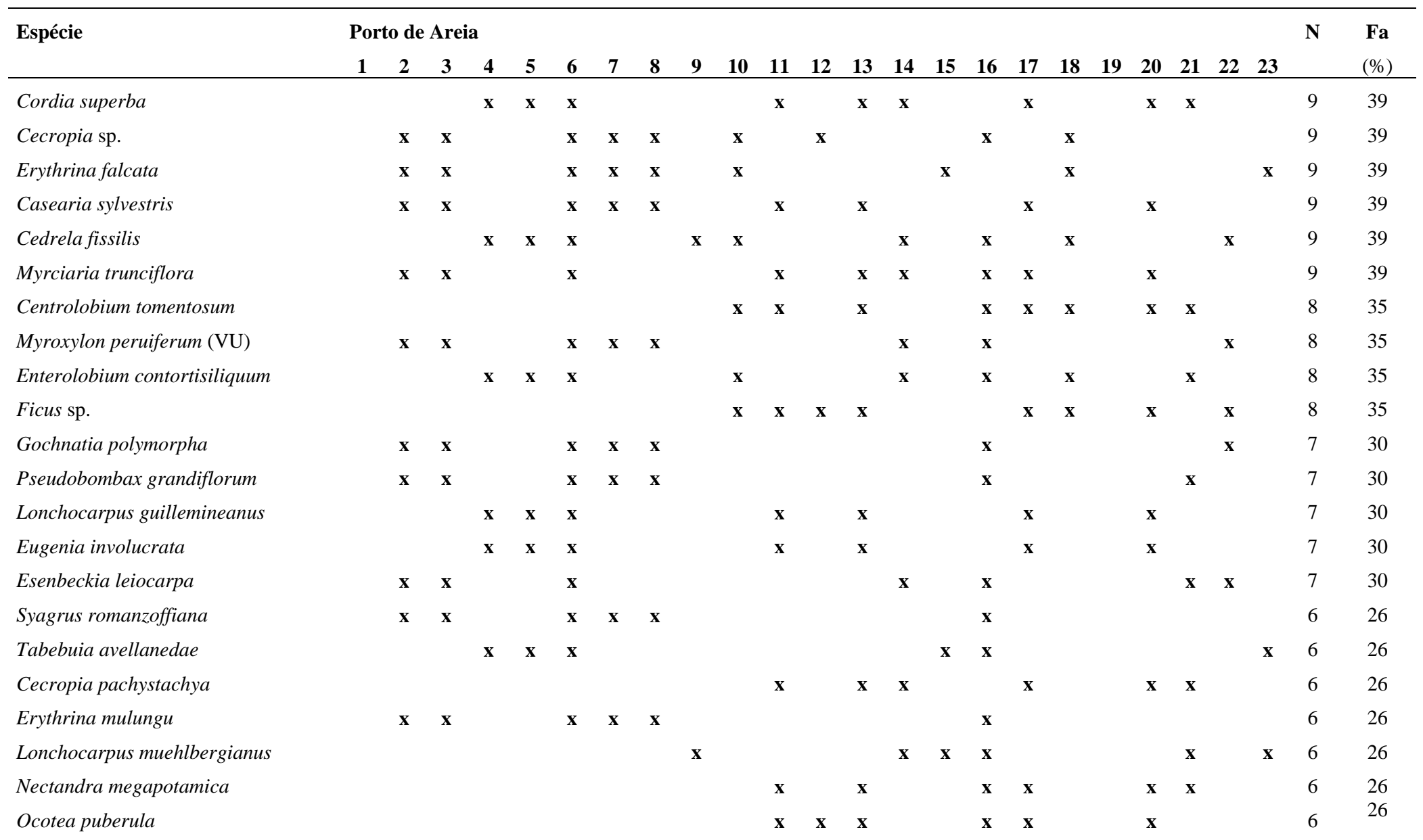


Tabela 11. Matriz binária de presença e ausência das espécies arbóreas indicadas nos projetos de plantios dos portos de areia da Bacia do Rio Corumbataí, SP

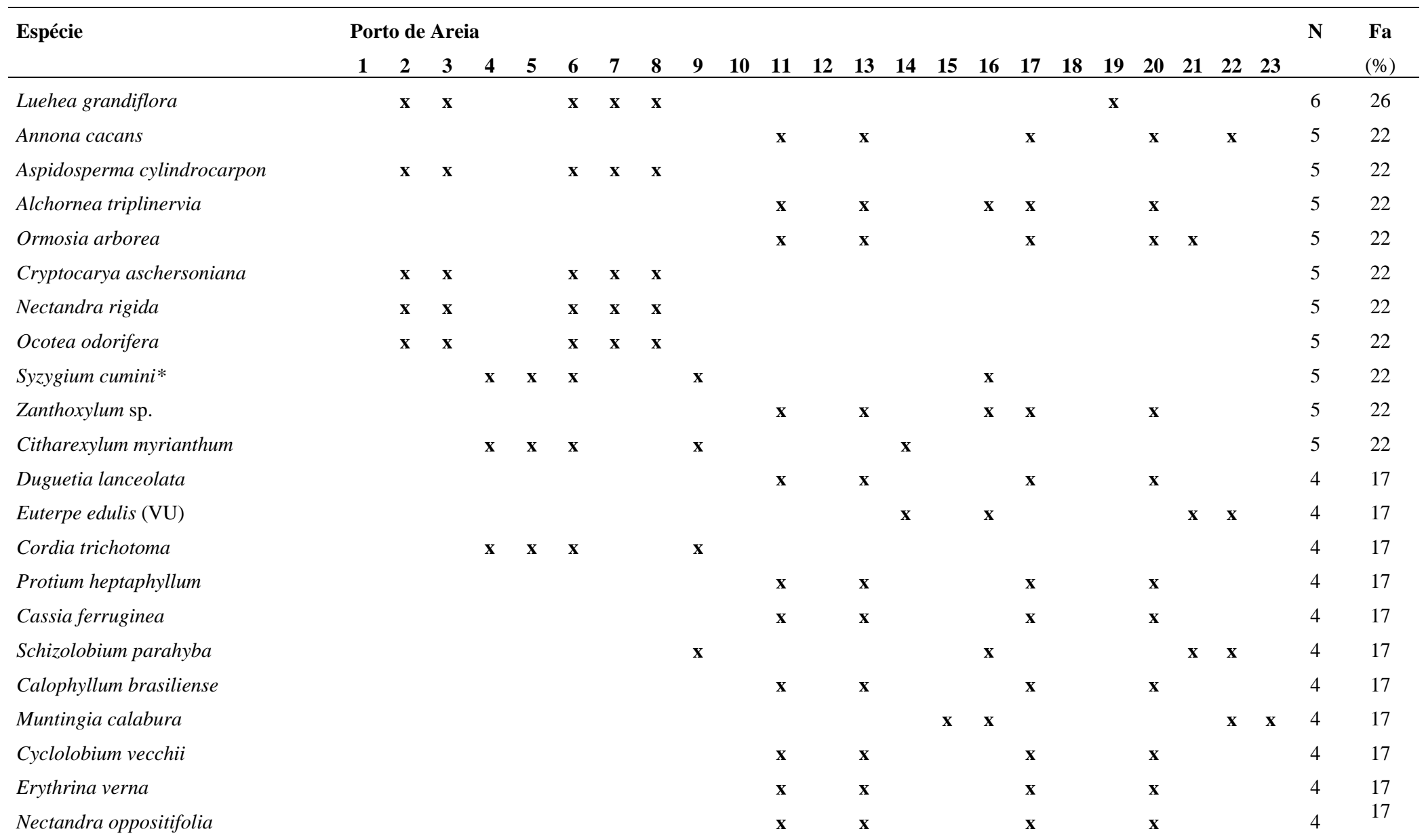


Tabela 11. Matriz binária de presença e ausência das espécies arbóreas indicadas nos projetos de plantios dos portos de areia da Bacia do Rio Corumbataí, SP

\begin{tabular}{|c|c|c|c|c|c|c|c|c|c|c|c|c|c|c|c|c|c|c|c|c|c|c|c|c|c|}
\hline \multirow[t]{2}{*}{ Espécie } & \multicolumn{23}{|c|}{ Porto de Areia } & \multirow[t]{2}{*}{$\mathbf{N}$} & \multirow{2}{*}{$\begin{array}{l}\mathbf{F a} \\
(\%)\end{array}$} \\
\hline & 1 & 2 & 3 & 4 & 5 & 6 & 7 & 8 & 9 & 10 & 11 & 12 & 13 & 14 & 15 & 16 & 17 & 18 & 19 & 20 & 21 & 22 & 23 & & \\
\hline Ocotea sp. & & & & & & & & & & & $\mathbf{x}$ & & $\mathbf{x}$ & & & & $\mathbf{x}$ & & & $\mathbf{x}$ & & & & 4 & 17 \\
\hline Hibiscus pernambucensis & & & & & & & & & & & $\mathbf{x}$ & & $\mathbf{x}$ & & & & $\mathbf{x}$ & & & $\mathbf{x}$ & & & & 4 & 17 \\
\hline Guarea guidonia & & & & & & & & & & & $\mathbf{x}$ & & $\mathbf{x}$ & & & & $\mathbf{x}$ & & & $\mathbf{x}$ & & & & 4 & 17 \\
\hline Trichilia pallida & & & & & & & & & & & $\mathbf{x}$ & & $\mathbf{x}$ & & & & $\mathbf{x}$ & & & $\mathbf{x}$ & & & & 4 & 17 \\
\hline Maclura tinctoria & & & & & & & & & & & $\mathbf{x}$ & & $\mathbf{x}$ & & & & $\mathbf{x}$ & & & $\mathbf{x}$ & & & & 4 & 17 \\
\hline Rapanea sp. & & & & & & & & & & & $\mathbf{x}$ & & $\mathbf{x}$ & & & & $\mathbf{x}$ & & & $\mathbf{x}$ & & & & 4 & 17 \\
\hline Eugenia brasiliensis (VU) & & & & & & & & & & & $\mathbf{x}$ & & $\mathbf{x}$ & & & & $\mathbf{x}$ & & & $\mathbf{x}$ & & & & 4 & 17 \\
\hline Eugenia leitonii & & & & & & & & & & & $\mathbf{x}$ & & $\mathbf{x}$ & & & & $\mathbf{x}$ & & & $\mathbf{x}$ & & & & 4 & 17 \\
\hline Chrysophyllum gonocarpum & & & & & & & & & & & $\mathbf{x}$ & & $\mathbf{x}$ & & & & $\mathbf{x}$ & & & $\mathbf{x}$ & & & & 4 & 17 \\
\hline Pouteria sp. & & & & & & & & & & & $\mathbf{x}$ & & $\mathbf{x}$ & & & & $\mathbf{x}$ & & & $\mathbf{x}$ & & & & 4 & 17 \\
\hline Pouteria torta & & & & & & & & & & & $\mathbf{x}$ & & $\mathbf{x}$ & & & & $\mathbf{x}$ & & & $\mathbf{x}$ & & & & 4 & 17 \\
\hline Guazuma ulmifolia & & & & $\mathbf{x}$ & $\mathbf{x}$ & $\mathbf{x}$ & & & $\mathbf{x}$ & & & & & & & & & & & & & & & 4 & 17 \\
\hline Astronium graveolens & & & & & & & & & & & & & & $\mathbf{x}$ & & $\mathbf{x}$ & & & & & $\mathbf{x}$ & & & 3 & 13 \\
\hline Myracrodruon urundeuva (VU) & & & & & & & & & & & & $\mathbf{x}$ & & & & $\mathbf{x}$ & & & & & & $\mathbf{x}$ & & 3 & 13 \\
\hline Aspidosperma ramiflorum & & & & & & & & & & & & & & & $\mathbf{x}$ & & & & & & $\mathbf{x}$ & & $\mathbf{x}$ & 3 & 13 \\
\hline Tabebuia umbellata & & & & & & & & & & $\mathbf{x}$ & & & & & & & & $\mathbf{x}$ & $\mathbf{x}$ & & & & & 3 & 13 \\
\hline Patagonula americana & & & & & & & & & & & & & & & $\mathbf{x}$ & $\mathbf{x}$ & & & & & & & $\mathbf{x}$ & 3 & 13 \\
\hline Holocalyx balansae & & & & & & & & & & & & & & & $\mathbf{x}$ & $\mathbf{x}$ & & & & & & & $\mathbf{x}$ & 3 & 13 \\
\hline Savia dictyocarpa & & & & & & & & & & & & & & $\mathbf{x}$ & & $\mathbf{x}$ & & & & & & $\mathbf{x}$ & & 3 & 13 \\
\hline Myrocarpus frondosus & & & & & & & & & & & $\mathbf{x}$ & & $\mathbf{x}$ & & & & $\mathbf{x}$ & & & & & & & 3 & 13 \\
\hline Tibouchina granulosa & & & & & & & & & & & & & & $\mathbf{x}$ & $\mathbf{x}$ & & & & & & & & $\mathbf{x}$ & 3 & 13 \\
\hline Cabralea canjerana & & $\mathbf{x}$ & $\mathbf{x}$ & & & $\mathbf{x}$ & & & & & & & & & & & & & & & & & & 3 & 13 \\
\hline
\end{tabular}


Tabela 11. Matriz binária de presença e ausência das espécies arbóreas indicadas nos projetos de plantios dos portos de areia da Bacia do Rio Corumbataí, SP

\begin{tabular}{|c|c|c|c|c|c|c|c|c|c|c|c|c|c|c|c|c|c|c|c|c|c|c|c|c|c|}
\hline \multirow[t]{2}{*}{ Espécie } & \multicolumn{23}{|c|}{ Porto de Areia } & \multirow[t]{2}{*}{$\mathbf{N}$} & \multirow{2}{*}{$\begin{array}{l}\mathbf{F a} \\
(\%)\end{array}$} \\
\hline & 1 & 2 & 3 & 4 & 5 & 6 & 7 & 8 & 9 & 10 & 11 & 12 & 13 & 14 & 15 & 16 & 17 & 18 & 19 & 20 & 21 & 22 & 23 & & \\
\hline Anadenanthera colubrina & & & & & & & & & & & & & & $\mathbf{x}$ & & $\mathbf{x}$ & & & & & & $\mathbf{x}$ & & 3 & 13 \\
\hline Piptadenia gonoacantha & & & & & & & & & & & & & & $\mathbf{x}$ & & $\mathbf{x}$ & & & & & $\mathbf{x}$ & & & 3 & 13 \\
\hline Eugenia sp. & & & & & & & & & & & & $\mathbf{x}$ & & & $\mathbf{x}$ & & & & & & & & $\mathbf{x}$ & 3 & 13 \\
\hline Triplaris sp. & & & & $\mathbf{x}$ & $\mathbf{x}$ & $\mathbf{x}$ & & & & & & & & & & & & & & & & & & 3 & 13 \\
\hline Prunus myrtifolia & & & & & & & & & & & & $\mathbf{x}$ & & & & $\mathbf{x}$ & & & $\mathbf{x}$ & & & & & 3 & 13 \\
\hline Allophylus edulis & & & & & & & & & & & & & $\mathbf{x}$ & & & & & & & $\mathbf{x}$ & & $\mathbf{x}$ & & 3 & 13 \\
\hline Luehea sp. & & & & & & & & & & $\mathbf{x}$ & & $\mathbf{x}$ & & & & & & $\mathbf{x}$ & & & & & & 3 & 13 \\
\hline Lithraea molleoides & & & & & & & & & & & & & & $\mathbf{x}$ & & & & & & & & $\mathbf{x}$ & & 2 & 9 \\
\hline Aspidosperma parvifolium & & & & & & & & & & & & & & $\mathbf{x}$ & & $\mathbf{x}$ & & & & & & & & 2 & 9 \\
\hline Acrocomia aculeata & & & & & & & & & & & & & & & $\mathbf{x}$ & & & & & & & & $\mathbf{x}$ & 2 & 9 \\
\hline Tabebuia dura & & & & & & & & & & $\mathbf{x}$ & & & & & & & & $\mathbf{x}$ & & & & & & 2 & 9 \\
\hline Tabebuia impetiginosa & & & & & & & & & & & & & & & & & & & & & $\mathbf{x}$ & $\mathbf{x}$ & & 2 & 9 \\
\hline Cordia ecalyculata & & & & & & & & & & & & & & & $\mathbf{x}$ & & & & & & & & $\mathbf{x}$ & 2 & 9 \\
\hline Bauhinia bongardii & & & & & & & & & & $\mathbf{x}$ & & & & & & & & $\mathbf{x}$ & & & & & & 2 & 9 \\
\hline Hymenaea stigonocarpa & & & & & & & & & & $\mathbf{x}$ & & & & & & & & $\mathbf{x}$ & & & & & & 2 & 9 \\
\hline Terminalia brasiliensis & & & & & & & & & & & & & & & $\mathbf{x}$ & & & & & & & & $\mathbf{x}$ & 2 & 9 \\
\hline Erythrina crista-galli & & & & & & & & & & & & & & & $\mathbf{x}$ & & & & & & & & $\mathbf{x}$ & 2 & 9 \\
\hline Poecilanthe parviflora & & & & & & & & & $\mathbf{x}$ & & & & & $\mathbf{x}$ & & & & & & & & & & 2 & 9 \\
\hline Nectandra membranacea & & & & & & & & & & $\mathbf{x}$ & & & & & & & & $\mathbf{x}$ & & & & & & 2 & 9 \\
\hline Tibouchina stenocarpa & & & & & & & & & & $\mathbf{x}$ & & & & & & & & $\mathbf{x}$ & & & & & & 2 & 9 \\
\hline Cedrela odorata & & & & & & & & & $\mathbf{x}$ & & & & & & & & & & $\mathbf{x}$ & & & & & 2 & 9 \\
\hline Swietenia macrophylla* & & & & & & & & & $\mathbf{x}$ & & & & & $\mathbf{x}$ & & & & & & & & & & 2 & 9 \\
\hline
\end{tabular}


Tabela 11. Matriz binária de presença e ausência das espécies arbóreas indicadas nos projetos de plantios dos portos de areia da Bacia do Rio Corumbataí, SP

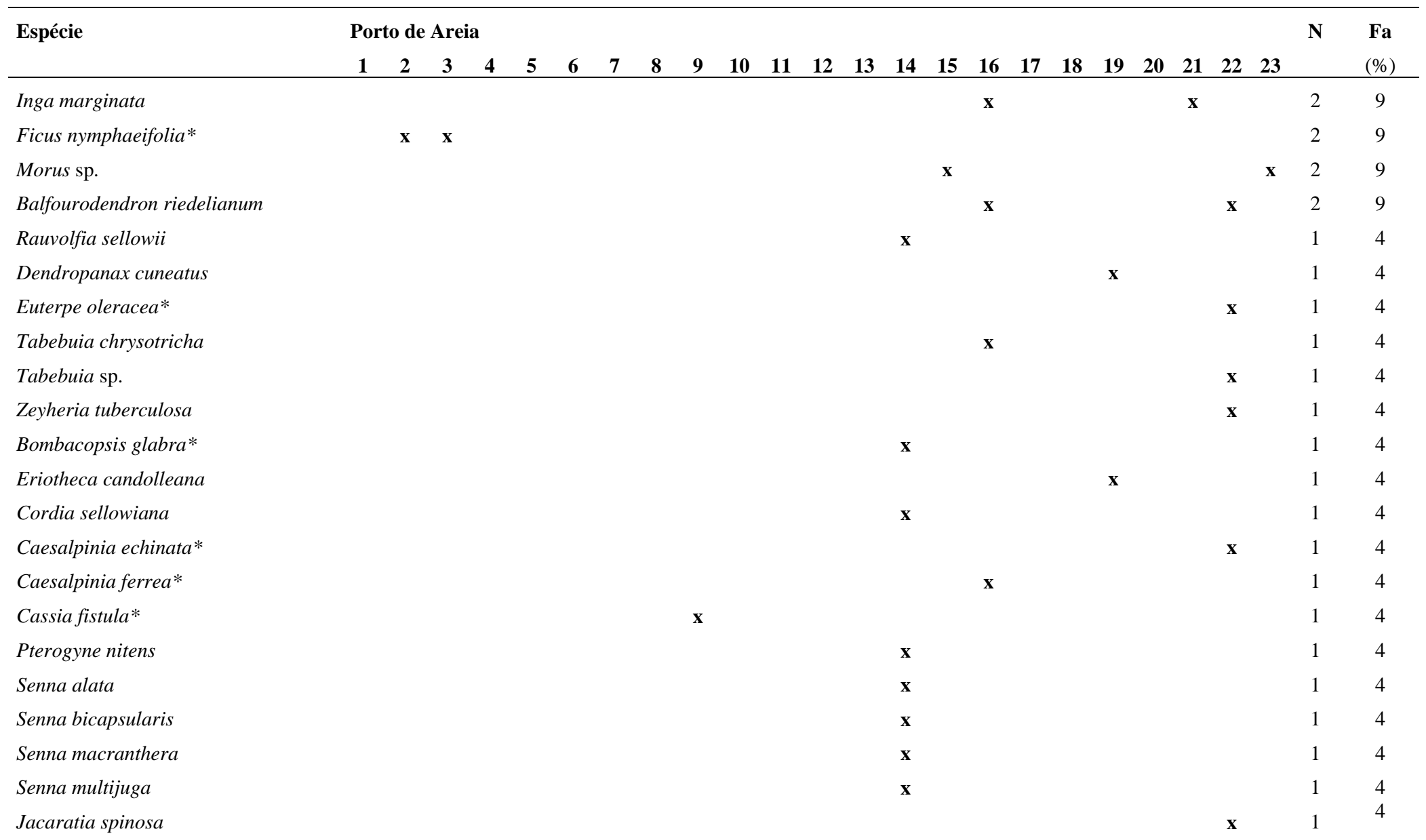


Tabela 11. Matriz binária de presença e ausência das espécies arbóreas indicadas nos projetos de plantios dos portos de areia da Bacia do Rio Corumbataí, SP

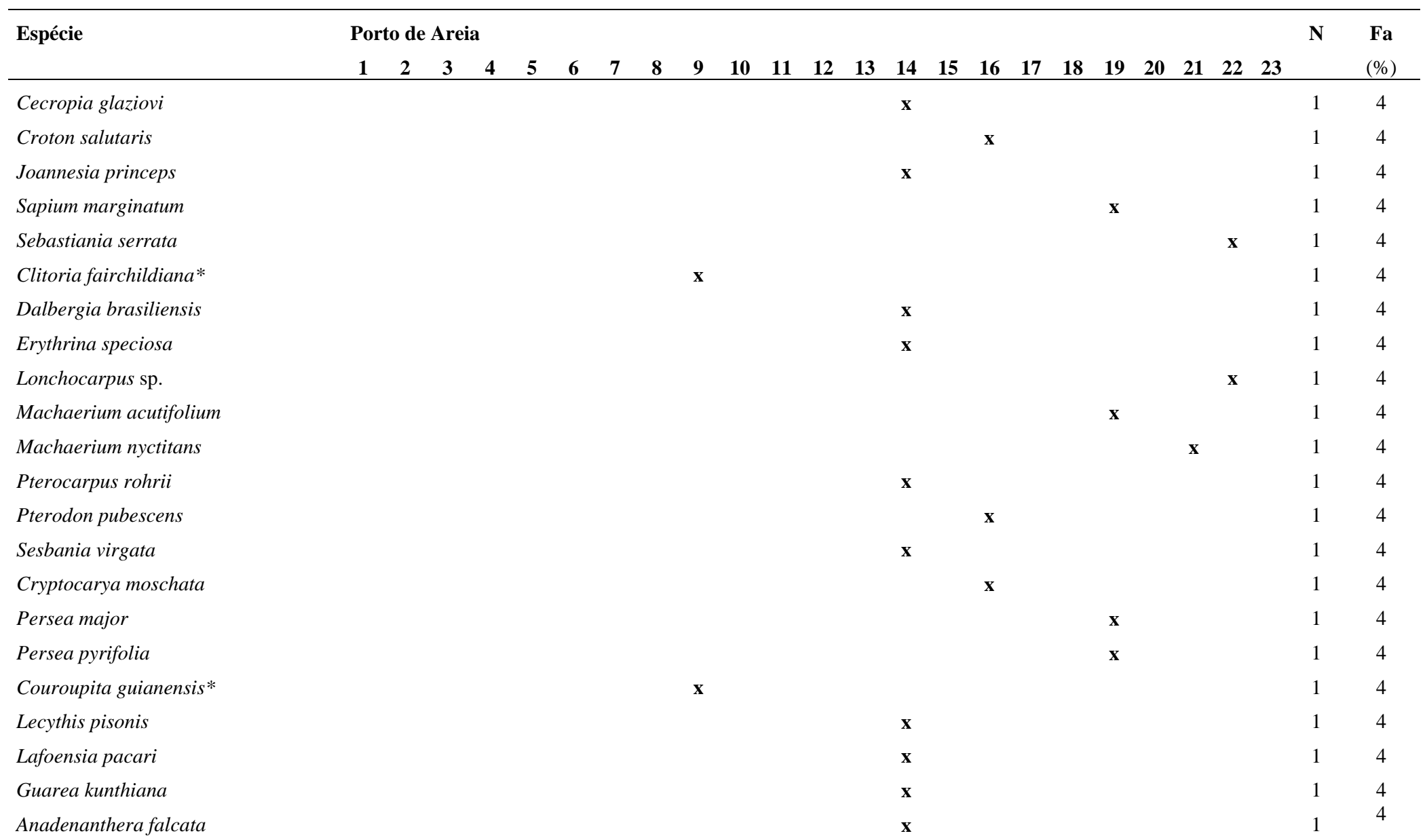


Tabela 11. Matriz binária de presença e ausência das espécies arbóreas indicadas nos projetos de plantios dos portos de areia da Bacia do Rio Corumbataí, SP

\begin{tabular}{|c|c|c|c|c|c|c|c|c|c|c|c|c|c|c|c|c|c|c|c|c|c|c|c|c|c|}
\hline \multirow[t]{2}{*}{ Espécie } & \multicolumn{23}{|c|}{ Porto de Areia } & \multirow[t]{2}{*}{$\mathbf{N}$} & \multirow{2}{*}{$\begin{array}{c}\text { Fa } \\
(\%) \\
\end{array}$} \\
\hline & 1 & 2 & 3 & 4 & 5 & 6 & 7 & 8 & 9 & 10 & 11 & 12 & 13 & 14 & 15 & 16 & 17 & 18 & 19 & 20 & 21 & 22 & 23 & & \\
\hline Anadenanthera peregrina & & & & & & & & & & & & & & & & $\mathbf{x}$ & & & & & & & & 1 & 4 \\
\hline Inga edulis & & & & & & & & & & & & & & & & $\mathbf{x}$ & & & & & & & & 1 & 4 \\
\hline Inga sessilis & & & & & & & & & & & & & & & & $\mathbf{x}$ & & & & & & & & 1 & 4 \\
\hline Leucaena leucocephala* & $\mathbf{x}$ & & & & & & & & & & & & & & & & & & & & & & & 1 & 4 \\
\hline Mimosa bimucronata & & & & & & & & & & & & & & $\mathbf{x}$ & & & & & & & & & & 1 & 4 \\
\hline Mimosa sp. & & & & & & & & & & & & $\mathbf{x}$ & & & & & & & & & & & & 1 & 4 \\
\hline Parapiptadenia rigida & & & & & & & & & & & & & & & & $\mathbf{x}$ & & & & & & & & 1 & 4 \\
\hline Ficus glabra & & & & & & & & & & & & & & & & $\mathbf{x}$ & & & & & & & & 1 & 4 \\
\hline Rapanea ferruginea & & & & & & & & & & & & & & & & & & & & & & $\mathbf{x}$ & & 1 & 4 \\
\hline Campomanesia phaea & & & & & & & & & & & & & & & & $\mathbf{x}$ & & & & & & & & 1 & 4 \\
\hline Campomanesia sp. & & & & & & & & & $\mathbf{x}$ & & & & & & & & & & & & & & & 1 & 4 \\
\hline Hexachlamys edulis & & & & & & & & & $\mathbf{x}$ & & & & & & & & & & & & & & & 1 & 4 \\
\hline Gallesia integrifolia & & & & & & & & & & & & & & & & & & & & & $\mathbf{x}$ & & & 1 & 4 \\
\hline Rhamnidium elaeocarpum & & & & & & & & & & & & & & $\mathbf{x}$ & & & & & & & & & & 1 & 4 \\
\hline Esenbeckia febrifuga & & & & & & & & & & & & & & & & & & & $\mathbf{x}$ & & & & & 1 & 4 \\
\hline Metrodorea nigra & & & & & & & & & & & & & & $\mathbf{x}$ & & & & & & & & & & 1 & 4 \\
\hline Solanum granuloso-leprosum & & & & & & & & & & & & & & $\mathbf{x}$ & & & & & & & & & & 1 & 4 \\
\hline Solanum pseudoquina & & & & & & & & & & & & & & & & & & & $\mathbf{x}$ & & & & & 1 & 4 \\
\hline Solanum sp. & & & & & & & & & & & & & & $\mathbf{x}$ & & & & & & & & & & 1 & 4 \\
\hline Guazuma sp. & & & & & & & & & & & & & & $\mathbf{x}$ & & & & & & & & & & 1 & 4 \\
\hline Aloysia virgata & & & & & & & & & & & & & & $\mathbf{x}$ & & & & & & & & & & 1 & 4 \\
\hline Vitex polygama & & & & & & & & & & & & & & & & $\mathbf{x}$ & & & & & & & & 1 & 4 \\
\hline
\end{tabular}


Tabela 11. Matriz binária de presença e ausência das espécies arbóreas indicadas nos projetos de plantios dos portos de areia da Bacia do Rio Corumbataí, SP

\begin{tabular}{|c|c|c|c|c|c|c|c|c|c|c|c|c|c|c|c|c|c|c|c|c|c|c|c|c|c|}
\hline \multirow[t]{2}{*}{ Espécie } & \multicolumn{23}{|c|}{ Porto de Areia } & \multirow[t]{2}{*}{$\mathbf{N}$} & \multirow{2}{*}{$\begin{array}{r}\text { Fa } \\
(\%)\end{array}$} \\
\hline & 1 & 2 & 3 & 4 & 5 & 6 & 7 & 8 & 9 & 10 & 11 & 12 & 13 & 14 & 15 & 16 & 17 & 18 & 19 & 20 & 21 & 22 & 23 & & \\
\hline Callisthene major & & & & & & & & & & & & & & & & & & & $\mathbf{x}$ & & & & & 1 & 4 \\
\hline Número total de espécies & 04 & 35 & 35 & 19 & 19 & 47 & 31 & 31 & 18 & 21 & 48 & 13 & 49 & 56 & 24 & 64 & 48 & 21 & 15 & 47 & 30 & 42 & 24 & & \\
\hline
\end{tabular}

* Espécie exótica para o Estado de São Paulo;

** Espécies organizadas em ordem decrescente de freqüência absoluta (Fa) e de Número de portos (N) com ocorrência da espécie;

VU = espécie vulnerável (Resolução SMA 48/04). 
Embora os projetos prescrevam um maior número de famílias, a proporção de espécies por família é muito semelhante ao aplicado em campo, com exceção de Lauraceae, que está representada por uma única espécie nos plantios analisados.

Conforme estudos de Sanchez et al. (1999) em áreas ripárias de Mata Atlântica, a maioria dos indivíduos dessa família é de categorias sucessionais mais avançadas. Essa seria uma primeira explicação para a baixa ocorrência de indivíduos dessa família nas áreas de plantio, já que as espécies plantadas são, na sua maioria, de estágios sucessionais iniciais. Outra explicação plausível é a dificuldade de encontrar mudas de Lauraceae em viveiros da região, já que estudos de Barbosa \& Martins (2005) mostraram que poucos viveiros têm mudas de Lauraceae disponíveis.

A comparação entre as listas de espécies observada (campo) e esperada (projeto) (Tabela 8 e 10) permitiu avaliar a percentagem de aproveitamento das listagens florísticas dos projetos teóricos de recuperação nas implantações florísticas dos plantios em campo. (Tabela 12).

As espécies utilizadas no campo são consideravelmente diferentes das propostas, já que, em média, os plantios utilizaram 28\% das espécies listadas nos projetos. O plantio com maior número de espécies comuns ao seu projeto, apresentou $68 \%$ de aproveitamento (Tabela 12).

Considerando que o DEPRN tem dificuldades em vistoriar todas as áreas de plantio compromissadas e de reconhecer em campo a diversidade de espécies previstas nos projetos (Beltrão, 2003), não há uma constatação segura de que as espécies que estão sendo utilizadas em campo sejam adequadas às estruturas e às diversidades vegetacionais locais. Com isso, mesmo que o projeto de revegetação tenha sito bem elaborado e rigorosamente analisado pelo DEPRN, não é garantia de efetivação ou de ganho ambiental.

Além disso, os esforços dos últimos anos, com a publicação das Resoluções SMA 21/01 e 47/03 que estabeleceram os procedimentos a serem adotados pelo DEPRN na análise dos projetos de revegetação, podem estar sendo desperdiçados.

A habilitação dos técnicos do DEPRN, no reconhecimento da diversidade de espécies, exigiria uma especialização técnica acadêmica na área de botânica que nem 
sempre é viável em função das inúmeras outras habilidades necessárias às funções que desempenham (Beltrão, 2003).

Tabela 12. Número de espécies, espécies comuns e percentagem de aproveitamento das listagens florísticas dos projetos teóricos de recuperação nas implantações florísticas dos plantios dos portos de areia da Bacia do Rio Corumbataí, SP

\begin{tabular}{ccccc}
\hline \multicolumn{4}{c}{ Número de espécies } & Aproveitamento \\
Portos & Projeto & Campo & Comuns & do projeto (\%) \\
\hline 1 & 4 & 1 & 0 & 0,0 \\
2 & 35 & 22 & 11 & 31 \\
3 & 35 & 25 & 10 & 29 \\
4 & 19 & 31 & 12 & 63 \\
5 & 19 & 22 & 9 & 47 \\
6 & 47 & 62 & 32 & 68 \\
7 & 31 & 9 & 3 & 10 \\
8 & 31 & 10 & 4 & 13 \\
9 & 18 & 22 & 4 & 22 \\
10 & 21 & 8 & 3 & 14 \\
11 & 48 & 30 & 11 & 23 \\
12 & 13 & 17 & 3 & 23 \\
13 & 49 & 43 & 21 & 43 \\
14 & 56 & 37 & 16 & 29 \\
15 & 24 & 21 & 5 & 21 \\
16 & 64 & 41 & 23 & 36 \\
17 & 48 & 24 & 8 & 17 \\
18 & 21 & 31 & 7 & 33 \\
19 & 15 & 13 & 1 & 7 \\
Média & 31,5 & 24,7 & 9,6 & 68 \\
Mínimo & 4 & 1 & 0 & \\
Máximo & 64 & 62 & 32 & 0,0 \\
\hline
\end{tabular}

A listagem dos projetos tem apenas quatro espécies (2\%) em extinção e apresentam 6\% exóticas (11), com destaque para $S$. cumini que aparece com freqüência nos projetos (22\%) (Tabela 11). Embora o número de exóticas indicadas nos projetos seja menor que o observado em campo, ainda assim, o uso de espécies nativas em projetos de reflorestamento em APP deve ser prioritário, conforme preconiza a Resolução SMA 21/01, que recomenda o uso de nativas sempre que possível. 
As espécies mais ocorrentes nos projetos foram C. urucurana em $83 \%$ dos portos; C. floribundus, Psidium guajava, Genipa americana e Copaifera langsdorffii em 78\% e; Eugenia pyriformis e Luehea divaricata em 61\% (Tabela 11).

Com exceção de C. urucurana, que foi a espécie de maior ocorrência nos projetos e plantios, todas as outras espécies, embora sejam de ocorrência natural em matas ciliares, podem não ter se adaptado bem às condições particulares dessas áreas, ou ainda, podem simplesmente não ter sido implantadas no campo conforme previsto pelos seus projetos, o que é mais provável.

Esses resultados demonstraram que, de modo geral, tanto os plantios efetivados, quanto os projetos de reflorestamento não atendem aos critérios mínimos estabelecidos pelas Resoluções SMA 21/01 e 47/03. Além disso, confirmaram as expectativas iniciais de que as condições estabelecidas no projeto de licenciamento dos empreendimentos para aprovação dos projetos propostos não foram, de modo geral, satisfatoriamente cumpridas.

Essas contradições, entre as propostas iniciais do projeto aprovadas e as realmente efetivadas, vêm sendo objeto de muitas discussões e reforça a necessidade de fortalecimento da etapa de acompanhamento, conforme discute Dias (2001).

\subsubsection{Similaridade florística}

A partir da matriz binária de presença e ausência das espécies registradas nos plantios e seus projetos (Tabelas 9 e 11), foram calculados os valores do índice de similaridade de Jaccard (ISJ) entre suas espécies, organizados em duas matrizes de Jaccard, uma para os plantios e outra para os projetos (Anexos B e C).

Os valores de Jaccard calculados variaram entre zero e um. Áreas de plantios ou projetos totalmente similares entre si tiveram ISJ $=1,0$ e áreas com inexistência de espécies comuns, tiveram ISJ = 0,0. Foram consideradas similares áreas com ISJ $\geq 0,25$, conforme Mueller-Dombois \& Ellenberg (1974).

Os dendrogramas (Figuras 18 e 19) baseados na média aritmética dos índices de similaridade (UPGMA) tiveram um baixo grau de distorção dos seus valores, 
evidenciado por altos coeficientes de correlação cofenética (CC = 0,90 para os plantios, e $\mathrm{CC}=0,98$ para os projetos).

A Figura 18 mostra a hierarquia entre os grupos formados a partir da similaridade de Jaccard entre as 19 áreas de plantio e uma área natural próxima. A área natural comparada foi a de uma floresta ribeirinha às margens do Rio Passa Cinco, em estudos realizados por Bertani et al. (2001), em que foram registradas 107 espécies em 0,36 ha de floresta. Essa comparação foi importante na identificação das áreas de plantios com florística semelhante às matas ciliares naturais da região.

A partir desse dendrograma (Figura 18), verificou-se que nenhuma das 19 áreas de plantio estudadas é similar à área de mata ciliar natural (ISJ < 0,25), mas que a maioria dessas áreas (79\%) é similar entre si (ISJ $\geq 0,25$ ).

A alta similaridade entre as áreas 11 e 18 (ISJ = 0,53) e entre as áreas 4 e 5 (ISJ $=0,39$ ), provavelmente é função do fato de pertencerem aos mesmos proprietários. Além disso, as áreas 4 e 5 possuem o mesmo projeto de plantio (ISJ = 1,0).

A similaridade entre as áreas 2 e 3 (ISJ = 0,31) pode ser atribuída à aquisição de mudas em uma mesma compra, conforme relatado pelos proprietários, além do fato de seus projetos de plantio serem idênticos (ISJ=1,0).

A dissimilaridade entre a área de plantio 1 a as outras áreas (ISJ $=0,0$ ) é recorrente do uso de apenas uma espécie (Salix humboldtiana) nesse reflorestamento. As áreas 7 e 8, ainda que pertencentes ao mesmo proprietário, foram dissimilares entre si (ISJ $=0,12$ ) e entre as demais áreas (ISJ $\leq 0,12$ ), também em função do baixo número de indivíduos empregados nesses plantios (9 e 10 espécies, respectivamente).

De maneira resumida, o dendrograma apresentou uma tendência à homogeneidade florística entre as áreas de plantio, ao contrário do verificado em áreas naturais, em que ocorre alta riqueza em espécies.

As florestas ciliares apresentam uma grande heterogeneidade florística natural, o que foi confirmado pelos estudos de Rodrigues \& Nave (2000), em que 43 áreas naturais de mata ciliar formaram um grande número de agrupamentos de similaridade florística através de classificação de UPGMA. 


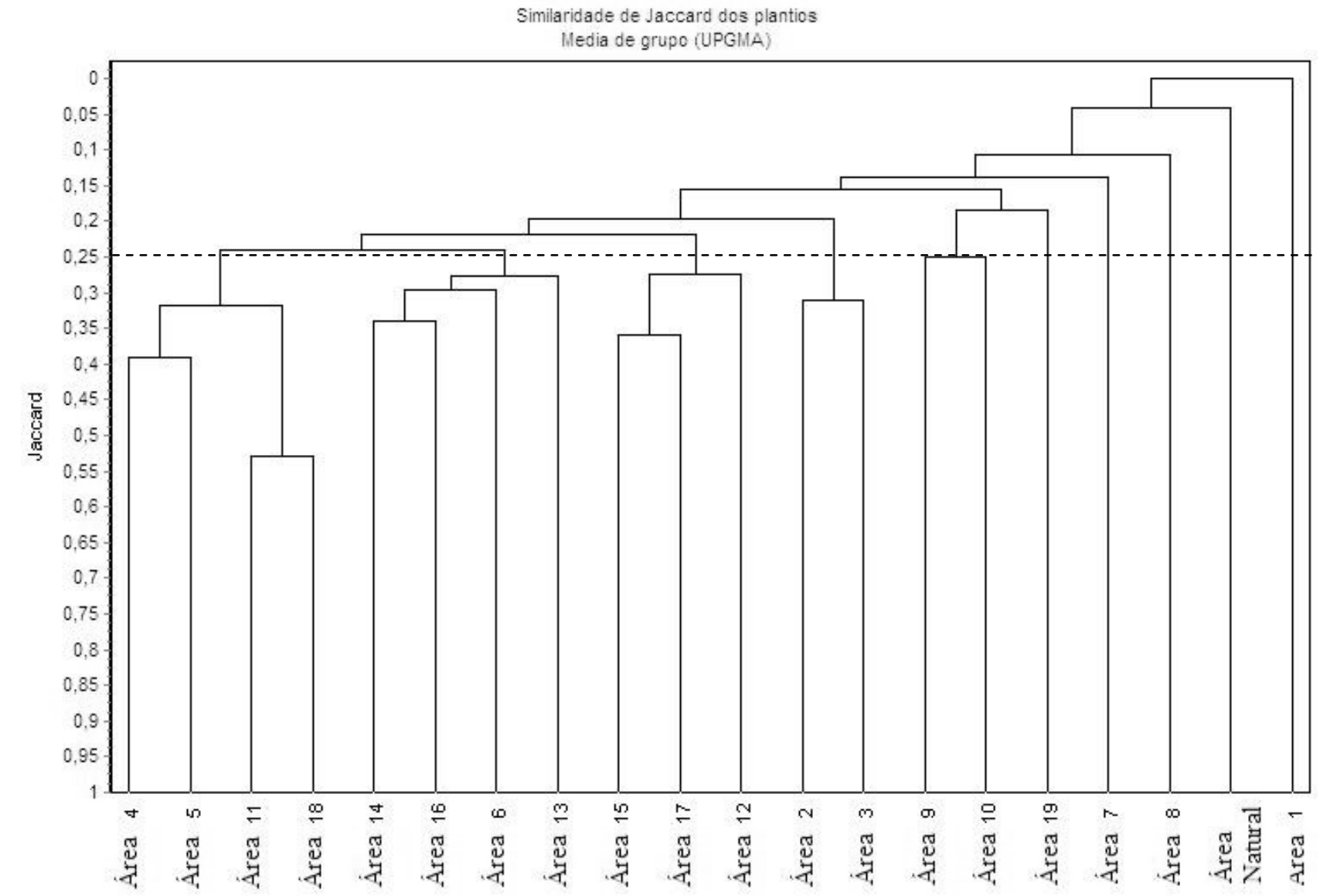

Figura 18 - Dendrograma de similaridade de Jaccard entre área natural e 19 áreas de plantio de portos de areia da Bacia do Rio Corumbataí, SP. A linha tracejada indica o valor mínimo de similaridade (Mueller-Dombois \& Ellenberg, 1974) 


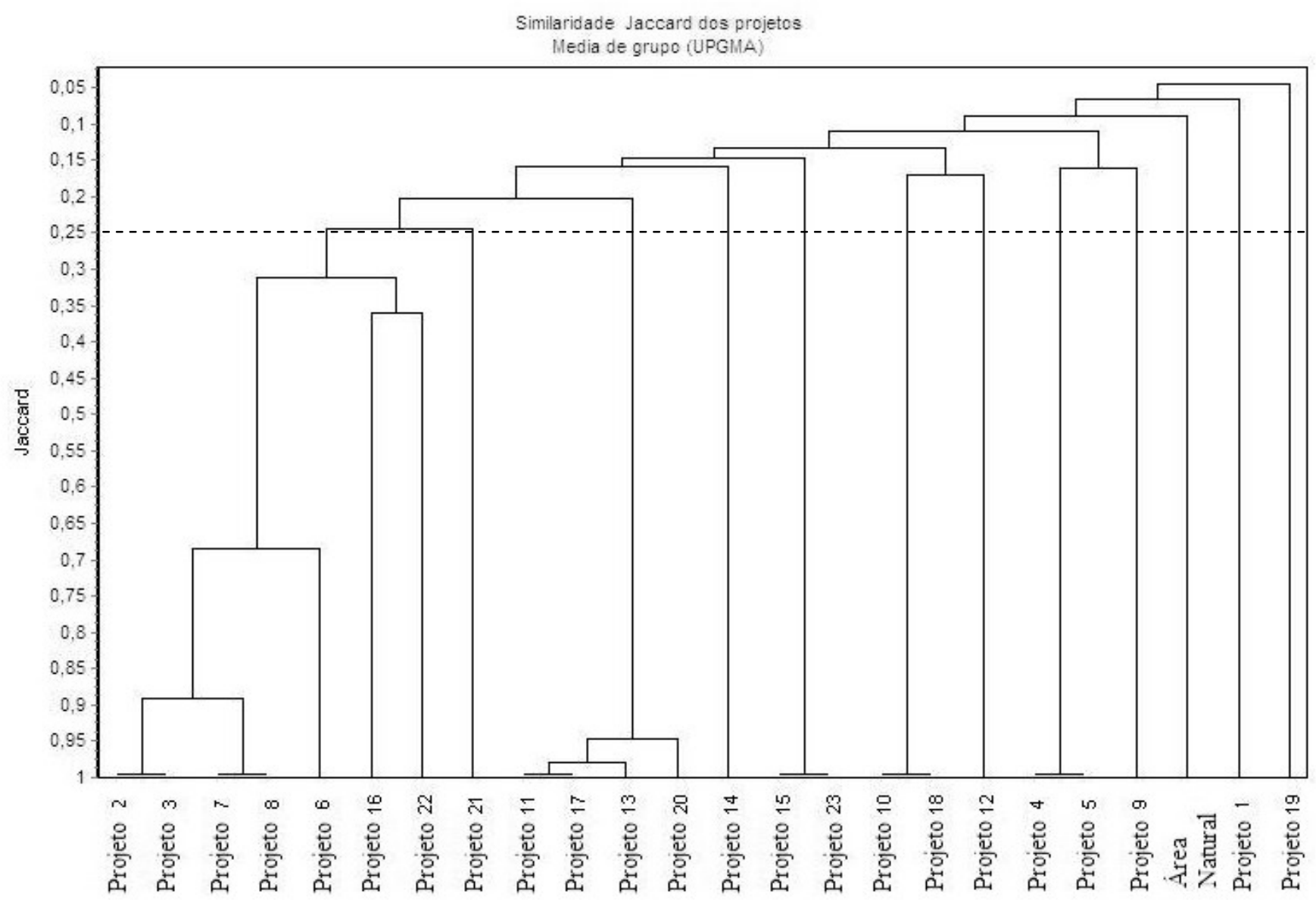

Figura 19 - Dendrograma de similaridade de Jaccard entre área natural e 23 projetos de plantio de portos de areia da Bacia do Rio Corumbataí, SP. A linha tracejada indica o valor mínimo de similaridade (Mueller-Dombois \& Ellenberg, 1974) 
A heterogeneidade florística das matas ciliares é atribuída à heterogeneidade ambiental, proporcionada pela topografia, luminosidade, encharcamento superficial do solo (Schiavini, 1992) e pelas flutuações do lençol freático e todos esses associados a diferentes graus de perturbação antrópica (Bertoni \& Martins, 1987; Salis et al., 1994).

A similaridade florística observada entre os plantios é função da baixa riqueza em espécies utilizadas, a qual é função de uma série de fatores. Entre eles, tem-se a dificuldade na obtenção de mudas em quantidade, com qualidade e diversidade de espécies (Santarelli, 2000), a priorização de espécies disponíveis no mercado com baixo custo financeiro, além de, em alguns casos, já mencionados anteriormente, da coincidência de proprietários ou responsáveis pela compra das mudas.

Não se pode esquecer da influência das semelhanças ambientais dessas áreas no estabelecimento das espécies, como a proximidade geográfica, a baixa variabilidade das condições edáficas e o histórico de uso e de exploração semelhante (item 4.3).

Apesar da recomposição de florestas nativas ser uma das prioridades da política de meio ambiente do País, em que o Estado de São Paulo participa e possui programas de incentivo a implantação de florestas voltadas a recuperação de matas ciliares, atualmente, o maior entrave para a produção de mudas nativas com a diversidade requerida está na obtenção de sementes (Yamazoe \& Vilas Boas, 2003). Isso se agrava com a restrição da coleta de sementes dentro das Unidades de Conservação apenas para fins de pesquisa científica, de acordo com a Lei do Sistema de Unidades de Conservação (SNUC).

O dendrograma apresentado na Figura 19 mostra as relações de similaridade formadas entre os 23 projetos de plantio e a área natural. Verificou-se que nenhum dos projetos é similar à área de mata ciliar natural (ISJ < 0,25), mas que 35\% deles formam um grande grupo similar entre si (ISJ $\geq 0,25$ ). Os outros projetos (75\%) formam quatro pequenos grupos que não respondem à similaridade mínima de 0,25 entre eles, mas que, dentro deles possuem alta similaridade (ISJ $\geq 0,96$ ) e muitas vezes são idênticos (ISJ = $1,0)$.

Os projetos de maior dissimilaridade foram o Projeto 19 (ISJ $\leq 0,08$ ), que propunha um plantio de espécies muito distinto dos normalmente empregados nas áreas 
de plantio da região e o Projeto 1 (ISJ $\leq 0,13$ ), pela baixa riqueza florística dessa proposta (quatro espécies).

Muitos projetos (52\% deles) apresentaram composição florística idênticas à de um dos outros projetos que foram elaborados pelas mesmas empresas de consultoria, aqui denominadas, como A, B e C. Isso ficou evidente na formação de pequenos subgrupos com ISJ = 1,0 entre os projetos 2 e 3, 4 e 5, 7 e 8 (elaborados pela empresa A), 11 e 17, 10 e 18 (elaborados pela empresa B), e, 15 e 23 (elaborados pela empresa C).

A empresa A também elaborou os projetos 2, 3, 6, 7 e 8, que formam um subgrupo bastante similar (ISJ $\geq 0,9$ ). Os projetos 11, 17, 13 e 20 (ISJ $\geq 0,94$ ), que também compõem um subgrupo similar, foram todos elaborados pela empresa B.

O dendrograma de similaridade entre os projetos mostrou que, na sua maioria (78\%), esses apresentam uma alta similaridade florística com pelo menos um projeto, o que é resultante da elaboração de listagens florísticas muito parecidas, ou até mesmo idênticas, pelas empresas A, B e C.

Se esses projetos fossem realmente implementados, as áreas formadas apresentariam uma homogeneidade florística com baixa riqueza em espécies que não é característica de áreas naturais, conforme verificado no dendrograma com o isolamento da área natural em relação aos projetos apresentados.

Essa alta similaridade encontrada em mais da metade dos projetos é preocupante com relação à perda de biodiversidade, o que inclui não apenas o número de espécies, mas também a diversidade genética.

As ações de manejo e restauração de florestas ciliares ainda não são passíveis de generalizações, devendo ser definidas respeitando as particularidades de cada caso, sob o risco de comprometimento da biodiversidade e do sucesso da proposta (Rodrigues \& Gandolfi, 1996; Silva Junior et al., 1998, citado por Rodrigues \& Nave (2000).

Uma recomendação na elaboração das listagens florísticas dos projetos de recuperação ciliar é de que sejam utilizadas, além das espécies de ampla distribuição em formações ciliares e de espécies regionais obtidas em listagens florísticas da região (Rodrigues \& Gandolfi, 2000), espécies locais definidas em um momento anterior à 
elaboração do projeto através de levantamento florístico das áreas de mata ciliar contíguas à área a ser revegetada. Esse não é um procedimento comum entre as empresas ambientais e não parece ser um procedimento facilmente implementado, embora venha sendo aplicado por alguns consultores ambientais que consideram essa fase de pré-projeto essencial no sucesso das áreas restauradas.

\subsubsection{Zoneamento dos plantios}

Variações na altura e na mortalidade das mudas qualificadas visualmente em campo permitiram o zoneamento da área de plantio de cada porto visitado em duas ou três zonas, indicadas neste trabalho por letras “a”, “b” e “c” de acordo com um gradiente decrescente de altura e de sobrevivência dos plantios (Tabela 13). A Figura 20 apresenta imagens de algumas zonas de plantio a título de exemplo.

Além de qualificadas visualmente, as variáveis mortalidade e altura também foram mensuradas nas linhas de plantio (Figuras 21 e 22).

Dos 21 portos de areia visitados, nove (43\%) apresentaram alguma irregularidade na área de efetivação do plantio proposto no projeto de revegetação, o que representou 4,74 ha de áreas de APP não revegetadas (26,2\% da área de revegetação prevista pelos seus projetos), dos quais 2,61ha não foram plantados e 2,13ha de plantio foram totalmente fracassados. Os portos 16, 20 e 21 representaram 60\% dessa área de APP não revegetada.

A não efetivação dos projetos de plantio aprovados pelo DEPRN pode ser atribuída a diversos fatores externos, entre eles a negligência por parte do empreendedor, fortalecida pela ineficiente fiscalização dos órgãos ambientais envolvidos; o alto custo de implementação dos plantios; e ainda a resistência dos empreendedores no uso da APP para fins que não econômicos. Esses fatores foram melhor investigados nas entrevistas realizadas em campo com os empreendedores. 
Tabela 13. Zoneamento das áreas de plantio dos 21 portos de areia visitados na Bacia do Rio Corumbataí, SP. As zonas estão indicadas pelas letras “a”, "b” e “c”, de acordo com um gradiente decrescente de altura e de sobrevivência dos plantios. Plantio: EF - efetivado; NEF - não efetivado; T - tentativa

\begin{tabular}{|c|c|c|c|c|c|}
\hline Zonas & $\begin{array}{l}\text { Área } \\
\text { (ha) }\end{array}$ & $\begin{array}{c}\text { Área } \\
(\%)\end{array}$ & $\begin{array}{c}\text { Plantio } \\
\text { EF/NEF/T }\end{array}$ & $\begin{array}{l}\text { Altura média } \\
(\mathrm{m})\end{array}$ & $\begin{array}{c}\text { Mortalidade } \\
(\%)\end{array}$ \\
\hline $1 \mathrm{a}$ & 0,03 & 10 & EF & 7,7 & 79 \\
\hline $1 \mathrm{~b}$ & 0,27 & 90 & NEF & & \\
\hline $2 a$ & 0,7175 & 41 & EF & 0,9 & 45 \\
\hline $2 \mathrm{~b}$ & 0,7175 & 41 & EF & 0,7 & 69 \\
\hline $2 c$ & 0,315 & 18 & NEF & & \\
\hline 3 & 1,8 & 100 & $\mathrm{EF}$ & 1,5 & 73 \\
\hline 4 & 0,9 & 100 & EF & 4,7 & 21 \\
\hline 5 & 0,6 & 100 & EF & 4,3 & 21 \\
\hline $6 a$ & 1,06 & 25 & EF & 2,8 & 23 \\
\hline $6 \mathrm{~b}$ & 2,12 & 50 & EF & 2,1 & 21 \\
\hline $6 c$ & 1,06 & 25 & $\mathrm{EF}$ & 1,3 & 69 \\
\hline $7 a$ & 0,28 & 33 & EF & 3,9 & 45 \\
\hline $7 b$ & 0,66 & 67 & $\mathrm{~T}$ & & 100 \\
\hline 8a & 0,12 & 33 & EF & 2,3 & 95 \\
\hline $8 b$ & 0,24 & 67 & $\mathrm{~T}$ & & 100 \\
\hline $9 a$ & 0,28 & 50 & EF & 3,2 & 20 \\
\hline $9 b$ & 0,168 & 30 & EF & 3,0 & 50 \\
\hline $9 c$ & 0,112 & 20 & $\mathrm{EF}$ & 1,7 & 25 \\
\hline 10 & 0,05 & 100 & $\mathrm{EF}$ & 8,2 & 76 \\
\hline 11a & 0,137 & 50 & $\mathrm{EF}$ & 0,9 & 11 \\
\hline $11 \mathrm{~b}$ & 0,137 & 50 & EF & 0,8 & 57 \\
\hline $12 \mathrm{a}$ & 0,05 & 33 & EF & & \\
\hline $12 \mathrm{~b}$ & 0,1 & 67 & EF & 3,9 & 78 \\
\hline 13 & 0,27 & 100 & EF & 4,2 & 23 \\
\hline $14 a$ & 0,59 & 75 & EF & 5,6 & 7 \\
\hline $14 \mathrm{~b}$ & 0,2 & 25 & EF & 2,6 & 18 \\
\hline 15a & 0,435 & 50 & EF & 3,3 & 21 \\
\hline 15b & 0,217 & 25 & EF & 4,8 & 55 \\
\hline $15 \mathrm{c}$ & 0,2175 & 25 & $\mathrm{~T}$ & & 100 \\
\hline $16 a$ & 0,25 & 19 & EF & 4,0 & 37 \\
\hline 16b & 1,05 & 81 & NEF & & \\
\hline $17 a$ & 0,499 & 75 & EF & 3,2 & 20 \\
\hline $17 \mathrm{~b}$ & 0,166 & 25 & EF & 1,3 & 54 \\
\hline 18 & 0,25 & 100 & $\mathrm{EF}$ & 1,0 & 3 \\
\hline 19a & 0,1 & 33 & EF & 0,9 & 68 \\
\hline $19 \mathrm{~b}$ & 0,2 & 67 & $\mathrm{~T}$ & & 100 \\
\hline 20 & 0,975 & 100 & NEF & & \\
\hline 21 & 0,817 & 100 & $\mathrm{~T}$ & & 100 \\
\hline
\end{tabular}



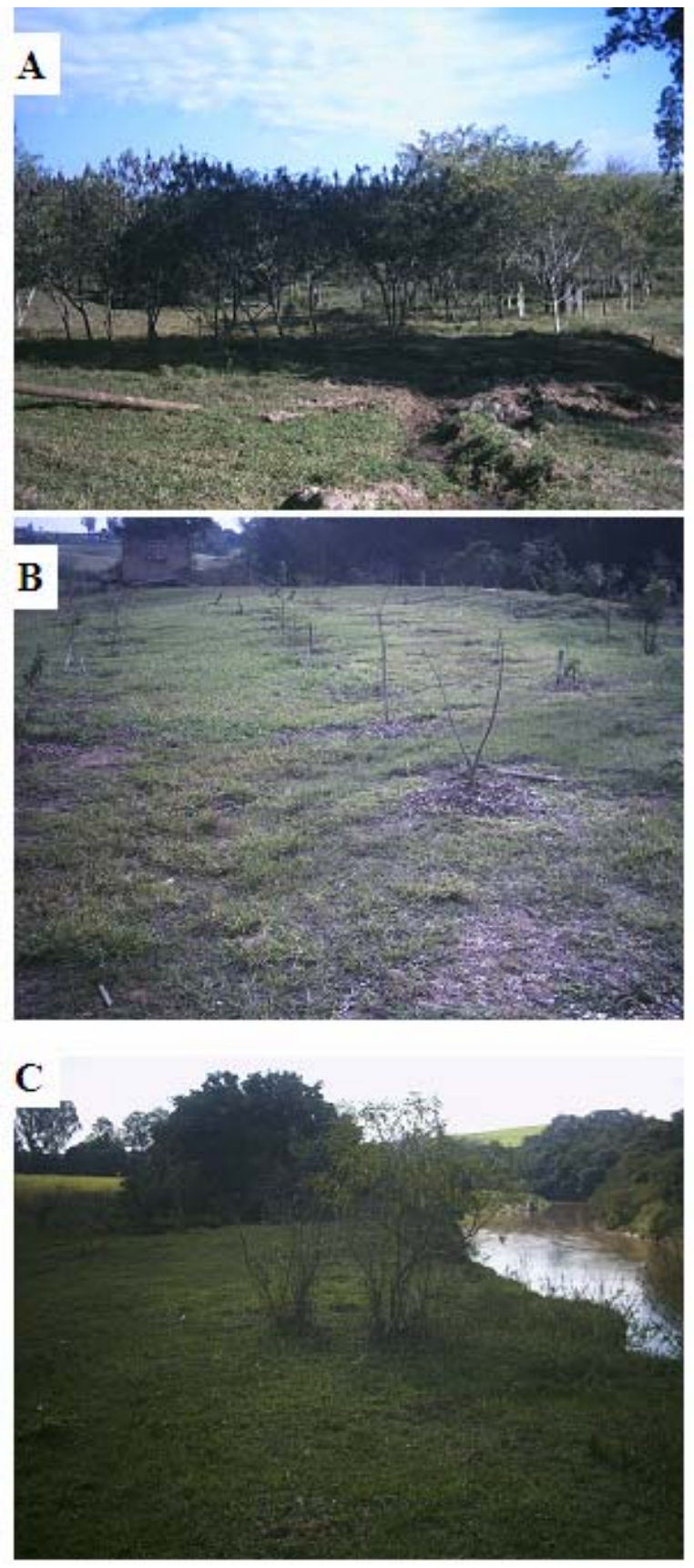

Figura 20 - Imagens do zoneamento das áreas de plantio dos portos de areia da Bacia do Rio Corumbataí. As zonas estão indicadas pelas letras “a”, "b” e “c”, de acordo com um gradiente decrescente de altura e de sobrevivência dos plantios 


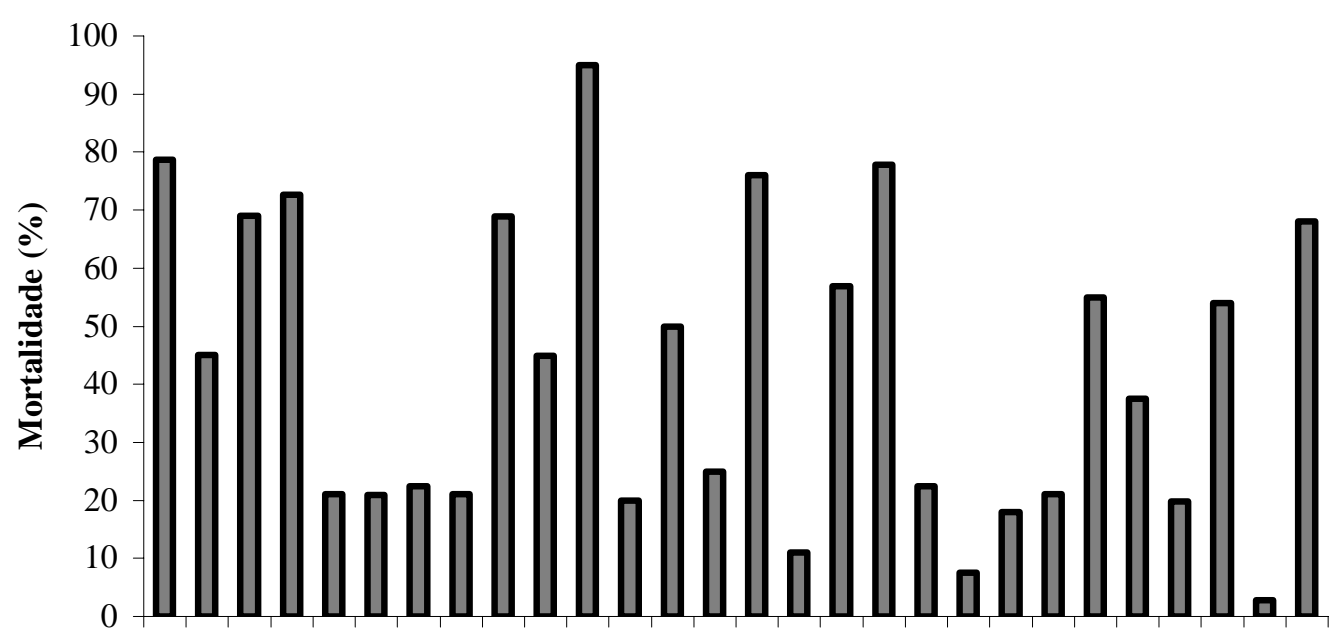

1a 2a 2b 345 6a 6b 6c 7a 8a 9a 9b 9c 1011al1b2b1314al4b15al5b16al7al7b1819a

Portos de areia

Figura 21 - Taxa de mortalidade das mudas nas zonas de plantio dos 19 portos de areia estudados na Bacia do Rio Corumbataí, SP

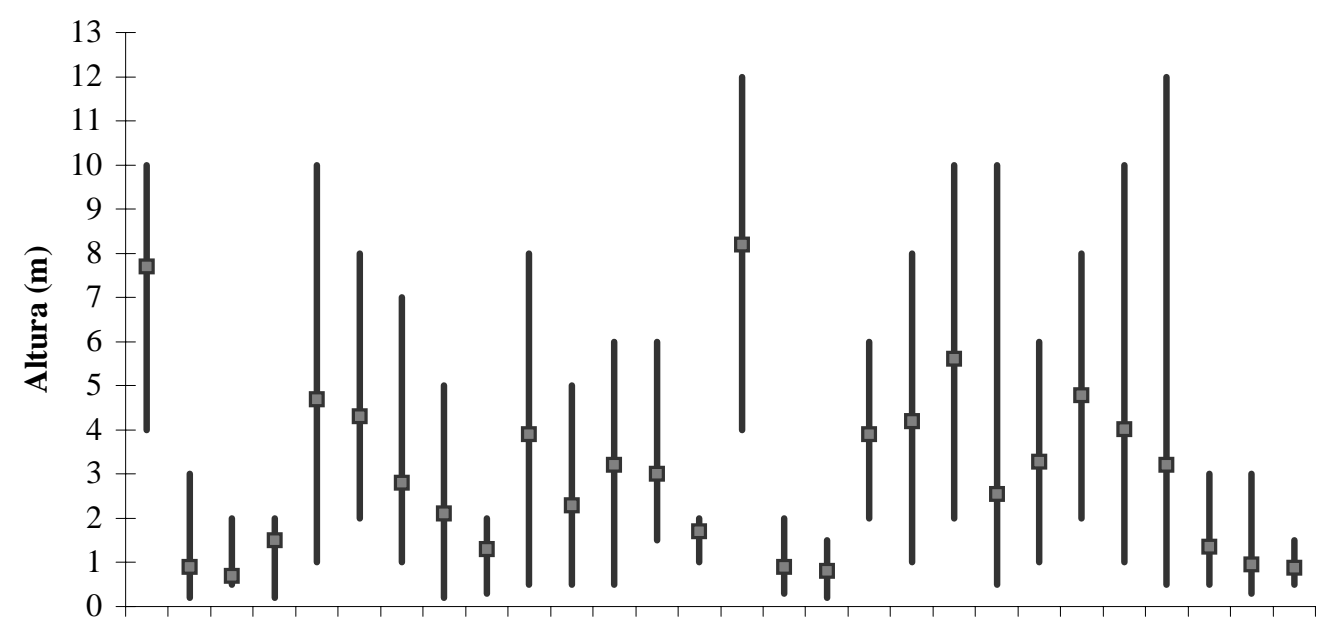

1a 2a 2b 345 6a 6b 6c 7a 8a 9a 9b 9c 1011al1b12b1314a14b15a15b16a17a17b1819a

Portos de areia

Figura 22 - Altura máxima, mínima e média das mudas nas zonas de plantio dos 19 portos de areia estudados na Bacia do Rio Corumbataí, SP 
Já o fracasso dos plantios pôde ser atribuído a falta de instruções técnicas em relação às adversidades ambientais observadas em campo, como a ocorrência de inundações periódicas (Portos 7, 8, 15 e 21) e de solos degradados (Porto 7, 15) ou mal drenados (Porto 19).

O Porto 19 apresenta solos mal drenados por problemas de infra-estrutura decorrentes da ausência de tubulação entre a lagoa de decantação e o corpo d'água. No caso dos solos sujeitos a inundações periódicas uma recomendação seria a de plantio em leiras, o qual melhora as condições de drenagem do solo e evita a morte de mudas e outros problemas por encharcamento.

Segundo Barbosa (2000), muitos projetos de reflorestamento heterogêneo com espécies nativas fracassaram devido ao pouco conhecimento dos técnicos e empreendedores sobre a biologia das espécies utilizadas ou do seu comportamento em reflorestamentos artificiais, além da falta de critérios técnicos fundamentados em investigações científicas sobre dinâmica de florestas naturais, tecnologia de colheita de sementes e produção de mudas.

O autor reforça que a implantação ou recomposição de matas ciliares requer o emprego de técnicas adequadas, geralmente definidas em função de avaliações detalhadas das condições locais e da utilização dos conhecimentos científicos existentes.

Hoje, as técnicas recomendadas para a restauração de áreas mineradas não são adequadas por desconsideram as modificações impostas ao meio físico pela atividade.

Estudos de Kopezinski \& Zuquette (1998), em áreas de exploração de bauxita, areia e brita a céu aberto, mostraram que, mesmo depois de 15 anos de finalizada a atividade, o processo de recuperação vegetal ainda estava sendo influenciado pela dinâmica degradacional. A exploração das camadas superiores propiciou a formação de processos erosivos e de assoreamento, bem como encurtamento do corpo d'água e surgimento de um escoamento superficial descontrolado, o que dificultou, segundo o autor, qualquer técnica de recomposição das camadas superficiais.

Na grande maioria dos portos não foi observada a reposição de mudas mortas prevista nos projetos de recuperação aprovados pelos órgãos. A mortalidade de mudas nas zonas de plantio foi elevada, com média de 51\% e com metade (51\%) das zonas com 
mortalidade igual ou superior a 50\% das mudas implantadas nas linhas de plantio (Figura 21).

Embora a Resolução SMA 42/96 seja válida apenas para a bacia hidrográfica do Paraíba do Sul, segundo essa resolução, um plantio está estabelecido e apto a receber espécies de estágios sucessionais mais avançados, quando há o sombreamento total da área ou quando as mudas iniciais atingem a altura média mínima de três metros. Considerando essa proposta, mais de $60 \%$ das zonas de plantio estudadas ainda não estão estabelecidas, o que implica na necessidade de contínua manutenção dessas áreas com a limpeza (roçadas e coroamentos periódicos), a reposição de mudas mortas e danificadas, o controle de pragas e doenças e a adubação e irrigação periódicas. Contudo, essas práticas não foram comumente observadas em campo.

A distribuição dos indivíduos amostrados nas linhas de plantio por classe de altura indicou a predominância de mudas (54\%) na classe inicial de altura (0-2m) (Figura 23), o que reafirma que a maioria dos plantios não é auto-suficiente na sua manutenção.

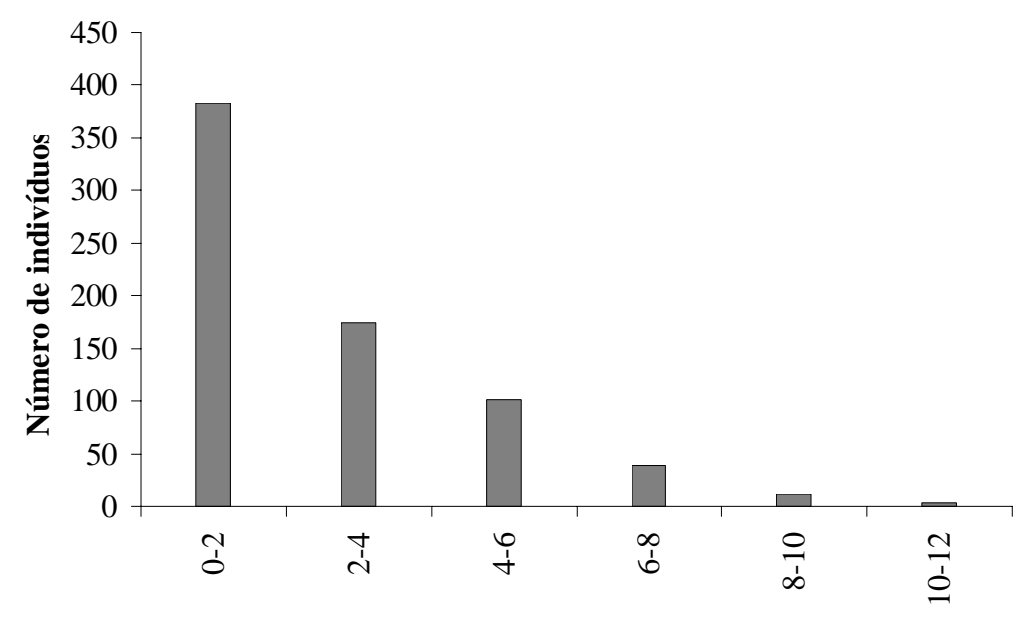

Classes de altura

Figura 23 - Distribuição das classes de altura dos indivíduos amostrados nas linhas de plantio dos 19 portos de areia de leito de rio estudados na Bacia do Rio Corumbataí, SP 


\subsubsection{Cobertura do solo por sombreamento da copa nas zonas de plantios}

As medidas lineares de projeção da copa sobre uma trena permitiram a medida do diâmetro da copa de cada indivíduo sobre as linhas de plantio. A partir desses valores de diâmetro e considerando o espaçamento e a densidade das mudas em 200m de comprimento de linha amostrada, foi possível determinar a percentagem ou valor relativo de cobertura da copa sobre e entre as linhas (área circular), considerando para tanto que cada copa correspondeu a um círculo perfeito.

O espaçamento e a densidade das mudas nos projetos e observados nas zonas de plantio estão apresentados na Tabela 14. Em 75\% das zonas de plantio analisadas foi verificado um espaçamento irregular ou com alguma diferença em relação ao proposto pelos projetos.

O espaçamento geralmente adotado na implantação de um reflorestamento é de 3,0m entre linhas e de 2,0m entre plantas, o que proporciona uma área de 6,0 $\mathrm{m}^{2} /$ árvore e uma densidade mínima de 1600ind./ha, propiciando uma situação favorável ao desenvolvimento das mudas em vários aspectos, entre eles, o rápido recobrimento vegetal da área a ser recomposta sem que haja concorrência inicial entre as plantas do reflorestamento.

Esse modelo de implantação obedece ao padrão de florestas conservadas, aumentando as chances de sustentabilidade do plantio por processo de interação biótica (Rodrigues, 2004). No entanto, os espaçamentos observados em campo, na maioria das vezes, não seguiram esse padrão de reflorestamento e de modo geral foram maiores do que os propostos pelos projetos, o que comprometeu a densidade dos plantios.

A densidade de indivíduos proposta nos projetos foi sempre superior a 1000ind./ha, no entanto, apenas 36\% das zonas de plantio analisadas apresentaram densidade equivalente ou superior a essa e somente em $7 \%$ das zonas de plantio foi verificada a densidade mínima de 1600ind./ha. Essas diferenças de densidade entre os projetos e os plantios variaram na proporção de uma a quatro vezes, ou seja, alguns portos chegaram a ter densidade quatro vezes menor do que a densidade proposta no projeto (Tabela 14). 
Tabela 14. Espaçamento e densidade apresentados nos projetos e observados nos plantios dos 19 portos de areia visitados na Bacia do Rio Corumbataí, SP

\begin{tabular}{|c|c|c|c|c|}
\hline \multirow{2}{*}{$\begin{array}{c}\text { Zonas } \\
\text { de plantio }\end{array}$} & \multicolumn{2}{|c|}{ Projeto } & \multicolumn{2}{|c|}{ Campo } \\
\hline & Espaçamento & Densidade & Espaçamento & Densidade \\
\hline $1 \mathrm{a}$ & $2 \times 2$ & 2333 & $2 \times 2$ & 533 \\
\hline $2 \mathrm{a}$ & $2 \times 3$ & 1600 & $2,5 \times 3$ & 733 \\
\hline $2 b$ & $2 \times 3$ & 1600 & $3 \times 3$ & 370 \\
\hline 3 & $3 \times 2$ & 1322 & $2 \times 3$ & 842 \\
\hline 4 & não consta & 1667 & $3,5 \times 3$ & 718 \\
\hline 5 & não consta & 1667 & $3,5 \times 3$ & 722 \\
\hline $6 a$ & $3 \times 2$ & 1600 & $2,5 \times 2,5$ & 1240 \\
\hline $6 b$ & $3 \times 2$ & 1600 & $2,1 \times 2,5$ & 1508 \\
\hline $6 c$ & $3 \times 2$ & 1600 & $2,3 \times 2,5$ & 526 \\
\hline $7 a$ & $3 \times 3$ & 1289 & $3 \times 3$ & 630 \\
\hline $8 a$ & $3 \times 3$ & 1111 & $2 \times 3$ & 400 \\
\hline $9 a$ & $2,5 \times 2,5$ & 1600 & *2,5 X 2,5 & 1280 \\
\hline $9 b$ & $2,5 \times 2,5$ & 1600 & *2,5 X 2,5 & 800 \\
\hline $9 c$ & $2,5 \times 2,5$ & 1600 & $* 2,5$ X 2,5 & 1200 \\
\hline 10 & $2 \times 2,5$ & 2000 & *2 X 2,5 & 480 \\
\hline $11 \mathrm{a}$ & $2 \times 3$ & 1668 & $2,2 \times 1,5$ & 2761 \\
\hline $11 b$ & $2 \times 3$ & 1668 & $2,6 \times 3$ & 513 \\
\hline $12 \mathrm{~b}$ & não consta & 1667 & $* * 3 \times 2$ & 800 \\
\hline 13 & $2,5 \times 2,5$ & 1593 & $2,5 \times 2,5$ & 1240 \\
\hline $14 \mathrm{a}$ & $3 \times 2$ & 1709 & $3 \times 2$ & 1605 \\
\hline $14 \mathrm{~b}$ & $3 \times 2$ & 1709 & $3 \times 2$ & 1364 \\
\hline $15 a$ & $2 \times 3$ & 1609 & $3 \times 3$ & 909 \\
\hline $15 b$ & $2 \times 3$ & 1609 & $3 \times 3$ & 500 \\
\hline $16 \mathrm{a}$ & $3 \times 3$ & 1100 & $3 \times 3$ & 713 \\
\hline $17 \mathrm{a}$ & $2,5 \times 2,5$ & 1600 & $2,2 \times 3$ & 1279 \\
\hline $17 \mathrm{~b}$ & $2,5 \times 2,5$ & 1600 & $2 \times 3$ & 767 \\
\hline 18 & $2 \times 2,5$ & 2000 & $* 2$ X 2,5 & 1971 \\
\hline 19a & $2 \times 3$ & 1600 & $2 \times 3$ & 533 \\
\hline
\end{tabular}

* Sem definição em campo e baseado no espaçamento do projeto ** Sem definições em campo e no projeto, baseado no espaçamento padrão 3 x 2

A menor densidade de mudas em campo em relação ao projeto, observada em 96\% dos plantios, é resultado da não reposição de mudas mortas e do uso de espaçamento irregular ou maior do que o proposto. Apenas o Porto 11, em sua zona “a”, apresentou densidade superior à proposta pelo projeto devido à utilização de um menor espaçamento em campo (Tabela 14). 
A grande maioria das zonas de plantio apresentou sombreamento parcial de suas linhas (Tabela 15). Apenas a zona "b” do porto 12 e a zona “a” do porto 14 apresentaram cobertura total da linha.

Tabela 15. Espaçamento e densidade apresentados nos projetos e observados nos plantios dos 19 portos de areia visitados na Bacia do Rio Corumbataí, SP

\begin{tabular}{|c|c|c|}
\hline \multirow{2}{*}{$\begin{array}{c}\text { Zonas } \\
\text { de plantio }\end{array}$} & \multicolumn{2}{|c|}{ Cobertura da copa (\%) } \\
\hline & Linha & Área \\
\hline $1 \mathrm{a}$ & 30,67 & 35,60 \\
\hline $2 a$ & 6,90 & 2,02 \\
\hline $2 b$ & 3,00 & 1,10 \\
\hline 3 & 6,91 & 2,00 \\
\hline 4 & 75,50 & 84,12 \\
\hline 5 & 74,50 & 74,09 \\
\hline $6 a$ & 64,50 & 53,64 \\
\hline $6 b$ & 72,90 & 68,01 \\
\hline $6 c$ & 13,30 & 8,12 \\
\hline $7 a$ & 54,55 & 59,52 \\
\hline $8 a$ & 23,20 & 28,55 \\
\hline $9 a$ & 74,20 & 76,26 \\
\hline $9 b$ & 38,00 & 25,76 \\
\hline $9 c$ & 40,60 & 21,74 \\
\hline 10 & 68,00 & 129,43 \\
\hline 11a & 20,60 & 8,96 \\
\hline $11 \mathrm{~b}$ & 11,25 & 4,60 \\
\hline $12 b$ & 104,00 & 197,9 \\
\hline 13 & 82,20 & 99,37 \\
\hline $14 a$ & 112,50 & 181,32 \\
\hline $14 \mathrm{~b}$ & 39,00 & 36,69 \\
\hline 15a & 70,00 & 64,26 \\
\hline $15 b$ & 53,33 & 54,98 \\
\hline 16a & 68,50 & 78,02 \\
\hline $17 a$ & 86,00 & 92,29 \\
\hline $17 \mathrm{~b}$ & 21,50 & 8,84 \\
\hline 18 & 28,43 & 8,87 \\
\hline 19a & 6,55 & 0,87 \\
\hline
\end{tabular}

Já na análise de sombreamento das mudas sobre as áreas de plantio (sobre e entre as linhas), além dessas zonas, os portos 10 e 13 (não zoneados) também apresentaram 
cobertura total da copa. Lembrando que percentagem de cobertura da copa por área está diretamente relacionada com a variação no espaçamento entre as linhas de plantio.

A Tabela 16 mostra uma grande amplitude de cobertura da copa, com valores superiores a $100 \%$ resultantes da sobreposição das copas dos indivíduos.

Tabela 16. Valores de percentagem de cobertura da copa por área de plantio e idade dos plantios dos 21 portos de areia visitados na Bacia do Rio Corumbataí, SP

\begin{tabular}{ccc}
\hline Porto & $\begin{array}{c}\text { Cobertura da copa } \\
(\%)\end{array}$ & $\begin{array}{c}\text { Idade } \\
\text { (anos) }\end{array}$ \\
\hline 1 & 3,56 & 16 \\
2 & 4,06 & $2-5$ \\
3 & 2,00 & 4 \\
4 & 84,12 & 7 \\
5 & 74,09 & 7 \\
6 & 49,45 & $6-7$ \\
7 & 19,64 & 6 \\
8 & 9,42 & 6 \\
9 & 50,21 & 7 \\
10 & 129,43 & 8 \\
11 & 6,78 & 3 \\
12 & $197,9 *$ & 14 \\
13 & 99,37 & 5 \\
14 & 145,16 & 4 \\
15 & 45,88 & 4 \\
16 & 14,82 & 6 \\
17 & 71,43 & 4 \\
18 & 8,87 & 3 \\
19 & 0,29 & 6 \\
20 & 0,00 & 0 \\
21 & 0,00 & 0 \\
\hline & & \\
& Cobertura da copa da zona $12 \mathrm{~b}$ & \\
& &
\end{tabular}

Apenas 19\% dos portos estudados (4) têm cobertura total do solo (Tabela 16). A insuficiência na cobertura do solo em $81 \%$ dos portos contradiz a proposta da Resolução SMA 42/96, válida para a bacia hidrográfica do Paraíba do Sul, a qual discute como um dos requisitos para um plantio estabelecido o sombreamento total da área.

Considerando as estimativas de cobertura do solo e a proposta da Resolução SMA 42/96, foi possível inferir que a maioria das zonas de plantio ainda não está 
estabelecida e necessita de maiores cuidados quanto à manutenção (roçadas e coroamentos periódicos, reposição de mudas mortas e danificadas, controle de pragas e doenças e a adubação e irrigação periódicas).

A Resolução SMA 42/96 discute ainda que na existência de sombreamento total, no caso os portos 10, 12, em sua zona "b”, 13 e 14, em sua zona "a”, pode ser dada continuidade no processo de revegetação, efetuando o plantio de espécies pertencentes aos estágios sucessionais mais avançados de forma a aumentar a biodiversidade da área.

Os plantios possuem média de idade de seis anos, no entanto a cobertura média do solo foi de 45\%, com cobertura máxima de 197,9\% (Porto 12) e mínima de 0,0\% (Portos 20 e 21). Considerando escalas de cobertura, segundo Braun-Blanquet (1932), essa cobertura média de 45\% é do tipo dispersa, pois está no intervalo entre 25 e 50\%, enquanto que, para Küchler (1967), esse mesmo intervalo de cobertura é classificado como “parque”. Já para Fosberg (1961), essa cobertura é do tipo aberta, onde, segundo o autor, as copas não se tocam, mas pelo menos cobrem 30\% da superfície.

Alguns portos com média de idade de oito anos apresentaram cobertura total do solo, o que seria esperado para um plantio com desenvolvimento normal. Entretanto, os valores de cobertura do solo de muitos portos não condizem com a idade de seus plantios.

Existem portos com idade avançada de plantio que não apresentam cobertura total do solo. Esse é o caso do Porto 1, o qual tem um plantio de 16 anos de idade e apresenta apenas 3,56\% de cobertura, composta por apenas uma única espécie arbórea, e de outros portos que têm plantios de até seis anos e coberturas inferiores a 20\% (Tabela 16).

Coberturas inferiores a 5\% são classificadas como esporádicas, por BraunBlanquet (1932) e Küchler (1967), e dispersas por Fosberg (1961), quando a distância entre as copas é o dobro de seus diâmetros.

Com base nos critérios estabelecidos na Resolução SMA 42/96, a grande maioria dos plantios não atinge condições para que sejam considerados como satisfatoriamente recuperados. É importante lembrar que esses critérios foram propostos para a 
implantação de reflorestamentos no Vale do Paraíba e, portanto, não são instrumentos de comando e controle oficialmente aplicados para a bacia em estudo.

Os plantios de reflorestamento estudados não utilizaram como critério de implantação a divisão em linhas de preenchimento e diversidade. Com base na definição de linha de preenchimento apresentada por Rodrigues (2004), as linhas avaliadas em campo podem ser consideradas como de preenchimento, compostas principalmente por espécies pioneiras e secundárias iniciais.

Os resultados demonstram que os plantios em APP dos portos em leito de rio da bacia do Corumbataí necessitam urgentemente de cuidados e manutenção.

A disposição das mudas no terreno não obedeceu às exigências de sombreamento das espécies não pioneiras, que, quando presentes, não tinham as condições de luz necessárias para o seu desenvolvimento.

A recomendação inicial para manutenção dessas áreas é a de replantio das mudas mortas com espécies de estágios iniciais de sucessão melhor adaptadas às condições ambientais locais. O rápido crescimento dessas espécies proporcionaria uma melhor condição de sombreamento da área, criando um ambiente favorável ao desenvolvimento de espécies de estágios finais de sucessão implantadas posteriormente, e ao mesmo tempo desfavorecendo o desenvolvimento de espécies competidoras como gramíneas.

Essas espécies de estágios finais de sucessão comporiam as linhas de diversidade que, segundo Rodrigues (2004), representam a diversidade local em espécies necessária à reconstituição da dinâmica florestal das áreas.

Esse modelo proposto resultaria em uma gradual substituição de espécies dos diferentes grupos ecológicos no tempo, caracterizando o processo de sucessão ecológica.

\subsubsection{Caracterização visual da vegetação das zonas de plantio}

A caracterização visual da fitofisionomia florestal baseada na presença e na ausência de estratificação vertical da vegetação indicou que poucos portos têm zonas de plantio com essa estratificação definida. Apenas oito portos (42\%) tiveram uma das 
zonas de plantio com dossel definido, todos com forma irregular e altura máxima entre 8 e $18 \mathrm{~m}$ (Tabela 17).

Desses oito portos com dossel definido, seis (32\% do total de portos) apresentaram um estrato de sub-boque, com altura máxima entre 2 e $6 \mathrm{~m}$ e apenas dois (10\% do total de portos) apresentaram os três hábitos, herbáceo, arbustivo e arbóreo.

Com exceção dos portos 11 e 18, que possuem uma média de idade entre dois e três anos de plantio, todas as outras áreas, considerando suas idades, já deveriam ter assumido uma fisionomia florestal ou, no mínimo, ter um dossel formado, como observado nos projetos de recuperação de mata ciliar bem sucedidos no Estado de São Paulo, descritos por São Paulo (2002).

Segundo Paula \& Lemos Filho (2001), mudanças na dinâmica e na estrutura do dossel levam a alterações de produtividade, evapotranspiração, temperatura foliar, penetração de luz, interceptação da chuva e temperatura do solo, podendo ainda levar à redução de biodiversidade e a mudanças na distribuição e abundância dos organismos.

A alta percentagem de recobrimento do solo nas entrelinhas de plantio observada em campo (Figura 24), evita maiores danos causados pela erosão, ainda que a maioria seja formada por gramíneas.

A alta percentagem de recobrimento do solo nas entrelinhas de plantio observada em campo (Figura 24), evita maiores danos causados pela erosão, ainda que a maioria dessa cobertura seja composta por gramíneas.

Somente $47 \%$ dos portos tiveram serapilheira cobrindo o solo, com quantidade (medida em espessura) variando entre abundante $(3 \mathrm{~cm})$, regular $(2 \mathrm{~cm})$ e escassa $(0,5 \mathrm{~cm})$, e apenas quatro (21\% do total de portos) apresentaram solo totalmente recoberto por serapilheira, com espessura de $3 \mathrm{~cm}$ (Tabela 17).

A quantificação da serapilheira permite a compreensão dos aspectos dinâmicos dos ecossistemas (Domingos et al., 1999, citado por Paula \& Lemos Filho, 2001), pois seu acúmulo na superfície do solo florestal permite que uma maior quantidade de nutrientes retorne ao sistema (Pagano, 1989). O material depositado constitui um ambiente acumulador de minerais e de nutrientes que são transferidos para a vegetação quando ocorre a sua decomposição (Leitão Filho et al., 1993). 
Tabela 17. Análise visual das zonas de plantio dos 19 portos de areia em leito rio da Bacia do Rio Corumbataí, SP

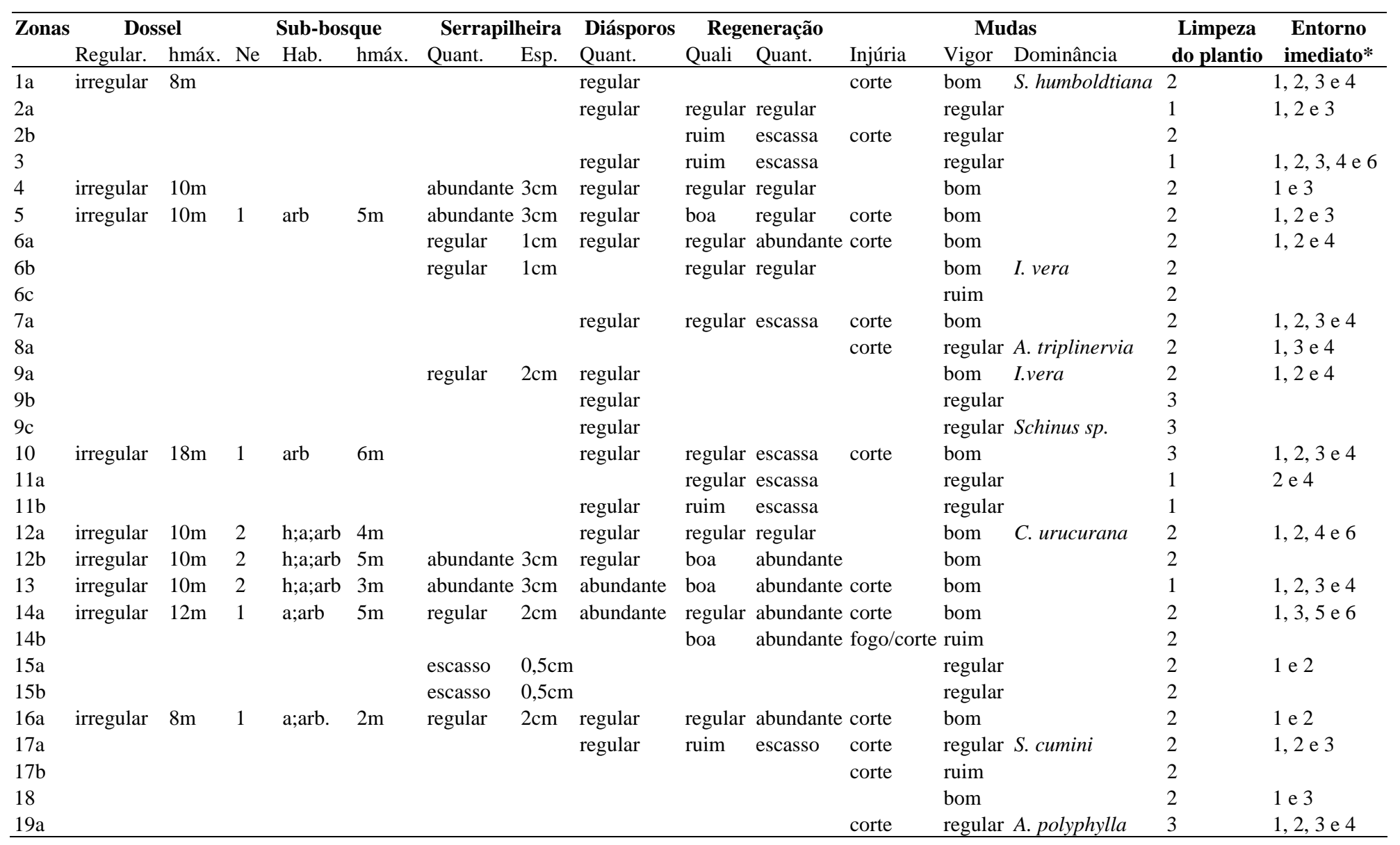

regular. = regularidade; hmáx.= altura máxima; Ne= número de estratos vegetacionais; Háb.= hábitos vegetacionais; $\mathrm{h}=$ herbáceo, a = arbustivo; arb = arbóreo; Quant. = quantidade; Qual. = qualidade; Esp. = espessura; 1 = coroamento e limpeza; 2 = coroamento ou limpeza e; 3 = ausência de coroamento e limpeza. * $(1)=$ fragmento natural; (2) pastagem; (3) monocultura de cana de açúcar; (4) silvicultura de Pinus ou Eucalipto; (5) mineração e (6) urbanização. 


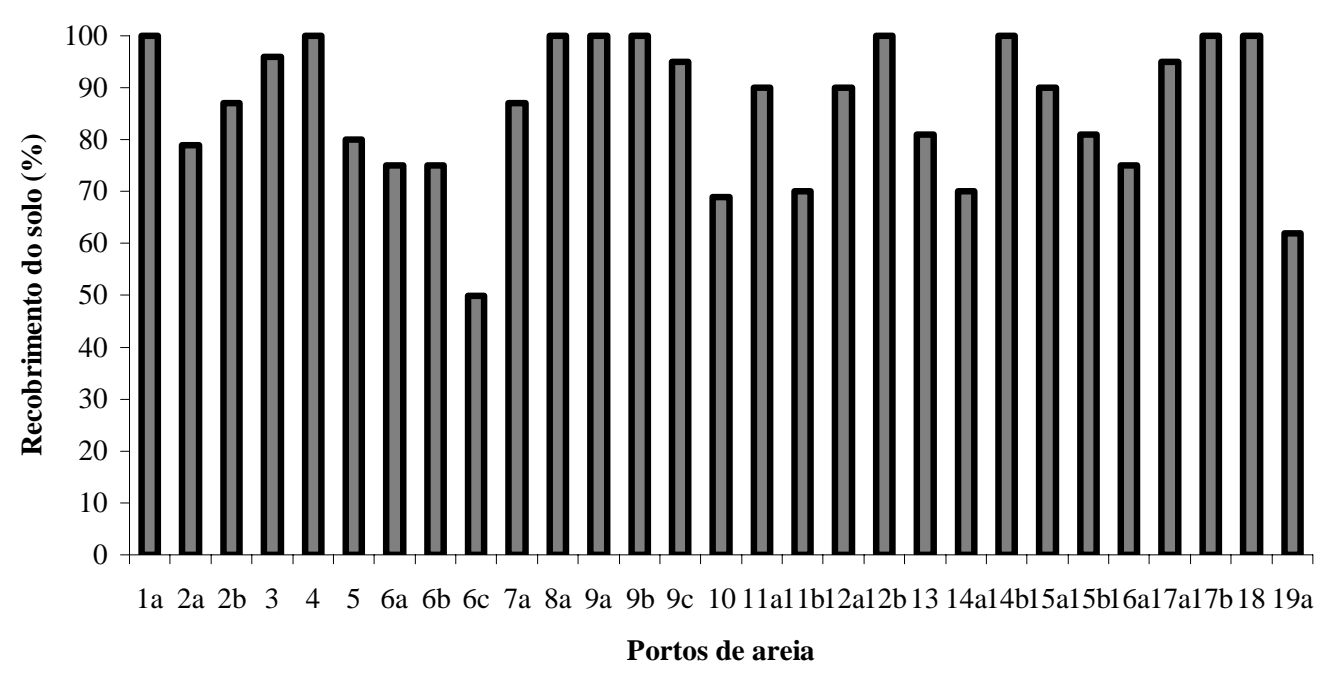

Figura 24 - Percentagem de recobrimento do solo com gramíneas ou serapilheira nas zonas de plantio dos 19 portos de extração de areia por dragagem em leito de rio da Bacia do Rio Corumbataí, SP

Além disso, a quantidade de serapilheira produzida apresenta um padrão bastante diversificado de acordo com o ecossistema e também com o seu estádio sucessional (Ewel, 1976). A Resolução Conama 10/93, em seu artigo $1^{\circ}$, e as especificações da Resolução 01/94 estabelecem parâmetros básicos para análise dos estádios de sucessão da Mata Atlântica. Dentre eles, está a presença e a ausência de serapilheira, além da determinação de sua quantidade e estádio de decomposição, que vão desde camadas finas e pouco decompostas, contínuas ou não, no caso de estádio inicial, até abundantes com intensa decomposição, no caso de estádio avançado de sucessão.

Considerando essas resoluções e os resultados anteriormente apresentados, podemos inferir que metade das áreas de plantio visitadas não iniciou seu processo sucessional, e ainda, que a outra metade que já iniciou esse processo, encontra-se, na maioria, em estágios iniciais de sucessão.

Os diásporos ou propágulos, entre eles as sementes e as suas formas de dispersão, possuem papel básico na determinação da estrutura fitossociológica (Major \& Pyott, 1966, citados por Roizman, 1993) e da florística da comunidade vegetal, principalmente 
em reflorestamentos artificiais de baixa densidade e diversidade florística. A vegetação das áreas de reflorestamento é dependente de um componente real, representado pela composição em espécies plantadas, e de um componente potencial, representado pelas sementes e outras formas de propágulo presentes no solo ou que chegaram à área por dispersão de fragmentos florestais próximos. Desta forma, o conhecimento do banco de sementes do local (Roizman, 1993) e da proximidade de fragmentos florestais permitem, de certa maneira, que se realizem previsões sobre o potencial florístico e sobre o desenvolvimento fitossociológico presentes no processo de sucessão que se segue.

Na maioria das áreas de plantio visitadas (79\%), foi verificada a existência de diásporos por observação da presença de sementes, frutos e rebrotas (Tabela 17). Essa constatação permite afirmar que essas áreas possuem um componente de regeneração em potencial.

No entanto, embora, na teoria, a presença de propágulos represente uma otimização do processo de regeneração, o número de áreas em regeneração (68\% dos portos) foi visualmente inferior ao esperado (79\% dos portos) pela presença de diásporos. Além disso, apenas três plantios (16\%) apresentaram regeneração qualificada visualmente em campo como boa e abundante. Esses plantios (12a, 13 e 14a) foram os únicos a apresentar clareiras naturais abertas na vegetação, o que representaria alguma dinâmica florestal nessas áreas.

A baixa regeneração dos plantios, provavelmente, é função principalmente da condição de degradação do solo dessas áreas, que não possuem um ambiente adequado para germinação e estabelecimento das mudas no campo.

Em áreas onde a textura do solo foi alterada com a deposição de silte e argila como conseqüência da exploração de areia, a recuperação da floresta nativa é impossível. A mudança na porosidade do solo parece ser o principal problema para o estabelecimento das plântulas (Joly et al., 2000).

Segundo Barbosa \& Santos Junior (2003), uma forma de melhorar os solos e suas condições físicas e químicas é a utilização prévia de leguminosas e gramíneas agressivas associadas à adubação nas covas de plantio, ou ainda a utilização de serapilheira como fonte de propágulos. 
A regeneração também pode estar relacionada com a qualidade e com a quantidade de diásporos disponíveis nessas áreas. Essas estruturas (diásporos), foram encontradas de forma mais abundante em apenas dois portos (10\%) (Tabela 17).

Embora a grande maioria das áreas plantadas (95\%) apresente fragmentos florestais em seu entorno imediato (paisagem que compõe o entorno mais próximo observado em campo) (Tabela 17) não se pode inferir a respeito de suas contribuições à regeneração dessas áreas. Durante o levantamento florístico dos plantios, não foram quantificadas as espécies regenerantes, o que impediu determinar se estava havendo dispersão alóctone proveniente desses fragmentos.

O processo de regeneração de algumas áreas de plantio, principalmente as de menor idade e desenvolvimento das mudas, pode ter sido prejudicado pelos impactos negativos da presença de gado nessas áreas. Durante as visitas ao campo, foi diagnosticado que 53\% das APPs dos portos visitados apresentavam vestígios de gado, como fezes e pegadas.

A circulação de gado e seu pisoteio nas áreas em processo de regeneração causam impactos, como compactação do solo e morte de mudas em início de desenvolvimento. Razão pela qual os órgãos ambientais exigem o isolamento das áreas de reflorestamento com cercas. Mesmo assim, o gado entra nessas áreas pela margem do rio, por descuido dos vizinhos, ou intencionalmente para roçada do capim, conforme relatado por muitos empreendedores.

A manutenção ou limpeza das áreas de plantio, com roçadas das gramíneas entre as linhas, é muito importante, pois o capim em excesso, além de dominar o estrato inferior, dificultando a sobrevivência e reprodução das espécies nativas, forma imensa quantidade de matéria seca no inverno, aumentando o risco e a intensidade de incêndios.

No entanto, de maneira geral, o tipo de manutenção que tem sido realizada nessas áreas não permite o crescimento de nenhuma espécie entre as linhas de plantio. O recomendado seria realizar corte seletivo, restringindo a limpeza a eliminação das ervas daninhas.

Das áreas visitadas, três (16\%) não praticavam o coroamento das mudas e a limpezas das entrelinhas, das quais apenas uma (5\%) não tinha seu estrato inferior 
dominado por gramíneas, pois tinha altura e sombreamento suficientes para a condução natural do plantio e da regeneração.

Outro fator que pode ter sido limitante à regeneração natural nessas áreas foi a constatação de injúrias em 58\% dos portos visitados, diagnosticadas pela presença de vestígios de fogo e corte. De modo geral, a proteção contra incêndios tem sido bem sucedida, com apenas uma área com evidências de fogo, enquanto que o corte de mudas e de espécies em regeneração foi constatado em 12 áreas de plantio.

Para um bom desenvolvimento do plantio, uma das preocupações que se deve ter é com relação ao vigor das mudas plantadas. Quanto a isso, os plantios visitados não apresentavam problemas que pudessem ser diagnosticados visualmente, pois a grande maioria era constituída de mudas com vigor bom (49\%) ou regular (42\%) (Tabela 17).

Já a diversidade florística das mudas implementadas nos plantios estava visualmente comprometida em 37\% das áreas visitadas, com dominância de uma única espécie.

Para efeito de comparação com as áreas de plantio em estudo, serão apresentados a seguir alguns resultados de plantios bem sucedidos em matas ciliares, agrupados pela Secretaria do Meio Ambiente do Estado de São Paulo, com o objetivo de desenvolver um programa de repovoamento florestal para o estado (São Paulo, 2002).

Em alguns projetos, após pouco tempo de implantação foi possível notar o restabelecimento dos processos ecológicos, com presença de grande diversidade de espécies e indicadores de regeneração natural. Plantios com três anos, considerados antigos, têm apresentado resultados promissores como aumento da capacidade de regeneração, proteção do solo e retorno gradativo da fauna nativa.

Entre esses projetos, o plantio de 128 espécies de ocorrência regional nas APPs da represa de abastecimento público de Iracemápolis, SP, já assumiu fisionomia florestal após três a quatro anos do plantio, readquirindo todos os processos ecológicos de uma floresta em plena atividade.

Em APPs dos Municípios de Santa Bárbara d’Oeste e de Piracicaba, plantios realizados com o emprego de espécies regionais e utilizando técnicas de espaçamento 
adensado adquiriram, em 18 meses, uma fisionomia florestal com processos ecológicos em pleno funcionamento, principalmente processos de regeneração natural.

Plantios com idade média de 20 anos, realizados pela Companhia Energética de São Paulo (CESP), em Paraibuna, SP, na Bacia do Rio Paraíba do Sul, atualmente, possuem intensa regeneração natural que fecha praticamente todo o sub-bosque que coexiste com um denso estrato herbáceo. Poucas espécies pioneiras persistiram em virtude do processo de sucessão que possibilitou a formação de um dossel heterogêneo com árvores com alturas que variam entre 13 e $20 \mathrm{~m}$.

Ainda na Bacia do Rio Paraíba do Sul, um plantio realizado em área de extração de areia na região de Caçapava, SP, com idade média de oito anos, apresentou intensa regeneração natural, com espécies típicas de sub-bosque, grande número de indivíduos adultos e evidências de dispersões provindas de remanescentes contíguos a essa área, isso, apesar da baixa diversidade em espécies (16) empregada na época do plantio.

\subsubsection{Integridade das margens dos corpos d’água}

Dos 21 portos de areia visitados, 80\% (16) deles tinham as margens do corpo d’água protegidas por algum tipo de cobertura vegetal, a maioria coberta por gramíneas, com apenas três casos de cobertura com espécies arbóreas.

Dentro desse critério de cobertura florestal, por gramíneas ou espécies arbóreas, $14 \%$ dos portos tiveram a integridade de suas margens classificadas como boa e $62 \%$ classificadas como regular, restando $24 \%$ dos portos (5) classificados como críticos em relação à integridade de suas margens, por estarem descobertas e em processo de erosão.

O Anexo D apresenta imagens das margens dos corpos d’água de portos de areia visitados, indicando sua classificação em relação à sua integridade física.

Ainda que seja relativamente baixa a percentagem de empreendimentos (24\%) com integridade física das margens comprometida, o problema da erosão não deixa de ser um fator preocupante para a Bacia do Rio Corumbataí que é, desde 2000, a principal fonte de abastecimento de água para 500.000 habitantes de Piracicaba e região. 
A desestabilização das margens pode provocar seu desbarrancamento, causando assoreamento do corpo hídrico e a perda de nutrientes e solos férteis. Com o assoreamento, o corpo hídrico diminui sua capacidade de armazenamento, o que pode ocasionar redução na capacidade de vazão que pode levar, entre outras coisas, a inundações, instabilidade do canal e comprometimento da vida aquática (Nelson \& Booth, 2002).

Além disso, iniciado o processo de erosão, os sedimentos finos transportados em suspensão causam problemas à qualidade da água nos corpos receptores, como o aumento na turbidez e a diminuição do oxigênio dissolvido, além de causar toxicidade à organismos aquáticos (Novotny \& Olem, 1994, citado por Reis, 2004), com redução de fitoplâncton e mortalidade de plantas macrófitas e peixes. Essas alterações na qualidade de água se tornam ainda maiores quando somadas ao aumento de material em suspensão resultante da atividade de dragagem em si, que, segundo Christensen (1998), citado por Espíndola et al. (2003), promove ainda, com a ressuspensão dos sedimentos, a redisponibilização de metais em níveis potencialmente tóxicos.

Para evitar essa seqüência de eventos prejudiciais à qualidade e quantidade da água da bacia, seriam necessárias políticas melhores de comando e controle desse tipo de empreendimento, o qual poderia chegar a ter um papel ambiental positivo para este manancial, com a dragagem de areia resultante do assoreamento de corpos d’água antropizados da bacia que, segundo IPEF (2001), possui apenas 12\% de cobertura florestal nativa.

No entanto, isso só seria possível se as margens não fossem desestabilizadas pela ausência de cobertura florestal e pela dragagem de forma indevida, exemplificadas pelas imagens do Anexo E, o que, ao contrário, contribui muito para o assoreamento do corpo d’água.

A idéia de que a dragagem tem conseqüências positivas é de senso comum no caso das bacias hidrográficas fortemente antropizadas, nas quais a carga de sedimentos aumenta muito em conseqüência das formas de uso do solo que induzem um aumento das taxas de erosão. Nesses casos, a mineração por dragagem em leito contribuiria para reduzir a freqüência e a intensidade das inundações, processo que é acelerado quando há 
assoreamento. Por outro lado, esses impactos positivos não são identificados no caso da extração em leitos de rios que drenam bacias bem conservadas, caso raro no sul e sudeste do Brasil (Sanches ${ }^{6}$ ).

Essa discussão ainda é pouco conclusiva na maioria das bacias hidrográficas, sendo necessários maiores avanços nesse sentido, tanto por parte das universidades, com a realização de pesquisas, como pelos órgãos licenciadores, no processo decisório de liberação e renovação de licenças.

Contrariando a realidade da Bacia do Rio Corumbataí, Reis (2004) defende que o manejo de microbacias de abastecimento público deve ter como objetivo principal a produção de água em quantidade e qualidade adequadas. Davies \& Mazumder (2003) afirmam que para se atingir esse objetivo são necessárias políticas efetivas que identifiquem, documentem e reduzam os riscos iminentes resultantes da ocupação humana dessas bacias, colocando como desafio a ser ultrapassado o descompasso existente entre os gerenciadores de políticas de controle, os instrumentos de controle e a ciência.

\subsubsection{Avaliação final da recuperação das APPs}

A avaliação final da recuperação das APPs baseada em categorias de qualidade indicou que mais da metade (52\%) dos plantios podem ser classificados como ruins, $38 \%$ classificados como regulares, enquanto apenas um plantio (5\%) pôde ser classificado como bom e outro como ótimo, conforme matriz de diagnóstico apresentada no Anexo F e imagens da Figura 25). Embora os plantios dos portos 11 e 18 estejam classificados como regulares, foram recentemente implantados, por isso ainda não possuem uma fisionomia florestal.

\footnotetext{
${ }^{6}$ SANCHES, L.H.S. (Universidade de São Paulo. Departamento de Engenharia de Minas da Escola Politécnica da USP, São Paulo). Correspondência pessoal, 2004.
} 

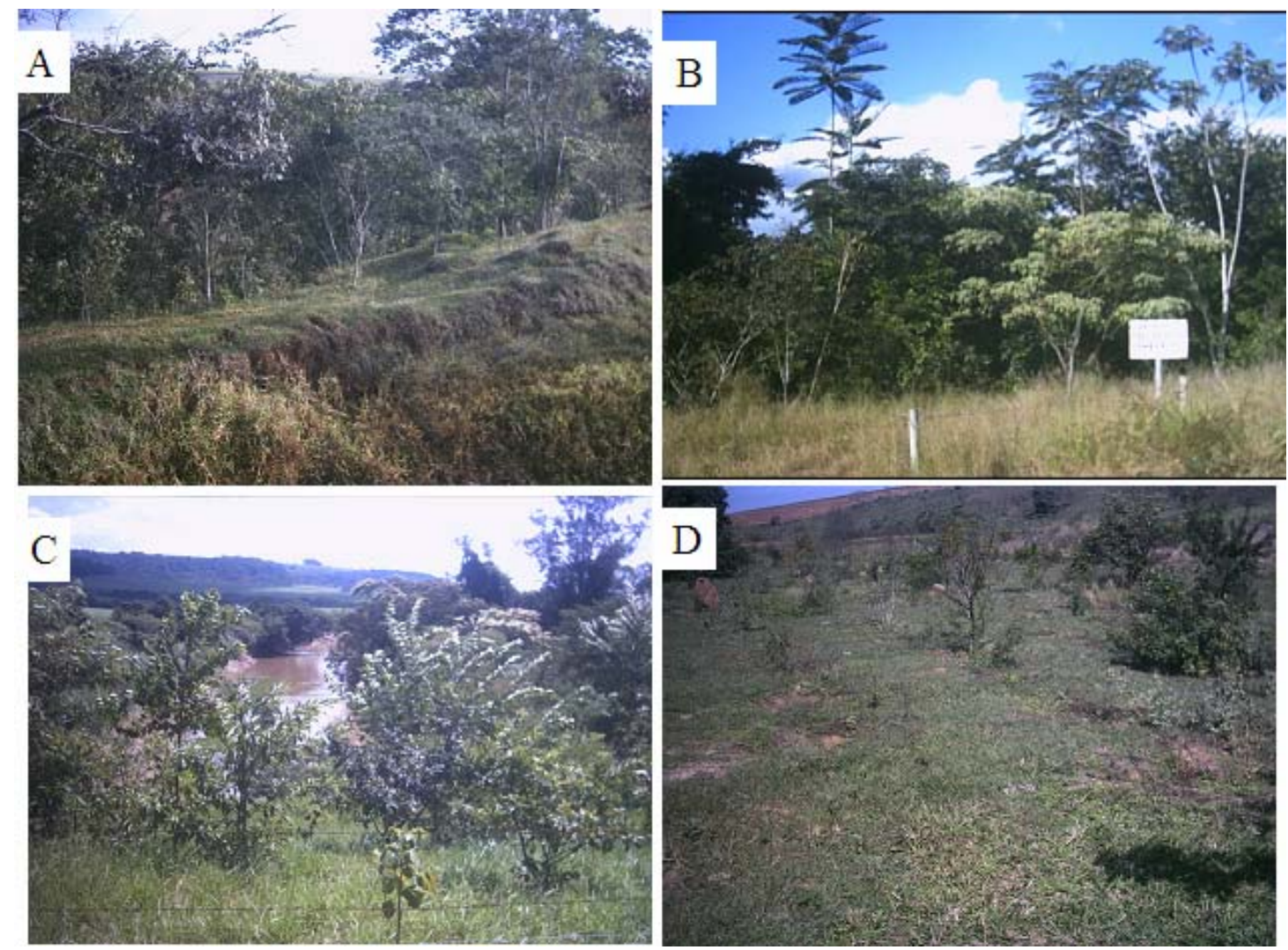

Figura 25 - Imagens da avaliação da recuperação das APPs de portos de areia da Bacia do Rio Corumbataí. Categorias de classificação: ótimo (A), bom (B), regular (C) e ruim (D)

O baixo sucesso dos plantios estudados indica que muitas dessas áreas não estão cumprindo com sua função esperada na proteção física do corpo d’água. Isso evidencia que pode não estar havendo proteção do solo e da qualidade e quantidade do recurso hídrico.

Além disso, o uso e a cobertura predominantemente agrícola da Bacia do Rio Corumbataí, em que apenas $12 \%$ de sua área são cobertas por florestas nativas, comprometem essa função de proteção física esperada. Mesmo que a cobertura do solo das áreas restauradas fosse adequada, isso não seria garantia de proteção em casos de bacias que apresentam uso inadequado do solo. 
Para que as áreas restauradas cumprissem com sua função de proteção biológica, deveriam, no mínimo, possuir diversidade florística semelhante à da floresta original da região para que, com o processo de sucessão, os componentes e as interações ecológicas do ecossistema fossem restabelecidos.

Além disso, para que haja essa proteção, seria necessária a presença de fragmentos ou "ilhas de diversidade" na paisagem que possibilitassem a recolonização de diversas espécies e o restabelecimento do fluxo gênico entre as populações vegetais, aumentando a biodiversidade e permitindo a restauração da conectividade, além de melhorar a qualidade da paisagem (Kageyama et al., 2003).

Essas “ilhas de diversidade” são representadas principalmente por Unidades de Conservação e áreas de reserva legal, pouco presentes na bacia. Mesmo se presentes, seria necessário o monitoramento contínuo dos plantios a partir de indicadores que evidenciassem o fluxo gênico e o seu uso como fonte de condições e recursos para a fauna e flora locais.

\subsection{Percepção ambiental e legal dos mineradores}

“Uma das dificuldades para a proteção dos ecossistemas naturais está na existência de diferenças nas percepções dos valores e da importância dos mesmos entre indivíduos de culturas diferentes ou de grupos sócio-econômicos que desempenham funções distintas no plano social nesses ambientes” (UNESCO, 1973, citado por Santos et al., 2000).

Os projetos de pesquisa que abordam as relações homem biosfera e o gerenciamento dos ecossistemas devem, necessariamente, incluir estudos da percepção ambiental (UNESCO, 1973, citado por Santos et al., 2000), uma vez que esse tipo de abordagem auxilia no planejamento do ambiente.

Considerando a importância dada aos estudos de percepção, foram realizadas 15 entrevistas, referentes a 19 portos de areia (90\% dos 21 portos visitados). A maioria dos entrevistados (87\%) era proprietário ou proprietário sócio dos empreendimentos. 
Os resultados apresentados nesse item são oriundos, única e exclusivamente, das informações obtidas durante as entrevistas, por isso refletem apenas a percepção dos mineradores em relação ao apresentado.

A maioria dos portos de areia iniciou suas atividades em meados da década de 80 até o início da década de 90. Dos empreendedores entrevistados, o primeiro se instalou na região em 1972 e o último em 2000.

O histórico de uso do solo das APPs ocupadas atualmente por esses portos de areia isentou seus proprietários da necessidade de pedidos de desmatamento, já que essas áreas eram ocupadas por atividades como pastagem, antigos portos de areia e várzeas abandonadas (Figura 26).

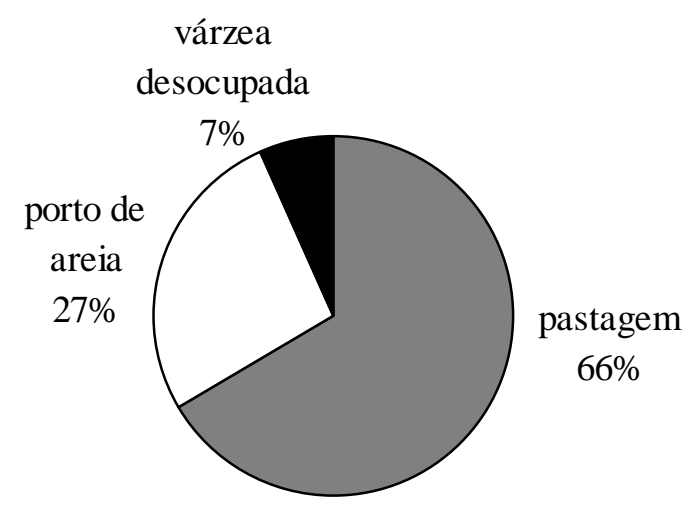

Figura 26 - Histórico de uso do solo de portos de areia de leito de rio da Bacia do Rio Corumbataí, SP. Informações obtidas em entrevistas junto aos proprietários

A partir desse histórico de uso do solo, foi possível inferir que esses solos já eram degradados, ou no mínimo perturbados, antes mesmo do início da atividade minerária, o que pode ter prejudicado o sucesso dos plantios realizados.

Embora a conceituação de área degradada ou perturbada seja bastante discutida nos meios técnicos e acadêmicos, pode-se adotar a definição apresentada por Carpanezzi et al. (1990), em que o ecossistema degradado é aquele que necessita da ação antrópica na sua recuperação já que, após distúrbios, teve eliminado, juntamente com a vegetação, os seus meios de regeneração, como banco de sementes, banco de plântulas, chuvas de 
sementes e rebrota, o que resulta em baixa resiliência. Já o ecossistema perturbado é aquele que sofreu distúrbios, mas manteve meios de regeneração e, por isso, a ação humana não é obrigatória, embora auxilie na sua recuperação.

Os esforços de recuperação podem estar sendo prejudicados pela compactação do solo característica de áreas com atividade de mineração e pecuária. A compactação é prejudicial ao crescimento das plantas por causa da redução da disponibilidade de oxigênio na rizosfera, além de reduzir a infiltração de água e criar barreiras físicas à penetração das raízes (Griffith \& Williams, 1989).

Segundo Griffith \& Williams (1989), a falta de estudo do material edáfico das áreas a serem reflorestadas leva a um fato muito comum nessas áreas que é a aplicação intuitiva de fertilizantes e, conseqüente deficiência de nutrientes.

Estas áreas atualmente ocupadas pela atividade de mineração possuem diversos usos potenciais e, ao final da atividade, com exceção do trecho que compõe a APP a ser restaurado, podem ser destinadas ao cultivo, à pastagem, ao reflorestamento, área de recreação, área residencial, entre outras atividades.

Segundo as expectativas dos proprietários, 40\% deles não têm plano de uso futuro dessas áreas, pensam em devolver o direito de uso do solo ao arrendatário no término da atividade de extração de areia. No entanto, a maioria pretende voltar a desenvolver a atividade mais comum da região, a pastagem (46\%) e apenas uma minoria pensa em jamais abandonar a atividade minerária (7\%) ou em iniciar outras atividades, como a de lazer e recreação (7\%) (Figura 27).

Com o resultado das entrevistas foi possível valorar os principais custos e benefícios dos empreendimentos, como os custos do plantio de mudas nas APPs, da regulamentação legal e da compra de equipamentos, além da valoração do metro cúbico de areia no mercado regional (Tabela 18). 


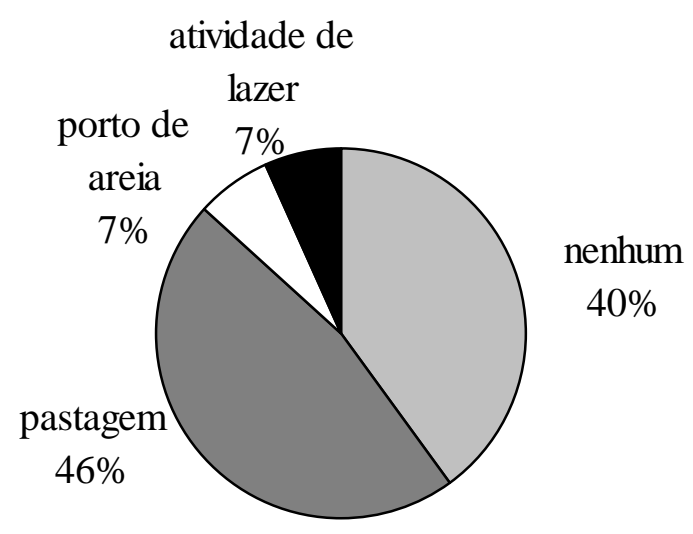

Figura 27 - Plano de uso futuro do solo de portos de areia de leito de rio da Bacia do Rio Corumbataí, SP. Informações obtidas em entrevistas junto aos proprietários

Tabela 18. Valores médio, mínimo e máximo referentes aos custos e benefícios dos portos de areia de leito de rio da Bacia do Rio Corumbataí, SP. Custos com plantio de mudas, legalização do empreendimento e aquisição de equipamentos. Benefícios referentes à venda de areia no porto. Informações obtidas em entrevistas junto aos proprietários

\begin{tabular}{ccccc}
\hline Valores (R\$) & Custo & Benefício \\
& Plantio & Legalização & Equipamentos & $\begin{array}{c}\text { B } \\
\mathrm{m}^{3} \text { areia }\end{array}$ \\
\hline Médio & $4 \mathrm{mil}$ & $30 \mathrm{mil}$ & $200 \mathrm{mil}$ & 10,00 \\
Mínimo & 600,00 & $10 \mathrm{mil}$ & $20 \mathrm{mil}$ & 6,00 \\
Máximo & $10 \mathrm{mil}$ & $60 \mathrm{mil}$ & $1 \mathrm{milhão}$ & 16,00 \\
\hline
\end{tabular}

A estimativa de custo dos plantios realizados na bacia variou entre R \$600,00 e R\$ 10.000,00, com custo médio de R\$ 4.000,00 (Tabela 19). Alguns proprietários (15\%) não tinham qualquer percepção de gasto com os plantios que realizaram e pouco mais que um terço (36\%) dos entrevistados demonstrou estar equivocado quanto à sua percepção de gasto, relatando valores exorbitantes como R\$ 66.0000,00 por hectare. Ao passo que $40 \%$ relataram valores de custo por hectare inferiores aos comumente praticados, variando entre $\mathrm{R} \$ 1.143,00$ e $\mathrm{R} \$ 2.220,00$. 
Segundo estudos de Joly et al. (2000), a estimativa de custo dos materiais e insumos utilizados na recomposição de um hectare de mata ciliar gira em torno de R\$ $2.600,00$ e $\mathrm{R} \$ 3.000,00$.

Em alguns casos, os custos foram inferiores em função da gratuidade na aquisição de mudas, junto ao Comitê de Bacia Hidrográfica $(\mathrm{CBH})$ ou prefeitura. Em outros casos, muito comuns, não são utilizados fertilizantes de qualquer natureza, o que reduz ainda mais o custo com o plantio.

A criação de um cooperativismo entre as empresas mineradoras da região na recuperação ambiental possibilitaria uma redução nos custos de implementação dos plantios, sem, no entanto, comprometer a qualidade das ações ambientais. O compartilhamento de técnicas e práticas de reflorestamento bem sucedidas ajudaria no controle da qualidade dessas ações (Toy \& Griffith, 2002).

A atividade de extração de areia, assim como qualquer outro tipo de atividade minerária, deve estar regularizada legalmente para iniciar suas atividades. Essa regularização demanda um custo referente à obtenção do licenciamento ambiental junto á CETESB e da titularidade minerária junto ao DNPM, para tanto, os empreendimentos ainda dependem de autorizações de outros órgãos, como DEPRN, prefeitura, DAEE, entre outros.

O custo médio da regularização legal dos portos de areia em estudo foi de $\mathrm{R} \$$ 30.000,00. Na prática esse custo se refere aos trâmites burocráticos, com pagamento das taxas da CETESB e do DNPM e dos serviços de assessoria empresarial e consultoria ambiental.

O investimento inicial necessário à instalação do empreendimento variou muito em função da área a ser explorada e de algumas particularidades. O porto de menor custo de regularização declarada foi de $\mathrm{R} \$ 10.000,00$, em um caso particular em que um conjunto de portos pertence a um mesmo proprietário, o que acabou reduzindo o custo final da legalização por porto. Já a regularização de maior custo corresponde ao único empreendimento de extração de areia da bacia que realizou EIA (Tabela 18).

O investimento financeiro das empresas em equipamentos foi muito variado, estando entre $\mathrm{R} \$ \mathbf{1 0 . 0 0 0 , 0 0}$ e $\mathrm{R} \$ \mathbf{1 . 0 0 0 . 0 0 0 , 0 0}$, demonstrando que essa atividade tem 
grande flexibilidade na demanda de capital de investimento. É em função dessa grande variação que a média desse investimento (R\$ 200.000,00) não teve representatividade (Tabela 18).

O valor médio, e mais comum, de venda da areia “in natura" para a construção civil (distribuída no porto) na região foi de R\$ 10,00 o metro cúbico. Há casos do exercício de um menor preço da areia, chegando a ser vendido a R\$ 6,00 o metro cúbico em função da longa distância dos centros consumidores da região e da granulometria mais fina da areia extraída (Tabela 18).

As minas de extração têm, necessariamente, de estar próximas aos centros consumidores, caso contrário o preço do frete pode aumentar sobremaneira o custo final do produto, tornando inviável a atividade.

A areia industrial destinada à produção de vidro teve um maior valor de venda ( $R \$ 16,00)$ em virtude do acréscimo de custo do tratamento desse material, que normalmente é vendido sem qualquer processamento para a construção civil (Tabela 18).

Segundo relato de muitos entrevistados, o preço da areia tem decaído em função da diminuição do consumo do produto. Em 1997, o presidente da Associação Nacional das Entidades de Produtores de Agregados para a Construção Civil - ANEPAC já alertava quanto aos baixos preços de mercado da areia, atribuindo essa queda à inadequação dos créditos à realidade atual da construção popular (PEQUENA e média mineração..., 1997).

Em 1997, segundo o então presidente da ANEPAC, além das poucas obras de construção civil, as pedreiras passaram a produzir areia artificial e as empresas a distribuir produtos que substituem o uso da areia, como massas prontas. As mineradoras também adquiriram equipamentos que permitiram ampliar a produção. Com isso, a falta de consumo aliada ao excesso de produção fez com que houvesse perda da lucratividade (PEQUENA e média mineração..., 1997).

Ainda que a areia não tenha um alto valor de mercado, é um produto que nunca deixará de ser utilizado na construção civil, o que garante a lucratividade e a perpetuação dessa atividade. 
Segundo os mineradores, são muitos os encargos pagos por essa atividade, como o recolhimento do CFEM (Compensação Financeira pela Exploração dos Recursos Minerais) sobre 2\% faturamento líquido, do IPI (Imposto sobre Produtos Industrializados), ICMS (Imposto sobre Circulação de Mercadorias e Prestação de Serviços), PIS (Programa de Integração Social) e COFINS (Contribuição para o Financiamento da Seguridade Social) sobre o faturamento bruto (17\%, 0,65\% e 2\%, respectivamente) e CSL (Contribuição Social sobre o Lucro) e IR (Imposto de Renda de Pessoa Jurídica) sobre o lucro bruto (7\% e 25\%, respectivamente) (Véras \& Silva, 1998).

Em compensação, é uma atividade que não precisa necessariamente de grandes investimentos iniciais e de contratação de mão de obra especializada. Além disso, o contingente de braçais ocupados na extração é baixo, sendo exigido apenas um orientador para a frente de lavra e um operador de máquina, que muitas vezes, conforme observação de campo, é função do próprio proprietário ou de seus familiares. Essa atividade ainda não tem quase custos de produção, pelo fato de ser um bem vendido, na maioria, "in natura".

O setor de mineração enfrenta há muitos anos enorme burocracia para regularização ambiental e mineral da atividade, dependendo da avaliação e anuência prévias de órgãos vinculados aos diferentes níveis de governo, cujas respostas, além de morosas, são interdependentes. Como conseqüência, o tempo de espera por um pedido de licença ambiental ou direito minerário levou muitas empresas a funcionarem na ilegalidade.

Mesmo com as dificuldades burocráticas, as principais regiões produtoras de areia do Estado de São Paulo já atingiram o importante objetivo de regularização ambiental e mineral junto aos órgãos envolvidos com a atividade (Akimoto, 2001).

Segundo relato dos proprietários, muitas empresas de extração de areia da bacia conseguiram sua regularização no final da década de 90, com tempo médio de seis anos, mínimo de dois anos e máximo de 20 anos.

O primeiro passo para a concretização dessa regularização foi a possibilidade, a partir de 1995, das empresas optarem junto ao DNPM pelo regime de autorização ou 
concessão, o que proporcionou às empresas a visão de planejamento de seus investimentos a longo prazo, livrando-se dos sobressaltos que as flutuações políticas municipais proporcionavam a cada eleição ou desavença política (Akimoto, 2001).

Muitos entrevistados (66\%) declararam dificuldades no processo de regularização legal de seus empreendimentos. Na maioria dos casos (70\% dos entrevistados que declararam dificuldades na regularização) o gargalo do processo de regularização esteve nos atrasos para obtenção da titularidade minerária junto ao DNPM, sem a qual os empreendimentos não podem se legalizar perante as esferas municipal, estadual e federal.

Embora a morosidade do licenciamento ambiental seja vista como a grande vilã do crescimento das atividades econômicas, apenas uma pequena parcela dos entrevistados declarou dificuldades na obtenção da licença ambiental, 20\% dos entrevistados que declararam dificuldades na regularização reclamaram de atrasos na CETESB e 10\% reclamaram do IBAMA e da prefeitura.

Esse resultado, provavelmente, está relacionado ao fato da grande maioria dos empreendimentos da bacia não estarem sujeitos aos EIAs, os quais demandariam análises mais demoradas. Apenas um porto de areia elaborou EIA/RIMA.

A regularização ambiental exige conhecimento legal e técnico da atividade com encaminhamento profissional especializado e competente, o que geralmente está fora do alcance dos pequenos empreendedores (Brandt, 2004).

Como pequenos empreendedores, muitos proprietários entrevistados (73\%) reconheceram essa carência de informações técnicas e legais a respeito dos procedimentos para a regularização de seus empreendimentos, concordando com a necessidade de uma cartilha informativa. Uma pequena parcela (27\%) não acha a cartilha necessária por estarem confiantes nos conhecimentos técnicos e legais das empresas terceirizadas contratadas para esse serviço (Tabela 19).

Embora seja desconhecido dos proprietários, a Secretaria do Meio Ambiente do Estado de São Paulo desenvolveu, em 1999, um manual com os procedimentos para o licenciamento ambiental integrado das atividades minerárias no estado (São Paulo, 
1999), iniciativa no sentido de orientar os diversos órgãos envolvidos e os empreendedores em relação à aplicação da Resolução SMA 04/99.

Tabela 19. Respostas dos proprietários dos portos de areia da Bacia do Rio Corumbataí, $\mathrm{SP}$, quanto à necessidade de uma cartilha informativa a respeito dos procedimentos legais e ambientais para o licenciamento mineral

\begin{tabular}{ll}
\hline Respostas dos entrevistados & Ocorrência \\
\hline Sim, pois falta informação e orientação & $11(73 \%)$ \\
Não, pois contrata empresa especializada & $4(27 \%)$ \\
\hline
\end{tabular}

Segundo a percepção dos proprietários, a Polícia Ambiental e a CETESB foram os órgãos que mais freqüentaram esses portos. O único órgão que não visitou nenhum dos empreendimentos em estudo foi o DAEE, órgão que, segundo legislação vigente (São Paulo, 1999), deveria emitir a outorga para implantação dos empreendimentos em leito de rio. Há portos que nunca foram visitados pelo DEPRN, DNPM, Polícia Ambiental e prefeitura (Figura 28). Deve-se ressaltar que nem sempre o proprietário acompanha a vistoria dos órgãos, o que pode ter distorcido, em parte, esses resultados.

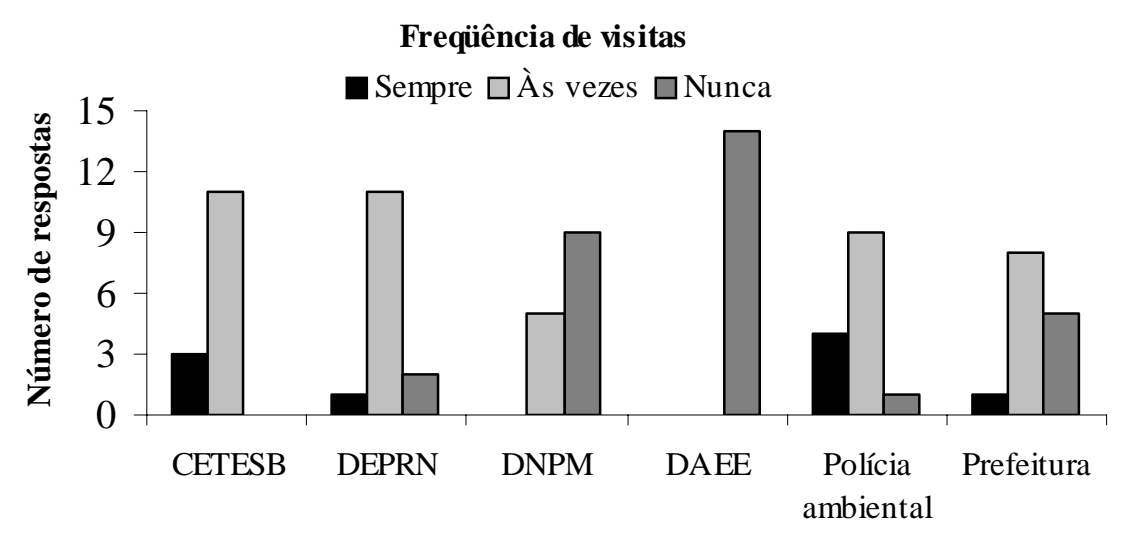

Figura 28 - Freqüência de visitas dos órgãos nas minerações de areia da Bacia do Rio Corumbataí, SP. Informações obtidas em entrevistas com os proprietários 
Durante as visitas dos órgãos competentes aos portos de areia nem sempre houve participação técnica ou assessoria nas questões ambientais e legais que envolvem a atividade. Mesmo o órgão que mais ajudou os empreendedores em relação a essas questões, a Polícia Ambiental, foi citado por apenas 36\% dos entrevistados (Tabela 20).

Tabela 20. Participação dos órgãos na prestação de assistência durante as visitas às mineradoras de areia da Bacia do Rio Corumbataí, SP. Informações obtidas em entrevistas

\begin{tabular}{lc}
\hline Órgão envolvido & Entrevistados (\%) \\
\hline Polícia Ambiental & 36 \\
CETESB & 29 \\
DEPRN & 29 \\
DNPM & 7 \\
Prefeitura & 7 \\
DAEE & 0 \\
\hline
\end{tabular}

A maior participação técnica da Polícia ambiental, talvez, esteja vinculada à maior proximidade sócio-cultural com os mineradores, além é claro, da maior proximidade física, diagnosticada pela freqüência de visitas desse órgão.

Com relação à percepção ambiental dos entrevistados, a grande maioria dos mineradores de areia (87\%) considera importante o reflorestamento das matas ciliares da Bacia do Rio Corumbataí. Quase metade (47\%) atribui à mata ciliar o importante papel de conservar as margens dos corpos d'água e de impedir seu assoreamento. Foram citadas muitas outras funções das vegetações ciliares, entre elas a de proteger o corpo d’água contra a poluição, embora algumas funções sejam conceitualmente equivocadas (Tabela 21).

Segundo Mueller (1998), a retirada indiscriminada da mata ciliar elimina a proteção do solo contra a compactação e a erosão provocadas pela chuva, com isso dificulta a penetração da água, prejudicando a realimentação dos lençóis freáticos, além disso, a chuva corre em direção dos corpos d'água carregando partículas do solo e outros resíduos que promovem o assoreamento, que vai gradualmente desfigurando o corpo 
d’água e contribuindo para a eliminação da vida aquática, além de intensificar a poluição da água que passa a ter maiores custos de purificação em caso de mananciais. O autor acrescenta ainda a perda de solo fértil e de refúgios da fauna, além da degradação da paisagem provocada pelo surgimento de deformações do solo (como regos, grotas e voçorocas) e desbarrancamento das margens dos corpos d’água.

Tabela 21. Resposta dos proprietários entrevistados a respeito da importância do reflorestamento das margens dos corpos d'água da Bacia do Rio Corumbataí, SP

\begin{tabular}{ll}
\hline Respostas dos entrevistados & Ocorrência \\
\hline Sim, conserva a margem do rio/impede o assoreamento & $7(47 \%)$ \\
Sim, protege/diminiu poluição & $3(20 \%)$ \\
Sim, para sobrevivência do rio & $1(7 \%)$ \\
Sim, diminui a evaporação da água & $1(7 \%)$ \\
Sim, responsável pelo clima local & $1(7 \%)$ \\
Sim, conserva as nascentes & $1(7 \%)$ \\
Sim, pelo aspecto paisagístico & $1(7 \%)$ \\
Sim, exigência legal & $1(7 \%)$ \\
Não, reflorestar as nascentes é mais importante & $1(7 \%)$ \\
Não, porque o plantio de árvores causa desbarrancamento das margens & $1(7 \%)$ \\
Não respondeu/não sabe & $1(7 \%)$ \\
\hline
\end{tabular}

Segundo Bren (1993), citado por Lima \& Zakia (2000), os valores atribuídos às matas ciliares pelos diferentes setores de uso da terra são bastante conflitantes. Para os pecuaristas, por exemplo, representam um obstáculo ao livre acesso do gado à água, enquanto que para o setor de produção florestal e mineral representam sítios de grande potencial econômico.

Embora tenham interesses econômicos nas matas ciliares, muitos mineradores defenderam seu reflorestamento, a maioria, baseados nas funções hidrológicas dessas áreas.

Segundo Lima \& Zakia (2000), as funções hidrológicas das matas ciliares ou zonas ripárias, como têm sido chamadas, estão representadas por suas ações diretas 
numa série de processos para a manutenção do ecossistema aquático, além da manutenção da qualidade e da quantidade da água.

Os autores ressaltam como contribuições hidrológicas das matas ciliares o aumento da capacidade de armazenamento da água na microbacia, a capacidade de filtragem da água que vai para o corpo hídrico, a estabilização das margens, o abastecimento do corpo d’água com material orgânico, que serve como fonte nutricional para a biota aquática, e a atenuação da radiação solar, que favorece o equilíbrio térmico da água e influencia positivamente a produção primária do ecossistema.

Além das funções hidrológicas apresentadas anteriormente, as zonas ripárias possuem importantes funções ecológicas. Essas importantes funções das matas ripárias são pouco conhecidas fora do meio acadêmico, inclusive não foram mencionadas por nenhum dos mineradores entrevistados.

Segundo Rodrigues \& Nave (2000), são raras as vezes que se propõe uma restauração florestal baseada nas questões ecológicas, como o restabelecimento da matas ciliares como corredores ecológicos naturais que interliguem fragmentos de hábitat. A conectividade da paisagem têm sido considerada extremamente importante na movimentação da fauna e na dispersão vegetal (Lima \& Zakia, 2000), além disso, a manutenção de fluxo gênico reduz os riscos de extinção local.

Para que as matas ciliares revegetadas cumpram suas funções naturais é preciso haver equilíbrio e sustentabilidade do novo ecossistema construído, sendo para isso essencial a manutenção da biodiversidade natural dessas áreas.

A restauração de ecossistemas tropicais degradados não pode desconsiderar a grande diversidade existente nessas áreas (Kageyama et al., 2003). O novo ecossistema deve ser o mais semelhante possível ao anteriormente existente, embora a restauração não deva ter a pretensão de refazer uma floresta exatamente igual à que existia antes, mas sim colocar no campo uma composição de espécies que forneça condições para que a nova comunidade tenha maior probabilidade de se desenvolver e se auto-renovar (Engel \& Parrota, 2000 citados por Kageyama et al., 2003). Mesmo porque a grande maioria das restaurações utilizam apenas espécies arbóreas, que representam apenas uma pequena parcela da diversidade vegetal dessas florestas. 
Além disso, o uso de espécies de diferentes grupos ecológicos tem sido essencial na restauração, pois considera as variações de características e de comportamentos na auto-renovação de suas populações naturais (Kageyama et al., 2003).

Os resultados das entrevistas em relação à percepção ambiental dos proprietários a respeito do uso de espécies em diversidade nos plantios mostrou que quase metade dos entrevistados (47\%) não soube explicar a importância da aplicação de plantios com diversidade de espécies. Alguns entrevistados (20\%) atribuíram à diversidade de espécies o objetivo de “imitar” a floresta natural, enquanto outros mineradores (20\%) justificaram o uso de várias espécies como uma alternativa para o sucesso do plantio, pois permitiria a seleção das espécies que melhor se adaptariam no ambiente (Tabela 22).

Tabela 22. Respostas dos proprietários entrevistados a respeito da necessidade de diversidade de espécies no reflorestamento das matas ciliares da Bacia do Rio Corumbataí, SP

\begin{tabular}{ll}
\hline Respostas dos entrevistados & Ocorrência \\
\hline Não respondeu/não sabe & $7(47 \%)$ \\
Imitar a floresta natural & $3(20 \%)$ \\
Selecionar as espécies que melhor se adaptam/melhor adaptação & $3(20 \%)$ \\
Cada espécie tem uma finalidade no ambiente & $1(7 \%)$ \\
Alimentar diferentes animais & $1(7 \%)$ \\
Permitir a sobrevivência de várias espécies & $1(7 \%)$ \\
\hline
\end{tabular}

Conforme discutido em itens anteriores, a mineração de areia é uma atividade que, via de regra, gera impactos negativos ao meio ambiente, embora, em casos particulares, também possa gerar impactos positivos.

No caso da Bacia do Rio Corumbataí, bacia de intensa atividade pecuária e agrícola, a atividade de mineração de areia pode estar trazendo benefícios ao meio ambiente, o que vai de encontro com a opinião de 100\% dos mineradores entrevistados. Mais da metade dos entrevistados (64\%) acha que a extração de areia na bacia está reduzindo o assoreamento dos corpos d’água, 36\% acham que a dragagem está 
promovendo a limpeza do rio, enquanto 28\% relacionaram a atividade com a diminuição de enchentes na região (Tabela 23).

Tabela 23. Respostas dos proprietários dos portos de areia da bacia do Rio Corumbataí, SP a respeito dos benefícios da atividade de extração de areia ao meio ambiente

\begin{tabular}{ll}
\hline Respostas dos entrevistados & Ocorrência \\
\hline Diminui/Evita assoreamento do rio & $9(64 \%)$ \\
Limpeza do rio (sujeira) & $5(36 \%)$ \\
Diminui enchentes & $4(28 \%)$ \\
Aumenta o número de peixes & $3(21 \%)$ \\
Reflorestamento das APPs & $1(7 \%)$ \\
Não respondeu & $1(7 \%)$ \\
\hline
\end{tabular}

Em contrapartida, apenas um dos 19 entrevistados (7\% do total) reconheceu um potencial negativo da atividade ao meio ambiente, destacando o prejuízo às populações de peixes de piracema.

A partir das respostas dos mineradores, pôde-se concluir que, embora possuam percepção ambiental da atividade, possuem pouco conhecimento ambiental e legal a respeito da atividade de extração de areia, confiando essa responsabilidade às empresas contratadas por eles para administração legal e consultoria ambiental de seus empreendimentos.

\subsection{Condições e recursos dos órgãos ambientais públicos envolvidos na mineração}

Uma abordagem mais abrangente para o estudo dos problemas ambientais pode ser realizada considerando, entre outros fatores, as instituições governamentais, os mecanismos legais e os processos políticos e ideológicos que condicionam os comportamentos sócio-econômicos e culturais (Dwivevi, 1988). 
Foi enviado um total de 21 questionários aos órgãos envolvidos no licenciamento ambiental e mineral da extração de areia, que são a Polícia Ambiental (5 questionários), a CETESB (5), o DNPM (5), o DEPRN (2), o DAEE (3) e as prefeituras municipais (1).

Desses 21 questionários enviados foi obtida resposta de 71\% (15 questionários). O órgão que contribuiu com o maior número de questionários respondidos foi a Polícia Ambiental, respondendo aos cinco questionários encaminhados ao oficial responsável pelo Batalhão da Polícia Ambiental de Rio Claro. Provavelmente, a maior participação desse órgão decorreu do incentivo dado aos oficiais, por parte de seu comandante.

A CETESB foi o segundo órgão em número de questionários respondidos, sendo obtidos quatro questionários (80\% dos enviados). Do DNPM, apenas três foram respondidos (60\% dos enviados), em virtude da recusa dos demais técnicos em respondê-lo.

Quanto ao DEPRN, em função da carência de técnicos na região em estudo (dois técnicos), apenas dois questionários foram enviados e respondidos.

Os órgãos que menos contribuíram na resposta dos questionários foram o DAEE e as prefeituras municipais. O DAEE respondeu a apenas um dos questionários enviados e a prefeitura, a qual foi remetido o questionário, em um primeiro contato se recusou a responder ao questionário encaminhado, em função de desconhecer suas atribuições quanto ao tema. Contudo, em um segundo contato, a prefeitura reconheceu o equívoco cometido e aceitou responder a apenas uma das seis perguntas contidas no questionário. Em virtude do embaraço ocorrido, tornaram-se inviáveis novos contatos com outras prefeituras.

Em 1997, segundo o então presidente da ANEPAC, as prefeituras não estão preparadas e equipadas para fiscalizar empreendimentos minerários, com raras exceções, como a prefeitura municipal de São Paulo. Mesmo as prefeituras do Vale do Paraíba, que estão diretamente identificadas com essa atividade, não contam com um corpo técnico adequado para atuar nessa área, como por exemplo, geólogos e engenheiros de minas (PEQUENA e média mineração..., 1997).

Segundo as informações obtidas junto aos órgãos, de maneira global, considerando o total de entrevistados, a principal forma de qualificação e atualização dos 
técnicos consiste na realização de cursos internos (60\% dos entrevistados), seguida pela participação em eventos organizados por outras instituições (40\%), como congressos e outros cursos (Tabela 24).

Tabela 24. Qualificação e atualização dos técnicos dos órgãos envolvidos no licenciamento de portos de areia em relação às questões ambientais e legais da extração mineral. Informações obtidas em entrevistas com os funcionários

\begin{tabular}{lcccccc}
\hline Respostas dos entrevistados & \multicolumn{7}{c}{ Ocorrência } \\
& CETESB & DEPRN & DNPM DAEE & Pol. Amb. Global \\
\hline Cursos internos & 4 & - & 1 & - & 4 & $9(60 \%)$ \\
Eventos de outras instituições & - & 2 & 1 & - & 3 & $6(40 \%)$ \\
Estudos individuais & 1 & - & 2 & - & - & $3(20 \%)$ \\
Cotidiano de trabalho & - & - & 1 & - & 2 & $3(20 \%)$ \\
Estágios internos & - & - & - & - & 3 & $3(20 \%)$ \\
Reuniões internas & - & 2 & - & - & - & $2(13 \%)$ \\
Experiência profissional & 2 & - & - & - & - & $2(13 \%)$ \\
Instruções de supervisores & - & - & - & - & 1 & $1(7 \%)$ \\
Contato com outros órgãos & - & - & - & - & 1 & $1(7 \%)$ \\
Cooperação entre os profisionais & 1 & - & - & - & - & $1(7 \%)$ \\
Resposta incoerente a pergunta & - & - & - & 1 & - & $1(7 \%)$ \\
\hline
\end{tabular}

Os funcionários da CETESB têm buscado sua qualificação e atualização principalmente através de cursos internos oferecidos pelo SEAQUA na forma de treinamentos teóricos, considerados insuficientes por alguns entrevistados. Têm contado também com a própria experiência profissional de seus funcionários (Tabela 24).

Com o intuito de compensar a falta de cursos internos, os funcionários do DEPRN buscam sua qualificação em eventos organizados por outras instituições e em reuniões internas periódicas com seus supervisores (Tabela 24).

Já no DNPM, essa qualificação ou atualização tem sido feita especialmente através de estudos individuais por parte de seus funcionários. Enquanto que a polícia ambiental tem cumprido essa tarefa principalmente através da realização de cursos e estágios internos anuais, além da participação em eventos promovidos por outras instituições (Tabela 24). 
Quanto à dificuldade de assegurar suas atribuições no licenciamento, em função das condições de recursos materiais, humanos e financeiros, os entrevistados do DNPM relataram dificuldades para fazer frente à fiscalização das quase 3.000 áreas de extração no estado e enfatizou que a carência desses recursos pode se agravar em virtude do aumento no número de pedidos de extração que estão dando entrada nesse órgão atualmente (Tabela 25). Mesmo sendo um órgão de arrecadação própria, apresenta dificuldades financeiras (Tabela 26).

Tabela 25. Respostas dos funcionários entrevistados a respeito se os recursos materiais, humanos e financeiros disponíveis aos seus órgãos estão assegurando suas atribuições no licenciamento das atividades de extração de areia em leito de rio na Bacia do Rio Corumbataí

\begin{tabular}{lcccccc}
\hline Respostas dos entrevistados & \multicolumn{7}{c}{ Ocorrência } \\
& CETESB & DEPRN & DNPM & DAEE & Pol. Amb. & Global \\
\hline Parcialmente & 4 & 1 & - & - & 1 & $6(40 \%)$ \\
Sim & - & 1 & - & 1 & 3 & $5(33 \%)$ \\
Não & - & - & 3 & - & 1 & $4(27 \%)$ \\
\hline
\end{tabular}

Tabela 26. Carência de recursos materiais, humanos e financeiros dos órgãos envolvidos no licenciamento da extração de areia. Informações obtidas em entrevistas com os funcionários

\begin{tabular}{lcccccc}
\hline Carência de recursos & \multicolumn{7}{c}{ Ocorrência } \\
& CETESB & DEPRN & DNPM & DAEE & Pol. Amb. & Global \\
\hline Humanos & 4 & 1 & 3 & - & 2 & $10(67 \%)$ \\
Materiais & 2 & - & 1 & - & 1 & $4(27 \%)$ \\
Financeiros & - & 1 & 2 & - & - & $3(20 \%)$ \\
\hline
\end{tabular}

Segundo os técnicos da CETESB entrevistados (4), seus recursos disponíveis asseguram parcialmente suas atribuições dentro do licenciamento (Tabela 25). Uma das dificuldades do órgão está no controle de alguns tipos de poluição, como o assoreamento, a erosão e a estabilidade de taludes, além do controle das interações entre esses fenômenos. Essa dificuldade de controle ambiental ocorre em função da carência 
de recursos materiais, representada principalmente pela falta de equipamentos específicos de monitoramento, e de recursos humanos (Tabela 26). Esse órgão relatou a necessidade de um maior investimento na qualificação do corpo técnico, bem como uma maior contratação de técnicos, principalmente com formação em geologia.

Segundo o único funcionário do DAEE entrevistado, “hoje, o DAEE, como órgão gestor do estado há mais de 50 anos, está respaldado, porém com a crescente procura dos recursos hídricos e de suas regularizações, o DAEE vai precisar, em um futuro bem próximo, de profissionais e de equipamentos, objetivando um melhor aproveitamento dos recursos hídricos, uma fiscalização mais atuante e a implantação de um sistema de informação para os diferentes usos e interferências nos recursos hídricos”"

Quanto ao DEPRN e a Polícia Ambiental, não houve um consenso entre os entrevistados com relação ao fato de suas atribuições serem asseguradas pelas suas condições e recursos disponíveis (Tabela 25). A carência de recursos humanos foi a principal dificuldade constatada nesses órgãos (Tabela 26). Segundo a Polícia Ambiental, essa carência é agravada pelas extensas áreas de cobertura que cada base de policiamento ambiental tem a percorrer, pois são responsáveis por muitos municípios.

Considerando o total de órgãos entrevistados, ficou constatado que o baixo contingente de técnicos contratados é a principal dificuldade (67\% dos entrevistados) dos órgãos no cumprimento de suas funções dentro do licenciamento da mineração de areia (Tabela 26).

Segundo os entrevistados, os principais procedimentos e critérios da CETESB na análise da poluição causada pela extração de areia em leito de rio estão divididos em atividades de campo e de escritório. Em campo, analisa as caixas de sedimentação de sólidos e seus efluentes gerados e o material particulado (poeira) nas vias de circulação, além de mensurar a largura do corpo d'água segundo normas específicas da CETESB para minerações por dragagem. As atividades de escritório se resumem no estabelecimento de exigências técnicas de controle dos efeitos ambientais da atividade, na emissão das licenças ambientais e suas renovações e na análise da demarcação da poligonal da área registrada junto ao DNPM, dos pareceres do DEPRN e do projeto de 
instalação do empreendimento, além de analisar os documentos de propriedade ou de arrendamento do terreno.

Não houve consenso em relação aos procedimentos adotados pelo DEPRN para análise da qualidade dos plantios implementados nas APPs. Um dos entrevistados relatou não existirem procedimentos e critérios gerais, enquanto o outro descreveu como procedimento a avaliação do desenvolvimento das mudas e da regeneração natural, observando as características das espécies com melhor desenvolvimento e seus grupos sucessionais.

Segundo o DNPM, não há um planejamento da extração de areia em leito de rio e o controle e a fiscalização da atividade se baseiam em denúncias. De acordo com relatos “devido à falta de pessoal há pouco planejamento na fiscalização, priorizam-se as denúncias feitas tanto por parte da população, quanto por parte da Promotoria Pública. As campanhas de fiscalização geralmente ocorrem em conjunto com a Polícia Ambiental, a CETESB e o IBAMA, sempre em caráter emergencial e com o objetivo de atender solicitações dos Ministérios Público e da Justiça, estadual e federal”.

De acordo com o DAEE, o procedimento para concessão de outorga às empresas de extração de areia em leito de rio, baseia-se na emissão de parecer técnico de outorga ao interessado que protocola a documentação exigida pela Portaria 717/96.

A Polícia Ambiental relatou como procedimentos para fiscalização dessa atividade a identificação das áreas propícias à atividade no planejamento da fiscalização, a inspeção da lavra para diagnóstico de possíveis danos ambientais, a averiguação da existência de licenças ambientais e das informações constantes nesses documentos, além da autuação e embargo de atividades irregulares e clandestinas.

Segundo relato, "No caso de empresa clandestina dá-se voz de prisão ao infrator, conduzindo-o, juntamente com os maquinários utilizados, para a Delegacia de Polícia local. Já no caso de empresa irregular, é feita autuação e apreensão das máquinas, além da confecção de Termo Circunstanciado para remessa ao Fórum local”.

Quase metade dos entrevistados (47\%) não conseguiu diagnosticar quais procedimentos, recursos e critérios, não aplicados atualmente, seriam importantes na 
avaliação do impacto dessa atividade. Muitos relataram a carência de estudos ambientais mais rigorosos (20\%) e a necessidade de maior integração entre os órgãos envolvidos (20\%) (Tabela 27).

Tabela 27. Procedimentos, recursos e critérios não aplicados e que seriam importantes na avaliação do impacto da atividade de extração de areia em leito de rio. Informações obtidas em entrevistas com os funcionários

\begin{tabular}{lccccccc}
\hline Respostas dos entrevistados & \multicolumn{7}{c}{ Ocorrência } \\
& CETESB & DEPRN & DNPM DAEE Pol. Amb. Global \\
\hline Não respondeu & 1 & 1 & 1 & 1 & 3 & $7(47 \%)$ \\
Estudos ambientais mais rigorosos & 1 & - & 1 & - & 1 & $3(20 \%)$ \\
Maior integração entre os órgãos envolvidos & 2 & - & - & - & 1 & $3(20 \%)$ \\
Planejamento de fiscalizações regulares & - & 1 & 1 & - & - & $2(13 \%)$ \\
Aumentar os recursos humanos na fiscalização & - & - & 1 & - & - & $1(7 \%)$ \\
Uso de recursos adequados ao controle da atividade & 1 & - & - & - & - & $1(7 \%)$ \\
\hline
\end{tabular}

Segundo a CETESB, a maior integração entre os órgãos da região se daria através do licenciamento ambiental em sistema de "balcão único" e os estudos ambientais seriam mais rigorosos se fosse intensificado o uso de cartografia digital e de geoprocessamento no acompanhamento do desenvolvimento da lavra, e se fosse realizada a batimetria do rio, que garantiria a extração apenas dos pacotes de assoreamento. Segundo relato, também "seria necessária uma estrutura que possibilitasse investigar a interferência conjunta no meio desses empreendimentos”.

Segundo respostas dos questionários, as principais leis e normas aplicadas pela CETESB são as Resoluções SMA relacionadas à atividade de mineração de areia, a Lei Estadual 997/76 e a Norma Cetesb D 7.010, a qual trata do licenciamento de atividades em leito de rio. Em relação ao DEPRN, o Código Florestal é a legislação mais pertinente, uma vez que esse órgão é o responsável pela emissão de parecer referente às intervenções na APP; quanto que para o DNPM, o Código de Mineração e as Normas reguladoras da mineração (NRM) são as legislações mais preponderantes. Para o DAEE, as legislações mais utilizadas são a portaria DAEE 717/96, que se refere à emissão de 
parecer técnico que dá o direito de extração de minério em leito de rio e a Lei Estadual 7.663/91 (Tabela 28).

Tabela 28. Principais leis e normas legais aplicadas pelos órgãos envolvidos, no que tange a extração de areia em leito. Informações obtidas em entrevistas junto aos funcionários

\begin{tabular}{lccccc}
\hline \multirow{2}{*}{ Leis e Normas legais mais aplicadas } & \multicolumn{5}{c}{ Ocorrência } \\
& CETESB & DEPRN & DNPM & DAEE & Pol. Amb. \\
\hline Código de Mineração (Decreto Lei 227/67) & 1 & - & 3 & - & 3 \\
Resoluções SMA relacionadas ao assunto & 4 & - & - & - & - \\
Lei Estadual no 997/76, regulamentada pelo Dec. Est. 8.468/76 & 4 & - & - & - & - \\
Lei de Crimes Ambientais (Lei 9.605/98) & - & - & - & - & 4 \\
Norma Cetesb D 7.010 & 4 & - & - & - & - \\
Código Florestal (Lei Federal no 4.771/65 e suas alterações) & - & 2 & - & - & 1 \\
Política Nacional do Meio Ambiente (Lei Federal 6.938/81) & - & 1 & - & - & 2 \\
Crime contra a ordem econômica (Lei 8.176/91) & - & - & - & - & 3 \\
Normas reguladoras da mineração - NRM & - & - & 3 & - & - \\
Resoluções CONAMA relacionadas ao assunto & 2 & 1 & - & - & - \\
Portarias DEPRN & - & 1 & - & - & - \\
Portaria DAEE 717/96 & - & - & - & 1 & - \\
Decreto Federal 750/93 & - & 1 & - & - & - \\
Lei Estadual 7.663/91, regulamentada pelo Dec. Est. 41.258/96 & - & - & - & 1 & - \\
Normas ABNT & 1 & - & - & - & - \\
Não respondeu & - & - & - & - & 1 \\
\hline
\end{tabular}

Todos os entrevistados consideram que o licenciamento ambiental de portos de areia traz alguma contribuição ambiental. Mais da metade (67\% dos entrevistados) tem certeza das contribuições que o processo de licenciamento traz, enquanto que a outra parte (27\% dos entrevistados) considera que esse mecanismo tem uma contribuição ambiental parcial (Tabela 29).

Segundo as respostas obtidas, as principais contribuições ou efeitos positivos do licenciamento estão no desassoreamento dos rios (60\% dos entrevistados), na disciplina da atividade (20\%) e no reflorestamento das margens dos rios (20\%) (Tabela 30).

Dos entrevistados da CETESB, três acreditam que o licenciamento traz contribuições ao meio ambiente e apenas um acha que essa contribuição é parcial 
(Tabela 29). Os principais argumentos desse órgão para a contribuição ambiental foram o reflorestamento das margens dos rios e a minimização de processos de degradação ambiental (Tabela 30).

Tabela 29. Resposta dos funcionários dos órgãos envolvidos a respeito da possibilidade do licenciamento ambiental de portos de areia trazer contribuições ambientais.

\begin{tabular}{lcccccc}
\hline Respostas dos entrevistados & \multicolumn{7}{c}{ Ocorrência } \\
& CETESB DEPRN & DNPM DAEE Pol. Amb. & Global \\
\hline Sim & 3 & 2 & 2 & 1 & 2 & $10(67 \%)$ \\
Parcialmente & 1 & - & 1 & - & 2 & $4(27 \%)$ \\
Não respondeu & - & - & - & - & 1 & $1(7 \%)$ \\
Não & - & - & - & - & - & - \\
\hline
\end{tabular}

Tabela 30. Contribuições ambientais do licenciamento ambiental de portos de areia. Informações obtidas em entrevistas junto aos funcionários dos órgãos envolvidos

\begin{tabular}{lcccccc}
\hline Contribuições ambientais & \multicolumn{5}{c}{ Ocorrência } \\
\hline & CETESB & DEPRN & DNPM DAEE Pol. Amb. & Global \\
\hline Desassoreamento dos corpos d'água & 1 & 1 & 2 & 1 & 4 & $9(60 \%)$ \\
Disciplina a atividade & 1 & 1 & 1 & - & - & $3(20 \%)$ \\
Reflorestamento das margens dos rios & 2 & 1 & - & - & - & $3(20 \%)$ \\
Minimiza processos de degradação ambiental & 2 & - & - & - & - & $2(13 \%)$ \\
Não respondeu & - & - & 1 & - & 1 & $2(13 \%)$ \\
Auxilia na identificação das fontes de poluição & 1 & - & - & - & - & $1(7 \%)$ \\
\hline
\end{tabular}

Apesar de atribuírem um benefício ambiental (desassoreamento) ao licenciamento, os entrevistados da CETESB comentam que "há necessidade de aferição desses ganhos ambientais por meio de indicadores de qualidade que não estão disponíveis atualmente. O que parece ser positivo, como o desassoreamento do rio, pode estar causando impactos ambientais que só podem ser visualizados a partir de estudos 
mais aprofundados”. Acreditam que o licenciamento é fundamental para a identificação das fontes de poluição e observação de adensamentos de empreendimentos de mineração. É um mecanismo que atenta a percepção do empreendedor de que há um órgão responsável pelo meio ambiente e que existem restrições ambientais a serem consideradas. Entretanto, como relatado, “ocorrem casos de empreendimentos que não são cobrados pelos impactos que causam e isso é resultado da forma como são atribuídas as atividades da CETESB e do DEPRN; às vezes nenhum dos dois atua”.

A visão dos funcionários do DNPM foi semelhante aos da CETESB. Dois entrevistados afirmaram as contribuições ambientais, enquanto outro relatou parcialidade nessas contribuições (Tabela 29). Apesar disso, as contribuições mais importantes apresentadas pelo DNPM diferem das argumentações apresentadas pela CETESB (Tabela 30).

Segundo relato dos entrevistados do DNPM, que se refere à parcialidade do licenciamento quanto às contribuições ambientais, esse mecanismo traz "poucas contribuições, destacando-se o desassoreamento em pontos críticos do rio que estão sujeitos à deposição de sedimentos arenosos”. Nesse caso, comentam da necessidade de avaliação de outros impactos, argumentando que "em geral a atividade de extração de areia em leito de rio provoca impactos ambientais ainda não mensurados no processo de licenciamento ambiental, como por exemplo, o desbarrancamento das margens dos rios".

O DEPRN e o DAEE foram unânimes quanto às contribuições ambientais do licenciamento (Tabela 29). Ambos colocaram o desassoremanto como importante argumento dessa afirmação. Entretanto, o DEPRN ainda argumenta que outras contribuições seriam a disciplina da atividade e o reflorestamento da margem dos rios (Tabela 30).

Os relatos obtidos da Polícia Ambiental foram contrabalançados, dois entrevistados afirmam essas contribuições, enquanto outros dois acreditam que essas são parciais (Tabela 29). O desassoremanto foi considerado a contribuição mais importante que o licenciamento traz ao ambiente (Tabela 30). Os entrevistados da Polícia Ambiental argumentaram a respeito da carência de estudos com relação a outros impactos da 
extração de areia em leito de rio, como por exemplo, "os que ocorrem com a ictiofauna local”, uma vez que "toda e qualquer ação humana em ambientes naturais traz algum prejuízo para o habitat local”.

Segundo os órgãos entrevistados, o principal argumento que justifica a demora na obtenção das licenças ambientais necessárias para a implantação dos portos de areia, foi a carência de recursos humanos. Outros argumentos foram a dificuldade dos mineradores no cumprimento das exigências feitas pelos órgãos (33\%) e os entraves burocráticos ocorrentes durante o processo de licenciamento (20\%). Apenas o DAEE não citou a carência de recursos, atribuindo a demora exclusivamente à complexidade e escassez de tempo para análise dos licenciamentos (Tabela 31).

Tabela 31. Principais causas da demora na obtenção das licenças ambientais necessárias para a implantação dos portos de areia. Informações obtidas em entrevistas com os funcionários

\section{Razões da demora do licenciamento}

Ocorrência

CETESB DEPRN DNPM DAEE Pol. Amb. Global

Carência de recursos humanos

$\begin{array}{llllll}2 & 1 & 1 & - & 2 & 6(40 \%)\end{array}$

Dificuldades do minerador no cumprimento das

exigências dos órgãos

Entraves burocráticos

Não respondeu

Fragilidade no sistema de emissão de títulos minerários no DNPM

Complexidade de análise dos processos de licenciamento

Carência de recursos materiais

Pouca integração entre os órgãos

Falta de instrumentos adequados à avaliação dos impactos

Legislação ambiental restritiva

Normas e técnicas mal definidas

\begin{tabular}{llllll}
1 & 2 & - & - & 2 & $5(33 \%)$ \\
1 & - & - & - & 2 & $3(20 \%)$ \\
- & - & 2 & - & 1 & $3(20 \%)$ \\
2 & - & - & - & - & $2(13 \%)$ \\
1 & - & - & 1 & - & $2(13 \%)$ \\
1 & - & - & - & 1 & $2(13 \%)$ \\
2 & - & - & - & - & $2(13 \%)$ \\
1 & - & - & - & - & $1(7 \%)$ \\
- & - & 1 & - & - & $1(7 \%)$ \\
- & - & 1 & - & - & $1(7 \%)$ \\
\hline
\end{tabular}

A CETESB, apesar de relatar a carência de recursos humanos e a pouca integração entre os órgãos responsáveis, foi o único órgão que atribuiu a demora às dificuldades de outros órgãos, como por exemplo, a fragilidade no sistema de emissão de 
títulos minerários por parte do DNPM e a carência de recursos humanos no DEPRN (Tabela 32). Atribui a demora a um sistema obsoleto do DNPM “que atualmente passa por momento de readequação dos procedimentos para emissão de títulos minerários, mas que ainda permite equívocos do sistema como a reserva de autorizações de lavra por muitos anos e a sobreposição de áreas de mineração".

Segundo a CETESB, a interdependência entre os órgãos em níveis federal, estadual e municipal, no processo de licenciamento, tem início na documentação expedida pelo DNPM e qualquer demora na expedição de um parecer, em qualquer um dos órgãos envolvidos, acarreta demora no licenciamento.

Apesar das dificuldades do minerador no cumprimento das exigências dos órgãos não ser uma das razões preponderantes da CETESB na demora do licenciamento, esse órgão comenta que “os mineradores, por serem mal assessorados, dão entrada no licenciamento com documentação incompleta”.

O DEPRN e a Polícia Ambiental atribuíram a demora no licenciamento à dificuldade dos mineradores, no que tange a falta de instruções, para o cumprimento das exigências feitas pelos órgãos. Outro argumento apresentado pela Polícia Ambiental foi o entrave burocrático durante o processo de licenciamento.

O DNPM foi o único órgão que se manifestou a respeito de restrições legais e normas mal definidas como as causas da demora na obtenção das licenças ambientais necessárias para a implantação dos portos de areia. Muitos dos entrevistados preferiram não responder a essa questão, “passando a questão aos técnicos ambientais”.

Os resultados dessas entrevistas evidenciam que, dentro das atribuições dos órgãos no licenciamento, a maior dificuldade está no monitoramento dos empreendimentos. Essa dificuldade decorre de diversos fatores, entre eles, as carências de recurso humano, de planejamento das fiscalizações, de interações entre os órgãos e de estudos ambientais mais rigorosos. 


\section{CONCLUSÕES}

Os projetos de recuperação por reflorestamento não são satisfatoriamente cumpridos pelos empreendedores. Grande parte dos plantios efetivados não segue a dimensão em área, a densidade, o espaçamento e a diversidade florística propostos nos projetos outrora aprovados pelos órgãos competentes.

Além disso, esses projetos, se fossem implementados, não seriam, na sua maioria, satisfatórios na reabilitação das áreas de APP, por não garantirem a manutenção da biodiversidade natural das matas ciliares.

Ficou evidenciada uma situação preocupante com relação a perda da biodiversidade, uma vez que a maioria dos plantios e projetos de reflorestamento possui alta similaridade florística e baixa diversidade em espécies. Se aplicada a premissa da Resolução SMA 21/2001, 63\% dos plantios e 43\% dos projetos não cumpriram com o número mínimo de espécies proposto. Em média, foram empregadas 25 espécies nos plantios e 31 espécies nos projetos. Tanto os projetos como os plantios apresentaram tendência à homogeneidade florística, ao contrário do verificado em áreas naturais, em que ocorre alta riqueza em espécies. Além disso, mais da metade dos projetos apresentavam listagem florística idêntica a de algum outro projeto, o que demonstrou pouca preocupação com as particularidades locais.

Chama a atenção o insucesso dos plantios efetivados. Grande parte deles apresentou alta mortalidade, baixa densidade, baixa cobertura do solo por sombreamento da copa, fisionomia florestal sem estrutura vertical bem definida, serapilheira ausente ou escassa e regeneração ausente ou de baixas quantidade e qualidade. 
Esse insucesso pode ser atribuído a falta de instruções técnicas adequadas à condição de solos que já eram degradados, ou no mínimo perturbados antes mesmo da mineração. Além de ser atribuído a manutenção inadequada das áreas de plantio que sofrem freqüentemente com injúrias por corte ou pela presença de gado nas APPs em recuperação.

A avaliação final dos plantios indicou que mais da metade são classificados como ruins, 38\% classificados como regulares e apenas $10 \%$ como bom e ótimo. Esses resultados indicam que as APPs reflorestadas não estão cumprindo com sua função esperada na proteção física do corpo d’água, mesmo porque o uso e a cobertura predominantemente agrícola da Bacia do Rio Corumbataí comprometem essa função de proteção física esperada.

Além disso, esses resultados mostram que os reflorestamentos não estão cumprindo também com sua função de proteção biológica, pois deveriam, possuir um mínimo de diversidade florística para que, com o processo de sucessão, os componentes e as interações ecológicas do ecossistema fossem restabelecidos.

Com isso, pode-se dizer que os atuais instrumentos legais do licenciamento ambiental dos portos de areia não contribuem para a recuperação das Áreas de Preservação Permanente (APP)da Bacia do Rio Corumbataí. Na maioria das vezes, as formas de reflorestamento utilizadas não atendem aos critérios mínimos para o restabelecimento da estrutura e da função de uma floresta. Contudo, o licenciamento ambiental da atividade parece estar contribuindo com a conservação das matas naturais ainda existentes na bacia, em função da atual política ambiental de não desmatamento de novas matas em APP.

Com exceção do DAEE, todos os órgãos envolvidos apresentam alguma dificuldade na atribuição de suas funções dentro do licenciamento. Essas dificuldades residem principalmente da carência de recurso humano, além de carência de recursos financeiros (DNPM e DEPRN) e de material (CETESB, DNPM e Polícia Ambiental). Reside também, em grande parte, das condições, ainda insuficientes, de preparo dos 
técnicos, embora a maioria tente sanar essa carência com a participação e a qualificação em cursos, estágios, reuniões internas e outros eventos.

Os resultados evidenciam que, dentro das atribuições dos órgãos no licenciamento, a maior dificuldade dos órgãos não está na análise dos projetos de recuperação e de instalação dos empreendimentos, mas sim no monitoramento de seus cumprimentos. Isso decorre de diversos fatores, entre eles, as carências de recurso humano, de planejamento das fiscalizações, de interações entre os órgãos e de estudos ambientais mais rigorosos.

As irregularidades ambientais e legais dos portos de areia são função de uma soma de fatores, entre eles, a falta de informação e negligência dos empreendedores, a morosidade nos processos de licenciamentos ambiental e mineral, além dos elevados custos da regularização legal.

Embora muitos empreendedores possuam percepção ambiental a respeito da importância das matas ciliares e de sua recuperação, existe reconhecidamente uma carência de informações a respeito das questões ambientais. Essa carência é função da transferência da responsabilidade desse conhecimento às empresas terceirizadas, contratadas para a administração legal e consultoria ambiental de seus empreendimentos.

Existem casos de negligência em relação às irregularidades ambientais, principalmente em relação ao sucesso dos plantios. Essa situação é fortalecida pela ineficiente fiscalização dos órgãos ambientais envolvidos e pelo custo de implementação dos plantios.

Os longos períodos para obtenção das licenças ambientais (média de dois anos) e principalmente dos diplomas minerais (média de seis anos em regime de concessão de lavra) também influenciaram nas irregularidades.

As irregularidades também podem ser função da grande contradição existente entre o pequeno investimento financeiro para compra de equipamentos necessário à extração de areia e os altos custos necessários à regularização legal e ambiental da atividade. Além dos custos para obtenção das licenças ambientais junto à CETESB e dos 
diplomas minerais junto ao DNPM, as atividades legalmente regularizadas pagam uma série de encargos e tributos.

\subsection{Recomendações}

Todos os resultados apresentados reforçam a necessidade de maior integração entre os órgãos envolvidos na atividade para que os problemas de degradação sejam melhores observados.

Com relação ao aspecto cultural dos mineradores e dos operadores de máquina, a CETESB, o DEPRN ou até mesmo as Universidades, em parceria com o SINDAREIA, poderiam oferecer cursos de credenciamento, como uma carteira de habilitação junto ao sindicato. Não só as técnicas de dragagem fariam parte da grade desse curso, como principalmente a educação ambiental. Mostrando a importância da conservação das matas ciliares e das margens dos corpos d'água, bem como do reflorestamento das APPs, além de tratar de outros temas pertinentes a atividade.

Em razão dos resultados apresentados nesse trabalho a respeito da qualidade e da efetivação dos plantios nas APPs acordados durante a fase de licença do empreendimento, mostram-se necessárias mudanças no processo de renovação das licenças ambientais. A recomendação é para que, a cada três anos, no ato de renovação da licença ambiental junto a CETESB, seja realizada novas exigências por parte do DEPRN na verificação do atendimento aos projetos de plantios. Não sendo expedida nova licença sem que os projetos de plantio tenham sido efetivados.

A SMA 04/99 está sendo revista atualmente, aumentando as expectativas de que melhores mudanças sejam incorporadas ao licenciamento dessa atividade e de que esses resultados possam contribuir nesse sentido. 
ANEXOS 
Anexo A. Apresentação das empresas mineradoras de areia da Bacia do Rio Corumbataí, SP, ativas no Cadastro Mineiro do DNPM em junho de 2004. Municípios: Analândia (NA), Charqueada (CH), Corumbataí (CO), Ipeúna (IP) e Rio Claro (RC)

\begin{tabular}{|c|c|c|c|c|c|c|}
\hline \multirow[t]{2}{*}{ Empresas } & \multirow{2}{*}{ Município } & \multirow{2}{*}{$\begin{array}{l}\text { Tipo de } \\
\text { extração }\end{array}$} & \multicolumn{2}{|r|}{ DNPM } & \multicolumn{2}{|r|}{ Uso da areia } \\
\hline & & & Lavra (ha) & Tipo de pedido & Início & \\
\hline Antonelli Extração e Comércio de Minérios Ltda & $\mathrm{CH}$ & LEITO & 27,91 & Concessão de lavra & 1998 & Construção civil \\
\hline Areia para Construção Serra d'água & IP & LEITO & 1,68 & Licenciamento & 1998 & Construção civil \\
\hline Areia para Construção Serra d'água Ltda - ME & IP & CAVA & 41,11 & Autorização de Pesquisa & 1999 & Contrução civil \\
\hline Areialex Extração e Comércio de Minérios Ltda - ME & $\mathrm{CH}$ & LEITO & 7,52 & Licenciamento & 1992 & Construção civil \\
\hline Cleri Teresa Hildebrand Nascimento - ME & AN & CAVA & 171,5 & Concessão de lavra & 1990 & Fundição \\
\hline CRS - Mineração Industrial Ltda & AN & CAVA & 655 & Concessão de lavra & 1985 & Fundição \\
\hline Empresa de Mineração José Emanoel Ltda & RC & CAVA & 51,98 & Concessão de lavra & 1977 & Fundição \\
\hline Extração de Areia Perissoto & $\mathrm{CO}$ & LEITO & 0,71 & Licenciamento & 1986 & Construção civil \\
\hline Extração e Comércio de Areia Vale do Sol Ltda & $\mathrm{CO}$ & LEITO & 49,97 & Requerimento de lavra & 1987 & Construção civil \\
\hline Extração e Comércio de Areia Corimbatá Ltda - ME & $\mathrm{RC}$ & LEITO & 77,56 & Concessão de lavra & 1973 & Construção civil \\
\hline Ezequiel Covre - FI (Min. Ipeúna) & IP & LEITO & 35,7 & Licenciamento & 1979 & Construção civil \\
\hline Germano Riggi - ME & $\mathrm{CH}$ & CAVA & 49,7 & Autorização de Pesquisa & 1999 & Construção civil \\
\hline Guarazemini Mineração Ltda & $\mathrm{CO}$ & CAVA & 48,81 & Licenciamento & 1999 & Construção civil \\
\hline Itaçu Comércio e Mineração Ltda & $\mathrm{RC}$ & LEITO & 13,47 & Requerimento de lavra & 1999 & Construção civil \\
\hline Jandira Aparecida Foito Abondanza - ME & IP & LEITO/CAVA & 27,36 & Licenciamento & * & Construção civil \\
\hline José Edvaldo Tietz & $\mathrm{CH} / \mathrm{IP}$ & LEITO & 43,25 & Requerimento de lavra & 1996 & Construção civil \\
\hline José Edvaldo Tietz & $\mathrm{CH} / \mathrm{IP}$ & LEITO & 34,21 & Requerimento de lavra & 1996 & Construção civil \\
\hline M.T. - Mineração Ltda - ME & IP & LEITO & 18,85 & Licenciamento & 1999 & Construção civil \\
\hline Marciano Ceccato (II) & $\mathrm{CO}$ & LEITO & 17,12 & Autorização de Pesquisa & 2000 & Construção civil \\
\hline Marciano Ceccato (I) & RC & LEITO & 49,92 & Autorização de Pesquisa & 1994 & Areia industrial \\
\hline Maristel Decarli Zaccariotto - FI & $\mathrm{CO}$ & CAVA & 43,34 & Requerimento de lavra & 1992 & Areia Industrial \\
\hline Melotto \& Montibeller Extração e Comércio de Areia Ltda - ME & $\mathrm{CH}$ & LEITO & 41,68 & Licenciamento & 2000 & Construção civil \\
\hline Mineração Barrocão Ltda - ME & $\mathrm{AL}$ & CAVA & 9,91 & Licenciamento & 2000 & Construção civil \\
\hline Mineração do Vale Ltda & $\mathrm{CO}$ & CAVA & 46,79 & Requerimento de lavra & 1998 & Construção civil \\
\hline Mineração do Vale Ltda & $\mathrm{CO}$ & LEITO & 20,3 & Concessão de lavra & 1973 & Construção civil \\
\hline Mineração do Vale Ltda & $\mathrm{CO}$ & LEITO & 257 & Concessão de lavra & 1980 & Fundição \\
\hline Mineração Dois Irmãos & $\mathrm{RC}$ & LEITO & 91,25 & Concessão de lavra & 1982 & Fundição \\
\hline Mineração Ferraz Indústria e Comércio Ltda (Min. Andorinhas) & $\mathrm{CO}$ & LEITO & 93,51 & Concessão de lavra & 1973 & Fund. e Const. civil \\
\hline
\end{tabular}


Anexo A. Apresentação das empresas mineradoras de areia da Bacia do Rio Corumbataí, SP, ativas no Cadastro Mineiro do DNPM em junho de 2004. Municípios: Analândia (NA), Charqueada (CH), Corumbataí (CO), Ipeúna (IP) e Rio Claro (RC)

\begin{tabular}{lclllll}
\hline Empresas & \multirow{2}{*}{ Município } & $\begin{array}{l}\text { Tipo de } \\
\text { extração }\end{array}$ & Lavra (ha) & $\begin{array}{c}\text { DNPM } \\
\text { Tipo de pedido }\end{array}$ & \multicolumn{2}{c}{ Uso da areia } \\
\hline Mineração Mandu Industria e Comércio Ltda & RC & CAVA & 32,63 & Concessão de lavra & 1981 & Fundição \\
Nelson Bolani - FI & CH & LEITO & 4,46 & Licenciamento & 1998 & Construção civil \\
Passa Cinco - Extração e Comércio de Minérios Ltda & IP & LEITO & 25 & Licenciamento & 1998 & Construção civil \\
Pedro Amstalden & CH & LEITO & 41,37 & Concessão de lavra & 1976 & Fund. e Const. civil \\
Tietz Extração e Comércio de Minérios Ltda & CH & LEITO & 23,9 & Licenciamento & 1998 & Construção civil \\
Vermac Comercial Ltda & CH & LEITO & 1,22 & Licenciamento & 1990 & Construção civil \\
\hline
\end{tabular}


Anexo B. Matriz de Similaridade de Jaccard entre uma área natural (Bertani et al., 2001) e 19 áreas de plantios dos portos de areia de leito de rio da Bacia do Rio Corumbataí, SP

\begin{tabular}{|c|c|c|c|c|c|c|c|c|c|c|c|c|c|c|c|c|c|c|c|c|}
\hline & 1 & 2 & 3 & 4 & 5 & 6 & 7 & 8 & 9 & 10 & 11 & 12 & 13 & 14 & 15 & 16 & 17 & 18 & 19 & Nat. \\
\hline 1 & 1,00 & & & & & & & & & & & & & & & & & & & \\
\hline 2 & 0,00 & 1,00 & & & & & & & & & & & & & & & & & & \\
\hline 3 & 0,00 & 0,31 & 1,00 & & & & & & & & & & & & & & & & & \\
\hline 4 & 0,00 & 0,18 & 0,14 & 1,00 & & & & & & & & & & & & & & & & \\
\hline 5 & 0,00 & 0,16 & 0,24 & 0,39 & 1,00 & & & & & & & & & & & & & & & \\
\hline 6 & 0,00 & 0,24 & 0,23 & 0,26 & 0,27 & 1,00 & & & & & & & & & & & & & & \\
\hline 7 & 0,00 & 0,11 & 0,13 & 0,14 & 0,19 & 0,09 & 1,00 & & & & & & & & & & & & & \\
\hline 8 & 0,00 & 0,07 & 0,06 & 0,11 & 0,10 & 0,11 & 0,12 & 1,00 & & & & & & & & & & & & \\
\hline 9 & 0,00 & 0,16 & 0,18 & 0,20 & 0,22 & 0,24 & 0,11 & 0,14 & 1,00 & & & & & & & & & & & \\
\hline 10 & 0,00 & 0,07 & 0,10 & 0,18 & 0,15 & 0,13 & 0,13 & 0,13 & 0,25 & 1,00 & & & & & & & & & & \\
\hline 11 & 0,00 & 0,18 & 0,20 & 0,36 & 0,24 & 0,24 & 0,15 & 0,11 & 0,21 & 0,12 & 1,00 & & & & & & & & & \\
\hline 12 & 0,00 & 0,11 & 0,14 & 0,17 & 0,18 & 0,18 & 0,13 & 0,04 & 0,18 & 0,25 & 0,15 & 1,00 & & & & & & & & \\
\hline 13 & 0,00 & 0,16 & 0,19 & 0,19 & 0,16 & 0,27 & 0,08 & 0,13 & 0,14 & 0,13 & 0,22 & 0,11 & 1,00 & & & & & & & \\
\hline 14 & 0,00 & 0,16 & 0,24 & 0,33 & 0,28 & 0,27 & 0,18 & 0,09 & 0,18 & 0,18 & 0,26 & 0,17 & 0,27 & 1,00 & & & & & & \\
\hline 15 & 0,00 & 0,16 & 0,24 & 0,24 & 0,26 & 0,20 & 0,20 & 0,15 & 0,19 & 0,16 & 0,19 & 0,27 & 0,21 & 0,26 & 1,00 & & & & & \\
\hline 16 & 0,00 & 0,21 & 0,25 & 0,20 & 0,24 & 0,32 & 0,11 & 0,11 & 0,24 & 0,14 & 0,22 & 0,14 & 0,29 & 0,34 & 0,19 & 1,00 & & & & \\
\hline 17 & 0,00 & 0,18 & 0,20 & 0,34 & 0,28 & 0,23 & 0,22 & 0,13 & 0,21 & 0,14 & 0,29 & 0,28 & 0,24 & 0,27 & 0,36 & 0,25 & 1,00 & & & \\
\hline 18 & 0,00 & 0,26 & 0,27 & 0,38 & 0,29 & 0,24 & 0,18 & 0,11 & 0,29 & 0,18 & 0,53 & 0,14 & 0,19 & 0,28 & 0,24 & 0,26 & 0,31 & 1,00 & & \\
\hline 19 & 0,00 & 0,13 & 0,15 & 0,07 & 0,09 & 0,14 & 0,05 & 0,10 & 0,13 & 0,24 & 0,10 & 0,07 & 0,14 & 0,14 & 0,13 & 0,17 & 0,09 & 0,10 & 1,00 & \\
\hline Nat. & 0,00 & 0,05 & 0,06 & 0,04 & 0,02 & 0,1 & 0,01 & 0,02 & 0,04 & 0,01 & 0,04 & 0,02 & 0,07 & 0,07 & 0,02 & 0,06 & 0,02 & 0,05 & 0,03 & 1,00 \\
\hline
\end{tabular}


Anexo C. Matriz de Similaridade de Jaccard entre uma área natural (Bertani et al., 2001) e 23 projetos de plantios dos portos de areia de leito de rio da Bacia do Rio Corumbataí, SP

\begin{tabular}{|c|c|c|c|c|c|c|c|c|c|c|c|c|c|c|c|c|c|c|c|c|c|c|c|c|}
\hline & 1 & 2 & 3 & 4 & 5 & 6 & 7 & 8 & 9 & 10 & 11 & 12 & 13 & 14 & 15 & 16 & 17 & 18 & 19 & 20 & 21 & 22 & 23 & Nat. \\
\hline 1 & \begin{tabular}{|l|}
1,00 \\
\end{tabular} & & & & & & & & & & & & & & & & & & & & & & & \\
\hline 2 & 0,08 & 1,00 & & & & & & & & & & & & & & & & & & & & & & \\
\hline 3 & 0,08 & 1,00 & 1,00 & & & & & & & & & & & & & & & & & & & & & \\
\hline 4 & 0,10 & 0,13 & 0,13 & 1,00 & & & & & & & & & & & & & & & & & & & & \\
\hline 5 & 0,10 & 0,13 & 0,13 & 1,00 & 1,00 & & & & & & & & & & & & & & & & & & & \\
\hline 6 & 0,06 & 0,71 & 0,71 & 0,40 & 0,40 & 1,00 & & & & & & & & & & & & & & & & & & \\
\hline 7 & 0,09 & 0,89 & 0,89 & 0,14 & 0,14 & 0,66 & 1,00 & & & & & & & & & & & & & & & & & \\
\hline 8 & 0,09 & 0,89 & 0,89 & 0,14 & 0,14 & 0,66 & 1,00 & 1,00 & & & & & & & & & & & & & & & & \\
\hline 9 & 0,00 & 0,02 & 0,02 & 0,16 & 0,16 & 0,10 & 0,02 & 0,02 & 1,00 & & & & & & & & & & & & & & & \\
\hline 10 & 0,09 & 0,17 & 0,17 & 0,11 & 0,11 & 0,19 & 0,18 & 0,18 & 0,05 & 1,00 & & & & & & & & & & & & & & \\
\hline 11 & 0,04 & 0,20 & 0,20 & 0,12 & 0,12 & 0,23 & 0,20 & 0,20 & 0,03 & 0,11 & 1,00 & & & & & & & & & & & & & \\
\hline 12 & 0,13 & 0,14 & 0,14 & 0,10 & 0,10 & 0,11 & 0,16 & 0,16 & 0,00 & 0,17 & 0,11 & 1,00 & & & & & & & & & & & & \\
\hline 13 & 0,04 & 0,20 & 0,20 & 0,11 & 0,11 & 0,23 & 0,19 & 0,19 & 0,03 & 0,11 & 0,98 & 0,11 & 1,00 & & & & & & & & & & & \\
\hline 14 & 0,02 & 0,15 & 0,15 & 0,14 & 0,14 & 0,21 & 0,13 & 0,13 & 0,09 & 0,08 & 0,13 & 0,05 & 0,13 & 1,00 & & & & & & & & & & \\
\hline 15 & 0,08 & 0,18 & 0,18 & 0,13 & 0,13 & 0,16 & 0,20 & 0,20 & 0,08 & 0,10 & 0,09 & 0,12 & 0,09 & 0,10 & 1,00 & & & & & & & & & \\
\hline 16 & 0,05 & 0,34 & 0,34 & 0,15 & 0,15 & 0,37 & 0,32 & 0,32 & 0,09 & 0,16 & 0,20 & 0,13 & 0,20 & 0,22 & 0,19 & 1,00 & & & & & & & & \\
\hline 17 & 0,04 & 0,20 & 0,20 & 0,12 & 0,12 & 0,23 & 0,20 & 0,20 & 0,03 & 0,11 & 1,00 & 0,11 & 0,98 & 0,13 & 0,09 & 0,20 & 1,00 & & & & & & & \\
\hline 18 & 0,09 & 0,17 & 0,17 & 0,11 & 0,11 & 0,19 & 0,18 & 0,18 & 0,05 & 1,00 & 0,11 & 0,17 & 0,11 & 0,08 & 0,10 & 0,16 & 0,11 & 1,00 & & & & & & \\
\hline 19 & 0,06 & 0,06 & 0,06 & 0,03 & 0,03 & 0,05 & 0,07 & 0,07 & 0,03 & 0,06 & 0,03 & 0,08 & 0,03 & 0,00 & 0,05 & 0,04 & 0,03 & 0,06 & 1,00 & & & & & \\
\hline 20 & 0,04 & 0,19 & 0,19 & 0,10 & 0,10 & 0,22 & 0,18 & 0,18 & 0,03 & 0,11 & 0,94 & 0,11 & 0,96 & 0,12 & 0,09 & 0,19 & 0,94 & 0,11 & 0,03 & 1,00 & & & & \\
\hline 21 & 0,06 & 0,23 & 0,23 & 0,14 & 0,14 & 0,24 & 0,22 & 0,22 & 0,09 & 0,16 & 0,24 & 0,08 & 0,23 & 0,19 & 0,15 & 0,31 & 0,24 & 0,16 & 0,05 & 0,22 & 1,00 & & & \\
\hline 22 & 0,07 & 0,31 & 0,31 & 0,13 & 0,13 & 0,29 & 0,30 & 0,30 & 0,09 & 0,19 & 0,18 & 0,15 & 0,20 & 0,21 & 0,18 & 0,36 & 0,18 & 0,19 & 0,04 & 0,19 & 0,26 & 1,00 & & \\
\hline 23 & 0,08 & 0,18 & 0,18 & 0,13 & 0,13 & 0,16 & 0,20 & 0,20 & 0,08 & 0,10 & 0,09 & 0,12 & 0,09 & 0,10 & 1,00 & 0,19 & 0,09 & 0,10 & 0,05 & 0,09 & 0,15 & 0,18 & 1,00 & \\
\hline Nat. & 0,01 & 0,12 & 0,11 & 0,02 & 0,02 & 0,12 & 0,12 & 0,12 & 0,02 & 0,06 & 0,13 & 0,01 & 0,13 & 0,10 & 0,06 & 0,15 & 0,12 & 0,04 & 0,03 & 0,13 & 0,11 & 0,11 & 0,06 & 1,00 \\
\hline
\end{tabular}


Anexo D. Integridade física das margens dos corpos d’água de portos de areia da Bacia do Rio Corumbataí. Classificação da integridade física como boa (A), regular (B) e crítica (C)
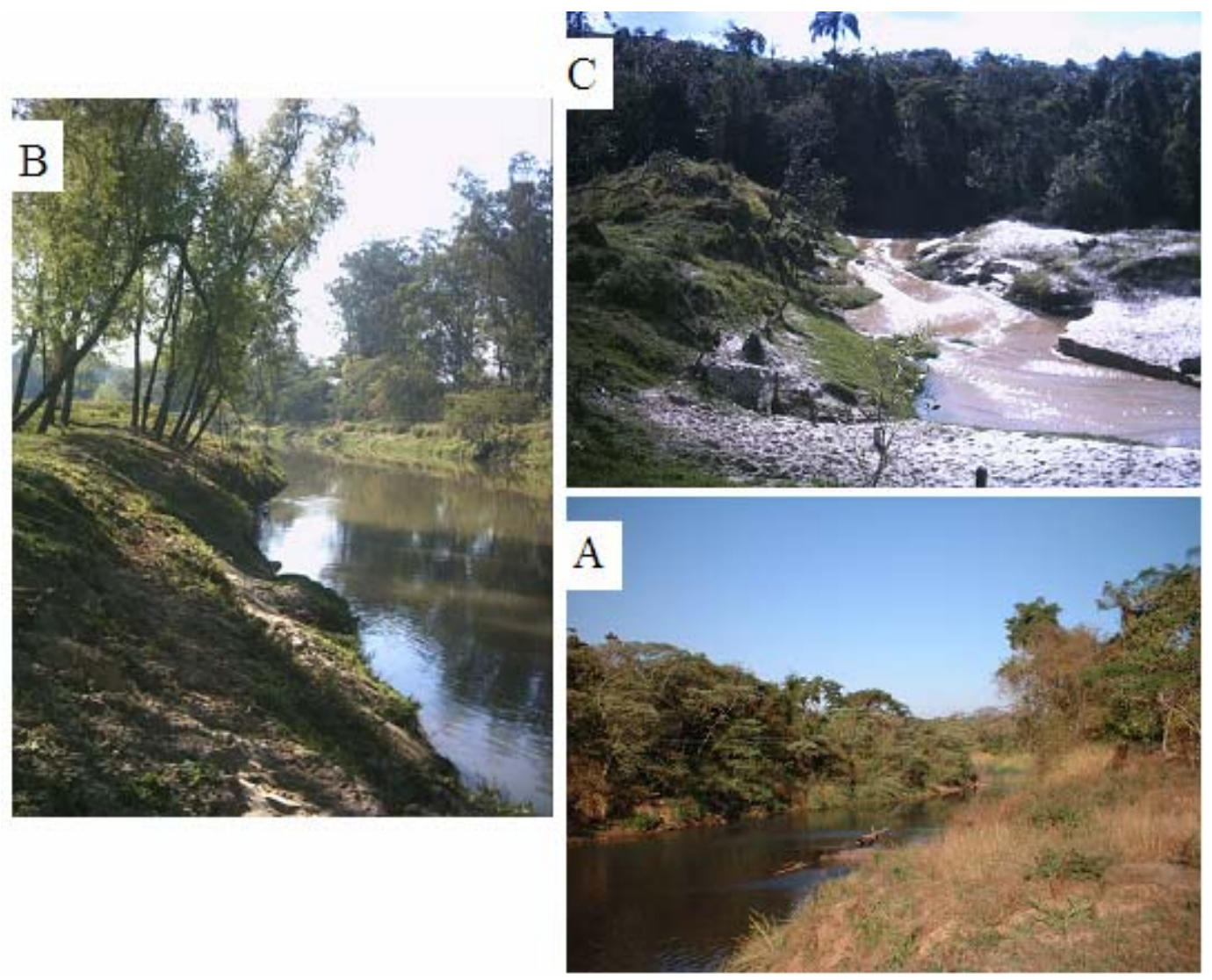
Anexo E. Desestabilização das margens (A) e conseqüente assoreamento (B) dos corpos d’água dos portos de areia da Bacia do Rio Corumbataí, resultantes da ausência de cobertura florestal (C) da dragagem das margens (D) e da elevação natural da vazão do rio
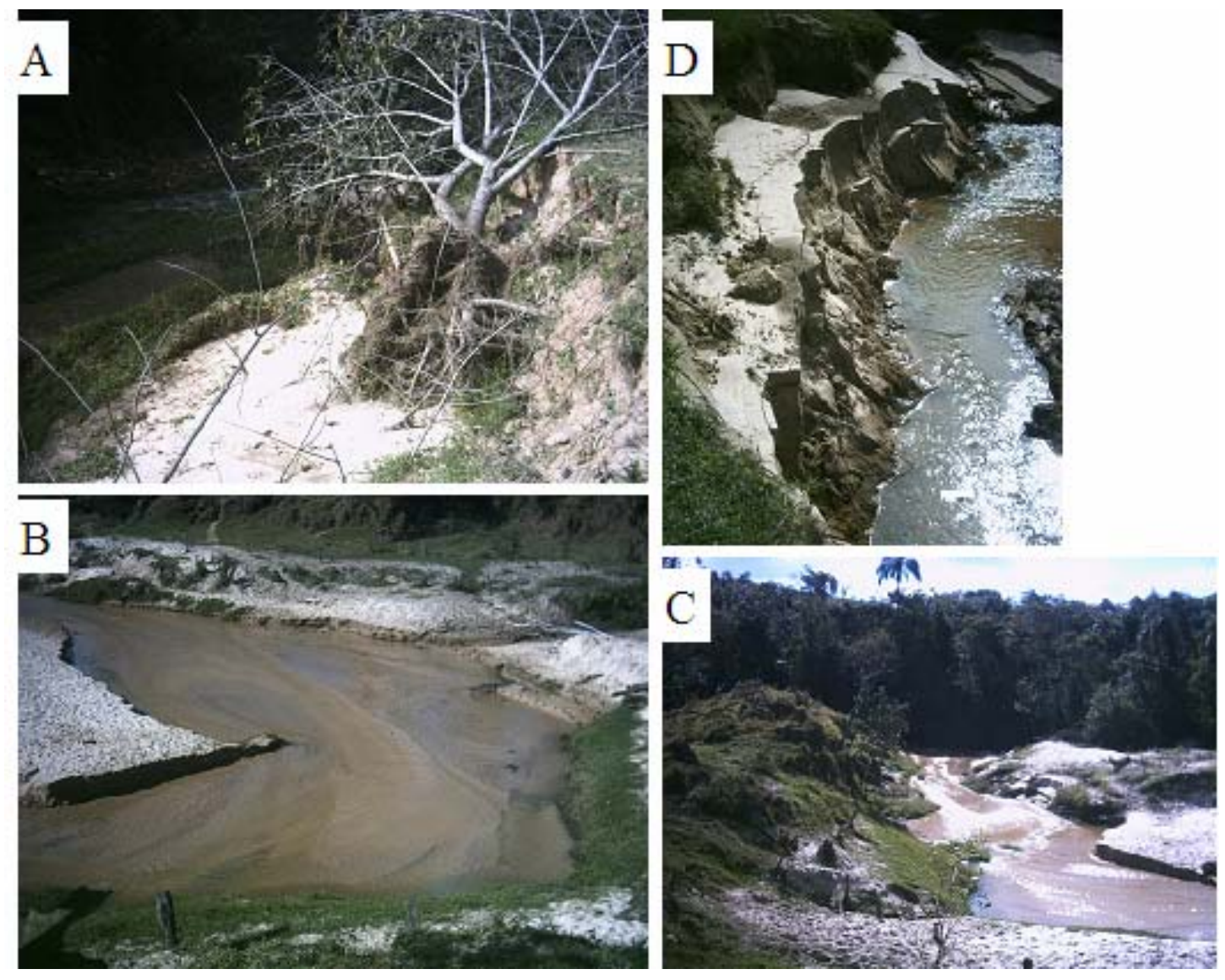
Anexo F. Matriz de diagnóstico e avaliação da recuperação das APPs de portos de areia da Bacia do Rio Corumbataí. Categorias de classificação: ótimo, bom, regular e ruim. * Plantios recentes

\begin{tabular}{|c|c|c|c|c|}
\hline Porto & Ruim & Regular & om & Ótimo \\
\hline | & $\mathrm{ND}(\mathrm{)}) \mathrm{OE}(\mathrm{X})$ & FF ( ) FI ( ) & \begin{tabular}{|l|l|}
$\mathrm{PE}(\mathrm{X})$ & $\mathrm{RI}(\mathrm{)}$ \\
\end{tabular} & $\mathrm{DF}(\mathrm{)}$ \\
\hline & $\mathrm{ND}(\mathrm{)}) \mathrm{OE}(\mathrm{X})$ & FF ( ) FI ( ) & \begin{tabular}{|l|l|}
$\mathrm{PE}()^{\prime}$ & $\mathrm{RI}(\mathrm{X})$ \\
\end{tabular} & DF ( ) \\
\hline ; & $\mathrm{ND}(\mathrm{O}) \mathrm{OE}(\mathrm{X})$ & FF ( ) FI ( ) & PE (X) RI ( ) & DF ( ) \\
\hline 4 & $\mathrm{ND}(\mathrm{)}) \mathrm{OE}(\mathrm{X})$ & FF ( ) FI (X) & \begin{tabular}{|l|l|}
$\mathrm{PE}()^{\prime}$ & $\mathrm{RI}(\mathrm{X})$ \\
\end{tabular} & DF ( ) \\
\hline 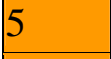 & $\mathrm{ND}(\mathrm{O}) \mathrm{OE}(\mathrm{X})$ & FF (X) FI ( ) & PE ( ) RI (X) & $\mathrm{DF}(\mathrm{)}$ \\
\hline p & $\mathrm{ND}(\mathrm{)} \mathrm{OE}(\mathrm{X})$ & FF ( ) FI (X) & \begin{tabular}{|l|l|} 
PE (X) & RI ( ) \\
\end{tabular} & DF ( ) \\
\hline & $\mathrm{ND}(\mathrm{)} \mathrm{OE}(\mathrm{X})$ & FF ( ) FI ( ) & \begin{tabular}{|l|l|} 
PE (X) & RI ( ) \\
\end{tabular} & DF ( ) \\
\hline & $\mathrm{ND}(\mathrm{)}) \mathrm{OE}(\mathrm{X})$ & FF ( ) FI ( ) & \begin{tabular}{|l|l|}
$\mathrm{PE}(\mathrm{X})$ & $\mathrm{RI}(\mathrm{)}$ \\
\end{tabular} & DF ( ) \\
\hline & $\mathrm{ND}(\mathrm{)}) \mathrm{OE}(\mathrm{X})$ & FF ( ) FI ( ) & \begin{tabular}{|l|l|}
$\mathrm{PE}(\mathrm{X})$ & $\mathrm{RI}(\mathrm{)}$ \\
\end{tabular} & $\mathrm{DF}(\mathrm{)}$ \\
\hline 10 & $\mathrm{ND}(\mathrm{)}) \mathrm{OE}(\mathrm{X})$ & FF $(X)$ FI ( ) & \begin{tabular}{|l|l|}
$\mathrm{PE}(\mathrm{X})$ & $\mathrm{RI}(\mathrm{)}$ \\
\end{tabular} & DF ( ) \\
\hline $11^{*}$ & $\mathrm{ND}(\mathrm{O}) \mathrm{OE}(\mathrm{X})$ & FF ( ) FI (X) & $\operatorname{PE}($ ) $\mathrm{RI}(\mathbf{)}$ & $\mathrm{DF}(\mathbf{)}$ \\
\hline 2 & $\mathrm{ND}(\mathrm{)}) \mathrm{OE}(\mathrm{X})$ & FF $(X)$ FI ( ) & PE (X) RI (X) & $\mathrm{DF}(\mathrm{X})$ \\
\hline 13 & $\mathrm{ND}(\mathrm{)}) \mathrm{OE}(\mathrm{X})$ & FF (X) FI (X) & \begin{tabular}{|l|l}
$\mathrm{PE}(\mathrm{X})$ & $\mathrm{RI}(\mathrm{X})$ \\
\end{tabular} & DF (X) \\
\hline 14 & $\mathrm{ND}(\mathrm{)}) \mathrm{OE}(\mathrm{X})$ & FF (X) FI (X) & PE ( ) RI (X) & DF ( ) \\
\hline 5 & $\mathrm{ND}(\mathrm{)}) \mathrm{OE}(\mathrm{X})$ & FF ( ) FI ( ) & PE ( ) $\mathrm{RI}($ ( ) & $\mathrm{DF}(\quad)$ \\
\hline 16 & $\mathrm{ND}(\mathrm{)} \mathrm{OE}(\mathrm{X})$ & FF (X) FI ( ) & PE ( ) RI (X) & DF ( ) \\
\hline 17 & $\mathrm{ND}(\mathrm{)}) \mathrm{OE}(\mathrm{X})$ & FF ( ) FI ( ) & PE ( ) $\operatorname{RI~(~)~}$ & DF ( ) \\
\hline 8* & $\mathrm{ND}(\mathrm{)} \mathrm{OE}(\mathrm{X})$ & FF ( ) FI (X) & PE ( ) $\mathrm{RI}($ ) & DF ( ) \\
\hline 9 & $\mathrm{ND}(\mathrm{)} \mathrm{OE}(\mathrm{X})$ & FF ( ) FI ( ) & PE (X) RI ( ) & DF ( ) \\
\hline 0 & $\mathrm{ND}(\mathrm{X}) \mathrm{OE}(\mathrm{)}$ & FF ( ) FI ( ) & PE ( ) $\mathrm{RI}($ ( ) & DF ( ) \\
\hline 1 & $\mathrm{ND}(\mathrm{X}) \mathrm{OE}(\mathrm{)}$ & FF ( ) FI ( ) & \begin{tabular}{l|l}
$\mathrm{PE}(\mathrm{X})$ & $\mathrm{RI}()$ \\
\end{tabular} & DF ( ) \\
\hline
\end{tabular}

ND (Nada) = Ausência de plantio;

OE (Ocupação do espaço) = Plantio implantado;

PE $($ Proteção do entorno $)=$ Presença de florestas naturais ou artificiais próximas ao plantio;

FF $($ Fisionomia florestal $)=$ Ocorrência de estratos na vegetação e presença de serapilheira;

FI (Florística implantada) = Implantação do número mínimo de espécies previstas pelas Resoluções SMA 21/2001 e 47/2003;

RI (Regeneração interna) = Presença de diásporos e indivíduos regenerantes;

DF $($ Dinâmica florestal $)=$ Presença de clareiras naturais e regeneração interna. 


\section{REFERÊNCIAS BIBLIOGRÁFICAS}

AB'SABER, A.N. O suporte geoecológico das florestas beiradeiras (Ciliares). In: RODRIGUES, R.R.; LEITÃO FILHO, H.F. (Ed.). Matas ciliares: conservação e recuperação. São Paulo: EDUSP; FAPESP, 2000. p.15-31.

AKIMOTO, H. Desafios da mineração de areia no Estado de São Paulo. Areia \& Brita, p.27-30, jan./ fev./mar. 2001.

ALMEIDA, R.O.P.O. Revegetação de áreas mineradas: estudo dos procedimentos aplicados em mineração de areia. São Paulo, 2002. 160p. Dissertação (Mestrado) Escola Politécnica, Universidade de São Paulo.

ANDERSEN, A.N. Ants as indicators of restoration success: relationship with soil microbial biomass in the Australian seasonal tropics. Restoration Ecology, v.5, n.2, p.109-114, 1997.

BACCI, D.L.C. Extração de areia na Bacia do Rio Corumbataí (SP). Rio Claro, 1994. 115p. Dissertação (Mestrado) - Instituto de Geociência e Ciências Exatas, Universidade Estadual Paulista “Julio de Mesquita Filho”.

BARBERI, A.; CARNEIRO. M.A.C.; MOREIRA, F.M.S.; SIQUEIRA, J.O. Nodulação em leguminosas florestais em viveiros no sul de Minas Gerais. Cerne, v.4, n.1, p.145-153, 1998. 
BARBOSA, L.M. Considerações gerais em modelos de recuperação de formações ciliares. In: RODRIGUES, R.R.; LEITÃO FILHO, H.F. (Ed.). Matas ciliares: conservação e recuperação. São Paulo: EDUSP; FAPESP, 2000. p.289-312.

BARBOSA, L.M.; MARTINS, S.E. Espécies arbóreas nativas: indicação por região e ecossistema do Estado de São Paulo. São Paulo: Instituto de Botânica. http://www.ibot.sp.gov.br/especie_arborea/especies_arboreas.htm (11 jan. 2005).

BARBOSA, L.M.; POTOMATI, A. A situação atual da recuperação de áreas degradadas no Estado de São Paulo e a importância da Resolução SMA 21 de 21/11/2001. In: BARBOSA, L.M.; POTOMATI; A. (Org.). Manual prático para recuperação de áreas degradadas e Anais do Seminário regional sobre recuperação de áreas degradadas: conservação e manejo de formações florestais litorâneas. Ilha Comprida: Secretaria do Meio Ambiente; Prefeitura de Ilha Comprida, 2003. p.31-32.

BARBOSA, L.M.; SANTOS JUNIOR, N.A. Princípios da recuperação vegetal de áreas degradadas. In: BARBOSA, L.M.; POTOMATI; A. (Org.). Manual prático para recuperação de áreas degradadas e Anais do Seminário regional sobre recuperação de áreas degradadas: conservação e manejo de formações florestais litorâneas. Ilha Comprida: Secretaria do Meio Ambiente; Prefeitura de Ilha Comprida, 2003. p.55-65. 
BARBOSA, L.M.; BARBOSA, J.M.; BARBOSA, K.C.; POTOMATI, A.; CARRASCO, P.G.; MARTINS, S.E.; ASPERTI, L.M. Como uma ação de política pública pode alterar os procedimentos sobre recuperação de áreas degradadas no Estado de São Paulo. In: BARBOSA, L.M.; POTAMATI, A. (Coord.). Manual prático para recuperação de áreas degradadas e Anais do Seminário regional sobre recuperação de áreas degradadas: conservação e manejo de formações florestais litorâneas. Ilha Comprida: Secretaria do Meio Ambiente; Prefeitura de Ilha Comprida, 2003. p.75-77.

BAUERMEISTER, K.H.; MACEDO, A.B.; LIOTTE, S.V. Produção para a região metropolitana de São Paulo. Brasil Mineral, n.152, p.20-24, 1997.

BEHLING, H.A. High resolution holocen pólen record from Lago do Pires, SE, Brazil: vegetation, climate and fire history. Journal of Paleolimnology, v.4, n.14, p.253268, 1995.

BELTRÃO, M.I. Exigências técnicas para aprovação de projetos de recuperação de áreas degradadas: efeitos da Resolução SMA 21, de 21/11/01 e perspectivas futuras. In: SEMINÁRIO TEMÁTICO SOBRE RECUPERAÇÃO DE ÁREAS DEGRADADAS, São Paulo, 2003. Anais. São Paulo: Instituto de Botânica, 2003. p.51-54.

BERNACCI, L.C.; LEITÃO FILHO, H.F. Flora fanerogâmica da floresta da Fazenda São Vicente, Campinas, SP. Revista Brasileira de Botânica, v.19, n.2, p.149-164, dez. 1996.

BERTANI, D.F.; RODRIGUES, R.R.; BATISTA, J.L.F.; SHEPHERD, G.J. Análise temporal da heterogeneidade florística e estrutural em uma floresta ribeirinha. Revista Brasileira de Botânica, v.24, n.1, p.11-23, mar. 2001. 
BERTONI, J.E.A.; MARTINS, F.R. Composição florística de uma floresta ripária na Reserva Estadual de Porto Ferreira, SP. Acta Botanica Brasílica, v.1, p.17-26, 1987.

BITAR, O.Y.; FORNASARI FILHO, N.; VASCONCELOS, M.M.T.; SILVA, W.S. A abordagem do meio físico nos estudos de recuperação ambiental de áreas de mineração de areia na região metropolitana de São Paulo. In: CONGRESSO BRASILEIRO DE GEOLOGIA E DE ENGENHARIA, 6., Salvador, 1990. Anais. Salvador: ABGE, 1990. p.251-260.

BITAR, O.Y. Avaliação da recuperação de áreas degradadas por mineração na região metropolitana de São Paulo. São Paulo, 1997. 161 p. Tese (Doutorado) - Escola Politécnica, Universidade de São Paulo.

BOTELHO, S.A.; DAVIDE, A.C.; PRADO, N.S.; FONSECA, E.M.B. Implantação de mata ciliar. Lavras: Editora UFLA, 1995. 28p.

BRANDT, W. Emaranhado legal dificulta a obtenção das licenças. Mineração \& Metalurgia, v.1, n.12, p.15-16, jan./fev. 2004.

BRAUN-BLANQUET, J.J. Plant sociology: the study of plant communities. Trad. de G.D. Fuller e H.S. Conrad. New York: McGraw-Hill, 1932. 451p.

BRIGANTE, J.; ESPÍNDOLA, E.L.G.; ELER, M.N. Análise dos principais impactos ambientais no Rio Mogi-Guaçu: recomendações para orientar políticas públicas. In: BRIGANTE, J.; ESPÍNDOLA, E.L.G. (Ed.). Limnologia fluvial: um estudo no Rio Mogi-Guaçu. São Carlos: RiMa, 2003a. p.203-242. 
BRIGANTE, J.; ESPÍNDOLA, E.L.G.; POVINELLI, J.; NOGUEIRA, A.M. Caracterização física, química e biológica da água do Rio Mogi-Guaçu. In: BRIGANTE, J.; ESPÍNDOLA, E.L.G. (Ed.). Limnologia fluvial: um estudo no Rio Mogi-Guaçu. São Carlos: RiMa, 2003b. p.55-76.

BRITO, C.M.S. Estudos exploratório da distribuição espacial dos fragmentos florestais da bacia hidrográfica do Rio Corumbataí, São Paulo. São Carlos, 2001. 79p. Dissertação (Mestrado) - Escola de Engenharia de São Carlos, Universidade de São Paulo.

BRUGNARO, C. Valor atribuído pela população às matas ciliares da Bacia do Rio Corumbataí, SP. Piracicaba, 2000. Tese (Doutorado) - Escola Superior de Agricultura Luiz de Queiroz, Universidade de São Paulo.

BRUMMIT, B.K.; POWELL, C.E. Authors of plants name. London: Royal Botanic Gardens Kew, 1992.

CAMARGO, J.C.G.; CESAR, A.A.; GENTIL, J.P.; PINTO, S.A.F.; TROPPMAIR, H. Estudo fitogeográfico da vegetação ciliar do Rio Corumbataí, SP. Série biogeografia, v.3, p.32-44, 1971.

CARPAMANEZZI, A.A.; COSTA, L.G.S.; KAGEYAMA, P.Y.; CASTRO, C.F.A. Funções múltiplas das florestas: conservação e recuperação do meio ambiente. In: CONGRESSO FLORESTAL BRASILEIRO, 6., Campos do Jordão, 1990. Anais. Campos do Jordão: SBS, 1990. p.216-217.

CARPI JUNIOR, S. Processos erosivos, recursos hídricos e riscos ambientais na bacia do rio Mogi-Guaçu. Rio Claro, 2001. 170p. Tese (Doutorado) - Instituto de Geociência e Ciências Exatas, Universidade Estadual Paulista “Julio de Mesquita Filho”. 
CENTRO INTEGRADO DE INFORMAÇÕES AGROMETEOROLÓGICAS. http://ciiagro.iac.sp.gov.br/dados/Relatorios/Listagens/DadosDiarios (12 fev. 2005).

COELHO, J.M. The mining of aggregates in the metropolitan region of São Paulo. International Institute for Environment and Development, n.121, p.1-11, Nov. 2001.

CONSEMA examina proposta de zoneamento do Vale do Paraíba. Areia \& Brita, n.6, p.26-27, jul./set. 1998.

CRONQUIST, A. The evolution and classification of flowering plants. New York: The New York Botanical Garden, 1988. 555p.

DAVIES, J.; MAZUMDER, A. Health and environmental policy issues in Canada: the role of watershed management in sustaining clean drinking water quality at surface sources. Journal of Environmental Management, v.68, n.3, p.273-286, Sep. 2003.

DIAS, L.E.; GRIFFITH, J.J. Conceituação e caracterização de áreas degradadas. In: DIAS, L.E.; MELLO, J.W.V. (Ed.). Recuperação de áreas degradadas. Viçosa: Editora Folha de Viçosa, 1998. p.1-8.

DIAS, E.G.C.S. Avaliação de impacto ambiental de projetos de mineração no Estado de São Paulo: a etapa de acompanhamento. São Paulo, 2001. 283p. Tese (Doutorado) - Escola Politécnica, Universidade de São Paulo.

DURIGAN, G.; LEITÃO FILHO, H.F. Florística e fitossociologia de matas ciliares do oeste paulista. Revista do Instituto Florestal, v.7, n.1, p.197-239, 1995. 
DURIGAN, G.; FIGLIOLIA, M.B.; KAWABATA, M.; GARRIDO, M.A.O.; BAITELLO, J.B. Sementes e mudas de árvores tropicais. 2.ed. São Paulo: Páginas \& Letras Editora e Gráfica, 2002. 65p.

DWIVEVI, O.P. Man and nature: an holistic aproach to a theory of ecology. Environmental Progress, v.10, p.8-15, 1988.

ESPÍNDOLA, E.L.G.; BRIGANTE, J.; ELER, M.N. Avaliação ambiental preliminar do uso e ocupação do solo da bacia hidrográfica do Rio Mogi-Guaçu. In: BRIGANTE, J.; ESPÍNDOLA, E.L.G. (Ed.). Limnologia fluvial: um estudo no Rio Mogi-Guaçu. São Carlos: RiMa, 2003. p.23-53.

EWEL, J.J. Litter fall and leaf decomposition in a tropical forest succession in eastern Guatemala. Journal of Ecology, v.64, p.293-308, 1976.

FELFILI, J.M. Floristic composition and phytosociology of the gallery forest alongside the Gama stream in Brasília, DF, Brazil. Revista Brasileira de Botânica, v.17, n.1, p.1-11, 1994.

FIGUEIRAS, T.S.; NOGUEIRA, P.E.; BROCHADO, A.L.; GUALA, I.I.G.F. Caminhamento - Um método expedito para levantamentos florístico qualitativo. Cadernos de Geociência, p.39-43, 1994.

FISHER, E.G. Proposição e aplicação de metodologia de gerenciamento integrado dos rios Corumbataí e Passa Cinco da bacia do Piracicaba por meio de banco de dados georeferenciados e modelagem matemática. Piracicaba, 2003. 110p. Tese (Doutorado) - Centro de Energia Nuclear na Agricultura, Universidade de São Paulo. 
FONSECA, R.C.B.; RODRIGUES, R.R. Análise estrutural e aspectos do mosaico sucessional de uma floresta semidecídua em Botucatu, SP. Scientia Forestalis, n.57, p.27-43, jun. 2000.

FOSBERG, F.R. A classification of vegetation for general purposes. Tropical Ecology, v.2, p.1-28, 1961.

FUNTOWICZ, S.; RAVETZ, J. Epistemología política: ciencia com la gente. Buenos Aires: Centro Editor da América Latina, 1993. 93p.

GANDOLFI, S.; LEITÃO FILHO, H.F.; BEZERRA, C.L.F. Levantamento florístico e caráter sucessional das espécies arbustivo-arbóreas de uma floresta mesófila semidecídua no município de Guarulhos, SP. Revista Brasileira de Biologia, v.55, n.4, p.753-767, 1995.

GANDOLFI, S. História natural de uma floresta estacional semidecidual no Município de Campinas (São Paulo, Brasil). Campinas, 2000. 520p. Tese (Doutorado) Instituto de Biologia, Universidade Estadual de Campinas.

GARCIA, L.B.R. Ocupação e desenvolvimento econômico da Bacia do Corumbataí - séculos XVIII a XX. http://www.ns.rc.unesp.br/igce/ceapla/atlas/atlas.swf (10 fev. 2005).

GODOY, A.L.P. Diagnósticos e prognósticos ambientais e aspectos legais de minerações de argila e areia inseridas nas Bacias Hidrográficas dos rios Mogi Guaçu e Pardo/SP. Rio Claro, 2002. 167p. Tese (Doutorado) - Instituto de Geociência e Ciências Exatas, Universidade Estadual Paulista “Julio de Mesquita Filho”. 
GOMES, J.C. Pluralismo metodológico en la producción y circulación del conocimiento agrario. Fundamentación epistemológica y aproximación empirica a casos del sur de Brasil. Córdoba, 1999. Tesis (Doctorado) - Universidad de Córdoba.

GRIFFITH, J.J.; WILLIAMS, D.F. Avaliação da recuperação de áreas mineradas no Brasil. Brasil Mineral, n.especial, p.60-72, out. 1989.

HERMANN, H. Política de aproveitamento de areia no Estado de São Paulo: dos conflitos existentes às compatibilizações possíveis. Rio de Janeiro: CETEM; CNPq, 1992. 186p.

INSTITUTO DE PESQUISA E ESTUDOS FLORESTAIS. Plano Diretor: conservação dos recursos hídricos por meio da recuperação e da conservação da cobertura florestal da Bacia do Rio Corumbataí. Piracicaba: IPEF; ESALQ; SEMAE, 2001. 301p.

IVANAUSKAS, N.M.; RODRIGUES, R.R.; NAVE, A.G. Fitossociologia de um trecho de floresta estacional semidecidual em Itatinga, São Paulo, Brasil. Scientia Forestalis, n.56, p.83-99, dez. 1999.

JANSEN, A. Terrestrial invertebrate community structure as an indication of the success of a tropical rainforest restoration project. Restoration Ecology, v.5, n.2, p.115-124, 1997.

JOLY, A.B. Botânica: introdução à taxonomia vegetal. São Paulo: Nacional, 1993. 777p.

JOLY, C.A. Flooding tolerance of some brazilian trees. Saint Andrews, 1982. Thesis (PhD) - University of Saint. Andrews. 
JOLY, C.A.; CRAWFORD, R.M.N. Variation in tolerance and metabolic responses to flooding in some tropical trees. Journal of Experimental Botany, v.33, p.799-809, 1982.

JOLY, C.A.; SPIGOLON, J.R.; LIEBERG, S.A.; SALIS, S.M.; AIDAR, M.P.M.; METZGER, J.P.W.; ZICKEL, C.S.; LOBO, P.C.; SHIMABUKURO, M.T.; MARQUES, M.C.N.; SALINO, A. Projeto Jacaré-Pepira: o desenvolvimento de um modelo de recomposição da mata ciliar com base na florística regional. In: RODRIGUES, R.R.; LEITÃO FILHO, H.F. (Ed.). Matas ciliares: conservação e recuperação. São Paulo: EDUSP; FAPESP, 2000. p.271-287.

KAGEYAMA, P.Y.; GANDARA, F.B. Recuperação de áreas ciliares. In: RODRIGUES, R.R.; LEITÃO FILHO, H.F. (Ed.). Matas ciliares: conservação e recuperação. São Paulo: EDUSP; FAPESP, 2000. p.249-269.

KAGEYAMA, P.Y.; CASTRO, C.F.A.; CARPANEZZI, A.A. Implantação de matas ciliares: estratégia para auxiliar a sucessão secundária. In: SIMPÓSIO SOBRE MATA CILIAR, Campinas, 1989. Anais. Campinas: Fundação Cargill, 1989. p.130- 143.

KAGEYAMA, P.Y.; GANDARA, F.B.; OLIVEIRA, R.E. Biodiversidade e restauração da floresta tropical. In: KAGEYAMA, P.Y.; OLIVEIRA, R.E.; MORAES, L.F.D. de; ENGEL, V.L.; GANDARA, F.B. (Org.). Restauração ecológica de ecossistemas naturais. Botucatu: FEPAF, 2003. p.29-48.

KOBIYAMA, M.; MINELLA, J.P.G; FABRIS, R. Áreas degradadas e sua recuperação. Informe Agropecuário, v.22, n.210, p.10-17, maio/jun. 2001.

KOFFLER, N.F. Uso das terras da bacia do rio Corumbataí em 1990. Geografia, v.18, n.1, p.135-150, abr. 1993. 
KOPEZINSKI, I. Mineração $\mathbf{x}$ meio ambiente: considerações legais, principais impactos ambientais e seus processos modificadores. Porto Alegre: Editora da UFRGS, 2000. 103p.

KOPEZINSKI, I; ZUQUETTE, L.V. Avaliação de áreas degradadas por mineração utilizando os procedimentos de mapeamento geotécnico. Geociências, v.17, n.1, p.209-228. 1998.

KÖPPEN, W.P. Climatologia: con un estudio de los climas de la tierra. México: Fondo de Cultura Economica, 1948. 478p.

KÜCHLER, A. Vegetation mapping. New York: Ronold Press, 1967. 472p.

LEITÃO FILHO, H.F. Aspectos taxonômicos da florestas do Estado de São Paulo. Silvicultura em São Paulo, v.16, n.1, p.197-206, 1982.

LEITÃO FILHO, H.F.; PAGANO, S.N.; CESAR, O.; TIMONI, J.L.; RUEDA, J.J. Ecologia da Mata Atlântica em Cubatão (SP). São Paulo: UNESP; UNICAMP, 1993. 184p.

LIEBERG, S.A.; JOLY, C.A. Inga affinis DC (Mimosaceae): germinação e tolerância de plântulas à submersão. Revista Brasileira de Botânica, v.16, p.175-179, 1993.

LIMA, W.P. Função hidrológica da mata ciliar. In: BARBOSA, L.M. (Coord.). Simpósio sobre mata ciliar. Campinas: Fundação Cargill, 1989. p.25-42, 1989.

LIMA, W.P.; ZAKIA, M.J.B. Indicadores hidrológicos em áreas florestais. Série técnica IPEF, v.12, n.31, p.53-64, abr. 1998. 
LIMA, W.P.; ZAKIA, M.J.B. Hidrologia de matas ciliares. In: RODRIGUES, R.R.; LEITÃO FILHO, H. de F. (Ed.). Matas ciliares: conservação e recuperação. São Paulo: EDUSP; FAPESP, 2000. p.33-44.

LIMA, W.P. Relações hidrológicas em matas ciliares. In: HENRY, R. (Org.). Ecótonos nas interfaces dos ecossistemas aquáticos. São Carlos: RiMa, 2003. p.293-300.

LOURENZO, J.S. Regeneração natural de uma área minerada de bauxita em Poços de Caldas, Minas Gerais. Viçosa, 1991. 151p. Dissertação (Mestrado) - Universidade Federal de Viçosa.

LUCHI, A.E. Anatomia do lenho de Croton urucurana Baill. (Euphorbiaceae) de solos com diferentes níveis de umidade. Revista Brasileira de Botânica, v.27, n.2, p.271-280, abr./jun. 2004.

MACHADO, P.A.L. Direito ambiental brasileiro. São Paulo: Editora Eletrônica, 2003. 1064p.

MAGURRAN, A.E. Ecological diversity and its measurement. Princenton: Princenton University Press, 1988.

MÄKINEN, H. Effect of stand density on radial growth of branches of scots pine in southern and central Finland. Canadian Journal of Forest Research, v.29, p.12161224, 1999.

MARTIN, K.; COKER, P. Vegetation description and analysis. London: Belhaven, 1992. 363p. 
MARTOS, H.L.; JUNIOR, M.G.; MARTOS, M.Y.H.G. Aspectos ambientais, técnicos, sócio-econômicos e legais na recuperação de áreas de degradadas por portos de areia na região de Sorocaba-SP. Revista do Instituto Florestal, v.4, n.3, p.760-765, mar. 1992.

MELO, A.C.G. Reflorestamentos de restauração de matas ciliares: análise estrutural e método de monitoramento no médio vale do Paranapanema (SP). São Carlos, 2004. 141p. Dissertação (Mestrado) - Escola de Engenharia de São Carlos, Universidade de São Paulo.

MENDES, J.C.T. Caracterização fitogeográfica como subsídio para a recuperação e a conservação da vegetação na Bacia do Rio Corumbataí. Piracicaba, 2004. 121p. Dissertação (Mestrado) - Escola Superior de Agricultura Luiz de Queiroz, Universidade de São Paulo.

MILARÉ, E. Direito do ambiente: doutrina, prática, jurisprudência, glossário. São Paulo: Editora Revista dos Tribunais, 2001. 783p.

MISSOURI BOTANICAL GARDEN. $\mathbf{W}^{\mathbf{3}}$ tropicos. http://mobot.org/W3T/Search/vast.html (02 ago. 2004).

MOREIRA, M.S. Passivo ambiental: o conceito em debate. Revista Banas Ambiental, maio 2004. http://www.indg.com.br/info/artigos/artigos.asp?25 (10 dez. 2004).

MUELLER, C.C. Gestão de matas ciliares. In: LOPES, I.V.; BASTOS FILHO, G.S; BILLER, D.; BALE, M. (Org.). Gestão ambiental no Brasil: experiência e sucesso. Rio de Janeiro: Editora Fundação Getúlio Vargas, 1998. p.185-214.

MUELLER-DOMBOIS, D.; ELLENBERG, H. Aims and methods of vegetation ecology. New York: John Wiley, 1974. 547p. 
NELSON, E.J.; BOOTH, D.B. Sediment sources in na urbanizing, mixed land-use watershed. Journal of Hidrology, v.264, n.1-4, p.51-68, Jul. 2002.

OLIVEIRA, D.M.S.; RIBEIRO JUNIOR., E.S. Técnicas gerais aplicadas à recuperação de áreas degradadas pela atividade de mineração. Ação ambiental, n.10, p.16-18, 2000.

OLIVEIRA, E.G. Hidrogeoquímica aplicada na avaliação do impacto ambiental em áreas de lavra de areia. Rio Claro, 2000. 112p. Tese (Doutorado) - Instituro de Geociências e Ciências Exatas, Universidade Estadual Paulista "Julio de Mesquita Filho”.

OLIVEIRA-FILHO, A.T.; RATTER, J.A. A study of the origin of central brazilian forests by analysis of plants species distribution patterns. Eddinburg Journal of Botany, v.52, n.2, p.141-194, 1995.

PAGANO, S.N. Produção de folhedo em mata mesófila semidecídua no município de Rio Claro, SP. Revista Brasileira de Biologia, v.49, n.3, p.633-639, 1989.

PAULA, S.A.; LEMOS FILHO, J.P. Dinâmica do dossel em mata semidecídua no perímetro urbano de Belo Horizonte, MG. Revista Brasileira de Botânica, v.24, n.4, p.545-551, dez. 2001.

PEQUENA e média mineração começam a se modernizar. Brasil Mineral, n.155, p.1417, out. 1997.

PRADO FILHO, J.F.; SOUZA, M.P. A importância do automonitoramento: parte 1. Brasil Mineral, n.203, p.35-37, mar. 2002a. 
PRADO FILHO, J.F.; SOUZA, M.P. A importância do automonitoramento: parte final. Brasil Mineral, n.204, p.44-48, abr. 2002b.

PROJETO PIRACENA. Banco de dados “geoprocessamento". http://www.cena.usp.br/piracena (10 jan. 2005).

REIS, A.; KAGEYAMA, P.Y. Restauração de áreas degradadas utilizando interações interespecíficas. In: KAGEYAMA, P.Y.; OLIVEIRA, R.E.; MORAES, L.F.D.; ENGEL, V.L.; GANDARA, F.B. (Org.). Restauração ecológica de ecossistemas naturais. Botucatu: FEPAF, 2003. p.29-48.

REIS, L.V.S. Cobertura florestal e custo do tratamento de águas em bacias hidrográficas de abastecimento público: caso do manancial do Município de Piracicaba. 215p. Piracicaba, 2004. Tese (Doutorado) - Escola Superior de Agricultura Luiz de Queiroz, Universidade de São Paulo.

RIBEIRO, L.T. A ação do policiamento florestal nas atividades minerarias na região de Sorocaba - SP: legislação pertinente à exploração minerária. http://www.peritocriminal.com.br/meioambiente5.htm (16 dez. 2004).

RODRIGUES, R.R. Análise de um remanescente de vegetação natural as margens do rio Passa Cinco, Ipeúna. SP. Campinas, 1992. Tese (Doutorado) - Instituto de Biologia, Universidade Estadual de Campinas.

RODRIGUES. R.R. A vegetação de Piracicaba e municípios do entorno. Circular Técnica IPEF, n.189. p.1-17, ago. 1999.

RODRIGUES, R.R. Florestas ciliares: uma discussão nomenclatural das formações ciliares. In: RODRIGUES, R.R.; LEITÃO FILHO, H.F. (Ed.). Matas ciliares: conservação e recuperação. São Paulo: EDUSP; FAPESP, 2000. p.91-106. 
RODRIGUES, R.R. Recuperação de áreas degradadas com alta diversidade. In: CAPELLARI JÚNIOR, L. (Coord.). Botânica geral: gestão ambiental. Piracicaba: ESALQ, LCB, 2004. p.166-184.

RODRIGUES, R.R.; GANDOLFI, S. Recomposição de florestas nativas: princípios gerais subsídios para uma definição metodológica. Revista Brasileira de Horticultura Ornamental, v.2, n.1, p.4-15, 1996.

RODRIGUES, R.R.; GANDOLFI, S. Restauração de florestas tropicais: subsídios para uma definição metodológica e indicadores de avaliação e monitoramento. In: DIAS, L.E.; MELO, J.W.V. (Ed.). Recuperação de áreas degradadas. Viçosa: Editora da UFV, Sociedade Brasileira de Recuperação de Áreas Degradadas, 1998. p.203-215.

RODRIGUES, R.R.; GANDOLFI, S. Conceitos, tendências e ações para a recuperação de florestas ciliares. In: RODRIGUES, R.R.; LEITÃO FILHO, H.F. (Ed.). Matas ciliares: conservação e recuperação. São Paulo: EDUSP; FAPESP, 2000. p.235347.

RODRIGUES, R.R.; NAVE, A.G. Heterogeneidade florística das matas ciliares. In: RODRIGUES, R.R.; LEITÃO FILHO, H.F. (Ed.). Matas ciliares: conservação e recuperação. São Paulo: EDUSP; FAPESP, 2000. p.45-71.

RODRIGUES, R.R.; SHEPHERD, G.J. Fatores condicionantes da vegetação ciliar. In: RODRIGUES, R.R.; LEITÃO FILHO, H.F. (Ed.). Matas ciliares: conservação e recuperação. São Paulo: EDUSP; FAPESP, 2000. p.101-107.

ROIZMAN, L.G. Fitossociologia e dinâmica do banco de sementes de populações arbóreas de floresta secundária em São Paulo, SP. São Paulo, 1993. 184p. Dissertação (Mestrado) - Instituto de Biociência, Universidade de São Paulo. 
ROZZA, A.F.; RODRIGUES, R.R.; BEDUSCHI, L.C.; MUNIZ, M.R.A. Recuperação florestal e produção de sementes e mudas de espécies nativas: projeto "Matrizes de árvores nativas”. In: SEMINÁRIO TEMÁTICO SOBRE RECUPERAÇÃO DE ÁREAS DEGRADADAS. Anais. São Paulo: Sociedade Brasileira de Recuperação de Áreas Degradadas, 2003. p.79-88.

SALIS, S.M.; TAMASHIRO, G.J.Y.; JOLY, C.A. Florística e fitossociologia do estrato arbóreo de um remanescente de mata ciliar no Rio Jacaré Pepira, Brotas, SP. Revista Brasileira de Botânica, v.17, n.2, p.93-103, dez. 1994.

SAMPAIO, A.B.; NUNES, R.V.; WALTER, B.M.T. Fitossociologia de uma área de mata de galeria na Fazenda Sucupira do Cenargen, Brasília, DF. In: LEITE, L.L.; SAITO, C.H. (Org.). Contribuição ao conhecimento ecológico do cerrado. Brasília: UNB, 1997. p.29-39.

SANCHEZ, M.; PEDRONI, F.; LEITÃO-FILHO, H.F.; CESAR, O. Composição florística de um trecho de floresta ripária na Mata Atlântica em Picinguaba, Ubatuba, SP. Revista Brasileira de Botânica, v.22, n.1, p.31-42, abr. 1999.

SANTARELLI, E.G. Produção de mudas de espécies nativas para florestas ciliares. In: RODRIGUES, R.R.; LEITÃO FILHO, H.F. (Ed.). Matas ciliares: conservação e recuperação. São Paulo: EDUSP; FAPESP, 2000. p.313-317.

SANTOS, J.E.; JESUS, T.P.; HENKE-OLIVEIRA, C.; BALLESTER, M.V.R. Caracterização perceptiva da Estação Ecológica de Jataí (Luiz Antônio, SP) por diferentes grupos sócio-culturais de nteração. In: SANTOS, J.E.; PIRES, J.S.R (Org.). Estação Ecológica de Jataí: estudos integrados em ecossistemas. São Carlos: RiMa, 2000. v.1, p.163-206. 
SÃO PAULO (Estado). Secretaria do Meio Ambiente. Manuais ambientais: procedimento de licenciamento ambiental integrado para atividades minerárias no estado de São Paulo. São Paulo: Secretaria do Meio Ambiente, 1999. 58p.

SÃO PAULO (Estado). Secretaria do Meio Ambiente. Mata ciliar: recuperações bem sucedidas. São Paulo: Secretaria do Meio Ambiente, 2002. 44p.

SAUTTER, K.D. Meso (Acari e Collenbola) e macrofauna (Oligochaeta) na recuperação de solos degradados. In: DIAS, L.E.; MELO, J.W.V. (Ed.). Recuperação de áreas degradadas. Viçosa: Editora da UFV; Sociedade Brasileira de Recuperação de Áreas Degradadas, 1998. p.197-202.

SCHIAVINI, I. Estrutura das comunidades arbóreas de mata de galeria da Estação Ecológica do Panga (Uberlândia, MG). Campinas, 1992. Tese (Doutorado) Instituto de Biologia, Universidade Estadual de Campinas.

SHEPHERD, G.J. FITOPAC: manual do usuário. Campinas: UNICAMP, Departamento de Botânica, 1995. 72p.

SILVA, C.M.S. Mineração de areia e cascalho e o meio ambiente num setor do rio Mogi-Guaçu (Município de Araras/SP). Rio Claro, 1997. 125p. Dissertação (Mestrado) - Instituto de Geociência e Ciências Exatas, Universidade Estadual Paulista “Julio de Mesquita Filho”.

SILVA, L.A.T. Zoneamento da mineração de areia na região do Vale do Paraíba. Areia \& Brita, n.6, p.24-27, 1998.

SILVÉRIO, P.F. Partição, biodisponibilidade e toxicidade de metais pesados a organismos bentônicos em sedimentos. São Carlos, 1999. 78p. Dissertação (Mestrado) - Universidade Federal de São Carlos. 
SIMÕES, L.B. A importância das matas ripárias no controle da poluição difusa. In: SIMPÓSIO ECÓTONOS NAS INTERFACES DOS ECOSSISTEMAS AQUÁTICOS, Botucatu, 2001. Anais. Botucatu: UNESP, Instituto de Biociências, 2001. p.24-35.

SNEATH, P.H.A.; SOKAL, R.R. Numerical taxonomy. San Francisco: Freeman, 1973.

SOUZA, P.A.; VENTURIN, N.; MACEDO, R.L.G.; ALVARENGA, M.I.N.; SILVA, V.F. Estabelecimento de espécies arbóreas em recuperação de área degradada pela extração de areia. Cerne, v.7, n.2, p.43-52, 2001.

TOY, T.J.; GRIFFITH, J.J. Evolução práticas nas lavras de Minas Gerais: parte final. Brasil Mineral, n.210, p.26-33, out. 2002.

TRIGUEIRO, A. Meio ambiente no Século 21. Rio de Janeiro: Sextante, 2003. 211p.

TROPPMAIR, H. A cobertura vegetal primitiva do Estado de São Paulo. Biogeografia, v.1, p.1-10, 1969.

VALENTE, R.O.A. Análise da estrutura da paisagem na Bacia do Rio Corumbataí, SP. Piracicaba, 2001. 144p. Dissertação (Mestrado) - Escola Superior de Agricultura Luiz de Queiroz, Universidade de São Paulo.

VALENTIN, J.L. Ecologia numérica: uma introdução à análise multivariada de dados ecológicos. Rio de Janeiro: Editora Interciência, 2000. 117p.

VAN DER HAVEREN, B.P.; WILLIANS, J.E.; PATISSON, M.L.; HAUGH, J.R. Restoring the ecological integrity of public lands. Journal of Soil and Water Conservation, p.226-231, Jul./Aug. 1997. 
VÉRAS, A.V.; SILVA, H.P. O impacto dos agregados na região de Salvador. Brasil Mineral, n.164, p.25-27, ago. 1998.

WILLIAMS, D.D.; BUGIN, A.; REIS, J.L.B.C. Manual de recuperação de áreas degradadas pela mineração: técnicas de revegetação. Brasília: MINTER; IBAMA, 1990. 96p.

YAMAZOE, G.; VILAS BÔAS, O. Manual de pequenos viveiros florestais. São Paulo: Páginas \& Letras Editora e Gráfica, 2003. 120p. 
APÊNDICES 
APÊNDICE 1. Ficha de coleta de dados nos arquivos de processos de licenciamento da CETESB e no cadastro mineiro do DNPM

Razão social:

\section{Ficha de dados - CETESB}

Localização: (município/bairro/endereço/coordenada geográfica)

Responsável:

Telefone de contato:

Área total (ha):

Área de lavra (ha):

Tipo de lavra: (leito ou cava)

Corpo d’água:

Propriedade: (Própria ou arrendada)

Produção de areia ( $\left.\mathrm{m}^{3} / \mathrm{mês}\right)$ : $\quad$ Destino de consumo da areia:

Ano inauguração da empresa:

Tempo de concessão de LI e LO (meses):

Vistorias Cetesb:

Situação legal na Cetesb:

Plano de recomposição vegetal (xerox)

Outras informações relevantes:

Ficha de dados -DNPM

Razão social:

Município/Coordenada geográfica:

Área de lavra (ha):

Tempo de autorização de pesquisa (TAP):

Tempo de concessão de lavra (TCL):

Tempo de registro de licença (TRL) 
APÊNDICE 2. Modelo do questionário aplicado em entrevistas junto aos mineradores de areia da Bacia do Rio Corumbataí

\begin{tabular}{|c|c|c|c|c|c|c|}
\hline & & UNIVER & DADE DE SÂ & PAULO & & \\
\hline & ESCOL & $\begin{array}{r}\text { SUPERIOR D } \\
\text { Departar }\end{array}$ & $\begin{array}{l}\text { AGRICULTU } \\
\text { to de Ciência }\end{array}$ & $\begin{array}{l}\text { "LUIZ DE Q } \\
\text { lorestais }\end{array}$ & IROZ” & \\
\hline Caracteriza & das empresas & $\begin{array}{r}\text { ineradoras de } \\
\text { legal de se }\end{array}$ & $\begin{array}{l}\text { reia do Rio C } \\
\text { empreendedo }\end{array}$ & $\begin{array}{l}\text { imbataí (Etap } \\
\text { s (Etapa 2) }\end{array}$ & I) e da perceps & ambiental e \\
\hline $\begin{array}{l}\text { Função do ent } \\
\text { Empresa vincl }\end{array}$ & tado: & & & & & \\
\hline ETAPA 1 & & & & & & \\
\hline 1. Desde $\mathrm{q}$ & do extrai areia & rio Corumbat & & & & \\
\hline 2. Qual é & tórico de uso & áreas? & & & & \\
\hline 3. Quais s & planos de us & uturo das áreas & & & & \\
\hline 4. Tem de & olvido ativida & de reflorestam & to? Qual é o ct & o médio do ref & estamento? & \\
\hline 5. Quanto & de o $\mathrm{m}^{3}$ de are & para os distribu & ores? & & & \\
\hline ETAPA 2 & & & & & & \\
\hline $\begin{array}{l}\text { 1. Qual fo } \\
\text { funcionam }\end{array}$ & $\begin{array}{l}\text { usto de impler } \\
\text { ? Houve algu }\end{array}$ & $\begin{array}{l}\text { ntação do seu } \\
\text { dificuldade na }\end{array}$ & $\begin{array}{l}\text { to? Qual foi o } \\
\text { tenção do lice }\end{array}$ & $\begin{array}{l}\text { mpo para obtel } \\
\text { iamento ambi }\end{array}$ & $\begin{array}{l}\text { o das licenças } \\
\text { al? }\end{array}$ & instalação e \\
\hline $\begin{array}{l}\text { 2. Você ac } \\
\text { plantio de }\end{array}$ & $\begin{array}{l}\text { mportante refl } \\
\text { as espécies? }\end{array}$ & estar as marger & lo Rio Corumb & aí (matas cilial & ? Por que? Por & Iê é exigido o \\
\hline 3. Os port & areia trazem & sum prejuízo o & enefício ao me & ambiente? & & \\
\hline 4. Com qu & qüência os ór & os ambientais & tam o seu port & Costumam as & sorar nas quest & técnicas? \\
\hline CETESB & DEPRN & Pol. Amb. & DNPM & DAEE & Prefeitura & Outros \\
\hline $\begin{array}{lll}N & S & A \\
\end{array}$ & $\begin{array}{lll}N & S & A \\
\end{array}$ & $\begin{array}{lll}\mathrm{N} & \mathrm{S} & \mathrm{A} \\
\end{array}$ & $\begin{array}{lll}N & S & A \\
\end{array}$ & 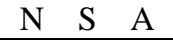 & $\begin{array}{lll}N & S & A \\
\end{array}$ & $\begin{array}{lll}\mathrm{N} & \mathrm{S} & \mathrm{A} \\
\end{array}$ \\
\hline $\mathrm{N}=$ nunca; & sempre; e A & às vezes & & & & \\
\hline $\begin{array}{l}\text { 5. A elaboraçã } \\
\text { ajudaria na im }\end{array}$ & $\begin{array}{l}\text { uma cartilha } \\
\text { ação do seu P }\end{array}$ & $\begin{array}{l}\text { m informações } \\
\text { to de areia? Se }\end{array}$ & $\begin{array}{l}\text { espeito do pro } \\
\text { o, por quê? }\end{array}$ & sso de licencia & ento da extraçã & hineral \\
\hline $\operatorname{Sim}(\square)$ & Não (_ & 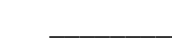 & & & & \\
\hline
\end{tabular}


APÊNDICE 3. Modelo dos questionários enviado aos órgãos licenciadores da atividade de extração de areia na Bacia do Rio Corumbataí

\section{UNIVERSIDADE DE SÃO PAULO \\ ESCOLA SUPERIOR DE AGRICULTURA “LUIZ DE QUEIROZ” \\ Departamento de Ciências Florestais \\ Programa de Pós-graduação em Recursos Florestais}

\section{Entrevista: Caracterização das condições e recursos dos órgãos ambientais envolvidos na mineração de areia da bacia do Rio Corumbataí}

Função do entrevistado:

Órgão vinculado:

1. Como é feita a qualificação e a atualização dos técnicos a respeito das questões ambientais e legais da extração mineral?

2. Os recursos materiais, humanos e financeiros disponíveis asseguram as atribuições desse órgão no que tange a extração de areia em leito de rio? Justifique.

3. Quais são os procedimentos e os critérios utilizados pelo órgão no que tange a extração de areia em leito de rio? Quais outros procedimentos, recursos e critérios seriam importantes na avaliação do impacto dessa atividade?

4. Quais são as principais legislações e normas legais utilizadas pelo órgão no que tange a extração de areia em leito de rio?

5. Você acha que o licenciamento de portos de areia em leito de rio traz contribuições ambientais?

6. Na sua opinião, quais são as principais causas de demora na obtenção das licenças ambientais necessárias para a implantação dos portos de areia? 